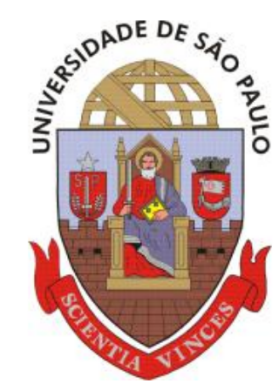

UNIVERSIDADE DE SÃO PAULO

ESCOLA DE ENGENHARIA DE SÃO CARLOS

PROGRAMA DE PÓS GRADUAÇÃO EM ENGENHARIA MECÂNICA

José Antonio Garcia Croce

AUMENTO DA EFICIÊNCIA DE UM

DISPOSITIVO ELETRO-HIDRODINÂMICO

ATRAVÉS DA ALTERAÇÃO DAS

CARACTERÍSTICAS GEOMÉTRICAS DO

ELETRODO ATIVO 

José Antonio Garcia Croce

\section{AUMENTO DA EFICIÊNCIA DE UM \\ DISPOSITIVO ELETRO-HIDRODINÂMICO \\ ATRAVÉS DA ALTERAÇÃO DAS \\ CARACTERÍSTICAS GEOMÉTRICAS DO \\ ELETRODO ATIVO}

Tese apresentada à Escola de Engenharia de São Carlos, da Universidade de São Paulo, para obtenção do título de Doutor em Engenharia Mecânica

Área de Concentração: Aeronaves

ORIENTADOR: Prof. Titular Fernando Martini Catalano

ESTE EXEMPLAR TRATA-SE DA VERSÃO CORRIGIDA.

A VERSÃO ORIGINAL ENCONTRA-SE DISPONÍVEL JUNTO AO

DEPARTAMENTO DE ENGENHARIA MECÂNICA DA EESC-USP.

São Carlos 
AUTORIZO A REPRODUÇÃO TOTAL OU PARCIAL DESTE TRABALHO, POR QUALQUER MEIO CONVENCIONAL OU ELETRÔNICO, PARA FINS DE ESTUDO E PESQUISA, DESDE QUE CITADA A FONTE.

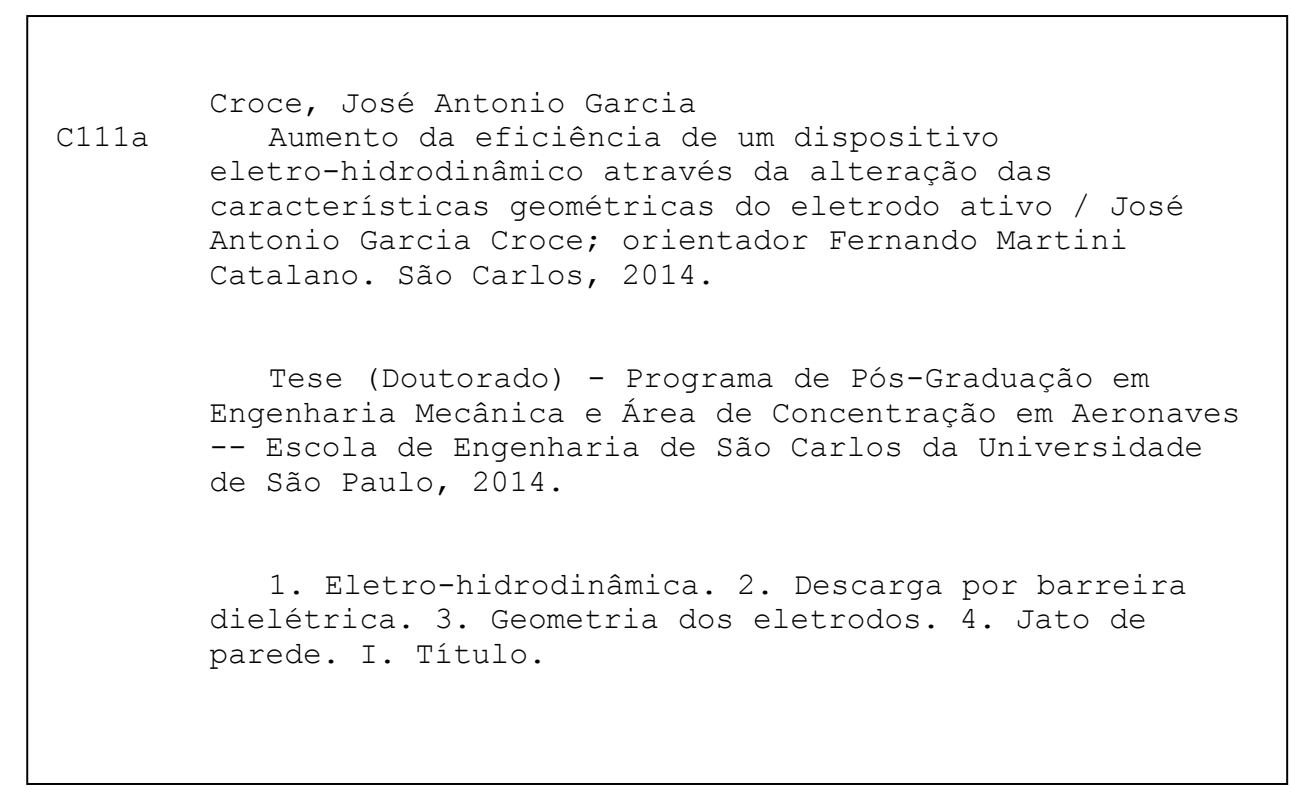




\section{FOLHA DE JULGAMENTO}

Candidato: Tecnólogo JOSÉ ANTÔNIO GARCIA CROCE.

Título da tese: "Aumento da eficiência de um dispositivo eletrohidrodinâmico através da alteração das características geométricas do eletrodo ativo".

Data da defesa: $31 / 10 / 2014$

Comissão Julgadora:

Resultado:

Prof. Titular Fernando Martini Catalano

APROVADO (Orientador)

(Escola de Engenharia de São Carlos/EESC)

Prof. Titular Eduardo Morgado Belo

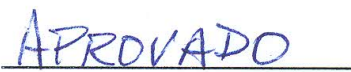

(Escola de Engenharia de São Carlos/EESC)

Prof. Dr. Sergio Henrique Evangelista

APROVROO

(Universidade Federal de São Carlos/UFSCar)

Prof. Dr. Osvaldo Missiato

APROUHDO

(Academia da Força Aérea/AFA)

Prof. Dr. Everthon Silva Fonseca

APROUADO

(Instituto Federal de Educação, Ciência e Tecnologia São Paulo/IFSP-

Catanduva)

Coordenador do Programa de Pós-Graduação em Engenheira Mecânica:

Prof. Associado Marcelo Areias Trindade

Presidente da Comissão de Pós-Graduação:

Prof. Associado Paulo César Lima Segantine 

Dedico esta Tese à minha Esposa, Margarete, e ao meu Filho, Vinícius, por toda a ajuda e paciência. 


\section{Agradecimentos}

- Agradeço ao Professor Titular Fernando Martini Catalano pela orientação;

- Agradeço ao Professor Titular Eduardo Morgado Belo pelo empréstimo de diversos equipamentos utilizados neste trabalho;

- Agradeço aos meus colegas do Departamento de Engenharia Aeronáutica por toda a ajuda e companheirismo;

- Agradeço aos Técnicos do Departamento de Engenharia Aeronáutica pela ajuda. 


\section{Resumo}

\section{CROCE, J. A. G. Aumento da eficiência de um dispositivo eletro-hidrodinâmico}

através da alteração das características geométricas do eletrodo ativo. 2014. 183 f. Tese (Doutorado) - Escola de Engenharia de São Carlos, Universidade de São Paulo, São Carlos, 2014.

Forças eletro-hidrodinâmicas apresentam boas qualidades para a utilização como meio de produzir e manipular escoamentos. Um de seus grandes méritos consiste na falta de partes móveis para a introdução de quantidade de movimento em escoamentos. Foi realizado um estudo experimental para a investigação e comparação de três diferentes configurações dos eletrodos usados para a produção de dispositivos eletro-hidrodinâmicos gerados por descarga de barreira dielétrica. Uma configuração é composto de eletrodos retangulares planos e a outra de um fio e um eletrodo retangular plano. A outra configuração usa uma nova configuração com um eletrodo plano de borda serrilhada, como eletrodo ativo, e um eletrodo retangular plano isolado. Todas as configurações foram investigados para entender o comportamento na produção de escoamento. Medições de tubo Pitot dos perfis de velocidade dos jatos de parede foram feitas em várias distâncias a partir da região da descarga elétrica. Na sequência, a medição do escoamento ao longo do eletrodo serrilhado foi realizada. Assim, pretende-se determinar as características de escoamento tridimensionais produzidas por esta configuração. Os resultados mostram melhores características da configuração serrilhado para ser utilizado na produção de escoamento mais intensos.

Palavras Chaves: Eletro-hidrodinâmica. Descarga por barreira dielétrica. Geometria dos eletrodos. Jato de parede. 


\section{Abstract}

CROCE, J. A. G. Increased efficiency of an electro-hydrodynamic device by changing the geometric characteristics of the active electrode. 2014. $183 \mathrm{f}$. Tese (Doutorado) - Escola de Engenharia de São Carlos, Universidade de São Paulo, São Carlos, 2014.

Electro-hydrodynamic forces have good qualities to be used to produce and manipulate flows. One of its great merits is the lack of moving parts to introduce momentum in flows. An experimental study for measure and comparing three different configurations of electrodes used for the production of electro-hydrodynamic devices generated by dielectric barrier discharge was performed. One configuration is composed of rectangular flat electrodes and the other of a wire electrode and a rectangular flat electrode. The other uses a new configuration with a serrated edge flat plane electrode, as the active electrode and an isolated rectangular flat. All configurations are investigated to understand the behavior in the production of the flow. Pitot tube measurements of velocity profiles of the wall jets are made at various distances away from the electrical discharge region. Further, the measurement of the flow along the serrated electrod is performed. Thus, it is intended to determine the three-dimensional flow characteristics produced by this configuration. The results show the best features of serrated configuration to be used in the production of more intense flow.

Keywords: Electrohydrodynamics. Dielectric barrier discharge. Electrodes geometry. Wall jet. 


\section{Lista de Figuras}

1.1 Gravura apresentando a ideia da Ionocraft de Seversky (Fantel (1964)). . . . . . 23

1.2 Utilização de dispositivos EAD em aeronaves. . . . . . . . . . . . . . . . . 25

2.1 Deflexão da Chama de uma Vela na Presença de um Campo Elétrico (ENGEL, 1965). . . . . . . . . . . . . . . . . . . 29

2.2 Arranjo genérico de uma bomba eletro-hidrodinâmica. . . . . . . . . . . . . . . 30

2.3 Esquema geral de uma bomba eletro-hidrodinâmica plana. . . . . . . . . . 32

2.4 Esquema geral do trabalho de El-Khabiry e Colver (1997) . . . . . . . . . . 33

2.5 Efeito eletro-hidrodinâmico aplicado em um Cilindro estudado po Artana

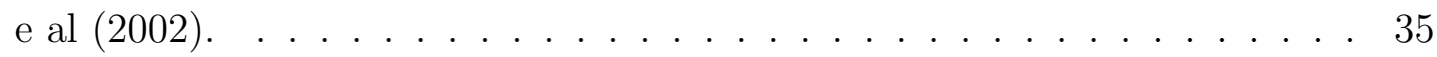

2.6 Esquema do Modelo utilizado por Hyun e Chun (2003) . . . . . . . . . . . . 36

2.7 Esquema dos dispositivos estudados por Enloe et al. (2004) . . . . . . . . . . . 37

2.8 Esquema dos dispositivos estudados por Durscher e Roy (2011) . . . . . . . . . 39

3.1 Cargas elétricas na presença de um campo elétrico . . . . . . . . . . . . . 42

3.2 Processo de Transferência da Quantidade de Movimento . . . . . . . . . . 43

3.3 Vento Corona produzido ao redor de pontas sujeitas à altas tensões . . . . 44

3.4 Dispositivo de indução eletro-hidrodinâmica de escoamentos (SIN, 2002). 45

3.5 Velocidade Induzida Teórica pela Força Paraelétrica . . . . . . . . . . . . . 48

4.1 Quantidade de Íons Produzidos na Atmosfera Terrestre (WÅHLIN, 1989). . . . 50

4.2 Representação dos Equipamentos de von Guericke. . . . . . . . . . . . . . . . 51

4.3 Tipos de plasmas encontrados na natureza ou produzidos artificialmente (BRAND,

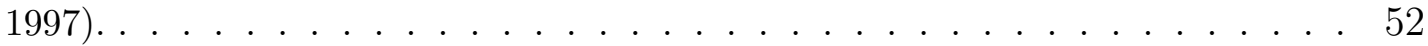

4.4 Esquema de um Tubo para Descarga Elétrica em Baixa Pressão. . . . . . . . . 57

4.5 Relação Corrente/Tensão em Descarga de Baixa Pressão (ROTH, 1995). ... . 58 
4.6 Descarga corona entre condutores cilíndricos concêntricos . . . . . . . . . . 61

4.7 Características Visuais de uma Descarga Brilhante (ENGEL, 1965). . . . . 63

4.8 Descarga brilhante por barreira dielétrica . . . . . . . . . . . . . . . . . . 64

4.9 Descarga Brilhante Uniforme . . . . . . . . . . . . . . . . . . . 65

5.1 Descarga brilhante atmosférica ao redor de eletrodos utilizada por Roth, Sherman e Wilkinson (1998). . . . . . . . . . . . . . . . . . . . . 68

5.2 Relação entre a Tensão Elétrica de Ruptura com pd (LIEBERMAN; LICHTENBERG, 1994). . . . . . . . . . . . . . . . . . . 69

5.3 Tensão/corrente características de uma descarga brilhante (ROTH; SHERMAN; WILKINSON, 1998). . . . . . . . . . . . . . . . 70

6.1 Circuito Esquemático da Fonte de Alimentação. . . . . . . . . . . . . . . . . 74

6.2 Fonte de Alimentação. . . . . . . . . . . . . . . . . . . . . . . . . . . . 74

6.3 Sonda de alta tensão. . . . . . . . . . . . . . . . . . . . . . . . . 75

6.4 Exemplo de medidas da tensão e corrente fornecidas aos eletrodos. . . . . . 75

6.5 Esquema Geral dos Componentes do Modelo. . . . . . . . . . . . . . . . . 77

6.6 Vista Frontal do Modelo. . . . . . . . . . . . . . . . . . . . . . 77

6.7 Vista Traseira do Modelo. . . . . . . . . . . . . . . . . . . . . . 78

6.8 Esquema Geral do Experimento de Visualização. . . . . . . . . . . . . . . . . . 79

6.9 Presença de um Sorvedouro no Bordo de Ataque do Cilindro. . . . . . . . . 80

6.10 Sem a presença da Descarga. . . . . . . . . . . . . . . . . 81

6.11 Escoamento ao redor do Cilindro - Descarga Ligada - Frequência de 1 kHz. 82

6.12 Dados de tensão e corrente para a frequência de $1 \mathrm{kHz}$. . . . . . . . . . . . 82

6.13 Escoamento ao redor do Cilindro - Descarga Ligada - Frequência de 2 kHz. 83

6.14 Dados de tensão e corrente para a frequência de $2 \mathrm{kHz}$. . . . . . . . . . . 83

6.15 Escoamento ao redor do Cilindro - Descarga Ligada - Frequência de 3 kHz. 84

6.16 Dados de tensão e corrente para a frequência de $3 \mathrm{kHz}$. . . . . . . . . . . . 84

6.17 Escoamento ao redor do Cilindro - Descarga Ligada - Frequência de 4 kHz. 85

6.18 Dados de tensão e corrente para a frequência de $4 \mathrm{kHz}$. . . . . . . . . . . . 85

6.19 Escoamento ao redor do Cilindro - Descarga Ligada - Frequência de 5 kHz. 86

6.20 Dados de tensão e corrente para a frequência de $5 \mathrm{kHz}$. . . . . . . . . . . 86

6.21 Escoamento ao redor do Cilindro - Descarga Ligada - Frequência de 6 kHz. 87 
6.22 Dados de tensão e corrente para a frequência de $6 \mathrm{kHz}$. . . . . . . . . . 87

6.23 Escoamento ao redor do Cilindro - Descarga Ligada - Frequência de 7 kHz. 88

6.24 Dados de tensão e corrente para a frequência de $7 \mathrm{kHz}$. . . . . . . . . . . 88

6.25 Escoamento ao redor do Cilindro - Descarga Ligada - Frequência de 8 kHz. 89

6.26 Dados de tensão e corrente para a frequência de $8 \mathrm{kHz}$. . . . . . . . . . . 89

6.27 Escoamento ao redor do Cilindro - Descarga Ligada - Frequência de 9 kHz. 90

6.28 Dados de tensão e corrente para a frequência de $9 \mathrm{kHz}$. . . . . . . . . . . 90

6.29 Escoamento ao redor do Cilindro - Descarga Ligada - Frequência de 10 kHz. 91

6.30 Dados de tensão e corrente para a frequência de $10 \mathrm{kHz}$. . . . . . . . . . 91

6.31 Valores da potência elétrica para as frequências analisadas. . . . . . . . . . 92

6.32 Escoamento ao redor do Cilindro - Descarga Desligada. . . . . . . . . . . . 93

6.33 Escoamento ao redor do Cilindro - Descarga Ligada - 5,0 kVolts. . . . . . . 93

6.34 Escoamento ao redor do Cilindro - Descarga Ligada - 6,0 kVolts. . . . . . . 94

6.35 Escoamento ao redor do Cilindro - Descarga Ligada - 7,0 kVolts. . . . . . . 95

6.36 Escoamento ao redor do Cilindro - Descarga Ligada - 8,0 kVolts. . . . . . . 95

6.37 Esquema da indução de um jato de parede através de um dispositivo eletrohidrodinâmico por barreira dielétrica . . . . . . . . . . . . . . . . 96

6.38 Arranjo esquemático da visualização do escoamento produzido sobre superfícies. . . . . . . . . . . . . . . . . 97

6.39 Sequência de Visualização do Escoamento Induzido. . . . . . . . . . . . . . 98

6.40 Sequência de imagens apresentando o vórtice inicial. . . . . . . . . . . . . . 99

7.1 Esquema dos dispositivos estudados por Enloe et al. (2004). . . . . . . . . 101

7.2 Tipos de Configurações dos Eletrodos: (A) Plano-Plano; (B) Fio-Plano;

(C) Serrilhado-Plano; (D) Serrilhado Triangular-Plano. . . . . . . . . . . . 102

7.3 Aspecto geral do equipamento construído. . . . . . . . . . . . . . . . . 104

7.4 Sistema Eletrônico de Medição de Pressão. . . . . . . . . . . . . . . . . . . 105

7.5 Tela do programa utilizada nas medições. . . . . . . . . . . . . . 106

7.6 Procedimento utilizado para medição dos perfis de velocidade . . . . . . . 107

7.7 Perfil de Velocidades Adimensionais Teórico para um Jato de Parede. . . . 110

7.8 Dados típicos de tensão e corrente elétrica medidos. . . . . . . . . . . . . . 111

7.9 Modelo com Eletrodo Externo Plano. . . . . . . . . . . . . . . . . . . . 112

7.10 Perfis de Velocidades produzidos pela configuração plano-plano. . . . . . . 113 
7.11 Perfis médios da configuração plano-plano. . . . . . . . . . . . . . . . . . 113

7.12 Modelo com Eletrodo Externo Fio. . . . . . . . . . . . . . . . 114

7.13 Perfis de Velocidades produzidos pela configuração cilindrico-plano. . . . 115

7.14 Perfis médios da configuração Fio-plano. . . . . . . . . . . . . . . . . 115

7.15 Modelo com Eletrodo Externo Serrilhado. . . . . . . . . . . . . 116

7.16 Perfis de Velocidades produzidos pela configuração serrilhado-plano. . . . . 117

7.17 Perfis médios da configuração serrilhado-plano. . . . . . . . . . . . . . 118

7.18 Velocidades máximas de cada configuração nas três etapas de medição. 119

7.19 Valores das velocidades máximas das configurações estudadas. . . . . . . . 119

7.20 Posição das velocidades máximas das configurações estudadas. . . . . . . . 120

7.21 Comparação entre as espessuras dos jatos para todas as configurações estudadas. . . . . . . . . . . . . . . . . . . . 121

7.22 Valores do fluxo da quantidade de movimento calculado para todas as etapas de medição realizadas. . . . . . . . . . . . . . . . . . . . 122

7.23 Esquema do experimento de medição ao longo da borda do eletrodo. . . . . 123

7.24 Perfis de velocidades medidos ao longo do eletrodo serrilhado a $10 \mathrm{~mm}$ de distância da borda do eletrodo. . . . . . . . . . . . . . . . . . . 124

7.25 Perfis de velocidades medidos ao longo do eletrodo serrilhado a $10 \mathrm{~mm}$ de distância da borda do eletrodo. . . . . . . . . . . . . . . . 125

7.26 Perfis de velocidades medidos ao longo do eletrodo serrilhado a $20 \mathrm{~mm}$ de distância da borda do eletrodo. . . . . . . . . . . . . . . . 126

7.27 Perfis de velocidades medidos ao longo do eletrodo serrilhado a $20 \mathrm{~mm}$ de distância da borda do eletrodo. . . . . . . . . . . . . . . . . . 127

7.28 Perfis de velocidades medidos ao longo do eletrodo serrilhado a $30 \mathrm{~mm}$ de distância da borda do eletrodo. . . . . . . . . . . . . . . . . . 128

7.29 Perfis de velocidades medidos ao longo do eletrodo serrilhado a $30 \mathrm{~mm}$ de distância da borda do eletrodo. . . . . . . . . . . . . . . . . 129

7.30 Perfis de velocidades medidos ao longo do eletrodo serrilhado a $40 \mathrm{~mm}$ de distância da borda do eletrodo. . . . . . . . . . . . . . . . . 130

7.31 Perfis de velocidades medidos ao longo do eletrodo serrilhado a $40 \mathrm{~mm}$ de distância da borda do eletrodo. . . . . . . . . . . . . . . . . . . . . 131 
7.32 Perfis de velocidades medidos ao longo do eletrodo serrilhado a $50 \mathrm{~mm}$ de distância da borda do eletrodo. . . . . . . . . . . . . . . . . . . . 132

7.33 Perfis de velocidades medidos ao longo do eletrodo serrilhado a $50 \mathrm{~mm}$ de distância da borda do eletrodo. . . . . . . . . . . . . . . . . . . 133

7.34 Aspecto da descarga elétrica do eletrodo serrilhado. . . . . . . . . . . . . . 134

7.35 Posição dos maiores valores de velocidade induzida ao longo da borda do eletrodo serrilhado. . . . . . . . . . . . . . . . . 135

7.36 Indução de velocidades ao longo do eletrodo serrilhado. . . . . . . . . . . . 136

A.1 Circuito Esquemático da Fonte de Alimentação. . . . . . . . . . . . . . . . 145

A.2 Fonte de Alimentação. . . . . . . . . . . . . . . . . . . . . . 145

A.3 Fonte de Alimentação C.C. Minipa. . . . . . . . . . . . . . . . . . . 146

A.4 Etapa de geração e controle do sinal. . . . . . . . . . . . . . . . . . . 147

A.5 Etapa amplificadora do sinal gerado. . . . . . . . . . . . . . . . . . 148

A.6 Etapa de Potência da Fonte de Alimentação. . . . . . . . . . . . . . . . . . 149

A.7 Etapa de Potência da Fonte de Alimentação. . . . . . . . . . . . . . . . . . 149

A.8 Esquema de ligação das duas bobinas de alta tensão . . . . . . . . . . . . 150

A.9 Equipamento Gerador do Sinal e Etapa de Potência . . . . . . . . . . . . . 151

A.10 Etapa Indicadora da Frequência de Saída da Fonte . . . . . . . . . . . . . 151

A.11 Equipamento Gerador do Sinal e Etapa de Potência . . . . . . . . . . . . . 152

A.12 Tensão no eletrodo externo com tensão na fonte C.C. de 5 Volts. . . . . . . 152

A.13 Tensão no eletrodo externo com tensão na fonte C.C. de 10 Volts. . . . . . 153

A.14 Tensão no eletrodo externo com tensão na fonte C.C. de 15 Volts. . . . . . 153

A.15 Tensão no eletrodo externo com tensão na fonte C.C. de 20 Volts. . . . . . 154

A.16 Tensão no eletrodo externo com tensão na fonte C.C. de 25 Volts. . . . . . 154

A.17 Tensão no eletrodo externo com tensão na fonte C.C. de 30 Volts. . . . . . 155

A.18 Relação entre a tensão da fonte C.C a a tensão no eletrodo externo. . . . . 155

B.1 Esquema Elétrico de um Divisor de Tensão RC. . . . . . . . . . . . . . . . 158

B.2 Resposta em frequência da sonda de alta tensão. . . . . . . . . . . . . . . . 159

B.3 Esquema Elétrico da Sonda. . . . . . . . . . . . . . . . . . . . 159

B.4 Esquema Elétrico da Sonda. . . . . . . . . . . . . . . . . . . 160

B.5 Esquema Elétrico da Sonda. . . . . . . . . . . . . . . . . . 160 
B.6 Sonda de alta tensão. . . . . . . . . . . . . . . . . . . . . . . . . . . . 161

B.7 Sinal senoidal $1 \mathrm{kHz}$ medido pela sonda e diretamente pelo osciloscópio. . . 161

B.8 Sinal senoidal de $5 \mathrm{kHz}$ medido pela sonda e diretamente pelo osciloscópio. 162

B.9 Sinal triangular $1 \mathrm{kHz}$ medido pela sonda e diretamente pelo osciloscópio. 162

B.10 Sinal triangular de $5 \mathrm{kHz}$ medido pela sonda e diretamente pelo osciloscópio. 163

B.11 Esquema Elétrico da Sonda para Simulação. . . . . . . . . . . . . . . . . . 164

C.1 Imagem do transformador de corrente modelo TA12-100 . . . . . . . . . . 166

C.2 Esquema do transformador de corrente modelo TA12-100. . . . . . . . . . . 166

C.3 Esquema do procedimento de medição da corrente. . . . . . . . . . . . . . 166

C.4 Imagem apresentando a tela do osciloscópio antes de salvar os dados. . . . 167

C.5 Esquema do transformador de corrente modelo TA12-100. . . . . . . . . . . 168

D.1 Esquema geral do experimento de visualização da descarga elétrica. . . . 170

D.2 Visualização da descarga elétrica da configuração plano-plano. . . . . . . . . . 170

D.3 Visualização da descarga elétrica da configuração cilíndrico-plano. . . . . . . 171

D.4 Visualização da descarga elétrica da configuração serrilhado-plano. . . . . . 171

E.1 Campos Magnéticos e Elétricos aplicados em um Meio Condutor. . . . . . 172

E.2 Magnetoidrodinâmica no controle de camadas limites (WIER, 2000). . . . 173

E.3 Controle de Escoamentos por Meios Magnetoidrodinâmicos (WIER, 2000). 174

E.4 Relação entre as forças de campo elétrica e magnéticas. . . . . . . . . . . . 177

F.1 Relação de Stoletow . . . . . . . . . . . . . . . . . . . . . 183 


\section{Lista de Tabelas}

7.1 Valores máximos de velocidades ao longo da borda dos eletrodos estudados. 120

7.2 Valores máximos de velocidades ao longo da borda do eletrodo serrilhado. . 135

7.3 Valores das potências elétricas das descargas. . . . . . . . . . . . . 137

A.1 Características Fundamentais da Fonte de Alimentação. . . . . . . . . . . . 144

A.2 Características Gerais da Fonte de Alimentação. . . . . . . . . . . . . . 146

B.1 Especificações do Resistor de Alta Tensão. . . . . . . . . . . . . . . . . . . 158

B.2 Especificações do Capacitor de Alta Tensão. . . . . . . . . . . . . . . . . 158

F.1 Dados de Vários Fluidos . . . . . . . . . . . . . . . . . . . . . . 181 


\section{Sumário}

1 Introdução $\quad 22$

1.1 Apresentação . . . . . . . . . . . . . . . . . . . . . 22

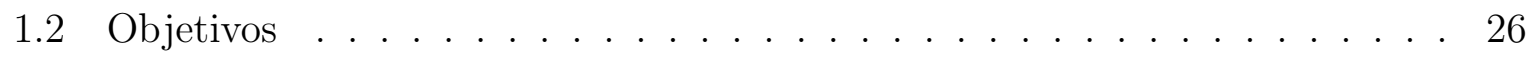

1.2.1 Objetivos Específicos . . . . . . . . . . . . . 26

1.3 Metodologia . . . . . . . . . . . . . . . . . 27

2 Eletro-hidrodinâmica: Resumo Histórico 28

2.1 Primórdios . . . . . . . . . . . . . . . . . . . . . . . . . . . 28

2.2 Aplicações Aeronáuticas . . . . . . . . . . . . . . . . . . 32

3 Mecanismo eletro-hidrodinâmico $\quad 40$

3.1 Introdução . . . . . . . . . . . . . . . . . . . . . . . . . . . . . . 40

3.2 Indução de Escoamentos . . . . . . . . . . . . . . . . . . . . . . . . 43

3.3 A Força de Campo Paraelétrica . . . . . . . . . . . . . . . . . . 44

4 Descargas Elétricas $\quad 49$

4.1 Introdução . . . . . . . . . . . . . . . . . . . . . . . . 49

4.2 Processos de Ionização . . . . . . . . . . . . . . . . . . 53

4.3 Processos de Deionização . . . . . . . . . . . . . . . . . 55

4.4 Descargas Elétricas em Baixa Pressão . . . . . . . . . . . . . 56

4.5 Descarga Corona . . . . . . . . . . . . . . . . . . . . . 59

4.6 Descarga Brilhante . . . . . . . . . . . . . . . . 61

4.6.1 Descarga Brilhante por Barreira Dielétrica . . . . . . . . . . 63

4.6.2 Descarga Brilhante Uniforme . . . . . . . . . . . . . . . 65

4.7 Arco Elétrico . . . . . . . . . . . . . . . . . . . 66 
5 Descarga Brilhante Atmosférica $\quad 67$

5.1 Introdução . . . . . . . . . . . . . . . . . . . . . 67

5.2 Produção de Descarga Brilhante Atmosférica . . . . . . . . . . . . . . . 68

5.3 Descarga brilhante atmosférica como um Dispositivo EHD . . . . . . . . . 71

6 Produção de Escoamentos EHD $\quad 73$

6.1 Introdução . . . . . . . . . . . . . . . . . . . . . . 73

6.2 Produção de Escoamentos ao redor de Cilindros . . . . . . . . . . . . 75

6.2.1 Descrição do Modelo . . . . . . . . . . . . . . . . . . . . . 76

6.2 .2 Equipamentos Utilizados . . . . . . . . . . . . . . 78

6.2.3 Indução de Escoamento ao redor do Modelo . . . . . . . . . . . . . 79

6.2.4 Variação da Frequência da Descarga . . . . . . . . . . . . . . . 81

6.2.5 Variação da Tensão Aplicada . . . . . . . . . . . . . . . . . . 92

6.3 Produção de Escoamentos sobre superfícies . . . . . . . . . . . . . . . 96

7 Efeitos Geométricos nos Dispositivos EHD 100

7.1 Introdução . . . . . . . . . . . . . . . . . . . . . . 100

7.2 Descrição do Experimento . . . . . . . . . . . . . . . . . . . . . 103

7.3 Análise dos Resultados . . . . . . . . . . . . . . . . . . 106

7.4 Resultados Experimentais . . . . . . . . . . . . . . . 111

7.4.1 Avaliação da Configuração Plano-Plano . . . . . . . . . . . . . . . . 111

7.4 .2 Avaliação da Configuração Fio-Plano . . . . . . . . . . . . . . . . . 113

7.4.3 Avaliação da Configuração Serrilhado-Plano . . . . . . . . . . . . . 116

7.4.4 Análise e Comparação dos Casos Estudados . . . . . . . . . . . . . 118

7.5 Medição lateral do jato induzido . . . . . . . . . . . . . . . . . 122

7.6 Discussão dos Resultados . . . . . . . . . . . . . . . . . . . . 134

8 Conclusões $\quad 138$

$\begin{array}{ll}\text { Referências } & 141\end{array}$

A Fonte de Alta Tensão e Alta Frequência $\quad 144$

A.1 Projeto e Construção da Fonte . . . . . . . . . . . . . . . . . . . . . . . . . 144

A.2 Fonte de Tensão C.C. . . . . . . . . . . . . . . . . . . . . . . . 146

A.3 Gerador de Sinal . . . . . . . . . . . . . . . . . . . 147 
A.4 Etapa de Potência . . . . . . . . . . . . . . . . . . . . . . . . . 148

A.5 Calibração e Ajustes . . . . . . . . . . . . . . . . . . . . 151

B Sonda de Alta Tensão 156

B.1 Introdução . . . . . . . . . . . . . . . . . . . . . 156

B.2 Projeto e Construção . . . . . . . . . . . . . . . . . . . . . . . . . 157

B.3 Construção . . . . . . . . . . . . . . . . . . . . . . 159

C Medição da Corrente de Alimentação 165

D Visualização da Descarga Elétrica $\quad 169$

D.1 Introdução . . . . . . . . . . . . . . . . . . . . . . . . . . . 169

E Magneto-hidrodinâmica 172

E.1 Introdução . . . . . . . . . . . . . . . . . . . . . . . . . . . . . 172

E.2 MHD versus EHD . . . . . . . . . . . . . . . . . . . 175

F Ionização e Exitação em um Campo Elétrico $\quad 179$

F.1 Lei de Paschen . . . . . . . . . . . . . . . . . . . . . . . . 179

F.2 Dependência da Temperatura . . . . . . . . . . . . . . . . . . . 181

F.3 Dependência da Umidade . . . . . . . . . . . . . . . . . . . . 182

F.4 Ponto de Stoletow . . . . . . . . . . . . . . . . . . . . . 182 



\section{Capítulo 1}

\section{Introdução}

\subsection{Apresentação}

A utilização de forças de campo de origem eletromagnética para a produção de escoamentos, propulsão e outros fins, começou a receber atenção a partir da segunda metade do Século XX. Esperava-se na época que, por estes meios, seria possível produzir veículos mais eficientes, com melhor aproveitamento da energia utilizada em seu movimento ou mesmo novas formas de propulsão. Desta forma, várias propostas surgiram para o aproveitamento das forças eletromagnéticas, como, submarinos e navios movidos por propulsores magneto-hidrodinâmicos, cápsulas espaciais tendo seu controle de reentrada na atmosfera por meios de força eletromagnéticas e até aeronaves propulsionadas por meio de forças de origem elétrica. Dentro desta última proposta, Fantel (1964) cita a impressionante proposta de Seversky feita em 1959 que estudou a possibilidade de construir uma aeronave movida unicamente por meio do vento iônico (Figura 1.1).

O vento iônico consiste, basicamente, na indução de um escoamento de baixa velocidade ao redor de corpos carregados eletricamente com tensões elevadas, da ordem de vários quilovolts. Ele é especialmente pronunciado ao redor de pontas metálicas carregadas eletricamente e pode ser considerado uma das mais incríveis manifestações das descargas elétricas. Sua identificação remonta a muito tempo, sendo que apenas no Século XVIII sua determinação como fenômeno de origem elétrica foi descrita. Este fenômeno será melhor descrito no Capítulo 2.

No entanto, todos estas propostas iniciais falharam em se tornarem aplicações reais por uma série de motivos distintos. Pode-se citar, entre outros, a falta de conhecimentos 


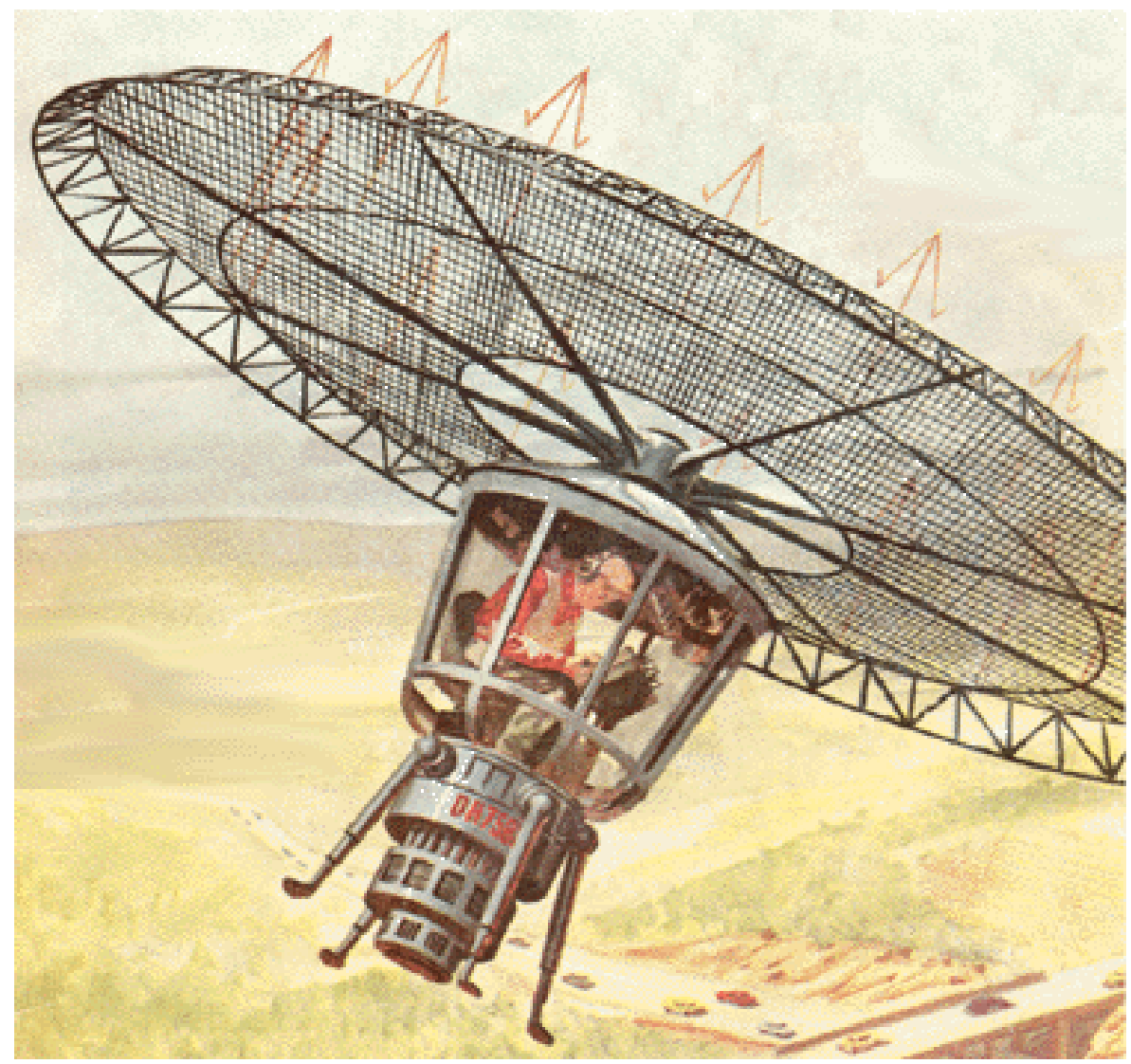

Figura 1.1 - Gravura apresentando a ideia da Ionocraft de Seversky (Fantel (1964)).

teóricos necessários aos estudos nesta área, bem como a falta de uma eletrônica de alta potência de pequeno porte e de alta eficiência, ainda ausente em meados do século XX. No entanto, muito se aprendeu com estas pesquisas iniciais, o que levou ao surgimento de uma nova área de pesquisa que desde então tem produzido diversas aplicações. Esta área foi denominada de eletro-hidrodinâmica.

O fenômeno eletro-hidrodinâmico trata do comportamento de fluidos eletricamente carregados, ou parcialmente carregados, na presença de campos elétricos. A eletrohidrodinâmica é uma área de estudos que consiste, em princípio, na fusão de duas grandes áreas da ciência: a Eletrodinâmica e a Mecânica dos Fluidos. É desta mistura que surge a promessa de produção, ou a alteração, de escoamentos aerodinâmicos sem que haja o envolvimento de partes móveis, ou seja, a ação ocorre diretamente nas partículas carregadas presentes no fluido que escoa. No entanto, este ramo da ciência ainda está em seus primórdios com relação à aplicações aeronáuticas. Mais à frente será adequadamente discutido que o efeito eletro-hidrodinâmico apresenta certos desafios para sua completa aplicação aerodinâmica. Pode-se citar principalmente o fato de o ar, nos estados comuns 
à aerodinâmica, não se encontrar ionizado, o que é fundamental para o efeito eletrohidrodinâmico. Desta forma, além da necessidade de dispositivos para a indução de um campo elétrico propriamente orientado e de magnitude desejada, existe também a necessidade de se produzir uma adequada ionização no fluido, preferencialmente através destes mesmos dispositivos.

Por outro lado, a eletro-hidrodinâmica já vem sendo desenvolvida desde o final do século XIX em várias aplicações. Vários sub-ramos de estudo como a produção de bombas eletro-hidrodinâmicas, o escoamento no interior de precipitadores eletrostáticos, o comportamento do plasma de alta temperatura em reatores de fusão e até o comportamento da atmosfera das estrelas (compostas principalmente por hidrogênio no estado de plasma) já estão em estágios avançados de compreensão e de aplicação. Atualmente, para citar um exemplo, bombas eletro-hidrodinâmicas estão sendo desenvolvidas para aplicações de refrigeração em microcircuitos eletrônicos que necessitam de uma refrigeração mais direta em suas partes quentes que são compostas de elementos microscópicos.

Como foi dito, um dos pontos principais do fenômeno eletro-hidrodinâmico é o fato de poder atuar nos escoamentos sem que haja partes móveis envolvidas. Desta forma, todo o efeito se apresenta integralmente no fluido circundante sem que haja perdas energéticas por atrito ou outro tipo de perdas em sistemas mecânicos com partes móveis. Sendo mais preciso, existe uma pequena perda causada pelo efeito Joule nos condutores do sistema elétrico que produz a energia necessária para a produção do efeito eletro-hidrodinâmico. No entanto, esta característica deletéria pode ser minimizada ao extremo com um bom dimensionamento do sistema elétrico que produz o efeito. Este é um dos grandes méritos do efeito eletro-hidrodinâmico perante outros meios de manipulação de escoamentos por meio de forças de campo de origem eletromagnéticas. Como pode ser visto no Apêndice E, em comparação com o efeito Magneto-hidrodinâmico, o efeito eletro-hidrodinâmico é extremamente mais eficiente em termos de consumo e perdas energéticas.

No entanto, quando se trata de aplicações aeronáuticas ainda encontra-se em estágios iniciais de desenvolvimento. Uma série de trabalhos vêm sendo desenvolvidos com a intenção de se aplicar dispositivos eletro-hidrodinâmicos em situações de interesse aeronáutico. Durante toda a década de 90 do século XX ocorreu uma consolidação desta área de pesquisa específica, com o surgimento de simpósios e congressos específicos sobre o tema. Atualmente, as pesquisas tanto se encontram em estágios de estudos teóricos 
quanto de tentativas de aplicações práticas. No Capítulo 2 será apresentado, de forma mais abrangente, os principais estudos sobre o tema.

O foco atual das pesquisas da eletro-hidrodinâmica em aeronaves consiste no desenvolvimento de dispositivos discretos que, utilizando o efeito eletro-hidrodinâmico, poderiam, em princípio, atuar de forma positiva no escoamento formado principalmente sobre as asas de uma aeronave. Estes dispositivos teriam que ser embutidos nas superfícies de interesse, sendo utilizados apenas quando necessário, tirando assim, outro impedimento de diversas técnicas de manipulação de escoamentos, ou seja, a presença de atuação apenas quando necessário. A Figura 1.2 apresenta uma ideia geral da aplicação de dispositivos eletro-hidrodinâmicos em aeronaves.

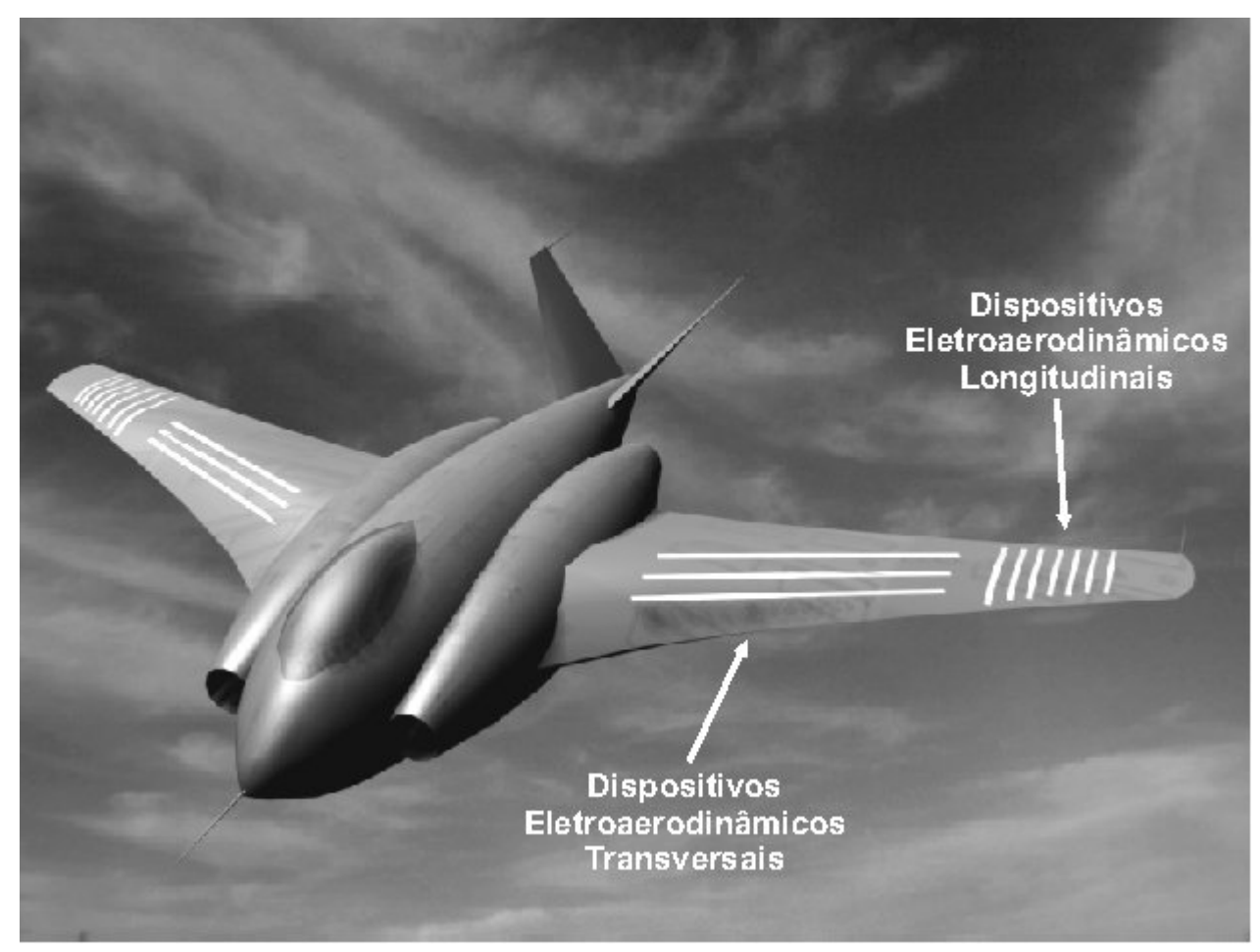

Figura 1.2 - Utilização de dispositivos EAD em aeronaves.

Idealmente, um dispositivo eletro-hidrodinâmico consistiria de um equipamento para a aceleração do escoamento sobre superfícies. Desta forma, diversas aplicações poderiam ser obtidas, como o atraso da separação do escoamento formado sobre asas ou até o aumento da sustentação. No entanto, estes equipamentos poderiam ser também utilizados em diversas aplicações. No caso de uma aeronave pode-se aplicar um dispositivo eletrohidrodinâmico para reduzir a tridimensionalização do escoamento sobre asas enflechadas ou aumentar a vazão nas tomadas de ar de turbinas, para citar apenas dois exemplos. 
Dadas as características inerentes aos dispositivos eletro-hidrodinâmicos, espera-se que várias aplicações aeronáuticas se tornem possíveis em um futuro bem próximo.

Assim, existem grandes desafios no desenvolvimento da eletro-hidrodinâmica para sua utilização em aeronaves. Isto implica na necessidade de se realizar pesquisas sistemáticas nesta área, procedendo também a integração dos diversos campos de conhecimento pertinentes, dado à grande multidisciplinaridade do tema. As primeiras etapas, obviamente, devem se ater as pesquisas de caráter mais fundamental, mas não se deve nunca perder a meta do desenvolvimento de dispositivos eficientes.

Desta forma, é necessário investigar mais detalhadamente as características de um dispositivo eletro-hidrodinâmico no tocante à sua capacidade de produção de escoamentos. Muitas perguntas ainda estão sem respostas e até serem respondidas, a aplicação em aeronaves de dispositivos eletro-hidrodinâmica fica postergada. Este trabalho tem o objetivo de determinar um possível efeito da geometria do dispositivo eletro-hidrodinâmico na sua capacidade de produção de escoamento. Espera-se fornecer dados válidos, mesmo que até certo ponto restritos, que possam ajudar no desenvolvimento de um dispositivo eletro-hidrodinâmico eficiente para aplicações aeronáuticas.

\subsection{Objetivos}

O principal objetivo do trabalho foi demonstrar que através da alteração da geometria da borda do eletrodo ativo de um dispositivo eletro-hidrodinâmico, produzido por uma descarga de barreira dielétrica, aumentou-se, então, a eficiência da produção de escoamentos sobre superfícies.

\subsubsection{Objetivos Específicos}

- Estudar experimentalmente as características dos escoamentos induzidos eletrohidrodinamicamente;

- Determinar o comportamento de três geometrias de eletrodos, sendo que duas são similares às que são encontradas em outros trabalhos e a terceira tem características novas; 
- Comparar as geometrias e determinar se a geometria tema deste trabalho apresenta melhor capacidade de produzir escoamento induzido;

\section{$1.3 \quad$ Metodologia}

Foi realizado um estudo experimental a respeito do comportamento de um dispositivo eletro-hidrodinâmico quando se altera alguns detalhes geométricos de sua estrutura. Desta forma, foi conduzidas uma investigação com relação a capacidade e a eficiência da indução de escoamentos junto a uma parede sólida. No entanto, dado à dificuldade inerente de se medir determinadas características dos escoamentos eletro-hidrodinamicamente induzido, algumas características foram inferidas indiretamente.

Os experimentos realizados contemplaram a análise da capacidade de indução de escoamentos quando se altera configurações geométricas dos eletrodos. Para tanto, três geometrias dos eletrodos foram utilizadas. Seria possível estudar mais algumas geometrias diferentes. No entanto, analisando as geometrias utilizadas foi possível capturar o comportamento diverso entre elas. Desta forma, foi possível produzir informação a cerca da eficiência de uma geometria com relação às outras.

Para tanto, foram realizadas duas investigações primárias nos modelos propostos. A mais fundamental de todas consistiu no levantamento dos perfis de velocidades induzidas pelas diversas configurações de eletrodos. Dados derivados, como a quantidade de movimento induzida, velocidade máximas e vazão, foram comparados. Assim, pôde-se determinar a eficiência das diversas geometrias. A outra análise experimental consistiu na determinação do comportamento do escoamento produzido pela configuração que foi proposta neste trabalho. Foi possível determinar as característica que fazem da configuração proposta mais eficiente em relação as demais.

Dando complemento as esta primeira investigação, foi realizada uma inspeção visual da descarga elétrica. Pôde-se correlacionar, então, o comportamento dinâmico das descargas elétricas produzidas pelos diversos eletrodos com determinadas diferenças entre os escoamentos produzidos. 


\section{Capítulo 2}

\section{Eletro-hidrodinâmica: Resumo Histórico}

\subsection{Primórdios}

Provavelmente, a descoberta do vento iônico pode ser atribuído a Hauskbee ao redor de 1719. Em uma experiência com um tubo carregado eletricamente Hauskbee afirmou ter sentido um pequeno vento em sua face. No entanto foi Chattok em 1899 que, aparentemente, pela primeira vez investigou este fenômeno de forma científica. Ele investigou a relação entre várias geometrias de eletrodos e as mobilidades dos íons no ar e estimou uma velocidade do vento iônico da ordem de $1 \mathrm{~m} / \mathrm{s}$. O vento iônico consiste no movimento localizado de ar no campo elétrico ao redor de um eletrodo carregado com alta tensão. Stuetzer (1959) apud Chattok ${ }^{1}$ realizou talvez a primeira descrição teórica sobre o vento iônico. Chattok observou que a presença de condução elétrica unipolar em um fluido produzia forças mecânicas no fluido. Relatou em seus estudos que conseguiu obter uma pressão máxima gerada pelo vento iônico, ao nível do mar, da ordem de 0,4 mm de coluna de água.

Engel (1965) apud Przibram em 1926 e Wilson em 1931² como sendo os primeiros que demonstraram o efeito eletro-hidrodinâmico em gases ionizados presentes no interior de chamas. Pode-se observar na Figura 2.1 que a chama de uma vela é defletida no

\footnotetext{
${ }^{1}$ Stuetzer, O. M. (1959). Ion Drag Pressure Generation. Journal of Applied Physics, v.30, n.7, julho.

${ }^{2}$ Von Engel (1965). Ionized Gases. 2.ed. Oxford Press
} 
sentido de um campo elétrico gerado entre dois eletrodos. As chamas em geral têm este comportamento devido ao fato de que parte das moléculas constituintes dos gás na chama estão ionizadas. Estes pesquisadores tiveram fundamental importância como semeadores de uma série de estudos posteriores sobre a capacidade de indução de escoamentos por meio de forças eletrostáticas.

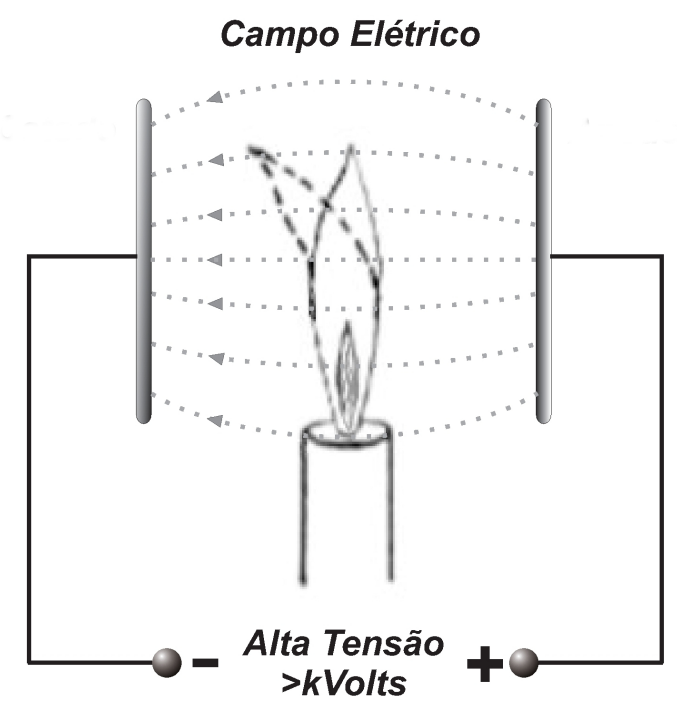

Figura 2.1 - Deflexão da Chama de uma Vela na Presença de um Campo Elétrico (ENGEL, 1965).

Estas primeiras avaliações no campo experimental logo levaram a formulação de teorias para a utilização prática do efeito eletro-hidrodinâmico. Estas aplicações teriam como objetivo a manipulação do escoamento para determinados fins e também a construção de equipamentos para a movimentação de um fluido apenas com o uso de forças de campo. No entanto, estas teorias barraram na falta de aplicação, ou de conhecimento, na época das novas teorias sobre camada limite. Foi a partir da metade do século XX que começaram realmente os estudos para a utilização do efeito eletro-hidrodinâmico.

Vários estudos sobre o uso de descargas elétricas próxima de uma superfície tem identificado várias aplicações em engenharia principalmente nas áreas de transferência de massa e calor, alterações no coeficiente de atrito, resfriamento superficial, precipitação eletrostática e cinemática de chamas. Foi demonstrado que o vento iônico pode aumentar a transferência de calor em até 200\%. Mas a primeira técnica de sucesso na produção de escoamentos utilizando-se descargas elétricas aplicadas em fluidos, ou seja efeito eletrohidrodinâmico, foi aplicada na confecção de bombas eletro-hidrodinâmicas.

Stuetzer (1959) explica que quando íons em um meio parcialmente ionizado movem-se sobre a influência de um campo elétrico, o atrito dos íons com o meio transfere quantidade 
de movimento a este último. As pressões criadas por este mecanismo podem ser apreciáveis se apenas íons de um mesmo sinal estão presentes. No caso mais comum usam-se quase sempre íons positivos, pois estes têm menor mobilidade iônica. Aplicações que exigem apenas a produção de movimento de um fluido fazem uso principalmente destas condições de produção de íons unipolares positivos. Já outras aplicações, como os Precipitadores Eletrostáticos, geram íons de ambos os sinais na mesma quantidade ou produzem até íons negativos que são mais adequados às condições de funcionamento do equipamento

Foi baseado nestes conhecimentos que surgiu a aplicação do efeito eletro-hidrodinâmico para a produção de bombas. Uma bomba eletro-hidrodinâmica transporta fluido através da interação entre o campo elétrico gerado por uma tensão aplicada no fluido através de eletrodos e as carga elétricas livres no fluido. A força de campo elétrico age diretamente no fluido, então uma bomba eletro-hidrodinâmica não usa partes móveis. Dentre os modelos de bomba eletro-hidrodinâmica, a bomba de arrasto iônica tem sido estudada por muitos pesquisadores. Este modelo tem a direção de escoamento fixada pela estrutura ou a forma dos eletrodos, o que significa que são unidirecionais. A Figura 2.2 apresenta um arranjo genérico de um destes dispositivos.

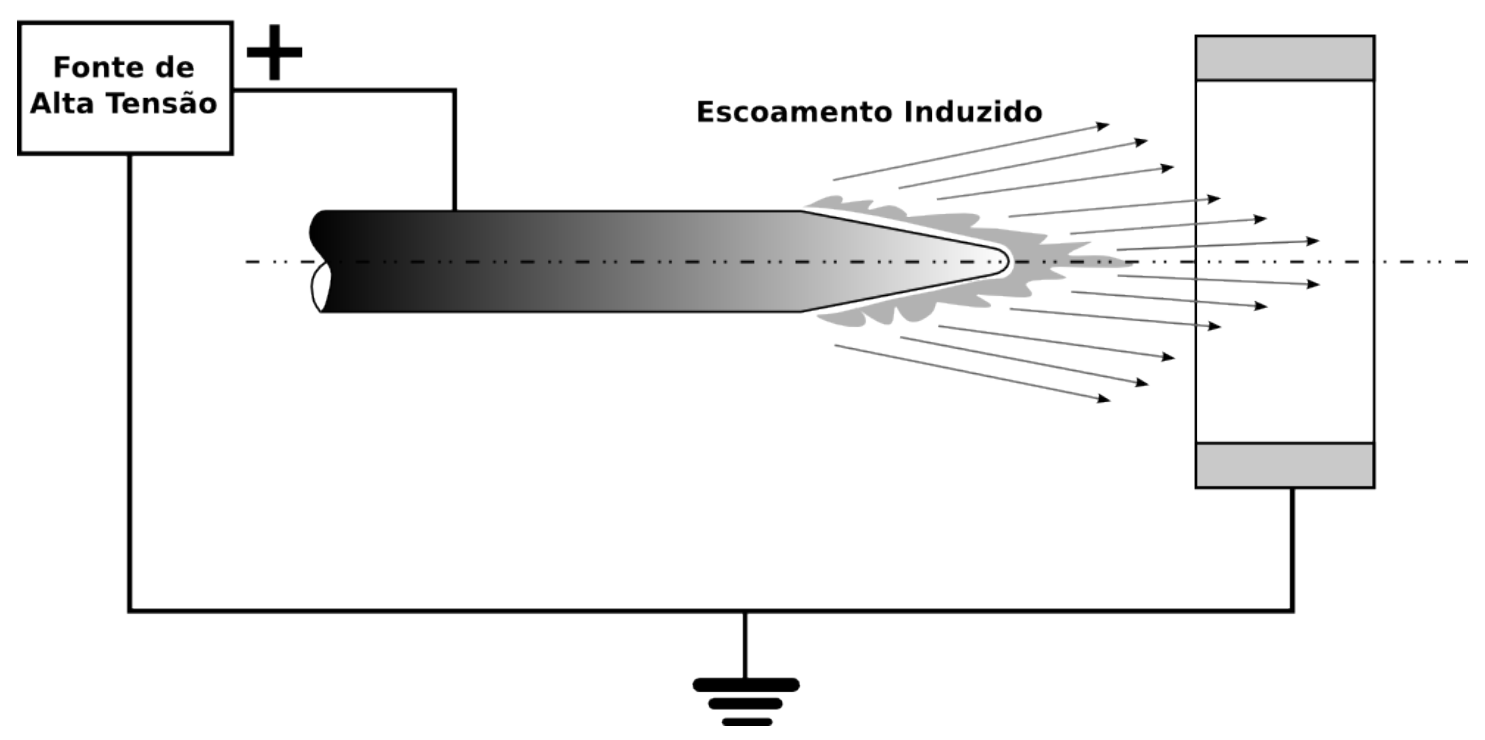

Figura 2.2 - Arranjo genérico de uma bomba eletro-hidrodinâmica.

Pode-se ver os dois eletrodos, o emissor e o coletor, montados de modo a provocar um escoamento no fluido interno ao duto no sentido do eletrodo emissor, produtor de íons menos móveis, para o eletrodo coletor. O eletrodo emissor também tem a função de produzir uma descarga elétrica ao seu redor com a consequente ionização do meio 
circundante. Isto é feito para que se possa trabalhar também com fluidos não condutores, deixando a função de polarização do meio para a bomba.

A bomba de arrasto iônica plana também utiliza campos elétricos agindo em cargas elétricas espalhadas no fluido. Estas cargas movem-se na direção do campo elétrico e arrastam o fluido circundante com elas. Estas são injetadas diretamente no fluido por pontas, ou pelas bordas, de um eletrodo, chamado de emissor. As cargas injetadas são arrastadas para o outro eletrodo, conhecido como coletor. Uma bomba de arrasto iônica plana também depende da condução unipolar no fluido. Para tanto, íons menos móveis contribuem melhor para o efeito. No entanto, este tipo de dispositivo pode produzir movimento do fluido em duas direções, dependendo apenas da polaridade da tensão aplicada nos eletrodos. Quando uma tensão contínua é aplicada em matriz de eletrodos como mostrado na Figura 2.3, íons positivos são injetados pelas bordas dos eletrodos positivos. Embora os eletrodos positivos têm eletrodos negativos em ambos os lados, os íons positivos injetados são arrastados para o mais próximo dos eletrodos negativos. Devido ao atrito, uma parte da quantidade de movimento dos íons positivos é transferida para o fluido circundante. Desta forma o fluido também se move na direção do eletrodo positivo para o negativo.

Ahn e Kim (1998) fabricaram e testaram uma micro-bomba eletro-hidrodinâmica plana. A bomba consiste de pares de eletrodos intercalados, montadas em um substrato de vidro, nos quais é aplicada uma tensão de corrente contínua e com a produção preferencial de cargas positivas. A característica mais importante deste tipo de bomba é sua diminuta dimensão. Nos ensaios realizados, álcool etílico foi bombeado em ambas direções em um canal de 100 ou $200 \mu m$ de profundidade e 3 mm de largura. Uma grande vantagem destes tipos de dispositivos consiste no fato de que podem ser montados diretamente em circuitos eletrônicos que serão refrigerados sem que haja grande influência por ruído elétrico, já que o campo elétrico gerado é baixa intensidade. Além deste fato, outra grande característica consiste no fato de que as dimensões desta bomba vão de encontro com a necessidade de uma maior miniaturização dos dispositivos eletrônicos aplicados na informática. 


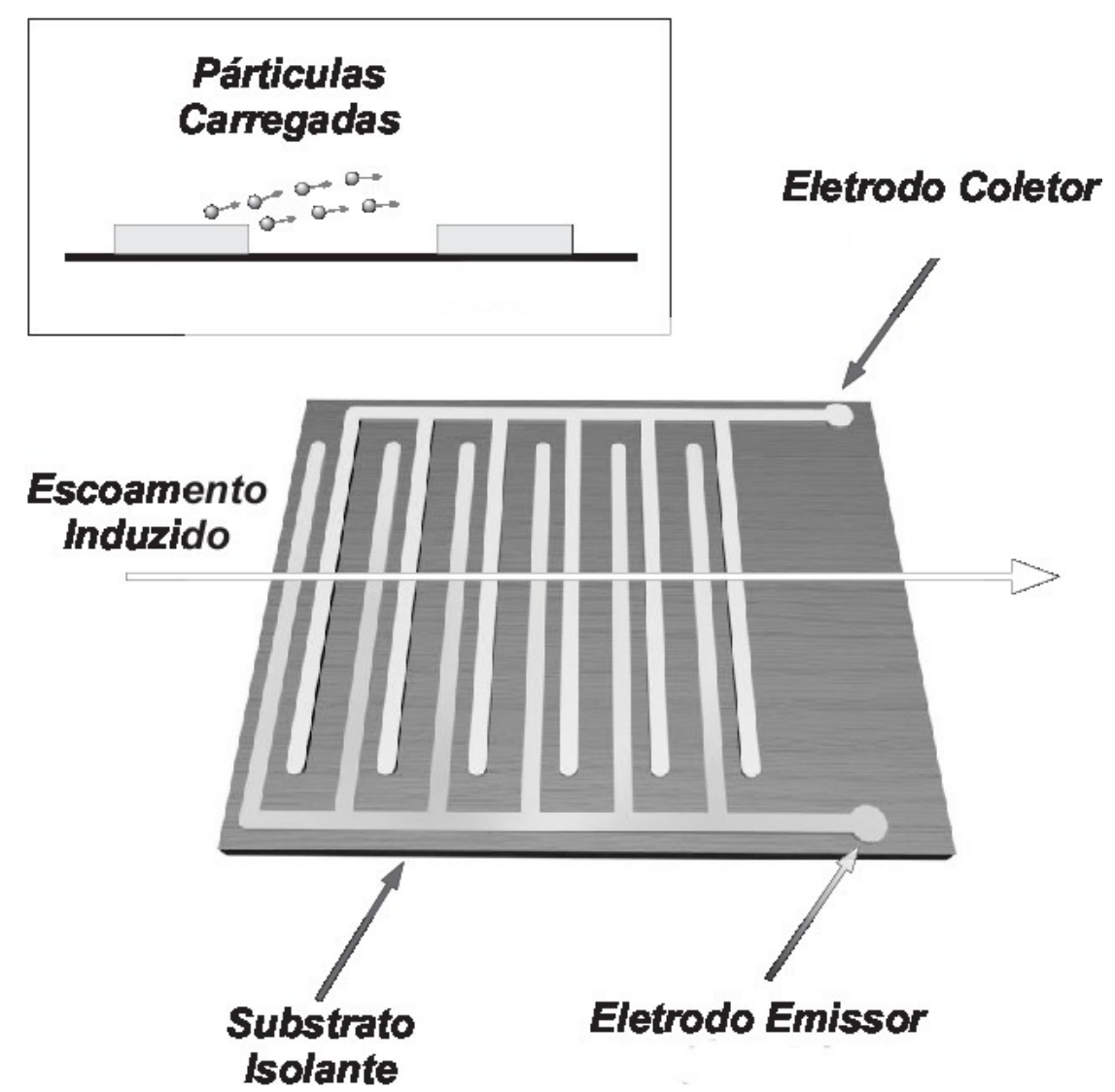

Figura 2.3 - Esquema geral de uma bomba eletro-hidrodinâmica plana.

\subsection{Aplicações Aeronáuticas}

A partir dos conceitos aplicados na confecção de bombas eletro-hidrodinâmicas, vários pesquisadores começaram a idealizar formas de utilizar estes conceitos na produção e ou controle de escoamentos aerodinâmicos. Wilkinson (1990) comenta que os estudos preliminares sobre o vento iônico em conjunto com alguns dados experimentais válidos indicam a possibilidade de redução do arrasto turbulento. No entanto, estes estudos são centrados na clássica abordagem de produção de um escoamento de baixa inércia próximo da parede, a região de menor velocidade relativa na camada limite. Desta forma, fica claro que nenhum esforço foi feito para se analisar a real influência da força de campo envolvida com o campo de escoamento presente.

O primeiro foco de estudos sobre o fenômeno eletro-aerodinâmico na aeronáutica consistiu nas pesquisas em corpos hipersônicos. Neste estágio do escoamento surge a vantagem de o ar ser mais facilmente ionizado. Estes estudos contemplaram a possibilidade de redução do arrasto supersônico e até a possibilidade de blindagem térmica de aeronaves em regimes hipersônicos. Estas pesquisas levaram vários outros estudos, como, por exem- 
plo, a possibilidade de controle de reentrada de cápsulas espaciais por meios de forças eletromagnéticas. No entanto, pouco se produziu de resultados práticos aplicados.

Desta forma, pode-se afirmar que a eletro-hidrodinâmica ainda se encontra nos estágios iniciais para aplicações aeronáuticas. Pode-se afirmar até que se encontra nas primeiras tentativas para a indução de escoamentos em aeronaves ou mesmo de controle de escoamentos. No entanto, como é discutido por Bushnell (1997), uma nova técnica aeronáutica necessita antes de tudo romper certos marcos tecnológicos para substituir técnicas em utilização. É necessário que ocorro avanços significativos em uma nova técnica para que novos métodos possam atuar onde as metodologias atuais são eficientes.

Malik e al. (1983) relatou uma velocidade de vento iônico de vários metros por segundo contribuindo para a quantidade de movimento de uma camada limite e com consequente redução de arrasto. Malik estudou o escoamento de Poiseuille em baixas velocidades na mesma faixa de velocidades do vento iônico e relatou reduções de arrasto da ordem de $20 \%$ para uma voltagem aplicada de 15 kVolts. Seus cálculos teóricos de um escoamento de uma camada limite laminar com uma descarga corona não mostrou resultados similares. Ele notou uma escassez de conhecimentos do fenômeno de uma descarga corona próxima de uma parede isolante para poder prosseguir com suas análises teóricas.

El-Khabiry e Colver (1997) realizaram um estudo numérico sobre a possibilidade da redução da espessura de uma camada limite laminar que atravessava sobre um arranjo especial de eletrodos. A Figura 2.4 mostra o esquema geral da ideia desenvolvida neste trabalho. Pode-se ver que sobre uma placa plana são montados dois fios eletricamente condutores, sendo o fio a montante ligado ao polo positivo e o fio a jusante ligado ao polo negativo de uma fonte de alta tensão de corrente contínua, capaz de fornecer uma tensão de até 7000 Volts.

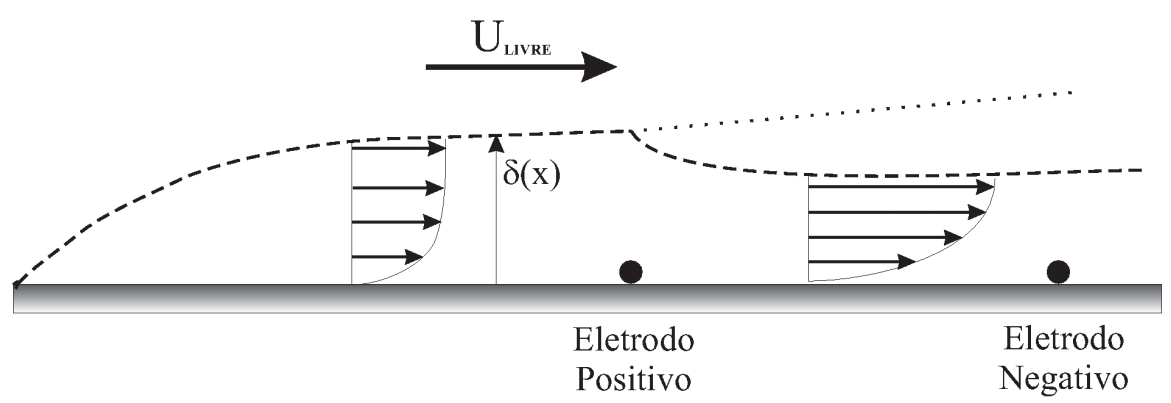

Figura 2.4 - Esquema geral do trabalho de El-Khabiry e Colver (1997) 
O trabalho de El Khabiry e Colver confirmou o afinamento da camada limite que passava pelo arranjo de eletrodos, isto devido à produção de um escoamento entre os dois eletrodos. Este escoamento sendo por sua vez consequência da presença de uma descarga elétrica que induz a formação de um vento iônico. Este trabalho teve um enfoque puramente teórico e, desta forma, nenhum esforço foi feito para a realização de uma investigação experimental.

Roth, Sherman e Wilkinson (1998) obtiveram redução de arrasto em uma placa plana através da geração de plasma à pressão atmosférica por um circuito RF (Rádio Frequência). Esta técnica de produção de íons apresenta uma grande vantagem em relação às outras, principalmente do ponto de vista de eficiência. Através desta técnica pode-se gerar uma quantidade apreciável de ionização em um fluido circundante com pouco gasto de energia elétrica quando comparada principalmente com técnicas convencionais de produção de íons. Os dados apresentados por Roth, Sherman e Wilkinson (1998) corroboram a aplicabilidade do efeito eletro-hidrodinâmico em escoamentos. Em um arranjo experimental com eletrodos montados paralelos ao escoamento, foi medido uma velocidade induzida da ordem de $4 \mathrm{~m} / \mathrm{s}$, sem a presença de um escoamento externo. Roth, Sherman e Wilkinson (1998) afirma, ainda, que com a ajuda do efeito eletro-hidrodinâmico é possível se reduzir o arrasto provocado por uma camada limite turbulenta. No entanto, nenhuma investigação mais detalhada sobre a influência do efeito eletro-hidrodinâmico na modificação das características de uma camada limite turbulenta foi realizada. O trabalho ficou mais restrito na demonstração da eficiência da técnica na produção de ionização em um fluido sobre a condição de estar em um escoamento interno à uma camada limite turbulenta.

Mais recentemente, Roth (2003) demostrou a eficácia da descarga brilhante para o controle de separação em aerofólios. Foi por ele ensaiado um aerofólio NACA 0015 contendo em seu extradorso uma matriz de eletrodos. Estes eletrodos foram ligado a uma fonte de alta tensão e alta frequência, o que produziu uma descarga elétrica ao redor deles. Por meio destes era produzido movimento superficial tangencial pelo efeito eletrohidrodinâmico.

Já Artana e al (2002) aplicaram um dispositivo eletro-hidrodinâmico bidimensional, orientado no sentido da envergadura dos modelos, tanto a um perfil aerodinâmico bidimensional quanto à um cilindro bidimensional. Neste último, demostraram que o efeito eletro-hidrodinâmico tem eficiência suficiente para a alteração das características da es- 
teira de vórtices formada pela separação da camada limite do corpo do cilindro, para uma grande faixa de número de Reynolds. Demonstraram, principalmente, que o comportamento dos vórtices vertidos na esteira foi expressivamente alterada, com possível redução do arrasto de pressão.

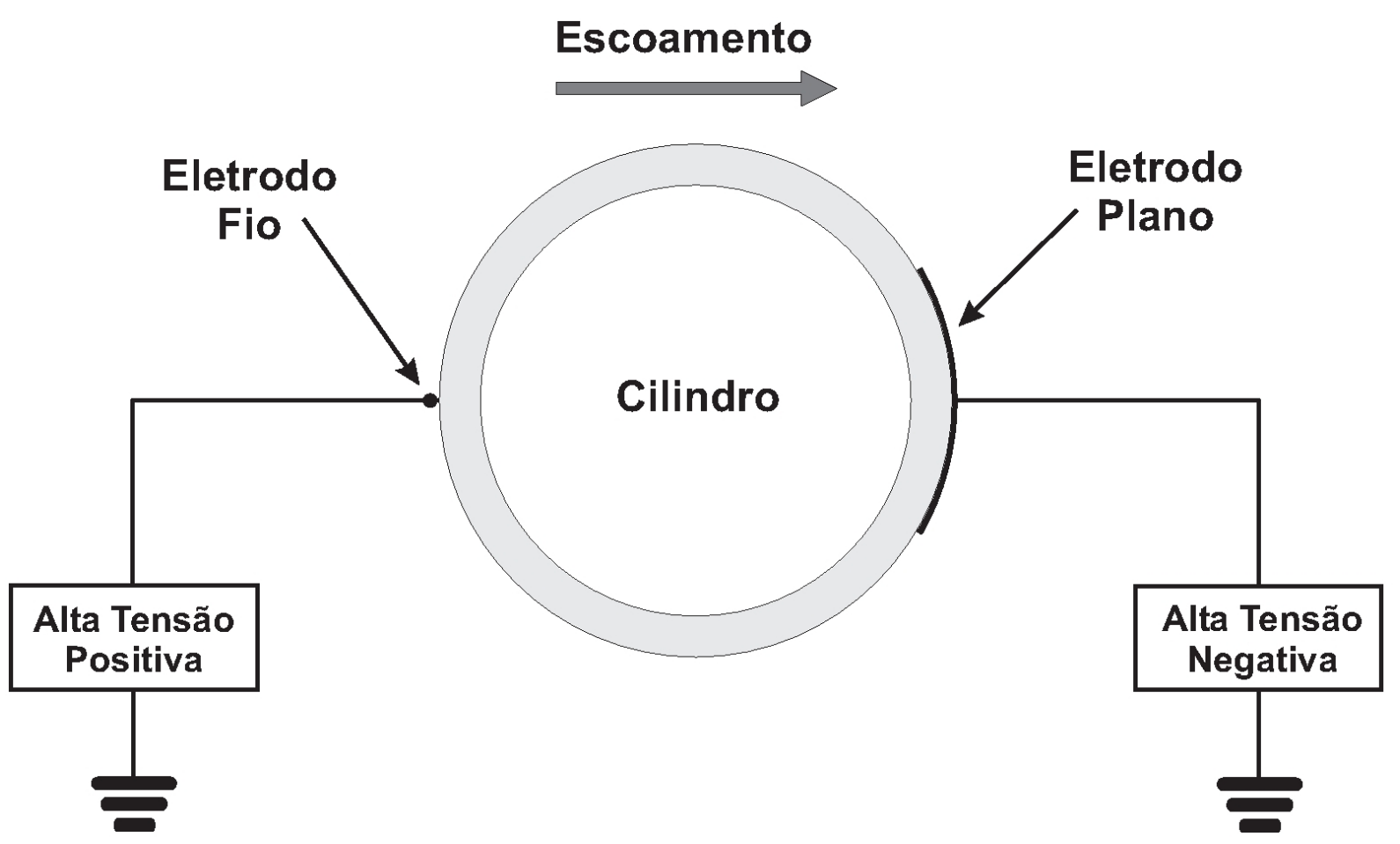

Figura 2.5 - Efeito eletro-hidrodinâmico aplicado em um Cilindro estudado po Artana e al (2002).

Hyun e Chun (2003) realizaram um estudo focalizado no controle da esteira formada a partir de um cilindro através da imposição adequada de um vento iônico. Uma novidade deste trabalho foi que os eletrodos ativos (que induzem o vento iônico) não foram montados embutidos na superfície do modelo, mas foram posicionados a uma certa distância do modelo, como pode ser visto na Figura 2.6. Já o modelo foi utilizado como o eletrodo aterrado (cátodo), sendo que uma folha de alumínio o recobriu por completo sendo então conectada ao terra da fonte de alimentação. Foi determinado pelos pesquisadores que vários tipos de controle do escoamento foram obtidos, dependendo principalmente da posição dos eletrodos. Desta forma, seis diferentes posições dos eletrodos foram examinadas, variando tanto a posição angular dos eletrodos ativos quanto a distância destes ao modelo. Duas etapas experimentais foram realizadas: a visualização do escoamento com fumaça em um número de Reynolds de 4000 e a medição da distribuição de coeficiente de pressão (Cp) ao redor do modelo com o número de Reynolds variando entre 4000 e 8000. Foi utilizada uma fonte de alta tensão contínua que fornecia tensão de 0 a 50 kVolts e 
corrente entre 0 a $4 \mathrm{~mA}$. No entanto, nos ensaios realizados a tensão máxima utilizada foi de 30 kVolts, pois além deste valor ocorria a ruptura elétrica do meio.

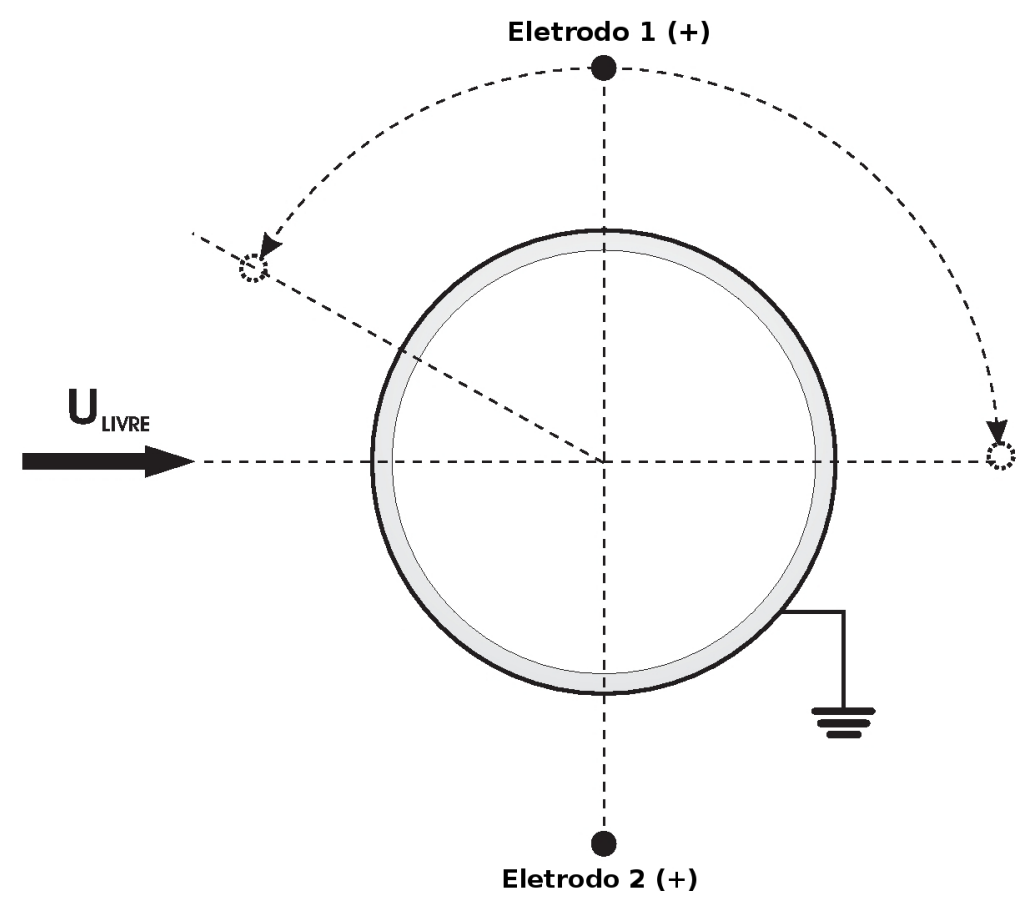

Figura 2.6 - Esquema do Modelo utilizado por Hyun e Chun (2003).

Soldati e Marchioli (2001) apud Schoppa e Hussain sugerem que o forçamento lateral do escoamento ao redor de uma camada limite turbulenta seria apropriado para reduzir o arrasto provocado por esta camada limite através do amortecimento do mecanismo de regeneração dos filamentos vorticais longitudinais de baixa velocidade. Especialmente, eles estudaram o efeito que grandes vórtices parados com os seus eixos orientados longitudinalmente com o escoamento logo acima da camada limite e procederam com análise da influência que estes vórtices teriam na tensão de cisalhamento na parede. Mais recentemente, Schoppa e Hussain (1998) demonstraram que estruturas de escoamento em forma de vórtices, longitudinais, sintéticas e de grande escala superimpostas em um escoamento turbulento de Poiseuille induzem a supressão do mecanismo de instabilidade dos vórtices filamentar de baixa velocidade, os quais, em princípio, parecem ser responsáveis pelo aumento do arrasto nos escoamentos turbulentos.

Desta forma, Soldati e Marchioli (2001) realizaram uma série de análises teóricas e experimentais com a intenção de estudar o efeito da produção de vórtices longitudinais através do efeito eletro-hidrodinâmico. Para tanto, uma série de eletrodos longitudinalmente orientados com o escoamento foram montados em uma placa plana. A intenção 
desta configuração seria a de se criar vórtices pela interação do escoamento produzido eletro-hidrodinamicamente com o escoamento livre. Isto levaria à imposição de vórtices de grandes dimensões, comparados com as estruturas de uma camada limite turbulenta, o que produziria o efeito do forçamento lateral da camada limite. No entanto, o trabalho persistiu na análise teórica do fenômeno e não apresentou nenhum dado experimental para a comprovação do fenômeno.

Um trabalho recente, abriu caminho para a análise da geometria utilizada na construção dos eletrodos. Realizado por Enloe et al. (2004), analisou e comparou duas configurações para a geometria dos eletrodos, variando também uma dimensão de um dos eletrodos (diâmetro para o eletrodo cilíndrico e espessura para o eletrodo plano). Os modelos utilizados consistem de um eletrodo exposto e de um eletrodo isolado (clássica configuração de um dispositivo que utiliza a descarga por barreira dielétrica). Neste caso, o eletrodo exposto apresentou duas geometrias diferentes, um eletrodo cilíndrico e um eletrodo plano. O primeiro teve seu diâmetro variado entre 0,36 a 0,98 mm enquanto que o eletrodo plano teve sua espessura estuda na faixa entre 0,08 a 0,64 mm. Para ambas as configurações o eletrodo isolado utilizado foi uma folha de alumínio com espessura de 0,08 mm e encapsulado por uma fita dielétrica de poliamida. Os resultados produzidos demonstraram um aumento significativo do jato de parede produzido pela configuração que utilizou o eletrodo em forma de fio, inclusive com um aumento expressivo na velocidade máxima do jato de parede.

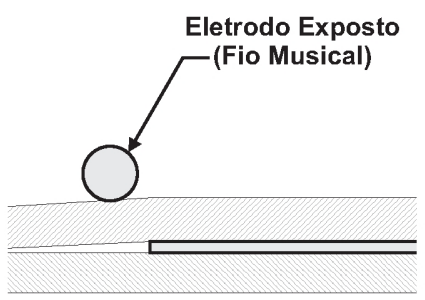

(a)

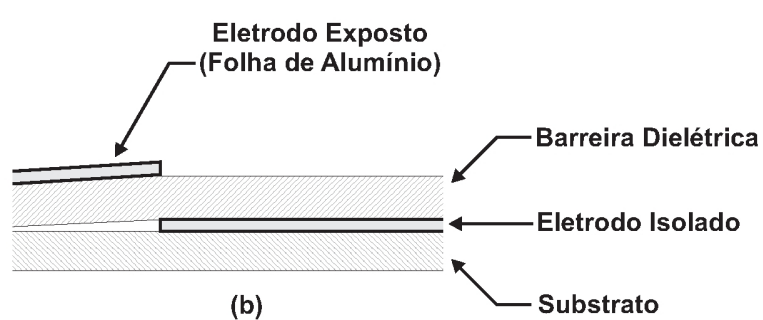

(b)

Figura 2.7 - Esquema dos dispositivos estudados por Enloe et al. (2004).

Baughn et al. (2006) mediram perfis de velocidades em vários locais do atuador, e calcularam a força de campo usando um volume de controle com abordagem de balanço de fluxo da quantidade de movimento. Eles observaram que a força não foi afetada na presença de um fluxo cruzado (por velocidades do escoamento livre da ordem de poucos metros por segundo), e a extensão da força foi limitada ao interior da camada limite. 
Além disso, a produção da força de campo diminui com entrada AC de frequência entre 5 e $20 \mathrm{kHz}$ quando a energia da mesma foi quase constante.

Porte et al. (2006) mediram a força de campo produzida durante a operação constante de um atuador eletro-hidrodinâmico. Foram examinados individualmente os efeitos da tensão AC de entrada e a frequência. Eles concluíram que a média da força de campo é linearmente proporcional à frequência de entrada $\mathrm{AC}$ entre 5 e $20 \mathrm{kHz}$ (para tensão de entrada constante) e não-linear com a tensão da entrada (para uma frequência constante). Além disso, eles observaram que o atuador "empurra" (com maior magnitude) e "puxa" (com menor magnitude) o fluído em direções opostas durante cada ciclo.

Já Forte et al. (2007) realizaram um estudo paramétrico a fim de aumentar a velocidade do vento iônico induzida por atuadores eletro-hidrodinâmicos produzidos através de descarga por barreira dielétrica. Os resultados mostram que uma optimização de parâmetros geométricos e elétricos permite a obtenção de uma velocidade do vento iônico média de até $8 \mathrm{~m} / \mathrm{s}$ a $0,5 \mathrm{~mm}$ da parede. Além disso, as medições não estacionárias do vento induzido foram realizados com registos sincronizados de sinais de corrente e tensão. Estas experiências mostram que o atuador eletro-hidrodinâmico parece gerar uma velocidade pulsada com a mesma frequência que a alta tensão aplicada.

Jayaraman, Thakur e Shyy (2007) consideraram uma aproximação linear para a distribuição do campo elétrico dentro de uma região de plasma, que consiste de uma área triangular localizada acima do eletrodo incorporado. Como a espessura dos eletrodos é muito pequena em relação à camada limite, produzindo um escoamento quase bidimensional, e levando-se em consideração a geometria do campo elétrico, pode-se linearizar as linhas do campo elétrico assim evitando a equação de Maxwell simplificando os cálculos. Eles propuseram que as assimetrias introduzidas através do arranjo dos eletrodos e, consequentemente, a estrutura da descarga tem uma função significativa na geração da descarga brilhante induzida no fluxo.

Mais recentemente, o trabalho experimental realizado por Durscher e Roy (2011) analisou uma geometria nova para os eletrodos envolvidos na produção do escoamento eletrohidrodinâmico. Eles construíram um par de eletrodos na forma de "serpentina", isolados por uma placa de acrílico com $3 \mathrm{~mm}$ de espessura. A Figura 2.8 mostra a configuração dos eletrodos. Os resultados para esta configuração indicaram um maior crescimento da espessura do jato de parede induzido quando comparado com os resultados produzido 
pela clássica configuração de eletrodos planos. Eles notaram, também, que a dinâmica de formação do jato aumentava tanto verticalmente quanto lateralmente. Isso pode ser explicado devido as grandes dimensões dos raios dos eletrodos $\left(\mathrm{r}_{1}=6 \mathrm{~mm}\right.$ e $\left.\mathrm{r}_{2}=4 \mathrm{~mm}\right)$, pois o escoamento induzido tende a se propagar na direção do campo elétrico. Desta forma, o jato induzido tinha uma direção preferencial normal ao contorno do eletrodo superior, o que pode indicar este comportamento lateral do jato.
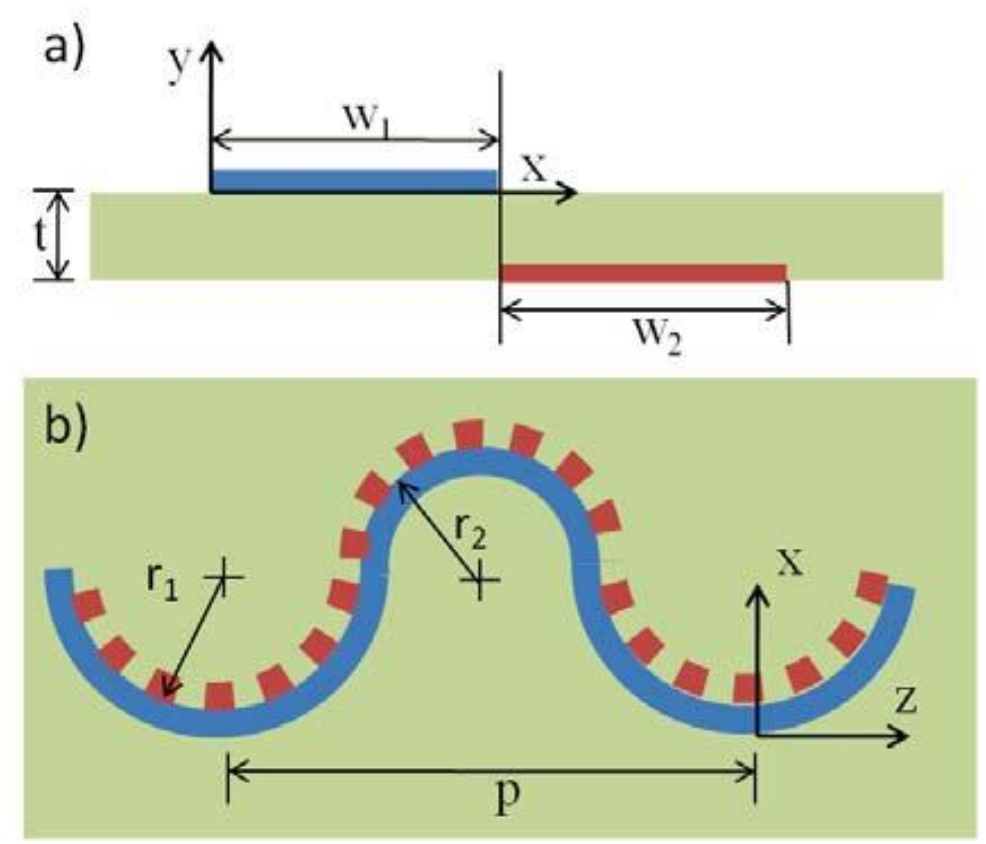

Figura 2.8 - Esquema dos dispositivos estudados por Durscher e Roy (2011) 


\section{Capítulo 3}

\section{Mecanismo eletro-hidrodinâmico}

\subsection{Introdução}

O mecanismo eletro-hidrodinâmico pode gerar movimento, escoamento localizado de baixa velocidade, para incrementar a transferência de massa e calor em escoamentos monofásicos ou bifásicos. Os coeficientes de transferência de massa e de calor entre uma superfície e o fluido circundante podem ser significativamente incrementados através da aplicação de um campo elétrico. O campo elétrico induz um movimento de fluido denominado vento iônico ou vento corona. Um vento iônico requer tanto um campo elétrico imposto e uma fonte de partículas carregadas. Ambas estas condições podem ser satisfeitas pela aplicação de uma fonte de alta voltagem em um eletrodo de pequenas dimensões. Os mecanismos eletro-hidrodinâmicos são baseados na força de Coulomb, na força dieletroforética e na força de eletroestricção.

- A Força de Coulomb é a única força que requer a presença de cargas elétricas livres. As cargas elétricas livres são geralmente produzidas em um fluído pela injeção direta de cargas livres por meio de uma fonte de descarga elétrica. Outra forma consiste no carregamento por indução, baseado no estabelecimento de um gradiente de condutividade elétrica perpendicular à direção desejada do escoamento do fluido.

- A Força Dieletroforética é gerada devido a uma constante dielétrica não uniforme ocorrendo, por exemplo, na interface de uma bolha de vapor com um líquido circundante. 
- A Força de Eletroestricção ocorre devido à alteração do valor da constante dielétrica com uma variação da densidade do meio. No entanto, esta força está presente apenas em fluidos compressíveis. A variação da densidade do fluido na região de uma onda de choque leva à uma variação da constante dielétrica local do fluido. Como a intensidade de um campo elétrico está relacionada com a constante dielétrica do meio, isto leva ao surgimento de um gradiente de campo elétrico na fronteira de variação de densidade do fluido.

Nos fluidos em estado normal a força de Coulomb é o mecanismo principal para a produção de movimento. Suponha uma partícula carregada com carga positiva colocada entre dois eletrodos planos, ver Figura 3.1. Suponha ainda que o eletrodo à direita esteja carregado positivamente, ânodo, e o eletrodo à esquerda esteja ligado ao terra, cátodo. A carga positiva irá se deslocar da direita para a esquerda, ou seja, a partir do mais alto potencial eletrostático para o menor. Por outro lado, um elétron, colocado também entre os eletrodos, irá se mover na direção contrária. Por definição, a direção do campo elétrico formado ente os eletrodos, $\vec{E}$, é determinado pelo movimento da carga positiva. Em unidades do Sistema Internacional, a força em uma partícula carregada será dada por,

$$
\vec{F}=q \vec{E} \text { (Newtons) }
$$

onde, $q$ é o valor da carga e $\vec{E}$ é o campo elétrico dado por,

$$
\vec{E}=-\nabla V(\text { Volts } / m)
$$

onde $V$ é a diferença de potencial eletrostático.

No entanto, o fenômeno eletro-hidrodinâmico não se apresenta apenas nas cargas elétricas livres no fluido. Durante o percurso de uma carga elétrica no fluido neutro circundante, esta carga pode se chocar com algumas moléculas do fluido neutro. Este processo é repetido em larga escala produzindo, então, um movimento no conjunto total 


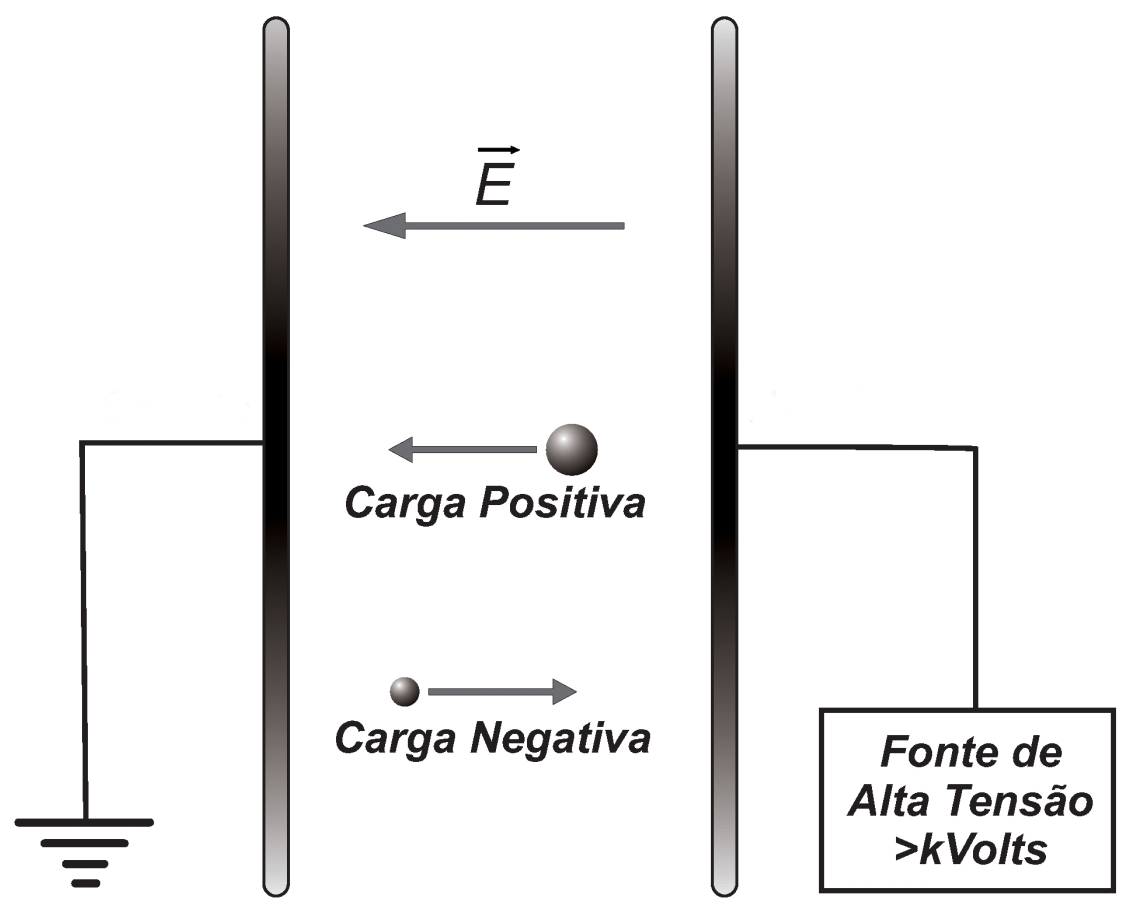

Figura 3.1 - Cargas elétricas na presença de um campo elétrico

do fluido. Para tanto, a análise deve ser feita no conjunto total das cargas elétricas espalhadas pelo fluido. Desta forma, a força eletrostática na densidade de cargas elétricas, $\rho_{c}$, será:

$$
\vec{F}_{E}=\rho_{c} \vec{E}
$$

onde, $\rho_{c}$ é a densidade de cargas elétricas livres no fluido e é dada por.

$$
\rho_{c}=e\left(Z n_{i}-n_{e}\right)
$$

onde, $Z$ é o estado de ionização do meio, $n_{i}$ é a densidade de íons e $n_{e}$ é a densidade de elétrons.

Segundo Roth (1998) os efeitos eletro-hidrodinâmicos são mais bem analisados mais com a análise de partículas individuais do que com a análise do fluido como um meio contínuo. Ele determinou que a abordagem teórica mais produtiva para o entendimento do efeito eletro-hidrodinâmico para a produção de escoamentos ou para o controle de 


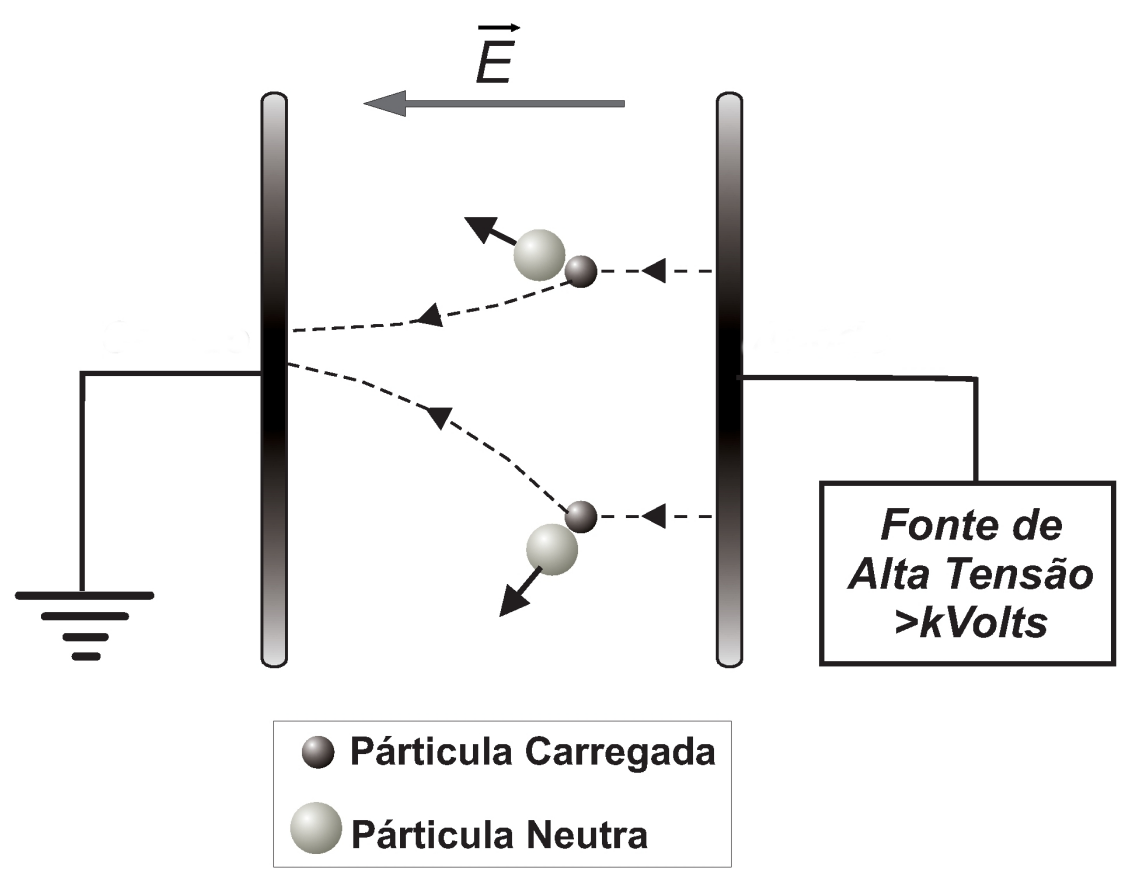

Figura 3.2 - Processo de Transferência da Quantidade de Movimento

escoamentos consiste no formalismo Lorentziano, no qual cada colisão de íons ou elétrons transfere às moléculas de um gás neutro toda a quantidade de movimento e a energia obtida, na média, desde as últimas colisões das duas primeiras entidades para as moléculas do gás neutro.

\subsection{Indução de Escoamentos}

A mais comum manifestação de um escoamento por meios eletro-hidrodinâmicos consiste na presença de um fraco escoamento de ar próximo à pontas submetidas à altas tensões. Considere um eletrodo metálico com uma de suas terminações na forma de uma ponta aguda (ver Figura 3.3). Considere, ainda, que o eletrodo é conectado em uma fonte de alta tensão, com uma tensão suficiente para produzir a ruptura elétrica do meio circundante, ou seja vários quilovolts. Desta forma, ocorre o aparecimento de cargas elétricas livres ao redor da ponta, com a mesma polaridade da tensão do eletrodo. A ação do campo elétrico criado pelas próprias cargas faz com que elas tenham uma concentração maior justamente na região da ponta. Nessa região as forças de repulsão entre as cargas são muito maiores o que significa um fenômeno adicional se a curvatura ou ponta do objeto for muito aguda. Existe um limite para a capacidade de retenção das cargas 
pelo objeto. Se houver uma concentração excessiva dessas cargas, ou seja, o potencial for muito elevado, e consequentemente a força de repulsão, as cargas podem escapar. As cargas que escapam ionizam o ar ambiente e os íons criados, por terem a mesma polaridade das cargas acumuladas na ponta são repelidos. Cria-se então um fluxo de íons que, em conjunto com os choques destas partículas com partículas neutras do meio induzem um escoamento a partir da ponta.

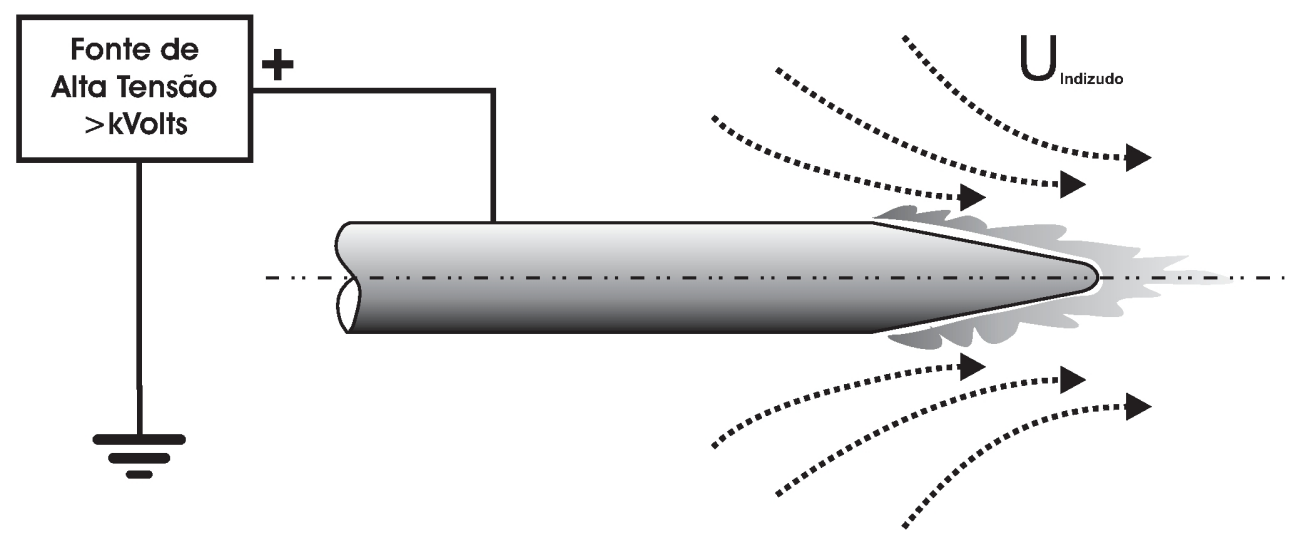

Figura 3.3 - Vento Corona produzido ao redor de pontas sujeitas à altas tensões

\subsection{A Força de Campo Paraelétrica}

Sin (2002) afirma que os efeitos paraelétricos são os análogos eletrostáticos do paramagnetismo e resultam de uma força de campo eletrostático agindo na densidade de carga espaçada de um meio ionizado para o acelerar na direção de um gradiente favorável de campo elétrico, $\partial \vec{E} / \partial x>0$. Estes efeitos se referem à habilidade de um campo elétrico não uniforme de exercer uma força unidirecional em um meio dielétrico eletricamente neutro, porém, polarizado. A velocidade resultante do escoamento do gás neutro em um atmosfera é da ordem de um a dez metros por segundo e a força resultante é na direção do aumento da intensidade do campo elétrico.

Segundo Sin (2002) o escoamento de gás neutro que resulta de efeitos paraelétricos podem ser entendidos em termo do formalismo Lorentziano no qual cada colisão de um íon ou elétron entrega ao gás neutro toda a quantidade de movimento adquirida do campo elétrico apenas desde a última colisão. A magnitude e a direção da aceleração induzida do gás neutro circundante são determinadas pela transferência de quantidade de movimento Lorentziano. Como é ilustrado na Figura 3.4, o plasma se move do gradiente de campo 
elétrico baixo para o alto, e arrasta o gás neutro com ele como resultado de colisões de íons com partículas neutras.

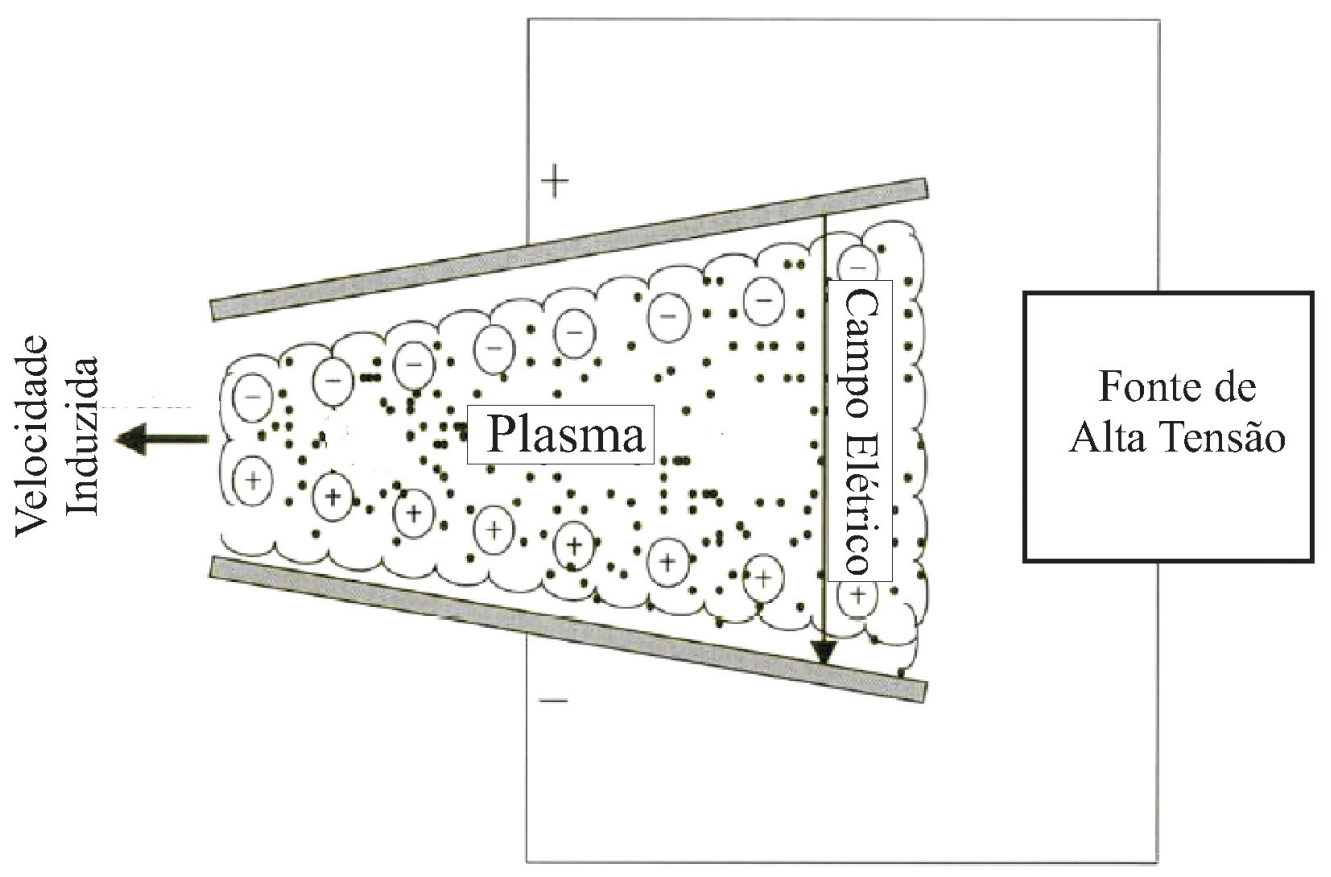

Figura 3.4 - Dispositivo de indução eletro-hidrodinâmica de escoamentos (SIN, 2002).

Segundo Roth (2001) para se formular uma teoria da força de campo paraelétrica que produzem escoamentos eletro-hidrodinâmicos, a força de campo eletrostática é analisada primeiro. A seguir é apresentada a análise demonstrada por Roth (2001),

$$
\vec{F}_{E}=\rho_{c} \vec{E} \quad \text { newtons } / m^{3}
$$

onde $\rho_{c}$ é a densidade líquida de carga,

$$
\rho_{c}=e\left(Z n_{i}-n_{e}\right) \quad \text { coulombs } / m^{3}
$$

$Z$ é o estado da ionização, $n_{i}$ é a densidade iônica e $n_{e}$ é a densidade eletrônica.

A equação de Poisson é utilizada para calcular a força de campo eletrostática, e pode 
ser dada por.

$$
\nabla \cdot \vec{E}=\frac{\rho_{c}}{\varepsilon_{o}}
$$

Onde $\varepsilon_{o}$ é a constante dielétrica. Substituindo-se a equação 3.7 na equação 3.5 e resolvendo para a direção $x$, a força de campo é dada por.

$$
\vec{F}_{E}=\varepsilon_{o} \vec{E} \nabla \cdot \vec{E}=\frac{d}{d x}\left(\frac{1}{2} \varepsilon_{o} \vec{E}^{2}\right)
$$

O termo entre parenteses pode ser expressado como uma pressão eletrostática, $p_{E}$, tendo unidades em Newtons $/ \mathrm{m}^{2}$.

$$
p_{E}=\frac{1}{2} \varepsilon_{o} \vec{E}^{2}
$$

Os gradientes de pressão de um gás ideal e de pressão eletrostática irão estar aproximadamente em equilíbrio se nenhuma força externa estiver atuando.

$$
\nabla p_{g}+\nabla p_{E}=\frac{d}{d x}\left(p_{g}+p_{E}\right)=0
$$

onde $p_{g}$ é a pressão de um gás ideal, $n k T$.

Substituindo $p_{E}$ e $p_{g}$ e resolvendo a equação 3.10, obtém-se.

$$
n k T+\frac{1}{2} \varepsilon_{o} \vec{E}^{2}=\text { constante }
$$

Da equação 3.11 pode-se entender que a pressão do gás neutro no plasma, $p_{g}$, é menor do que a de regiões ao redor sem a presença de campos elétricos. Isto provoca um escoamento do gás circundante em alta pressão na direção do gás de baixa pressão. O termo 
"efeitos paraelétricos"implicam que os íons do plasma e o gás neutro estão acoplados, portanto, os íons podem transferir suas quantidades de movimento para as moléculas neutras e acelerar o gás neutro para fora de uma região de altos gradientes de campo elétrico.

Se o gás neutro escoando para longe do plasma tem uma velocidade $v_{0}$, a pressão dinâmica será igual à pressão eletrostática,

$$
p_{d}=\frac{1}{2} \rho v_{0}^{2}=\frac{1}{2} \varepsilon_{o} \vec{E}^{2} \quad \text { newtons } / m^{2}
$$

onde $p_{d}$ é a pressão dinâmica, e $v_{0}$ é a velocidade do gás neutro.

A velocidade do escoamento induzido do gás neutro $v_{0}$ pode ser obtida por,

$$
v_{0}=\vec{E} \sqrt{\frac{\varepsilon_{o}}{\rho}} \quad \mathrm{m} / \mathrm{s}
$$

Observa-se, desta forma, que a velocidade induzida no gás é uma função da densidade de massa do gás, $\rho\left(1,3 \mathrm{~kg} / \mathrm{m}^{3}\right)$ para o ar nas condições normais de temperatura e pressão) bem como do campo elétrico, $\vec{E}$. Resolvendo para uma geometria de eletrodos planos, com a distância de separação mantida constante, o campo elétrico torna-se função apenas da diferença de tensão aplicada nos eletrodos, que para os cálculos realizados ficaram na faixa de 100 a 5000 Volts. Desta forma, obtêm-se os resultados mostrados na Figura 3.5.

Pode-se constatar que quando o campo elétrico nos cálculos é máximo, $\vec{E}=1,6667 \times$ $10^{6}$, a velocidade teórica induzida no gás é igual à $4,3496 \mathrm{~m} / \mathrm{s}$. Desta forma, para a indução de escoamentos localizados em regiões próximas às superfícies, a força paraelétrica demonstra claramente que pode ser aplicada para o controle de escoamentos, pois, para uma faixa média de número de Reynolds, a velocidade de uma camada limite nesta região é, em princípio, menor. 


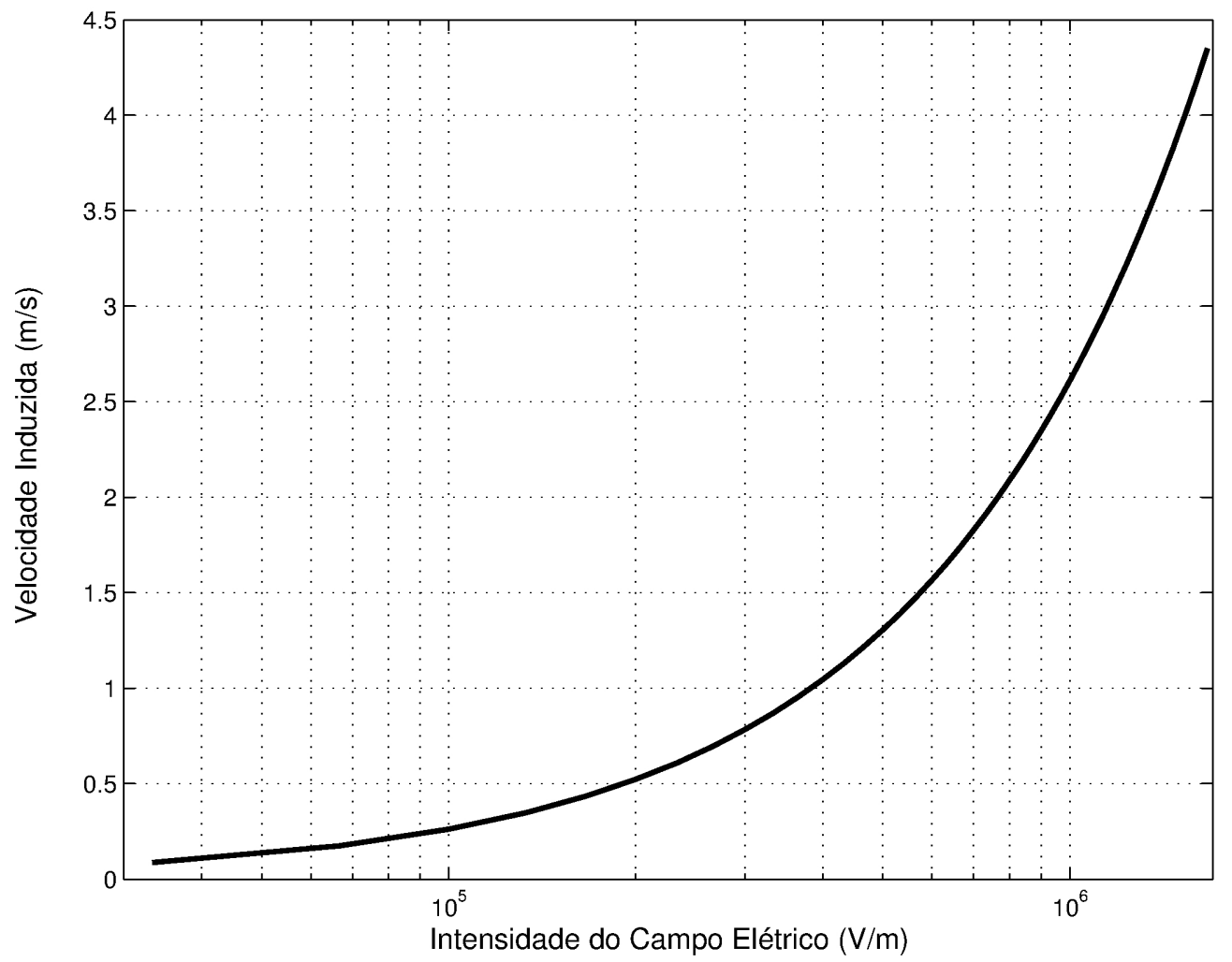

Figura 3.5 - Velocidade Induzida Teórica pela Força Paraelétrica 


\section{Capítulo 4}

\section{Descargas Elétricas}

\subsection{Introdução}

Como foi visto no Capítulo anterior, os mecanismos de produção de movimento por meio do efeito eletro-hidrodinâmico utilizam a força produzida por um campo elétrico em partículas eletricamente carregadas. No entanto, partículas eletricamente carregas não são encontradas em grandes quantidades nos fluidos em condições normais de pressão e temperatura. Para efeito de exemplificação, a ionização na atmosfera terrestre é causada por raios cósmicos, que interagem com as moléculas do ar, e em menor escala no interior de nuvens de tempestade por descargas elétricas. A Figura 4.1 mostra a razão de produção de íons atmosféricos por raios cósmicos com relação à altitude de atmosfera.

Desta forma, para a aplicação do efeito eletro-hidrodinâmico, primeiro é necessário injetar uma grande quantidade de partículas eletricamente carregadas na região de aplicação do campo elétrico. Existem diversas formas de se produzir certas quantidades de partículas eletricamente carregadas. Pode-se citar, por exemplo, a ionização de gases por meio da irradiação do meio por raios X, a elevação brutal da temperatura de um gás (acima de milhões de graus Celsius), ou a utilização de raios ultravioletas de alta intensidade. No entanto, o meio mais acessível de se produzir uma quantidade apreciável de partículas eletricamente carregadas, em gases principalmente, consiste na utilização de uma descarga elétrica. No interior destas ocorre um processo dinâmico contínuo de aparecimentodesaparecimento de íons (moléculas do gás carregadas eletricamente). Desta forma, o gás no interior de uma descarga elétrica é determinado como estando ionizado. O tipo mais 
básico de descarga elétrica consiste na luminosidade que aparece ao redor de um eletrodo que termina em uma ponta aguda. Quando uma tensão elétrica de determinada magnitude é aplicada neste eletrodo, ocorre um grande acumulo de cargas elétrica na ponta do eletrodo. Neste momento, ocorre o salto de algumas cargas na região que circunda o eletrodo, com o consequente surgimento de uma região de fraca luminosidade.

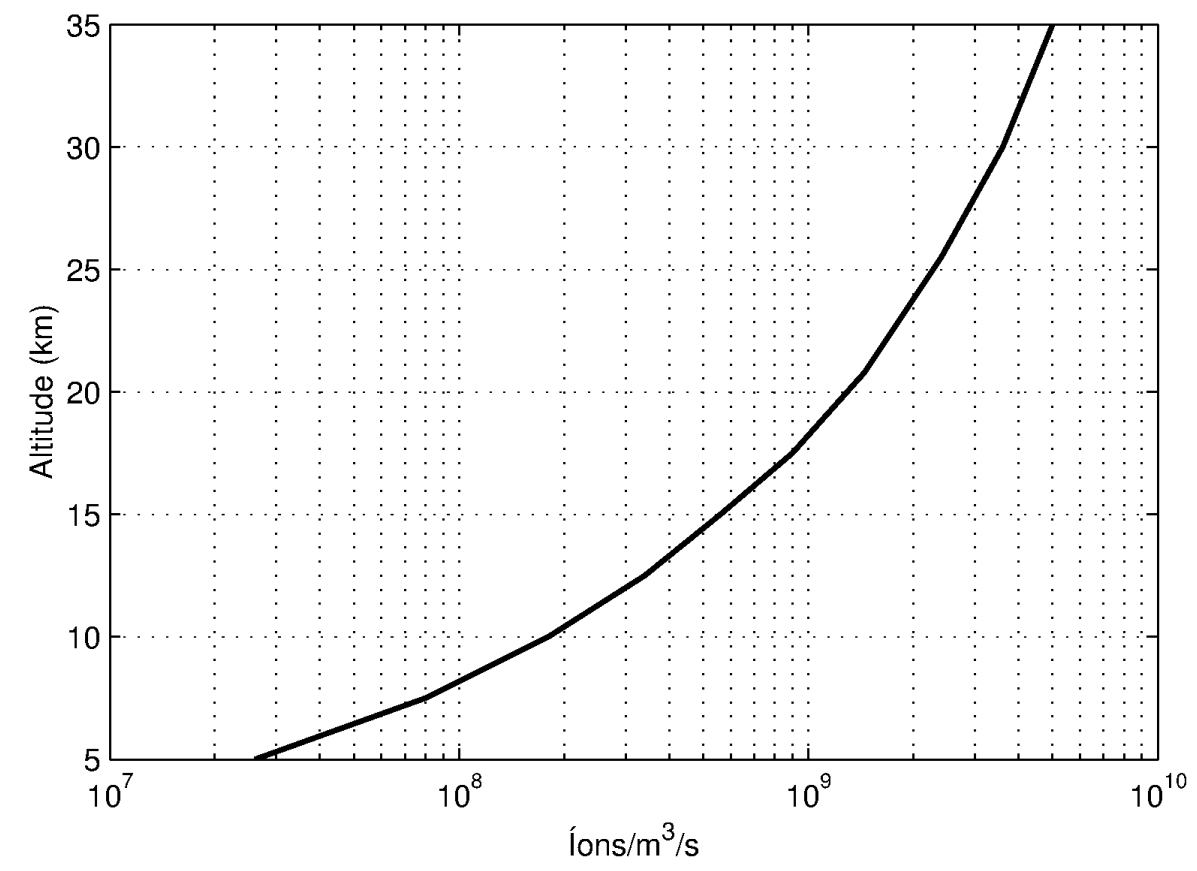

Figura 4.1 - Quantidade de Íons Produzidos na Atmosfera Terrestre (WÅHLIN, 1989).

Segundo Engel (1965) a primeira observação das descargas elétricas foi realizada em 1668 por Otto von Guericke através da utilização de um gerador eletrostático composto de uma grande esfera de enxofre que era esfregada por um tecido. Este equipamento, mostrado na Figura 4.2, era capaz de acumular uma grande quantidade de cargas elétricas, suficiente para provocar o aparecimento de descargas elétricas na esfera. No entanto, foi na natureza o primeiro grande encontro da humanidade com as descargas elétricas produzidas durantes tempestades (relâmpago) a partir de nuvens eletricamente carregadas. Em 1751, Benjamin Franklin, através de seus ensaios com fios condutores suspensos por pipas, conseguiu induzir grandes descargas elétricas atmosféricas.

Após estas primeiras realizações o interesse pela utilização prática das descargas elétricas começou a tomar forma. Em 1777, Lichtenberg estudou os efeitos de descargas elétricas quando atravessavam uma superfície isolante (dielétrica). No início do século XIX, Davy na Inglaterra e Petrov na Rússia descobriram, de forma independente, o arco elétrico. 


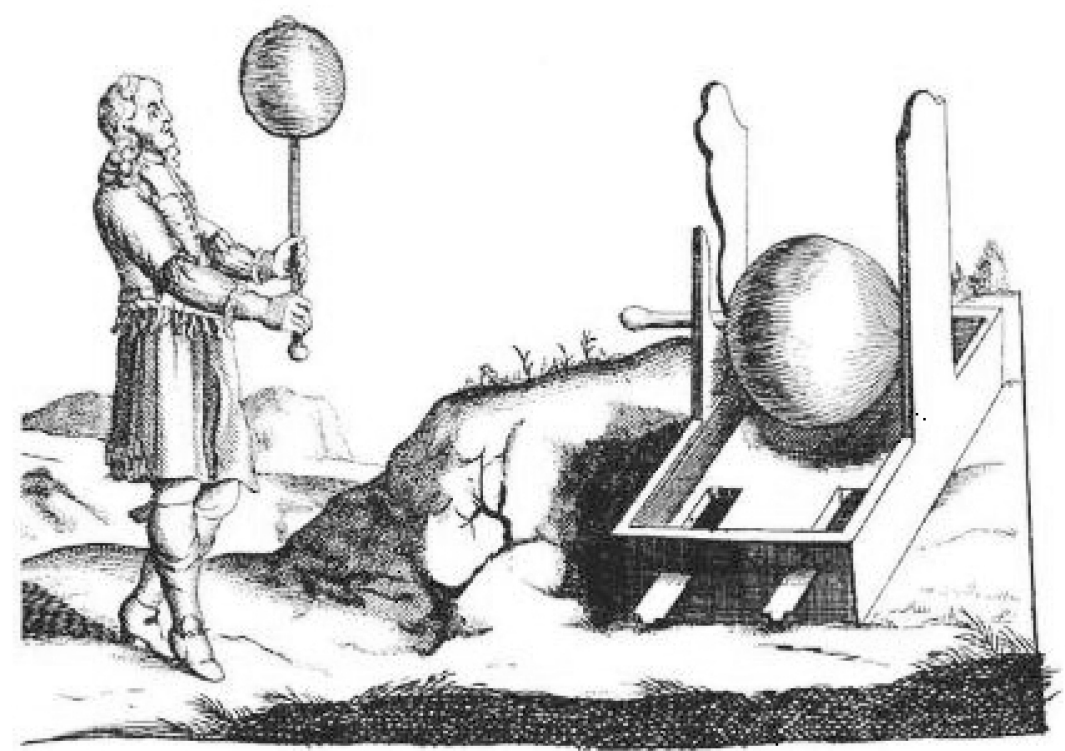

Figura 4.2 - Representação dos Equipamentos de von Guericke.

Através de um experimento rudimentar foi possível observar que quando as pontas de dois pedaços de carvão em contato, conectadas a uma fonte de tensão elétrica, eram separadas, um tipo intenso de descarga elétrica contínua, similar à um pequeno relâmpago, aprecia no espaço entre as pontas de carvão.

Engel (1965) cita Faraday como descobridor de uma nova manifestação das descargas elétricas, a descarga brilhante. Através de pesquisas com descargas elétricas em reservatários contendo um gás a baixa pressão, Faraday pôde observar que a descarga obtida era de maior intensidade luminosa do que as descargas elétricas que ocorriam à pressão atmosférica.

A descarga elétrica consiste na produção de uma grande alteração nas moléculas de um fluido submetido, principalmente, a uma grande diferença de potencial elétrico. Esta alteração consiste na retirada de um ou mais elétrons das orbitas dos átomos constituintes do fluido em questão, ou até na anexação de mais elétrons aos átomos. A partir deste fato, o fluido começa a ficar ionizado e, na maioria dos casos, a produzir desde uma pequena quantidade de luminosidade como também uma grande quantidade de luz por conta da rutura de um arco elétrico no meio ionizado. Neste estágio, pode-se afirmar que o fluido está no estado de plasma, conhecido, de forma genérica, como o quarto estado da matéria.

Um fluido em estado de plasma é um meio composto por partículas eletricamente carregadas e, na maioria dos casos, também por partículas neutras. Existem na natureza diversos estágios de um plasma. Alguns são fluidos que estão completamente levados a 


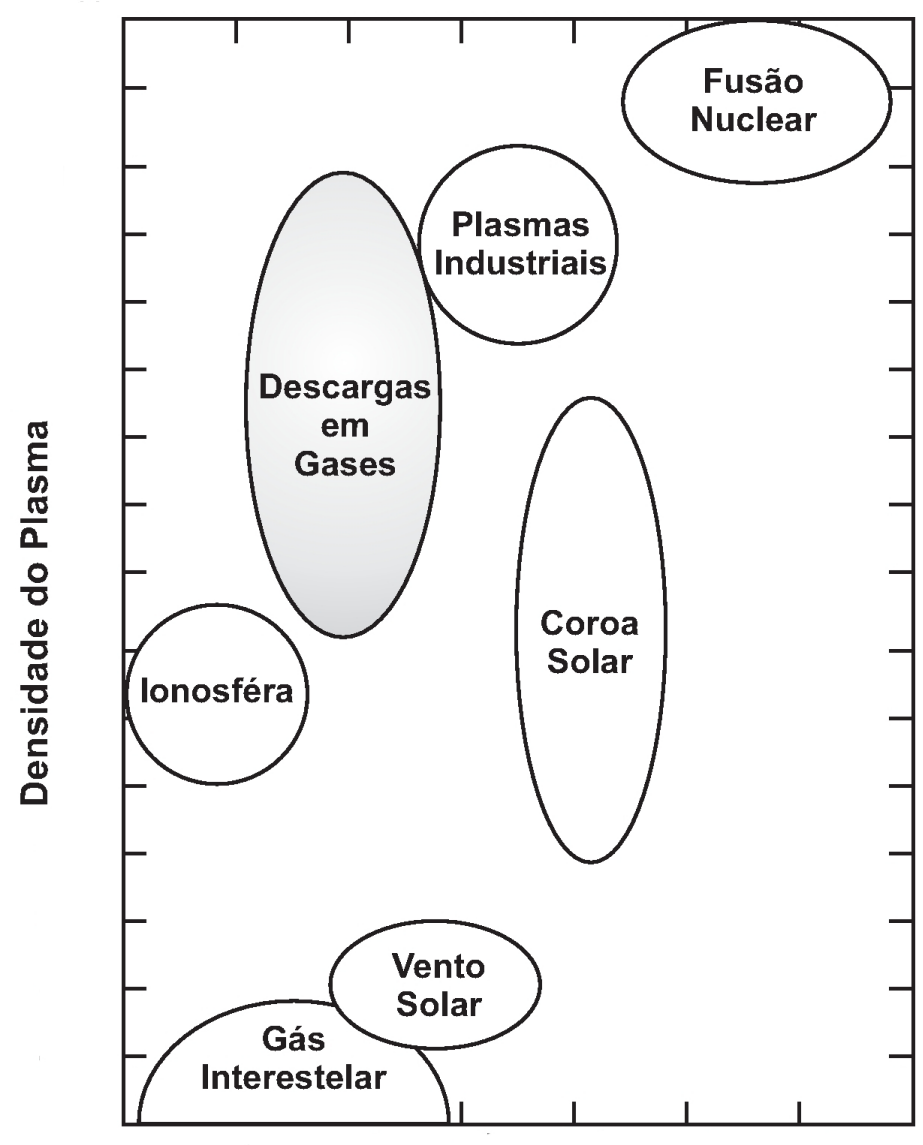

Temperatura Elétrons

Figura 4.3 - Tipos de plasmas encontrados na natureza ou produzidos artificialmente (BRAND, 1997).

situação de um meio eletricamente carregado, ou seja, todas as moléculas que compõem o fluido estão ionizadas. Outros casos são meios que estão parcialmente ionizados. Plasmas do primeiro tipo são aqueles que estão em temperaturas muito altas, pois este é o único meio de se chegar a este estágio de ionização. Já plasmas parcialmente ionizados podem ser encontrados em estágios de baixa temperatura. São estes que mais têm aplicações práticas.

Gases em estado de plasma são encontrados no interior de pequenas descargas elétricas e até em relâmpagos de alta intensidade; pode-se afirmar que mais do que noventa e cinco por cento da matéria conhecida no universo está no estado de plasma, como por exemplo, no interior do Sol. Segundo Sin (2002) o termo plasma foi primeiramente introduzido por Irving Langumir em 1926 e significa uma coleção de íons e elétrons que se encontra neutra. 


\subsection{Processos de Ionização}

Segundo Akyuz (2002) as descargas elétricas são resultantes do balanço entre os processos de ionização e de deionização de um meio gasoso. Na ausência de uma fonte de ionização, o meio está em um estado aproximadamente neutro (possivelmente em algum estado de excitação devido à temperatura do meio diferente do zero absoluto). No entanto, com a presença de uma fonte de ionização o equilíbrio entre a razão de ionização e de deseionização será alterado. Existem muitas fontes de ionização que são capazes de alterar este equilíbrio entre as razões de ionização e de deionização de um meio gasoso. No campo da física das descargas elétricas, a fonte mais importante é um campo elétrico, onde o meio é ionizado por processos de choques com elétrons, na maioria dos casos. Os elétrons que iniciam o processo também podem se originar da radiação cósmica ou da radioatividade, mas também podem ser emitidos foto-eletricamente pela irradiação de um dos eletrodos.

Ainda de acordo com Akyuz (2002) partículas carregadas na presença de um campo elétrico irão, no geral, experimentar uma força em uma direção paralela ao campo elétrico. Como resultado, em adição ao movimento aleatório, as partículas carregadas irão se acelerar sobre a influência do campo elétrico e produzirão colisões com os átomos neutros do gás circundante. Isso resultará em uma perda de energia cinética obtida através do campo elétrico. A energia dissipada para os átomos neutros do gás aumenta com o aumento da velocidade das partículas carregadas e as estas obterão finalmente uma certa velocidade constante denominada de velocidade de deriva (drift velocity). A razão entre a velocidade de deslocamento e o campo elétrico é denominada de mobilidade da partícula carregada. A ruptura elétrica dos gases (descarga elétrica) ocorre como um resultado das colisões entre elétrons, ou fótons, e as moléculas neutras do gás. Um processo de colisão entre duas partículas pode ser definido da seguinte forma: se a distância relativa entre duas particulas diminui em um primeiro instante e então aumenta, uma colisão aconteceu se uma mudança física em qualquer das partículas ocorreu durante o processo. A ionização por colisões eletrônicas é o processo mais comum, no qual íons positivos e elétrons livres são produzidos. É um processo provocado por colisões inelásticas entre moléculas e elétrons com uma energia cinética acima do potencial de ionização da molécula alvo. Dois dos vários processos possíveis de ionização podem ser simbolicamente representados por: 


$$
\begin{aligned}
& e+A B \rightarrow A B^{+}+2 e \quad \text { (Ionização direta) } \\
& e+A B \rightarrow A+B^{+}+2 e \quad \text { (Ionização dissociativa) }
\end{aligned}
$$

Onde, $A$ e $B$ representam tanto espécies atômicas quanto moleculares, o sobrescrito + indica espécies ionizadas e $e$ indica um elétron. A ionização por impacto com fótons é outro processo no qual íons positivos e elétrons livres podem ser produzidos. Este processo é muito importante na propagação de um filamento elétrico (streamer). De acordo com Akyuz (2002) a fotoionização pode ser indicada simbolicamente por:

$$
h v+A B \rightarrow A B^{+}+e \quad(\text { fotoionização })
$$

Onde, $h v$ representa a energia quântica de um fóton incidente. Existem ainda outros processos que podem aumentar o número dos elétrons livres. O processo de destacamento, a liberação de um elétron a partir de um íon negativo, é um importante exemplo. Muito provavelmente os primeiros elétrons necessários para a inicialização de uma descarga elétrica no ar são produzidos por este processo. O destacamento consiste principalmente de um processo de colisão na qual um terceiro corpo é envolvido na interação. No ar, é a molécula de nitrogênio que age como o terceiro corpo quando destaca um elétron de íons negativos de $\mathrm{O}_{2}$.

Cada processo de ionização e de reação individual pode ser descrito por um coeficiente relacionando a razão de reação. Este coeficiente pode ser definido como o ganho de espécies por unidade de comprimento. No entanto, desde que uma enorme quantidade de reações ocorrem no geral, por razões práticas um coeficiente de ionização médio, $\alpha$, é definido. Este coeficiente representa todas as reações possíveis em várias aplicações. O coeficiente de ionização $\alpha$ (ou o primeiro coeficiente de ionização de Townsend) é definido como o número médio de colisões ionizantes por unidade de comprimento, realizadas por um elétron movendo-se na direção do campo elétrico. De acordo com Akyuz (2002) a partir da teoria cinética, Townsend derivou uma expressão para o coeficiente de ionização $\alpha$ no ar como uma função do campo elétrico e da pressão do meio, ou seja,

$$
\frac{\alpha}{p}=A \cdot e^{-B /\left(\frac{E}{p}\right)}
$$


Onde, $p$ é a pressão do meio, $E$ é o campo elétrico e $A$ e $B$ são constantes. No entanto, mesmo sabendo-se que as previsões da Equação 4.1 são confirmadas experimentalmente, ela não é utilizada na prática para se determinar o coeficiente de ionização $\alpha$ no ar. Neste caso específico certas relações especiais devem ser utilizadas.

\subsection{Processos de Deionização}

Os processos de ionização apresentados anteriormente resultam da criação de elétrons livres. No entanto, Akyuz (2002) afirma que em um volume de gás quando partículas opostamente carregadas (íons e elétrons) se aproximam, elas têm também a tendência de se recombinarem. Isso é especialmente importante em plasmas decaindo e em descargas elétricas de alta densidade de ionização. Abaixo são ilustrados dois modos possíveis nos quais uma recombinação entre um elétron e um íon ocorre, ou seja,

$A B^{+}+e \rightarrow A B$ (recombinação elétron-íon)

$A^{+}+e \rightarrow A^{*}+h v \quad$ (recombinação radioativa)

Onde, $A^{*}$ denota um estado exitado da espécie $A$ e $h v$ denota, de novo, a energia quântica de um fóton. A espécie exitada $A^{*}$ pode ir para o estado neutro pela emissão de outro fóton.

Ainda segundo Akyuz (2002) outro processo importante, no qual elétrons livres podem ser retirados de uma descarga elétrica, é o processo de anexação em gases eletronegativos $\left(F, C l, \mathrm{O}_{2}, e t c\right)$. Estes átomos e moléculas têm uma tendência de atrair elétrons livres, pois lhes faltam um ou dois elétrons em suas camadas eletrônicas mais externas. Mesmo sabendo-se que o número de espécies carregadas não irá se reduzir, o número de elétrons livres que podem contribuir para a multiplicação de elétrons irá ser reduzido, o que irá inibir de forma efetiva a descarga elétrica no meio.

Continuando, Akyuz (2002) afirma que sendo o coeficiente médio de ionização $\alpha$ definido como o número de novos elétrons produzidos por unidade de distância, pode-se definir um coeficiente de anexação, $\eta$, como o número médio de elétrons livres perdidos por unidade de distância. Este parâmetro é também uma média de todas as razões de 
reação e de todos os mecanismos possíveis em que elétrons podem ser retirados do meio ionizado (recombinação, anexação, etc.).

Akyuz (2002) afirma que existe sempre uma competição entre os processos de ionização e deionização na presença de um campo elétrico. Os processos de ionização tendem a aumentar o número de elétrons livres enquanto os processos de deseionização tentam reduzir este número. A eficiência relativa desses dois processos em competição depende da magnitude do campo elétrico presente. Na prática, a razão $\alpha-\eta$ produzirá uma razão efetiva de crescimento dos elétrons para todas as reações envolvidas. O termo $\alpha-\eta$ é denominado de coeficiente efetivo de ionização e é expresso por $\bar{\alpha}$. Desde que a ionização cumulativa é apenas possível se $\alpha>\eta$, o campo elétrico deve ser de tal magnitude afim de se atingir este valor crítico no meio antes que a ruptura elétrica possa ocorrer. Este valor é denominado de campo elétrico de ruptura e no ar e é de aproximadamente 2,6 MVolts/m nas condições normais de pressão e temperatura.

Um dos requerimentos básicos para experimentos eletromagnéticos é se providenciar um meio eletricamente condutor em um ambiente controlado. A condutividade elétrica do ar pode ser aumentada em muito tanto pela utilização de materiais semeadores ou pela ionização. A ionização do ar através de uma descarga elétrica é, no geral, a forma mais eficiente do ponto de vista energético, na qual apenas os elétrons da camada mais externa, os elétrons da camada de valência, são removidos. O potencial de ionização para remover um elétron de uma mistura de ar é estritamente determinada pelos potenciais de ionização individuais de seus componentes. Os potenciais de ionização do $\mathrm{N}_{2}$ e do $\mathrm{O}_{2}$ são 15,6 e 12,1 eV, respectivamente. No geral, o potencial de ionização requerido para remover um elétron é baixo para metais alcalinos e a alto para gases (3,9 eV para o Césio e 24,6 eV para o Hélio). Portanto, os materiais semeadores preferidos são, normalmente, o Césio, Potássio ou o Sódio.

\subsection{Descargas Elétricas em Baixa Pressão}

As pesquisas modernas sobre a física das descargas elétricas foram iniciadas através do estudo do clássico tubo de descarga elétrica de baixa pressão. Esta configuração foi o protótipo das lâmpadas de neon e fluorescente. Consiste, basicamente, de um tubo de vidro com o interior em estado de baixa pressão $\left(P_{\text {int }}<<P_{a t m}\right)$ e com os lados contendo 
eletrodos em forma de disco. Estes eletrodos, por sua vez, são ligados á uma fonte de tensão contínua de alta tensão. Desta forma, o cátodo começa a emitir elétrons que por sua vez dão início ao processo de ionização de todo o gás no interior do tubo. A partir deste estágio, ocorre o surgimento de uma luminescência entre os eletrodos, como decorrência do estabelecimento de uma descarga elétrica no meio. Por conta da grande emissão de luz, este fenômeno ficou conhecido como a descarga elétrica brilhante. Como será visto mais adiante, esta descarga elétrica é um dos melhores meios de se produzir apreciáveis níveis de ionização em um meio gasoso.

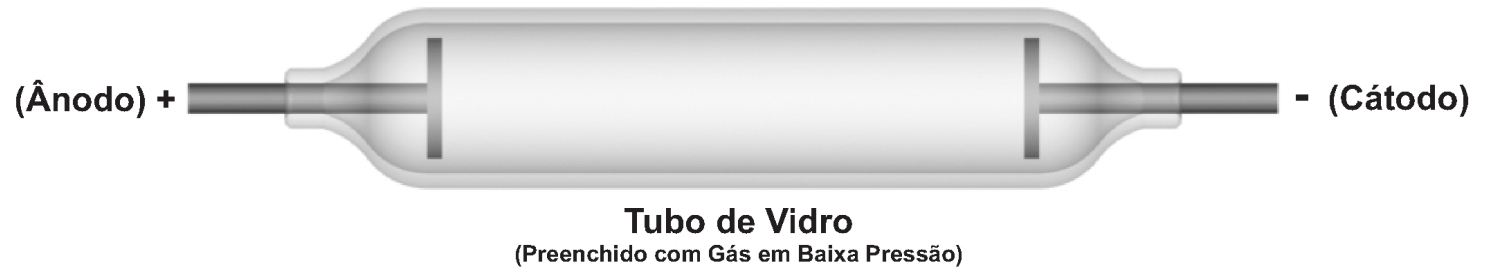

Figura 4.4 - Esquema de um Tubo para Descarga Elétrica em Baixa Pressão.

Basicamente, em um tubo contendo um gás em baixa pressão é possível se obter três tipos distintos de descargas elétricas, ou seja, a descarga escura, a descarga brilhante e o arco elétrico. Estes três regimes dependem de determinadas condições físicas do tubo no qual são produzidas. Pode-se citar, principalmente, a distância de separação entre os eletrodos, o tipo de gás que preenche o tubo (ou mistura de gases) e a razão tensão-corrente que alimenta os eletrodos. No entanto, é usual para diferenciar os regimes de operação das descargas elétricas manter constantes as dimensões do tubo bem como a composição do meio em seu interior e se variar a relação entre a corrente e a tensão elétrica. Ou seja, privilegiam-se as características elétricas da descarga, o que, em princípio, pode ser extrapolado para outros tipos de dispositivos em que se produzem descargas elétricas.

De acordo com Roth (1995) os regimes da relação entre a corrente e a tensão para uma descarga elétrica de baixa pressão são mostrados, esquematicamente, na Figura 4.5. Pode-se ver claramente os três regimes distintos da descarga. No primeiro estágio, descarga escura, existe uma pequena curva onde a corrente varia entre $10^{-10}$ a $10^{-9}$ amperes (aproximadamente) onde a ionização se processa basicamente de modo natural, ou seja, através de raios cósmicos ou de outra fonte de ionização de fundo. Ainda neste estágio, pode-se notar que durante um certo intervalo a corrente se mantém constante mesmo sendo elevada a tensão de alimentação dos eletrodos. Neste etapa as espécies excita- 
das criadas na região anterior, íons e elétrons, são retirados do volume da descarga e os elétrons injetados pelos eletrodos não possuem energia suficiente para produzir nova ionização. Porém, logo a seguir, os elétrons injetados pelos eletrodos adquirem suficiente energia do campo elétrico para que possam agora ionizar algumas moléculas do gás neutro circundante. Este estágio é denominado de Regime de Townsend, e leva a um rápido crescimento do valor da corrente que flui pela descarga com o aumento da tensão de alimentação. Ainda neste estágio a primeira descarga elétrica visível ocorre durante as fases finais do regime de Townsend. Conhecida por Descarga Corona, ela também surge por conta da grande concentração do campo elétrico (gradiente) em pontas, nas bordas ou nas asperezas da superfície dos eletrodos.

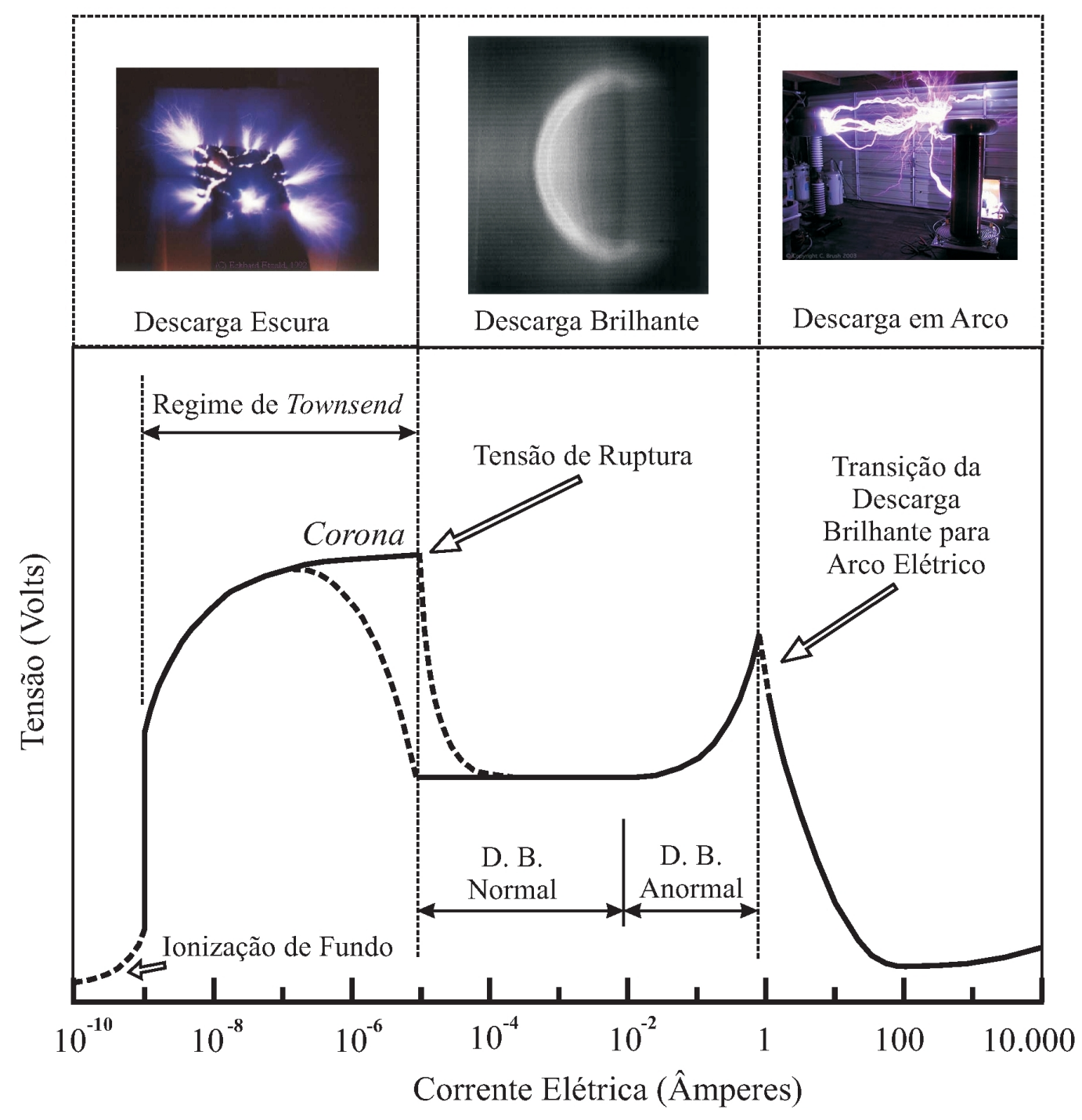

Figura 4.5 - Relação Corrente/Tensão em Descarga de Baixa Pressão (ROTH, 1995).

Após a ruptura elétrica, a região interior do cilindro atinge o regime de descarga 
brilhante. Neste estágio a corrente elétrica que flui pelo gás é suficientemente grande para que uma grande quantidade de moléculas do gás neutro se ionizem. Ocorre também uma mudança significativa no regime da descarga elétrica, pois agora o plasma é claramente visível, o que produz a denominação deste regime de descarga elétrica (como já foi citado anteriormente). Este tipo de descarga elétrica apresenta dois estágios de existência como pode ser visto na Figura 4.5. Logo após uma transição descontínua (parte tracejada descendente da curva) a descarga entra no regime de descarga brilhante normal, na qual a tensão é praticamente independente da corrente para várias ordens de magnitude. A densidade de corrente elétrica entre os eletrodos é independente da corrente total neste regime. Ou seja, o plasma está em contato com apenas uma pequena região da superfície do cátodo com baixa corrente elétrica. Logo após este estágio a descarga entra no regime de descarga brilhante anormal onde a tensão aumenta significativamente com o aumento da corrente elétrica total para forçar a densidade de corrente elétrica no cátodo acima de seu valor natural.

O regime que sucede a etapa de descarga brilhante apresenta uma grande alteração no comportamento do gás entre os eletrodos. Este estágio começa quando os eletrodos tornam-se suficientemente quentes, o que permitem que o cátodo comesse a emitir elétrons de forma termoiônica. Se a fonte de tensão elétrica tiver uma resistência elétrica interna suficientemente baixa a descarga irá atingir a transição para uma descarga em arco elétrico. O regime da descarga em arco apresenta a tensão elétrica na descarga decrescendo com o aumento da corrente elétrica, até que grandes correntes elétricas são estabelecidas e finalmente tendo a tensão elétrica aumentando vagarosamente com o aumento da corrente elétrica. Com relação à luminosidade, este regime apresenta a emissão da maior quantidade de luz com relação aos outros estágios da descarga elétrica em baixa pressão.

\subsection{Descarga Corona}

Segundo Carr (1997) a descarga corona consiste de uma descarga escura que pode ocorrer à pressão atmosférica, devido basicamente à presença de altos gradientes de campo elétrico ao redor de condutores, pontas finas ou bordas finas. Consiste, geralmente, na 
mais comum manifestação de altas tensões elétricas. Ela pode ser facilmente observada em linhas de transmissão de energia elétrica durante à noite ou pode ser facilmente obtida aplicando-se uma tensão de vários quilovolts em um eletrodo que termina em uma ponta fina. Seu estranho nome foi bem descrito por Goldman e Sigmond (1982) como pode ser visto a seguir:

Normalmente pode-se assumir que a descarga corona recebeu seu nome da similaridade entre a coroa de um rei e a região de ionização ao redor da ponta de um eletrodo. No entanto, o reverso é mais provavelmente a verdade: a coroa de um rei deve simular o misterioso poder visto irradiando de mastros (fogo de St. Elmo), ou do Sol durante um eclipse total (coroa solar)...1

Tanto campos elétricos de corrente contínua ou alternada podem ser utilizados para se produzir uma descarga corona, desde que o tensão aplicada exceda um certo limite. A descarga corona pode ser do tipo unipolar ou bipolar, dependendo do número de eletrodos ativos, ou seja, se apenas um ou os dois eletrodos são alimentados por uma fonte de tensão elétrica. Uma descarga corona unipolar é positiva ou negativa dependendo da polaridade do eletrodo ativo. O eletrodo com tensão positiva é cercado por fina região de ionização onde cargas livres são produzidas. Os elétrons do espaço entre os eletrodos são impulsionados na direção do eletrodo de descarga e, na presença do intenso campo elétrico, produzem muitas avalanches de elétrons (processo de multiplicação da ionização) que são responsáveis pela manutenção da descarga. As avalanches de elétrons movemse na direção da descarga deixando atrás íons positivos formados durante o processo. Estes íons positivos movem-se na direção do campo elétrico e transmitem sua quantidade de movimento para as moléculas de gás neutro através de colisões. Isto resulta em um movimento do fluido como um todo conhecido por vento iônico ou corona. Se o eletrodo ativo estiver com polaridade negativa, íons negativos movem-se na direção do eletrodo aterrado e produzem o vento iônico na direção do eletrodo aterrado também. Segundo Carr (1997) a tensão de ruptura da descarga, em temperaturas e pressão atmosféricas para o ar seco é dada por:

$$
V_{\text {corona }}=3000 d+1,35
$$

\footnotetext{
${ }^{1}$ Goldman, M. et al. (1982). Corona and Insulation. IEEE Trans. Elec. Insul., v.E-17, n.2, April.
} 
onde o campo elétrico para a ruptura da descarga é dado por:

$$
E_{\text {corona }}=\frac{V_{\text {corona }}}{d} \quad(k \text { Volts } / m)
$$

onde d é a distância de separação entre os eletrodos. A Figura (4.6) apresenta um esquema geral do estabelecimento de uma descarga corona entre eletrodos cilíndricos concêntricos. Esta configuração é muito comum em equipamentos para a precipitação eletrostática de contaminantes presentes em gases (poeira, fuligem, etc).

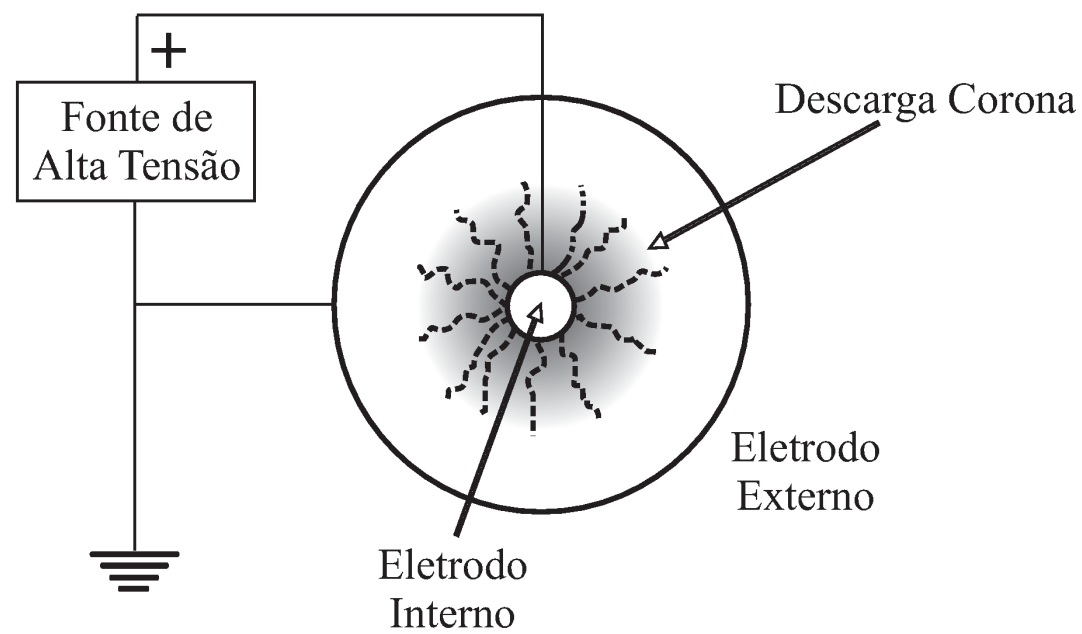

Figura 4.6 - Descarga corona entre condutores cilíndricos concêntricos

\subsection{Descarga Brilhante}

Mohan (2004) afirma que de acordo com a Lei de Paschen, a tensão de ruptura elétrica de um gás depende do produto da pressão do gás, $P_{\text {gás }}$, e da distância de separação entre os eletrodos, $d$. Existe sempre um único valor de $P_{\text {gás }} d$, conhecido como ponto de Stoletow, quando a ionização volumétrica do gás é máxima. A descarga brilhante (glow discharge) opera no ponto de Stoletow, quando o custo energético da produção de um par íon-elétron é mínimo. De todos os tipos de descargas elétricas como um meio produtor de espécies eletricamente carregadas, a descarga brilhante é a que apresenta melhores qualidades para a aplicação em fluidos à pressão atmosférica. Estas qualidades podem ser brevemente descritas e sumarizadas em apenas duas de maior importância: 
- A baixa quantidade de energia requerida face à grande capacidade de produção de espécies carregadas eletricamente;

- A facilidade de implementação técnica dos sistemas necessários para a sua produção.

Segundo Engel (1965) a descarga brilhante é convenientemente descrita como uma descarga na qual o cátodo emite elétrons sujeito ao bombardeamento de partículas e quanta de luz do gás. O campo do cátodo é essencialmente determinado por cargas espaçadas positivas. Efeitos térmicos são tanto ausentes ou uma condição não necessária para a manutenção da descarga.

A descarga brilhante deriva seu nome por conta da região luminosa que se desenvolve perto do cátodo e é separada dele por uma região escura. Quando uma descarga brilhante de corrente contínua é estabelecida em um tubo cilíndrico longo, preenchido com um gás nobre (Neon, Argônio, etc.) a uma pressão entre 0,1 e $1 \mathrm{mmHg}$, a luz visível emitida da descarga é distribuída sobre todo o comprimento do tubo como pode ser visto na Figura 4.7 .

Começando no cátodo existe algumas vezes um muito estreito espaço escuro (de Aston) perto a ele e seguido por uma fina e relativamente fraca camada luminosa o brilho do catado que por sua vez é seguida pelo espaço escuro do cátodo. O espaço escuro de Aston e o brilho do cátodo não são sempre claramente visíveis. Uma fronteira fina separa o espaço escuro do cátodo do brilho negativo, a qual se torna progressivamente obscurecida na direção do Espaço Escuro de Faraday. No fim positivo disto está a coluna positiva. Esta é tanto uma região de luminosidade uniforme quanto de regularmente estriada. No fim positivo da coluna positiva existe algumas vezes visível um espaço escuro de ânodo seguido pelo brilho do ânodo perto do ânodo.

Ainda segundo Engel (1965) existe uma variedade de descargas brilhantes e suas aparências variam com a natureza do gás, a pressão, a dimensão do vaso, o tipo, tamanho, separação e material dos eletrodos. Quando a distância ente o ânodo e o cátodo de uma descarga brilhante é alterada é achado que o comprimento axial da zonas negativas, quer dizer, aquelas próximas do cátodo, permanecem inalteradas enquanto o comprimento da coluna positiva varia. De fato a coluna positiva pode ser mais estendida a qualquer comprimento desde que a voltagem para se manter e iniciar a descarga seja suficientemente grande. 


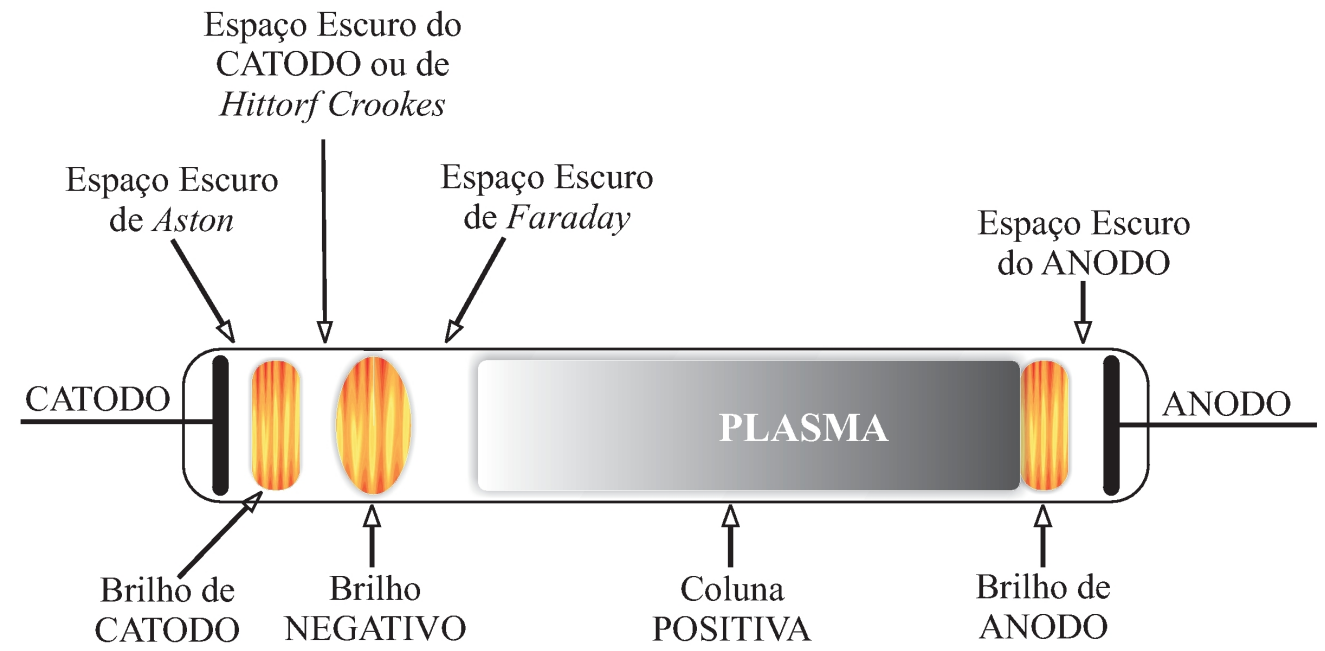

Figura 4.7 - Características Visuais de uma Descarga Brilhante (ENGEL, 1965).

\subsubsection{Descarga Brilhante por Barreira Dielétrica}

Um tipo de descarga brilhante que pode funcionar à pressão atmosférica é a Descarga Brilhante por Barreira Dielétrica. Esta consiste basicamente na produção de um plasma filamentar, à pressão atmosférica, criado a partir de avalanches de elétrons entre os eletrodos dieletricamente isolados. A descarga brilhante por barreira dielétrica foi um dos primeiros tipos de plasma de aplicação industrial. Esta técnica foi primeiramente introduzida por W. Siemens ${ }^{2}$ em 1857 com intenção de produzir ozônio no ar. Ainda no século XIX, a descarga brilhante por barreira dielétrica foi utilizada com um meio eficaz de se produzir ozônio para o tratamento do fornecimento público de água potável em várias regiões do Europa. No entanto, esta descarga não era uniforme, o que levava as peças em contato com a descarga, como os próprios eletrodos que a formavam, a se danificarem rispidamente. Isto tornava a operação da descarga brilhante por barreira dielétrica custosa até certo ponto o que, no entanto, não impediu assim mesmo a sua ampla utilização.

Em 1932, Buss ${ }^{3}$ relatou que em uma fenda plana e paralela a ruptura elétrica do ar ocorre em um certo número de pequenos canais. Utilizando uma placa fotográfica com a emulsão recobrindo a fenda de descarga Buss determinou que se pode esperar 10 microdescargas por $\mathrm{cm}^{2}$, cada uma duração inferior a um microssegundo. Um grande esforço tem sido realizado no sentido de entender o fenômeno físico por trás das microdescar-

\footnotetext{
${ }^{2}$ Mangolini, L. (2000). Experimental study of Atmospheric Pressure Glow Discharges controlled by Dielectric Barrier. Advanced Plasmas Technology.

${ }^{3}$ Mangolini, L. (2000). Experimental study of Atmospheric Pressure Glow Discharges controlled by Dielectric Barrier. Advanced Plasmas Technology.
} 
gas. Técnicas de aquisição de imagens em alta velocidade têm sido utilizadas junto às sofisticadas simulações bidimensionais.

De acordo com Carr (1997) a descarga por barreira dielétrica é formada quando uma alta tensão elétrica de corrente alternada é aplicada à dois eletrodos separados por uma fenda e com um, ou os dois, eletrodos recobertos por placas dielétricas, como mostrado na Figura 4.8. A tensão elétrica deve exceder a tensão de ruptura de Paschen para o gás no qual se produzirá a descarga. Aparecerá, então, entre os eletrodos uma série de filamentos brilhantes, que consistem de descargas separadas altamente condutoras. A física da descargas de barreira dielétricas (DBD) pode, em uma primeira aproximação, ser sumarizada em poucas sentenças: em alta pressão o bem conhecido colapso de Townsend é substituído pelo colapso de filamentos (streamer) o qual leva ao aparecimento de um ou múltiplos canais altamente condutivos. Na prática é quase impossível de produzir uma descarga brilhante à pressão atmosférica entre dois eletrodos de metal desde que depois do colapso toda corrente iria fluir através dos canais altamente condutivos e localizados, cujas características são análogas as de um arco de plasma de corrente contínua.

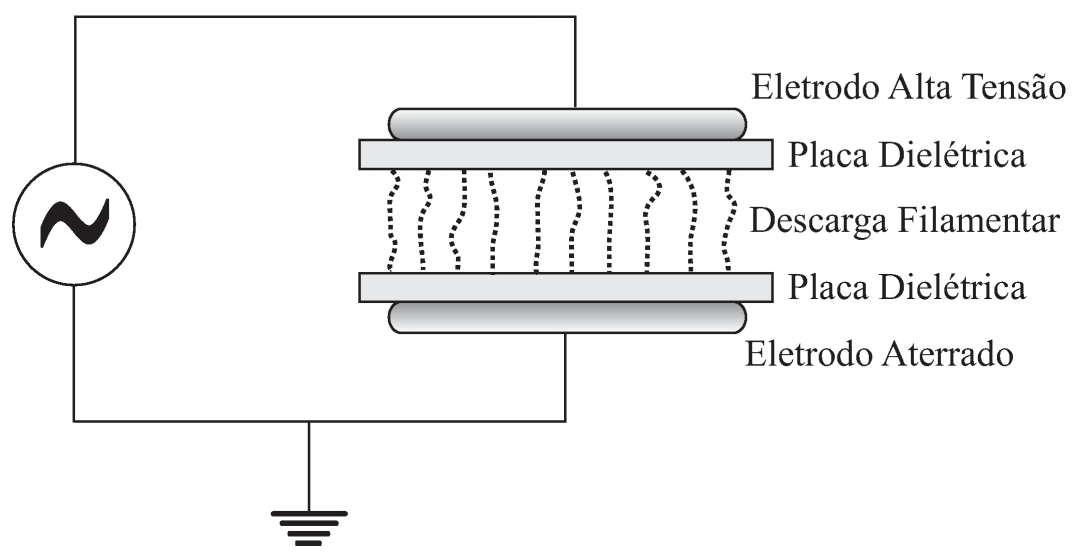

Figura 4.8 - Descarga brilhante por barreira dielétrica

Na descarga por barreira dielétrica leva-se a vantagem do fato de que assim que o gás é ionizado cargas são depositadas nas placas isolantes; isto age na descarga como uma realimentação negativa, diminuindo e finalmente parando o fenômeno do colapso. Pela simples colocação de uma placa isolante no caminho da corrente da descarga foi-se possível evitar a geração do típico plasma de alta pressão, caracterizado pelo equilíbrio térmico, e para produzir plasma de alta pressão em não equilíbrio. 
Isto é apenas uma descrição geral da descarga por barreira dielétrica e com o mesmo tipo de equipamento diferentes regimes podem ser observados. Em certas condições o aparecimento de múltiplos canais condutivos podem ainda serem observados, em outras condições a descarga mostra uma estrutura que é completamente análoga as de uma descarga brilhante de corrente contínua.

\subsubsection{Descarga Brilhante Uniforme}

Se algumas das características da descarga brilhante forem alteradas, ela passa do regime filamentar para um regime onde a descarga apresenta uma região de brilho uniforme entre os eletrodos. Este estágio é denominado de descarga brilhante uniforme e pode ser visto esquematicamente na Figura 4.9. De fato, todas as características já demonstradas para uma descarga brilhante à baixa pressão são encontradas neste tipo de descarga. O ponto diferente aqui é que neste regime a pressão do meio pode ser levada até à pressão atmosférica (101500 Pa nas condições normais), e até além desta marca. No entanto, como será mostrado a seguir, este estágio da descarga brilhante necessita de certas condições para que possa se manter estável nestas condições, ou seja, para que não retorne ao estado filamentar nem que rompa em um arco elétrico.

Se as condições de pressão e temperatura forem mantidas constantes, a forma mais fácil de se alcançar este estágio é fazer com que a distância de separação entre os eletrodos seja diminuída com relação ao estágio filamentar. Outra forma consiste em se aumentar a frequência da tensão alternada de alimentação dos eletrodos.

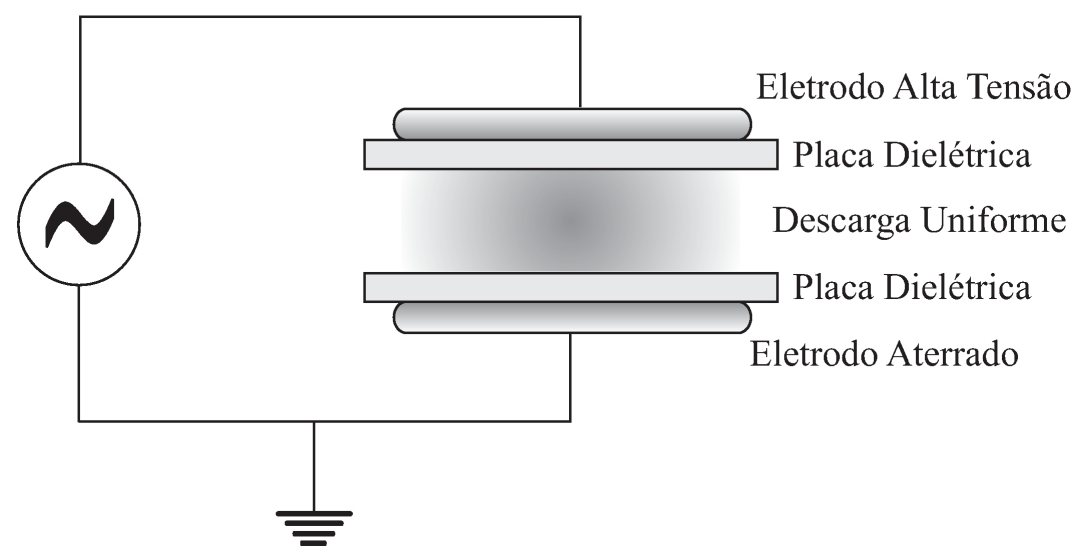

Figura 4.9 - Descarga Brilhante Uniforme 


\subsection{Arco Elétrico}

Este tipo de descarga não apresenta praticamente nenhuma aplicação na manipulação de escoamentos aerodinâmicos. No entanto, como faz parte dos regimes de uma descarga elétrica, será brevemente discutido. O que mas difere este regime de descarga elétrica das outras descargas reside no fato de que o canal luminoso que caracteriza este regime de descarga consiste em um condutor elétrico. Ou com outras palavras, o gás na região do canal luminoso está praticamente ionizado por completo e elétrons fluem por ele da mesma forma que fariam por um bom condutor metálico, ou seja, com baixíssima resistência elétrica. No entanto algumas aplicações na aerodinâmica são encontradas na literatura, principalmente na introdução de perturbações em escoamentos desde na faixa de baixos valores de números de Reynolds até em escoamentos super ou hipersônicos. Lachowicz e al. (1994) utilizaram pequenas descargas elétricas em arco para introduzirem perturbações sobre o escoamento hipersônico sobre um corpo em forma cônica. 


\section{Capítulo 5}

\section{Descarga Brilhante Atmosférica}

\subsection{Introdução}

A descarga brilhante atmosférica é talvez a forma mais prática de produzir uma razoável ionização em gases para aplicações aeronáuticas. Como o próprio termo deixa claro, é um tipo de descarga brilhante iniciada e mantida à pressão atmosférica. Como será visto mais à frente, este tipo de descarga ainda mantém, em geral, todos os aspectos de uma descarga brilhante em baixa pressão. No entanto, devido ao fenômeno fundamental de uma descarga brilhante, requer determinadas condições para seu funcionamento adequado. Seu desenvolvimento é, até certo ponto, motivo de muita pesquisa, pois ainda não se determinaram todas as suas características de funcionamento. No entanto, já se chegou a um ponto em que aplicações práticas desta forma de descarga estão sendo testadas nas mais diversas áreas. Como ponto de referência, pode-se citar os seguintes tópicos básicos de aplicação:

1. Geradores de Ozônio;

2. Esterilização;

3. Processamento de Materiais;

4. Manipulação de Escoamentos.

Para aplicações de esterilização, a descarga brilhante é ideal por conta de suas características de longa duração, uniformidade e baixa densidade de corrente. Não requer 
sistemas em vácuo com a adição de reagentes químicos ou gases bem como não necessita de expor o material a ser tratado à altas pressões ou altas temperaturas.

Massines et al. (1998) utilizaram a descarga brilhante atmosférica no tratamento de superfícies de polipropileno. Foi determinado que a exposição à descarga brilhante atmosférica aumenta a energia da superfície de forma muito mais rápida do que com a utilização da descarga filamentar.

A manipulação de escoamentos com o uso da descarga brilhante atmosférica é sua mais recente forma de aplicação. Roth, Sherman e Wilkinson (1998) utilizando uma técnica de produção da descarga brilhante atmosférica modificaram de forma significativa o escoamento sobre uma placa plana. Eles utilizaram uma disposição de eletrodos paralelos ao escoamento, com os quais obtiveram sucesso na redução de arrasto sobre uma placa plana, na qual foram montados os eletrodos. A Figura 5.1 apresenta uma imagem da descarga elétrica ao redor dos eletrodos utilizados nos ensaios de Roth, Sherman e Wilkinson (1998).

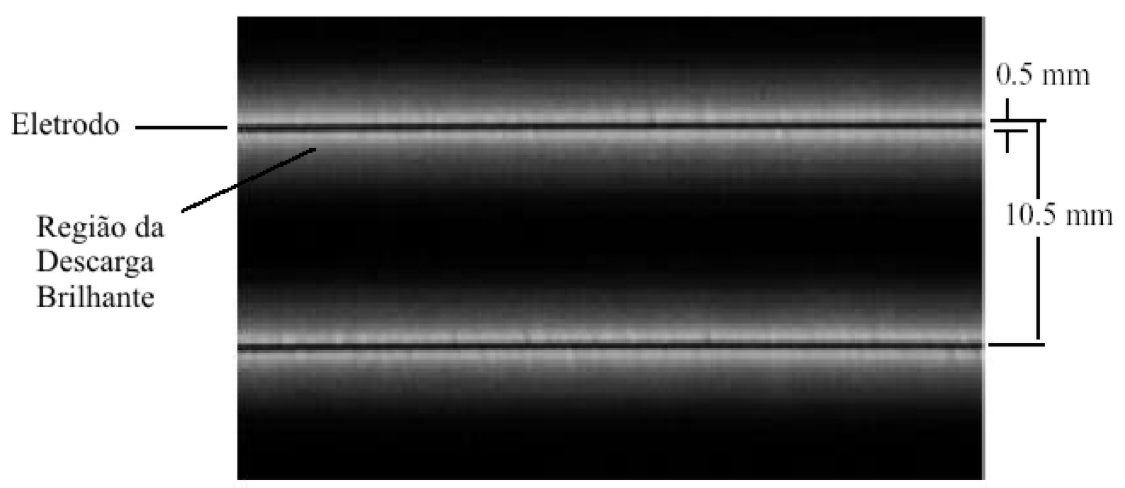

Figura 5.1 - Descarga brilhante atmosférica ao redor de eletrodos utilizada por Roth, Sherman e Wilkinson (1998).

\subsection{Produção de Descarga Brilhante Atmosférica}

A descarga brilhante atmosférica é, atualmente, a forma mais eficiente de produzir ionização do ar do ponto de vista energético. Isto é provocado devido ao fato de que apenas os elétrons da camada mais externa dos átomos, ou seja, os elétrons da camada de valência são removidos. Outros meios de se produzir ionização em larga escala, como tochas de plasma ou jatos de arco elétrico, utilizam em alguns casos mais de mil vezes mais energia do que uma descarga brilhante atmosférica. No entanto, uma descarga brilhante 
atmosférica deve apresentar algumas características para funcionar de forma eficiente e uniforme. De outra forma, a descarga que se formaria seria ou no estado filamentar ou poderia até decair para a ruptura de uma descarga em arco.

- Alta Tensão Elétrica de Ruptura - Para se iniciar uma descarga elétrica a tensão aplicada nos eletrodos deve ser maior do que a tensão de ruptura do dielétrico do gás que recobre os eletrodos. Segundo Lieberman e Lichtenberg (1994) esta tensão é, no entanto, extremamente dependente do produto da pressão do gás, $p$, pela distância de separação dos eletrodos, $d$. A Figura 5.2 apresenta resultados da relação Tensão com pd para o ar em $20^{\circ} \mathrm{C}$. Desta forma, para a produção de uma descarga brilhante à pressão atmosférica é necessário que a tensão aplicada tenha valores na casa dos quilovolts. Por outro lado, pequenas distâncias de separação entre os eletrodos podem diminuir a mínima tensão requerida para o início da descarga.

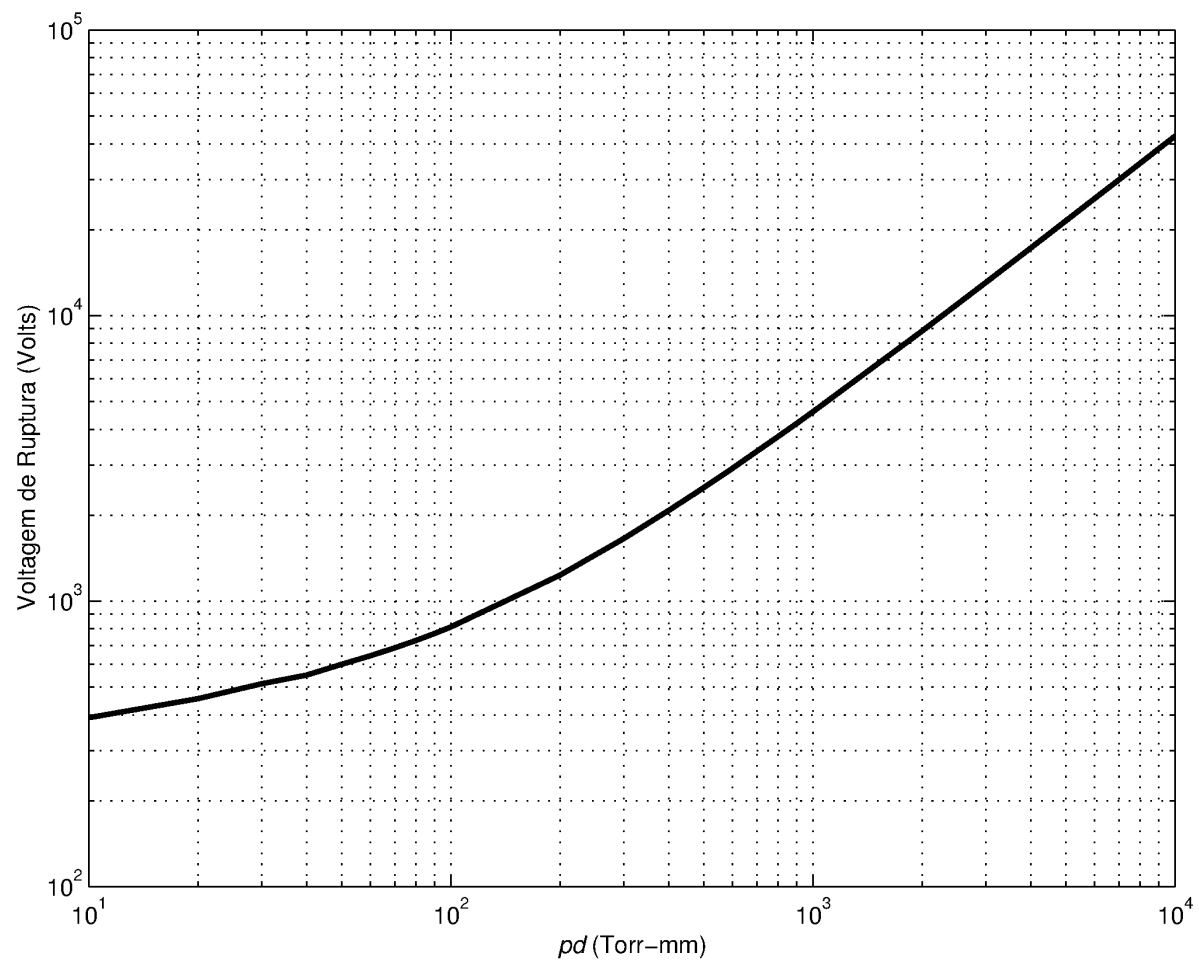

Figura 5.2 - Relação entre a Tensão Elétrica de Ruptura com pd (LIEBERMAN; LICHTENBERG, 1994).

- Tensão Alternada - Para se obter uma descarga brilhante estável na pressão atmosférica uma tensão elétrica em corrente alternada na faixa de vários quilo-hertz é requerida (ver Figura 5.3). Segundo Massines et al. (1998), em uma frequência menor do que $1 \mathrm{kHz}$ uma descarga filamentar aparece; quando a frequência é aumentada para $10 \mathrm{kHz}$ as características da descarga brilhante surgem desde que 
as outras condições permaneçam as mesmas. Entre estes dois estágios, existe um estado de transição. Sempre existe uma faixa de frequência para se obter uma descarga brilhante estável, que depende também do tipo de gás e do material utilizado como barreira dielétrica.

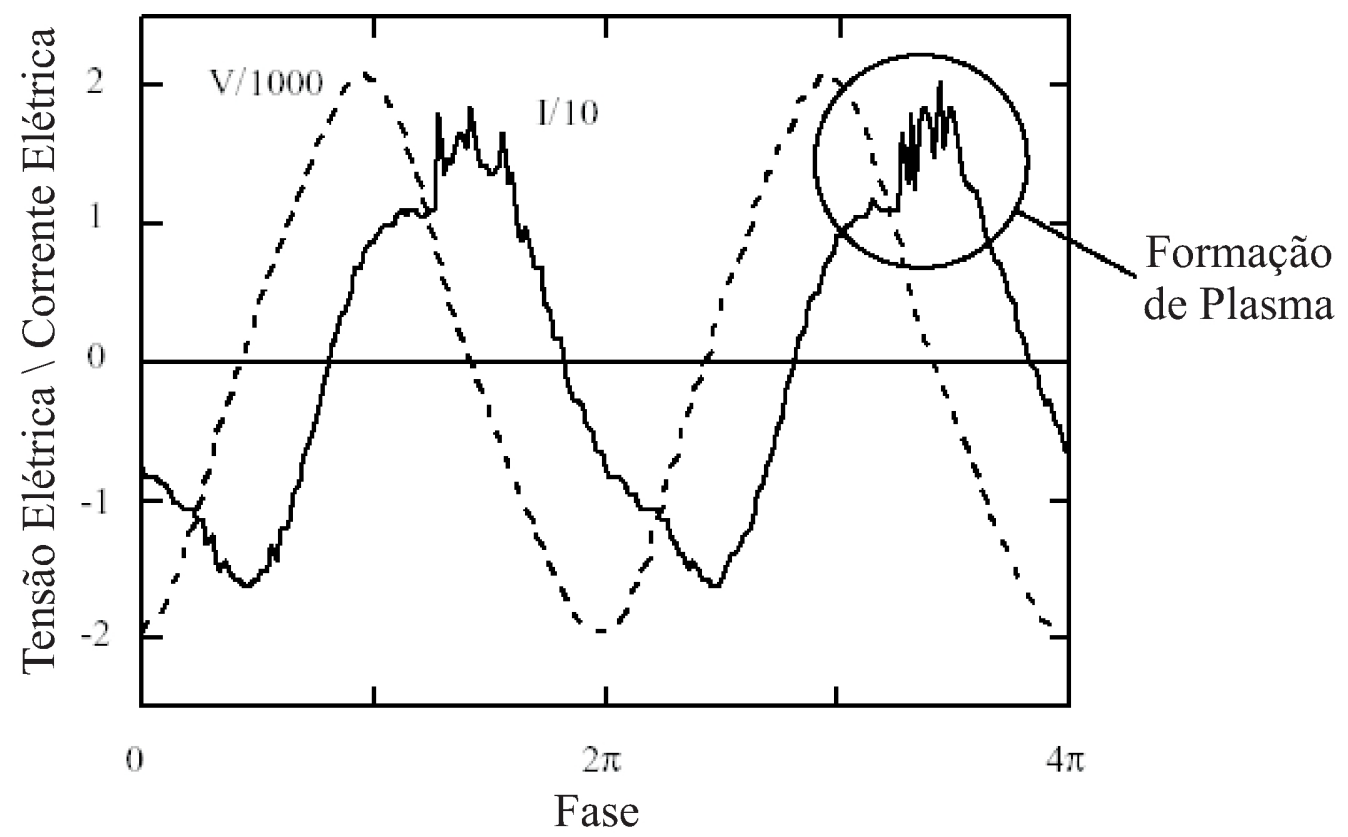

Figura 5.3 - Tensão/corrente características de uma descarga brilhante (ROTH; SHERMAN; WILKINSON, 1998).

- Mecanismo de Prevenção de filamentos - Nos plasmas em altas pressões os elétrons colidem mais frequentemente com os átomos do gás neutro, o que faz com que avalanches de elétrons cresçam em intensidade mais rapidamente. No campo elétrico, a nuvem de elétrons se move na direção do ânodo com uma esteira de íons atrás, resultando em um dipolo elétrico. A superposição do campo externo aplicado com o campo elétrico provocado por este dipolo leva à formação de duas frentes de ionização, uma na cabeça e a outra na cauda da nuvem de elétrons. O desenvolvimento da frente de ionização no lado do cátodo irá levar a um rápido desenvolvimento de um canal filamentar altamente condutivo, o que faz surgir uma ponte na fenda que separa os eletrodos. Neste regime, a fenda é preenchida com descargas filamentares transientes não uniformes, randomicamente distribuídas. A descarga filamentar facilmente se transforma em uma indesejável descarga em arco. Barreiras dielétricas são frequentemente utilizadas para controlar o aparecimento de descargas filamentares. A acumulação de cargas espaçadas na placa dielétrica produz um campo elétrico oposto, e desta forma, diminuindo a tensão elétrica através 
da fenda que separa os eletrodos, suprimindo o crescimento da intensidade da avalanche de elétrons (ZHANG, 2004).

Para a manutenção da descarga brilhante em regime permanente e funcionando de forma estável e constante, algumas considerações quanto ao estado do gás na qual ocorre a descarga devem ser feitas. Vale a pena sempre lembrar que agora a descarga brilhante ocorre à pressão atmosférica e, portanto, o fluido é o ar. Desta forma, pode-se considerar o seguinte:

- Aumentar a Densidade Líquida de Cargas no Gás Antes Ruptura do Meio: Altas densidades eletrônicas podem aumentar a multiplicação de ionização em um campo elétrico fraco e, portanto, será mais fácil produzir a descarga brilhante. Por outro lado, altas densidades de elétrons e íons, que se acumulam nas placas dielétricas, podem aumentar em muito a intensidade do campo elétrico no espaço entre os eletrodos na próximo meio ciclo de tensão o que, por sua vez, irá ajudar a produzir a descarga mais rapidamente (ZHANG, 2004).

- Aumento do Coeficiente de Ionização em um Campo Elétrico de baixa intensidade: Alguns tipos de impurezas têm uma grande razão de ionização, o que leva ao aumento da frequência de ionização. Mas segundo Massines et al. (1998) a presença de uma grande quantidade de impurezas no ar irá induzir o regime filamentar na descarga brilhante.

- Presença de escoamento: Gherardi e Massines (2001) demonstraram que a presença de um escoamento laminar de baixo Reynolds tem alguma influência na amplitude e na frequência requeridas para produzirem uma descarga brilhante atmosférica.

\subsection{Descarga brilhante atmosférica como um Dispo- sitivo EHD}

Os plasmas produzidos por uma descarga brilhante atmosférica requerem apenas campos elétricos. Não requerem campos magnéticos ou sistemas de vácuo de baixa pressão. 
A descarga brilhante atmosférica é produzida por fontes de corrente alternada de baixa frequência ao invés do uso de tensões de corrente constante. Deslocamentos de correntes são utilizados para produzir a descarga brilhante atmosférica, e correntes reais não são requeridas. A frequência utilizada para produzir a descarga brilhante atmosférica é normalmente menor do que $10 \mathrm{kHz}$.

De acordo com Sherman (1998) a característica fundamental da descarga brilhante atmosférica é o mecanismo de aprisionamento de íons. Este mecanismo consiste na oscilação restrita e periódica de íons ao longo de linhas de campo elétrico. A tensão RF induz uma oscilação dos íons com a frequência aplicada nos eletrodos da descarga brilhante atmosférica, tal que os íons transitam pela fenda que separa os eletrodos mas não atingem os eletrodos durante um meio ciclo da tensão RF aplicada. Roth (1995) demonstra que a frequência necessária para se obter o mecanismo de aprisionamento de íons é dada pela seguinte relação,

$$
\nu_{0}=\frac{Z V_{r m s} e}{\pi M d^{2} v_{c}}
$$

onde $\nu_{0}$ é a frequência $\mathrm{RF}$ requerida para aprisionar os íons, $Z$ é a carga dos íons, $V_{r m s}$ é a tensão $r m s$ aplicada, $M$ é a massa iônica, $d$ é a distância de separação entre os eletrodos e $v_{c}$ é a frequência de colisão entre as partículas neutras e os íons.

O plasma produzido pela descarga brilhante atmosférica não está em equilíbrio. Diferente das descargas brilhantes de corrente contínua em baixas pressão, a temperatura cinética do elétron, densidade eletrônica e a densidade iônica são dependentes do tempo e variam com o ciclo da tensão de alta frequência. Segundo Mohan (2004) o custo energético da produção da descarga brilhante atmosférica é baixo, pois, como se trata de uma descarga brilhante, ela opera no ponto de Stoletow, onde o custo energético da produção de um par íon-elétron é mínimo, ou seja, $81 \mathrm{eV}$ para o ar. Os dispositivos produtores de descarga brilhante atmosférica são leves devido à ausência de magnetos e de grandes correntes dissipativas. Portanto, podem ser utilizados no controle do escoamento de camada limite ou em aplicações de redução de arrasto. 


\section{Capítulo 6}

\section{Produção de Escoamentos EHD}

\subsection{Introdução}

O objetivo central deste trabalho consiste na obtenção de dados que indiquem possíveis melhorias no desempenho da produção de escoamentos eletro-hidrodinâmicos através da escolha adequada da geometria dos eletrodos. Entretanto, se faz necessário antes adquirir experiência na produção de escoamentos eletro-hidrodinâmicos, bem como testar os elementos principais que serão utilizados na etapa experimental. Para tanto, foram realizados dois experimentos simples: primeiro a visualização do escoamento ao redor de um cilindro em um túnel de vento de baixa velocidade e a visualização da indução de escoamentos eletro-hidrodinâmicos sobre uma placa plana utilizando uma configuração clássica da geometria dos eletrodos (eletrodos planos).

Para a suprir a necessidade de uma fonte de energia elétrica, uma fonte de alta tensão e alta frequência foi desenvolvida e construída especificamente para este trabalho. O Apêndice A apresenta este equipamento de forma pormenorizada. Para uma breve descrição, vale ressaltar que esta fonte pode fornecer uma tensão que varia entre aproximadamente 1 kVolts até 10 kVolts, com uma máxima corrente de saída da ordem de $20 \mathrm{~mA}$. Este fonte de alta tensão fornece estas tensões sobre a forma de corrente alternada na faixa de frequências de $1 \mathrm{kHz}$ a $10 \mathrm{kHz}$.

Para a medição da tensão de alimentação dos eletrodos foi utilizada uma sonda de alta tensão especialmente construída para esta investigação. Este equipamento tem a característica fundamental de reduzir a tensão de entrada a uma razão de 1000:1, ou 


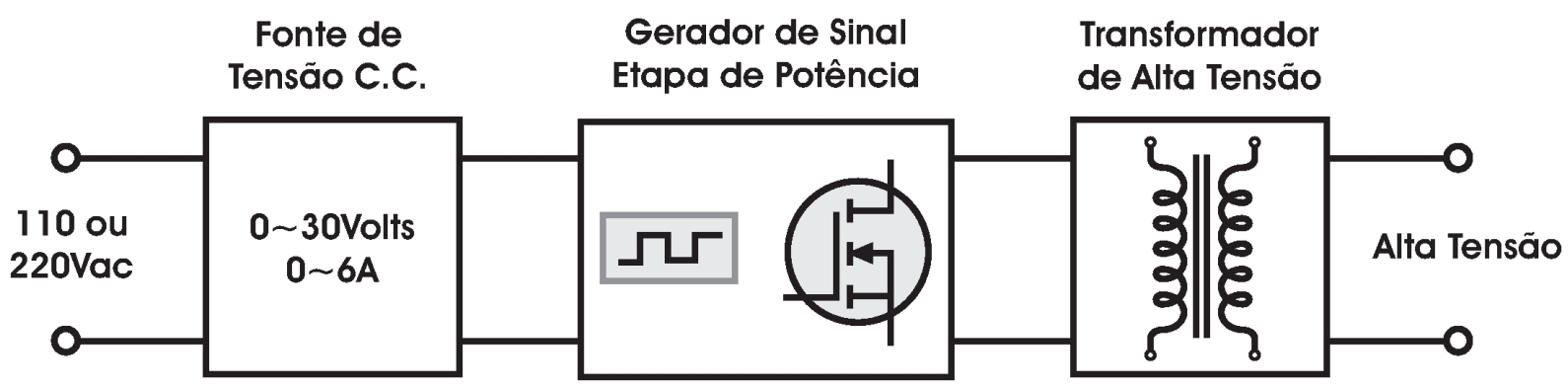

Figura 6.1 - Circuito Esquemático da Fonte de Alimentação.

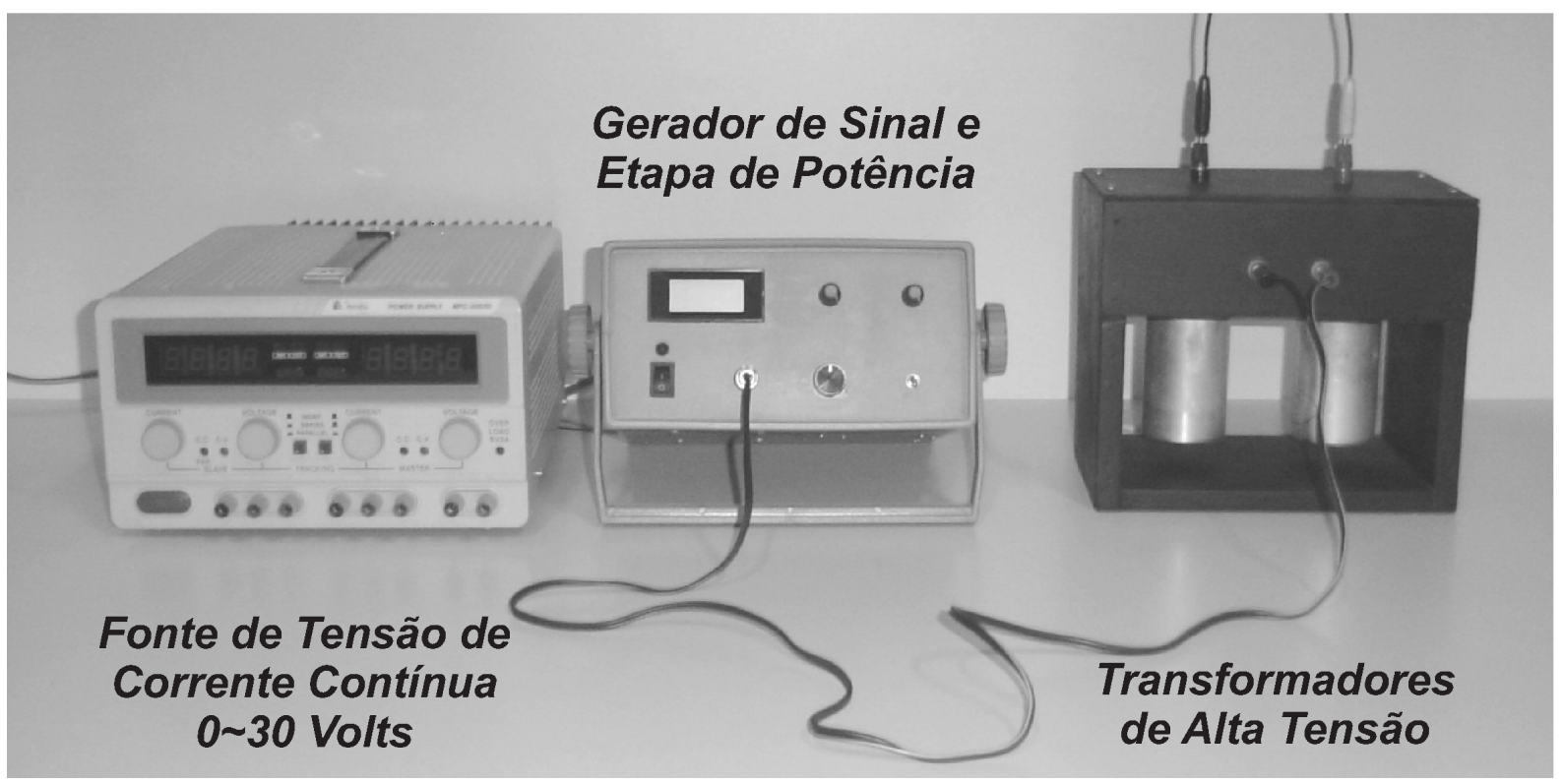

Figura 6.2 - Fonte de Alimentação.

seja, apresenta em sua saída uma tensão 1000 vezes menor do que a de entrada. Maiores detalhes sobre este equipamento podem ser obtidos no Apêndice B. A Figura 6.3 mostra este equipamento.

Para a medição da corrente fornecida aos eletrodos foi utilizando um transformador de corrente modelo TA12-100 (ver Apêndice C). Este componente tem a característica de medir a corrente induzida ao longo de um fio condutor e fornecer uma saída em tensão proporcional a corrente medida. Ou seja, é um componente que mede de forma não invasiva a corrente que flui por um condutor. Isto é extremamente adequado para a medição de correntes que fluem por condutores submetidos a elevadas tensões. Suas principais características são: faixa de corrente de entrada de 0 a 5 A, razão de 1000:1 na tensão proporcional de saída e capacidade de medir corrente por 1 minuto quando o condutor está submetido a uma tensão de corrente alternada de 6,0 kVolts. 

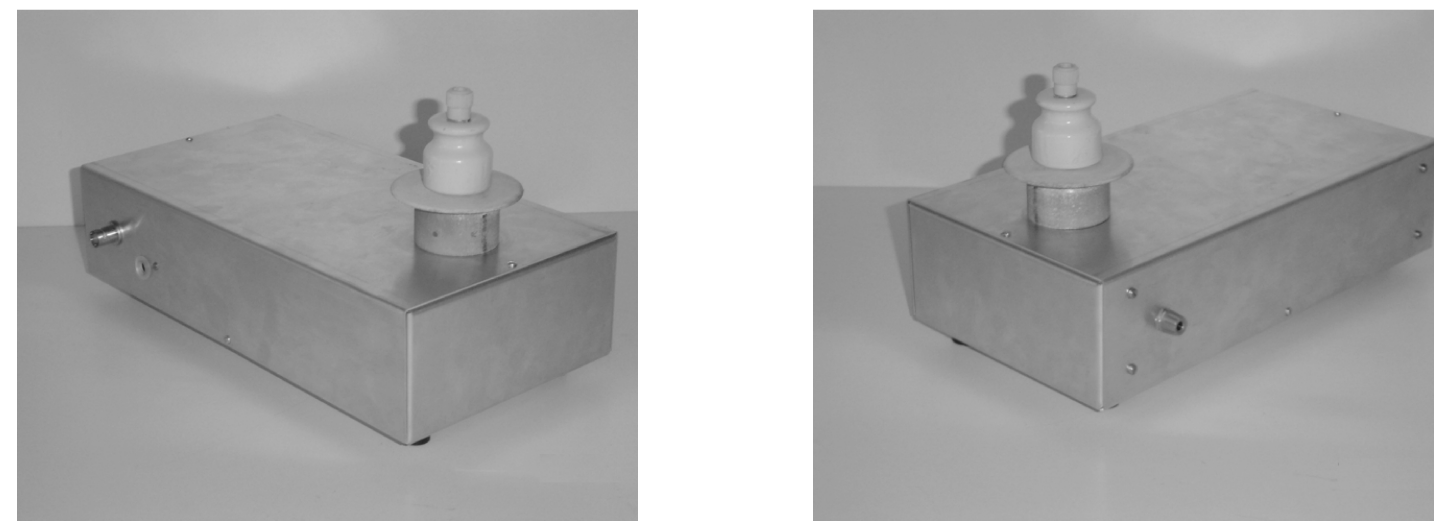

Figura 6.3 - Sonda de alta tensão.

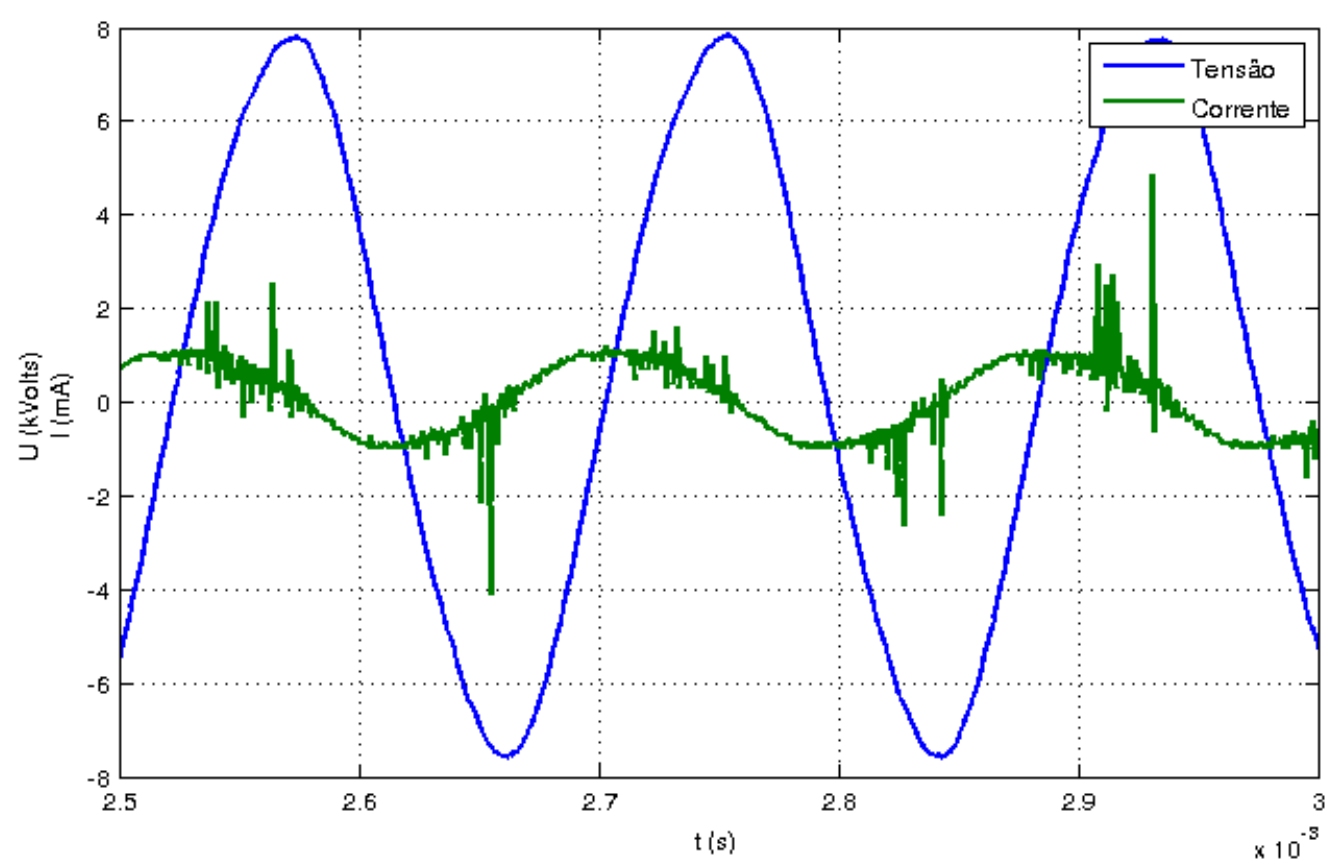

Figura 6.4 - Exemplo de medidas da tensão e corrente fornecidas aos eletrodos.

\subsection{Produção de Escoamentos ao redor de Cilindros}

O objetivo primordial desta etapa experimental consiste na verificação de evidências da alteração do escoamento ao redor de um cilindro com a utilização de uma descarga por barreira dielétrica. Uma descarga elétrica formada entre um condutor cilíndrico e uma placa condutora, separados por uma placa dielétrica, induz a formação de uma fina camada de fluido ionizado que apresenta a indução de um escoamento tangencial à placa dielétrica. Através deste artifício, espera-se alterar o comportamento do escoamento ao redor do modelo em estudo. 
Esta etapa experimental foi realizada em um número de Reynolds baixo, $R e \sim 6000$ (escoamento bidimensional, com o diâmetro do cilindro igual a $54 \mathrm{~mm}$ e velocidade do escoamento da ordem $1,5 \mathrm{~m} / \mathrm{s}$ ). No entanto, a intenção nesta avaliação é a de demonstrar o mecanismo fundamental da interação de uma descarga por barreira dielétrica com o escoamento ao redor de um corpo não espera-se determinar as escalas de funcionamento adequadas para aplicações de altos valores de números de Reynolds.

\subsubsection{Descrição do Modelo}

O modelo que foi utilizado nestes ensaios consistiu em dois cilindros de PVC, um montado internamente ao outro. Este conjunto tinha um comprimento igual à profundidade da câmara de ensaio do túnel de vento utilizado, 15 centímetros, e diâmetro externo de 6 centímetros. Um eletrodo consistindo em um fino fio de cobre, com diâmetro igual a 0,6 mm, foi montado sobre o cilindro externo ao redor da região onde o escoamento encontra o cilindro em ângulo reto, ou seja, na linha de estagnação. O comprimento deste foi ajustado em $13 \mathrm{~cm}$, deixando, desta forma, $2 \mathrm{~cm}$ de folga entre a ponta do fio e a parede do túnel de vento. Isto foi feito com o intuito de se evitar a formação de um arco elétrico entre a ponta não conectada do fio e a parede do túnel, composta de uma chapa metálica. Por outro lado, o eletrodo foi estendido pela outra ponta do cilindro e encaminhado, através de um tubo plástico isolado montado no interior do modelo, até o exterior do túnel de vento. Foi por meio desta extremidade que se fazia a alimentação deste eletrodo.

Separado do eletrodo externo pela espessura do corpo do cilindro externo, foi montado no cilindro interior uma fina chapa de cobre (espessura ao redor de 0,1 mm) com comprimento igual a $11 \mathrm{~cm}$. Este eletrodo tinha uma largura angular de $\pm 90^{\circ}$, tomando como referência a posição do eletrodo externo. O comprimento da chapa foi adotado com o valor supracitado para minimizar a formação de uma descarga elétrica parasita entre a ponta do eletrodo externo e o eletrodo interno. A Figura 6.5 apresenta uma vista lateral do conjunto, destacando principalmente os elementos constituintes do modelo (sem respeitar as escalas). Já as Figuras 6.6 e 6.7 apresentam uma visão global do modelo. Pode-se ver que a alimentação do eletrodo interno foi realizada através de um fio rígido, moldado de forma a se conectar com este eletrodo e ser levado através de um orifício isolado na parede do túnel de vento até o exterior. 


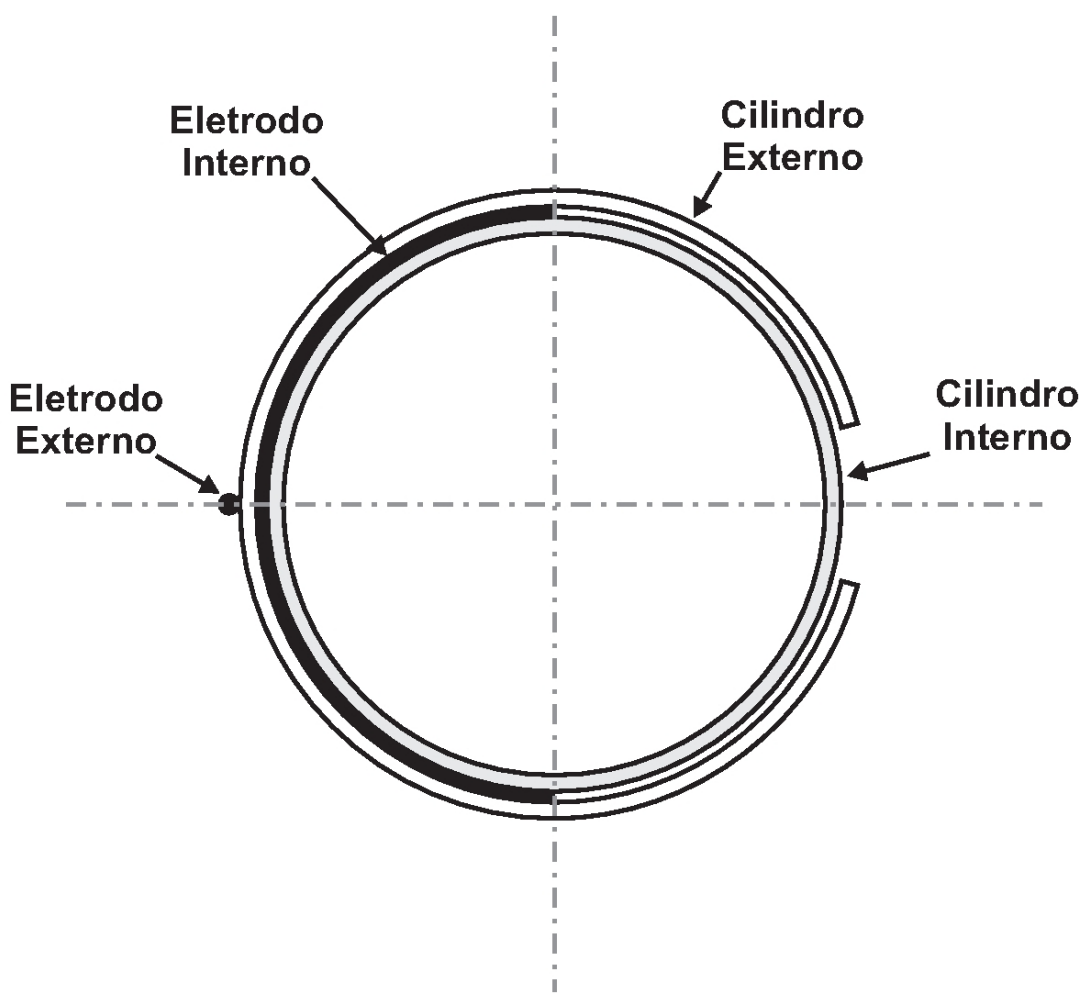

Figura 6.5 - Esquema Geral dos Componentes do Modelo.

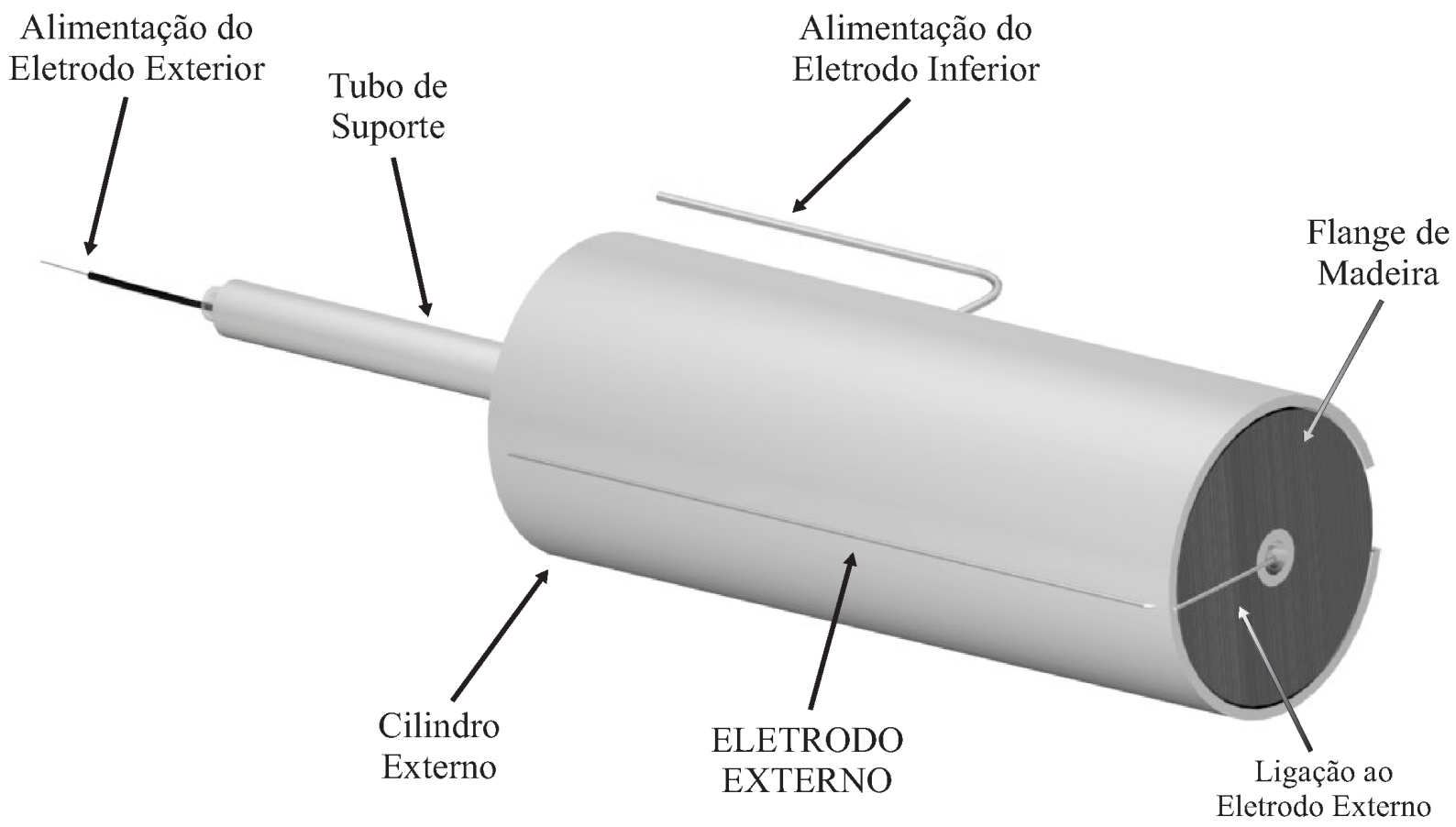

Figura 6.6 - Vista Frontal do Modelo. 


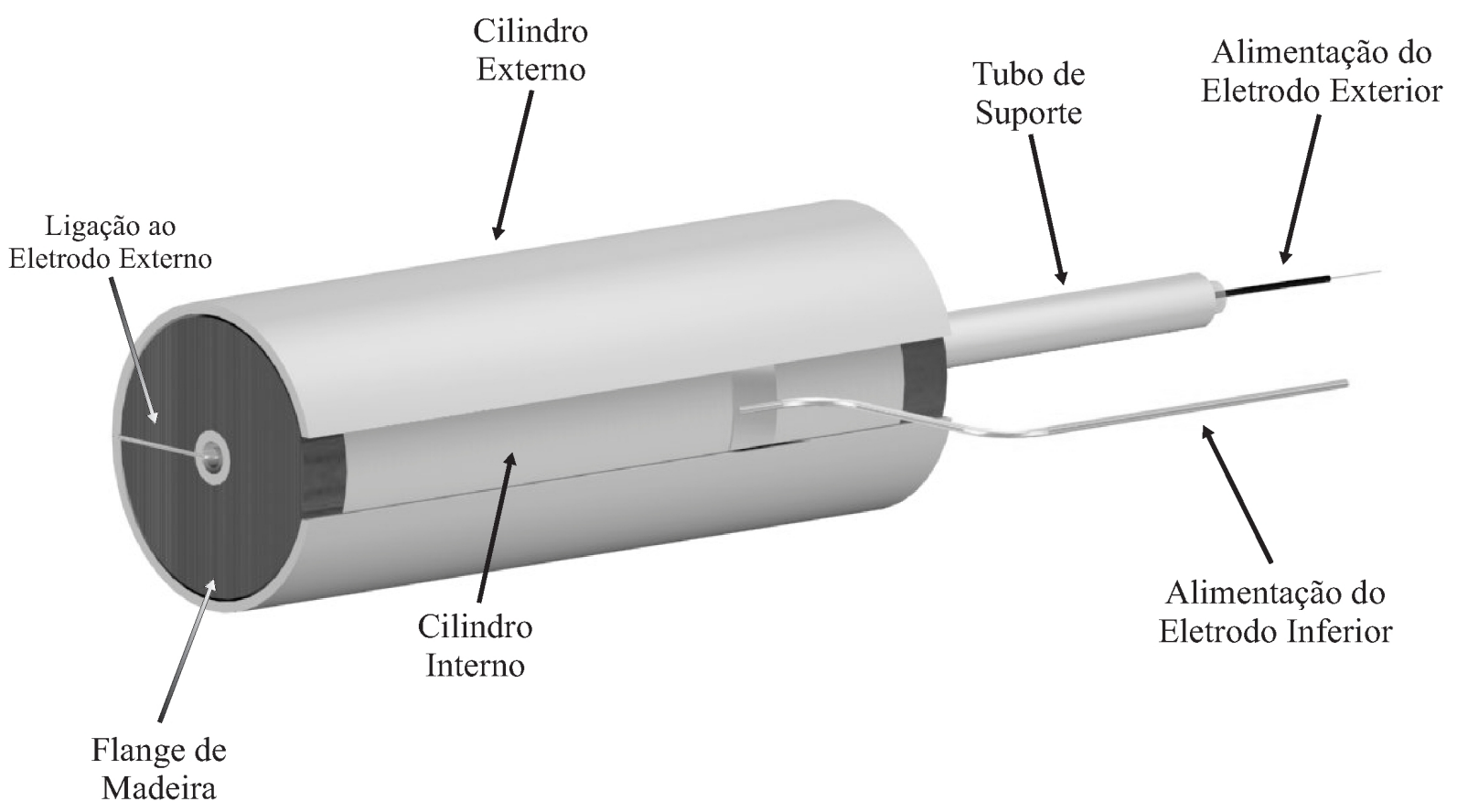

Figura 6.7 - Vista Traseira do Modelo.

\subsubsection{Equipamentos Utilizados}

O primeiro ensaio no sentido de evidenciar a possibilidade de controle de separação de uma camada limite consistiu na análise visual do escoamento ao redor de um cilindro circular. Esta etapa consistiu no registro fotográfico do comportamento de linhas de fumaças presentes no escoamento. Este experimento foi realizado em um túnel de vento vertical. Este equipamento tem sua câmara de ensaio com as seguintes dimensões: 0,7 metros de comprimento, 35 centímetros de largura e 15 centímetros de profundidade. A velocidade do escoamento pode ser ajustada em dois valores: aproximadamente $1 \mathrm{~m} / \mathrm{s}$ e aproximadamente $1,5 \mathrm{~m} / \mathrm{s}$. Um dispositivo que produz fumaça, a partir de uma mistura de um óleo mineral e querosene, está conectado a um pente de tubos, os quais despejam a fumaça logo no início da câmara de ensaio do túnel.

O cilindro foi montado na linha de centro da câmara de ensaio e posicionado a 25 centímetros do fim da contração do túnel. Desta forma, espera-se que não haja efeito deletério por conta da proximidade da saída da contração bem como espera-se que a distância do cilindro até o fim da câmara de ensaio seja suficiente para se visualizar adequadamente a esteira formada. A Figura 6.8 apresenta o arranjo geral do experimento de visualização. 


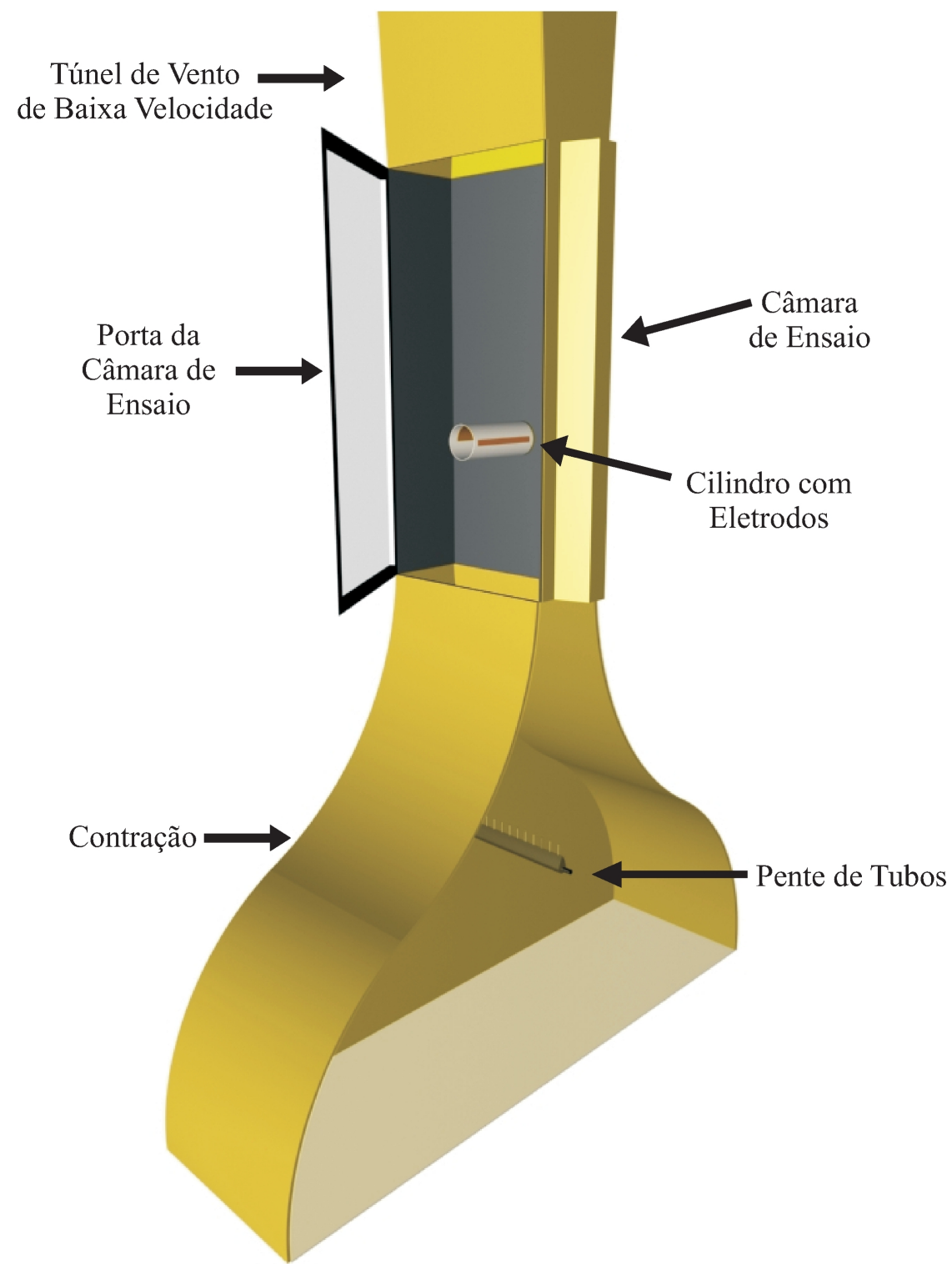

Figura 6.8 - Esquema Geral do Experimento de Visualização.

\subsubsection{Indução de Escoamento ao redor do Modelo}

Para uma melhor compreensão da forma como a descarga elétrica induz um escoamento, o modelo foi montado no túnel de vento e a câmara de ensaio foi preenchida com fumaça. Quando as condições se apresentavam adequadas, ou seja, a fumaça preenchia por igual o interior da câmara de ensaio, a descarga elétrica foi acionada. Pode-se constatar que logo que a descarga elétrica foi ligada, um escoamento ao redor do modelo foi induzido. No entanto, a ocorrência mais significativa foi a grande região de baixa pressão (sucção) que apareceu na região do bordo de ataque do modelo. Todavia, como a descarga elétrica induz um movimento tangencial na superfície do modelo, sem a injeção de massa, é necessário, para a manutenção da condição de continuidade do escoamento, que 
certas parcelas do fluido circundante sejam primeiro succionadas em direção ao eletrodo externo para depois serem sopradas tangencialmente na superfície do modelo. De fato, a descarga introduz apenas uma determinada quantidade de movimento no fluido ao redor do eletrodo. Pode-se até, mantendo as devidas diferenças, considerar o efeito produzido pela descarga elétrica como sendo um jato sintético.

Os eletrodos foram alimentados com a máxima tensão fornecida de pela fonte, ou seja, igual a $8 k$ Volts $_{p p}$. Pode ser visto na Figura 6.9 (a), que ocorre o aparecimento de uma grande alteração na concentração da fumaça ao redor do modelo. Três regiões podem ser distinguidas. A primeira, e a mais significativa, consiste na grande sucção logo à frente do eletrodo externo. Pode-se ver claramente que a densidade de fumaça se reduz drasticamente. Isto demonstra de que forma um dispositivo eletro-hidrodinâmico pode alterar de forma significativa as condições do fluido ao redor de um corpo. Na Figura 6.9 (b), fica mais evidenciada a situação na região em discussão. Esta Figura foi tomada em perspectiva, o que produziu uma clara prova da intensidade do escoamento induzido. Pode-se ver que linhas de fumaça são atraídas em direção ao eletrodo externo.
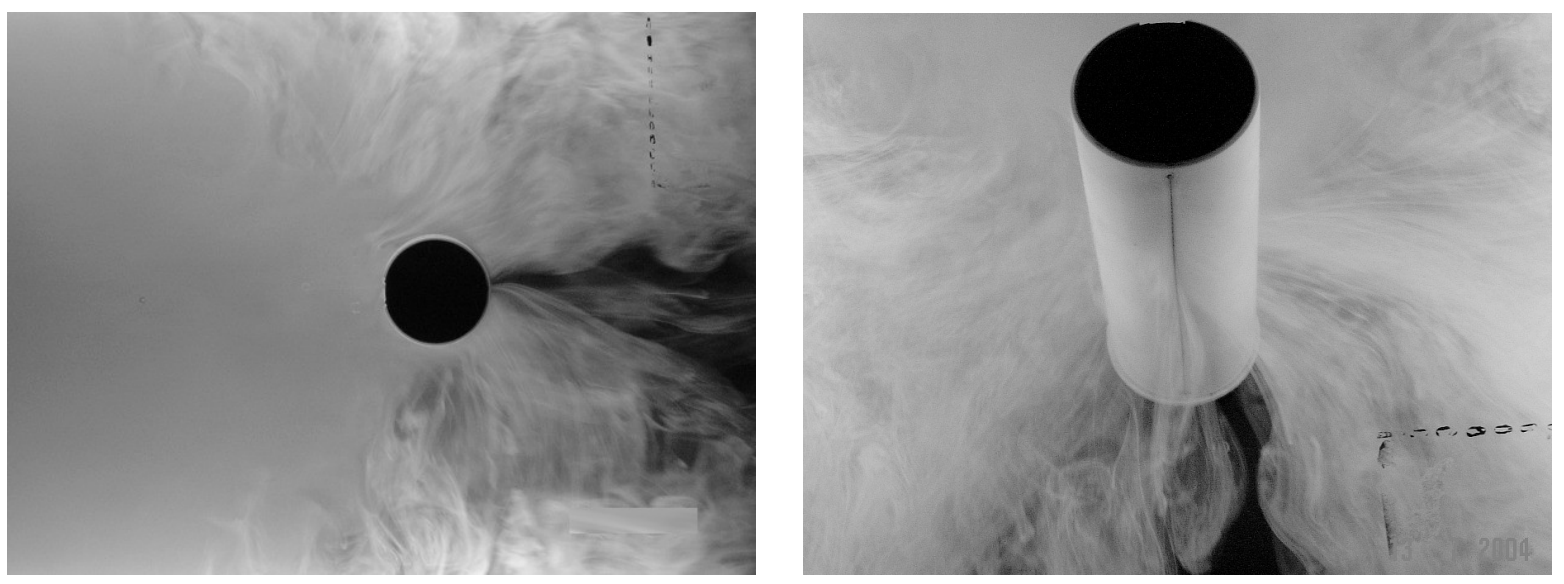

Figura 6.9 - Presença de um Sorvedouro no Bordo de Ataque do Cilindro. 


\subsubsection{Variação da Frequência da Descarga}

O comportamento do escoamento ao redor do modelo foi analisado tomando como ponto de referência a variação da frequência da tensão de alimentação dos eletrodos. Desta forma, espera-se determinar como a velocidade induzida pela descarga elétrica varia em função da frequência e na presença do escoamento ao redor do modelo. Este é um ponto decisivo quando se pensa na produção de uma velocidade induzida adequada a uma determinada abordagem de controle do escoamento, como, por exemplo, para o atraso da separação da camada limite.

Desta forma, analisou-se visualmente o comportamento do escoamento ao redor do modelo através da introdução de fumaça traçadora. A velocidade do escoamento foi mantida, inicialmente, na velocidade mais alta do túnel de vento, ou seja, ao redor de 1,5 m/s. A tensão de alimentação do sistema de produção da descarga elétrica foi mantida, também, em seu máximo valor igual a 8 k Volts. A partir desta configuração inicial procedeu-se a aquisição de imagens iniciando-se com o escoamento com a descarga elétrica desligada. A Figura 6.10 apresenta esta configuração inicial.

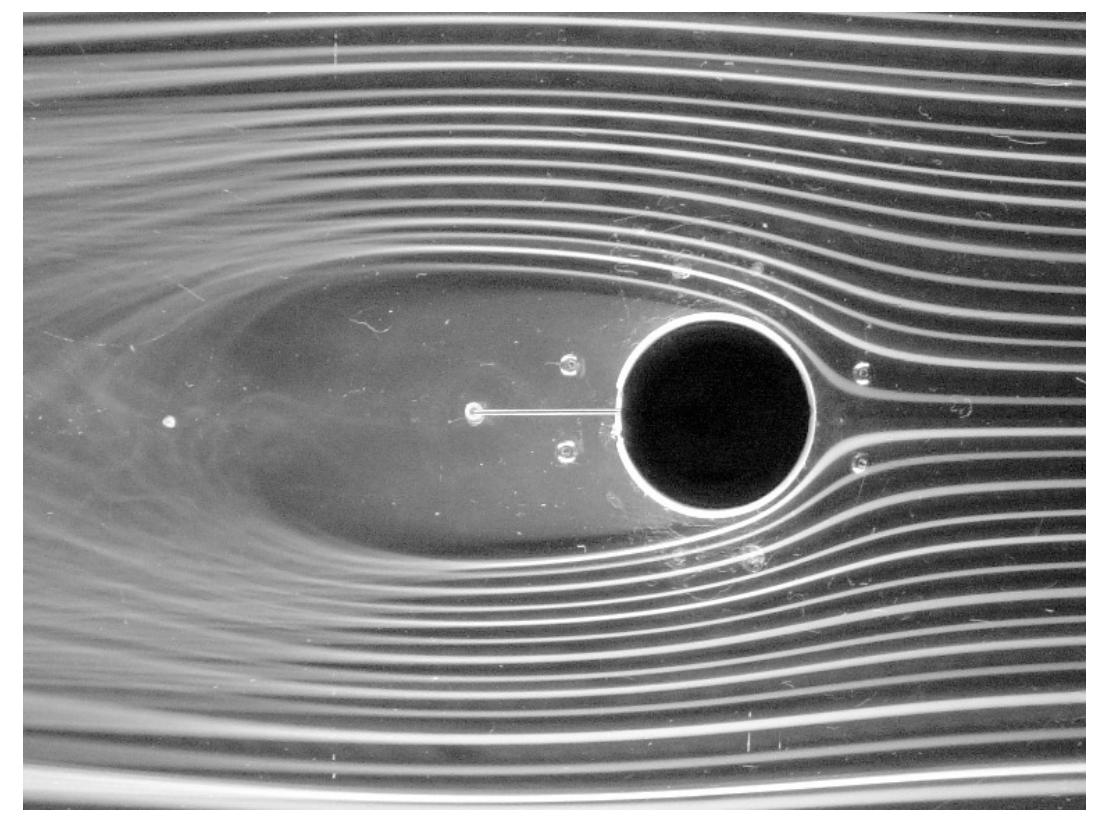

Figura 6.10 - Sem a presença da Descarga. 
A seguir, a descarga elétrica foi acionada com a tensão de alimentação na frequência inicial de $1 \mathrm{kHz}$. Neste ponto, como pode ser visto na Figura 6.11, não foi detectado, aparentemente, nenhuma alteração na configuração do escoamento. Podendo-se até concluir previamente que este estágio apresenta as mesmas características principais obtidas no escoamento sem a presença da descarga elétrica. A descarga elétrica gerada não se apresentou de forma estável. Aparentemente, esta frequência não produz uma descarga por barreira dielétrica no regime adequado, pois os parâmetros do modelo e da descarga elétrica não induzem corretamente a descarga por barreira dielétrica. A Figura 6.12 apresenta os dados de tensão e corrente medidos nesta etapa.

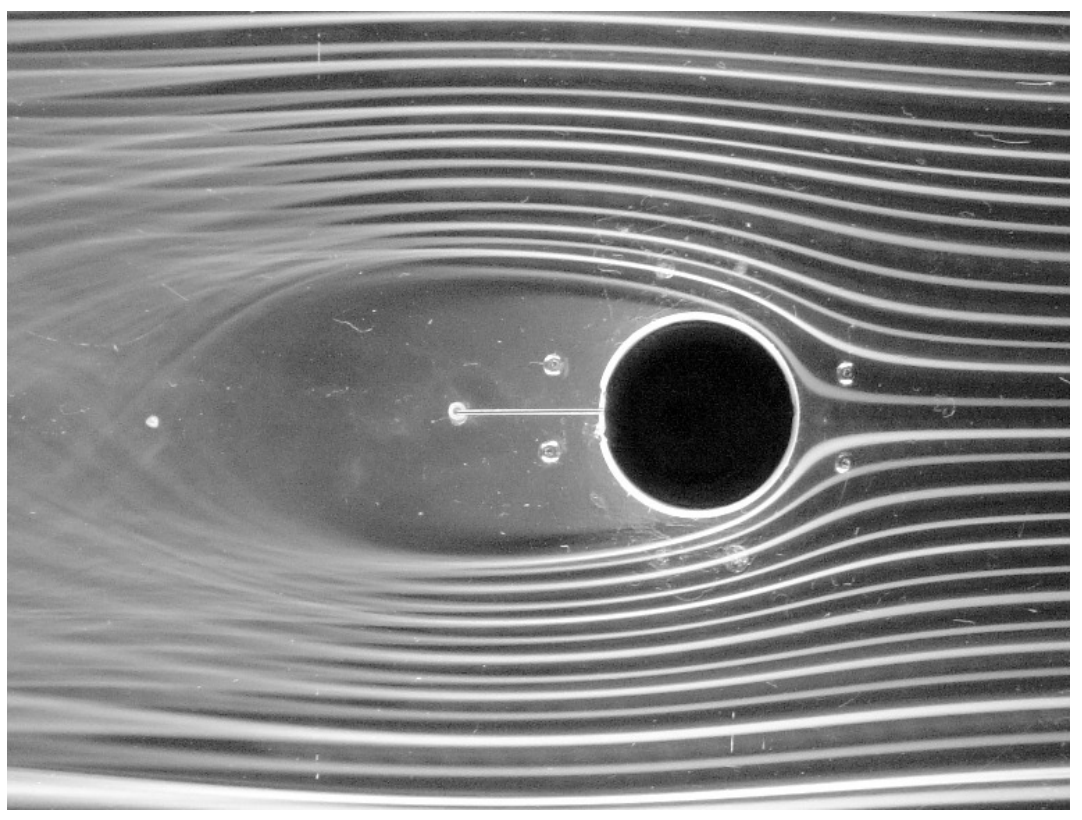

Figura 6.11 - Escoamento ao redor do Cilindro - Descarga Ligada - Frequência de 1 kHz.

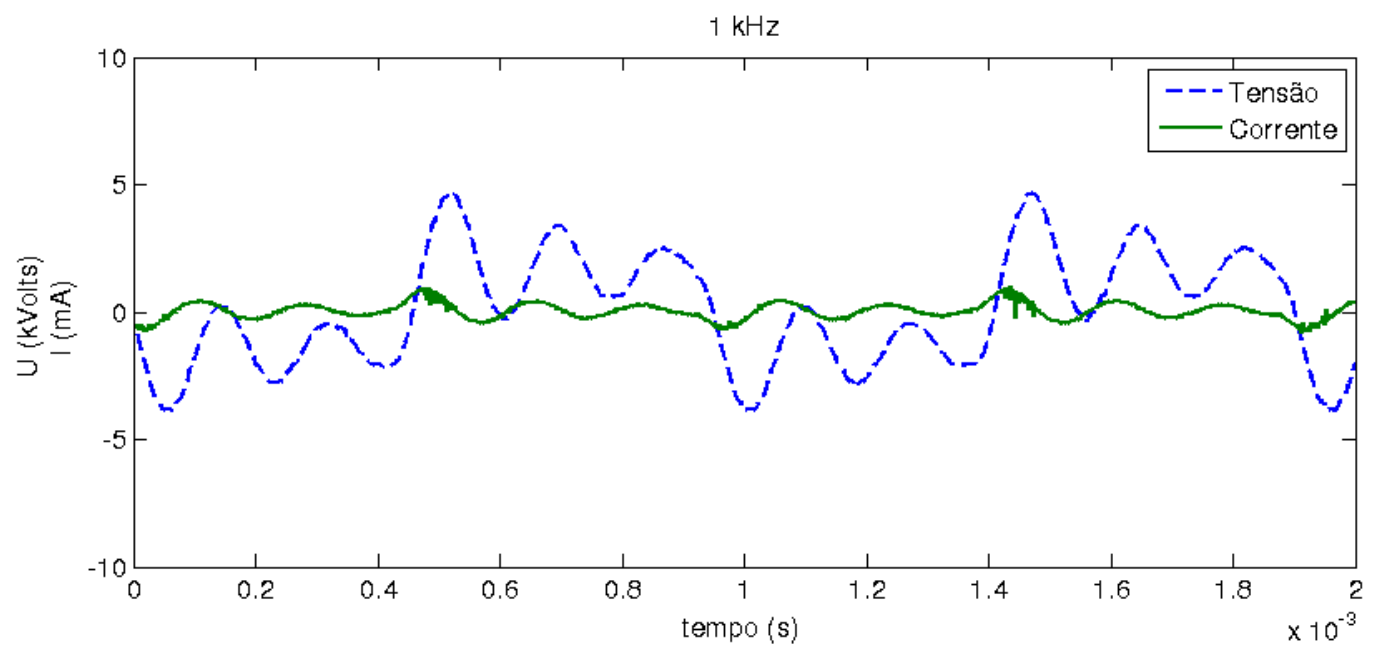

Figura 6.12 - Dados de tensão e corrente para a frequência de $1 \mathrm{kHz}$. 
No entanto, a partir do momento em que a frequência foi aumentada para o valor de $2 \mathrm{kHz}$, ver Figura 6.13, já é possível discernir uma pequena alteração na região ao redor do ponto de estagnação do modelo. Aparentemente, a linha de fumaça central inferior é atraída em direção à região de estagnação. A esteira também apresenta aparentemente uma pequena alteração em suas dimensões. A Figura 6.14 apresenta os dados de tensão e corrente medidos. Pode-se ver mais uma vez que a descarga não se estabeleceu de forma adequada. Entretanto, já é possível ver pelos dados da corrente elétrica que ocorreu a formação parcial da descarga em regime adequado em alguns pontos.

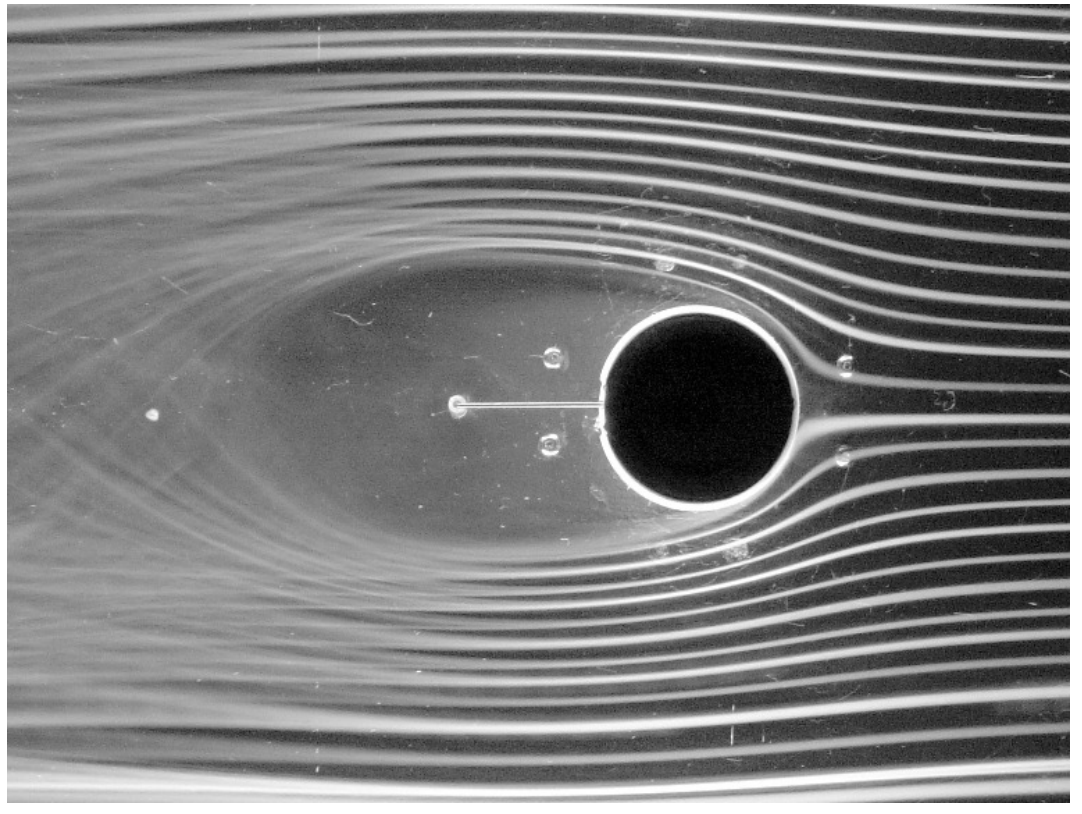

Figura 6.13 - Escoamento ao redor do Cilindro - Descarga Ligada - Frequência de 2 kHz.

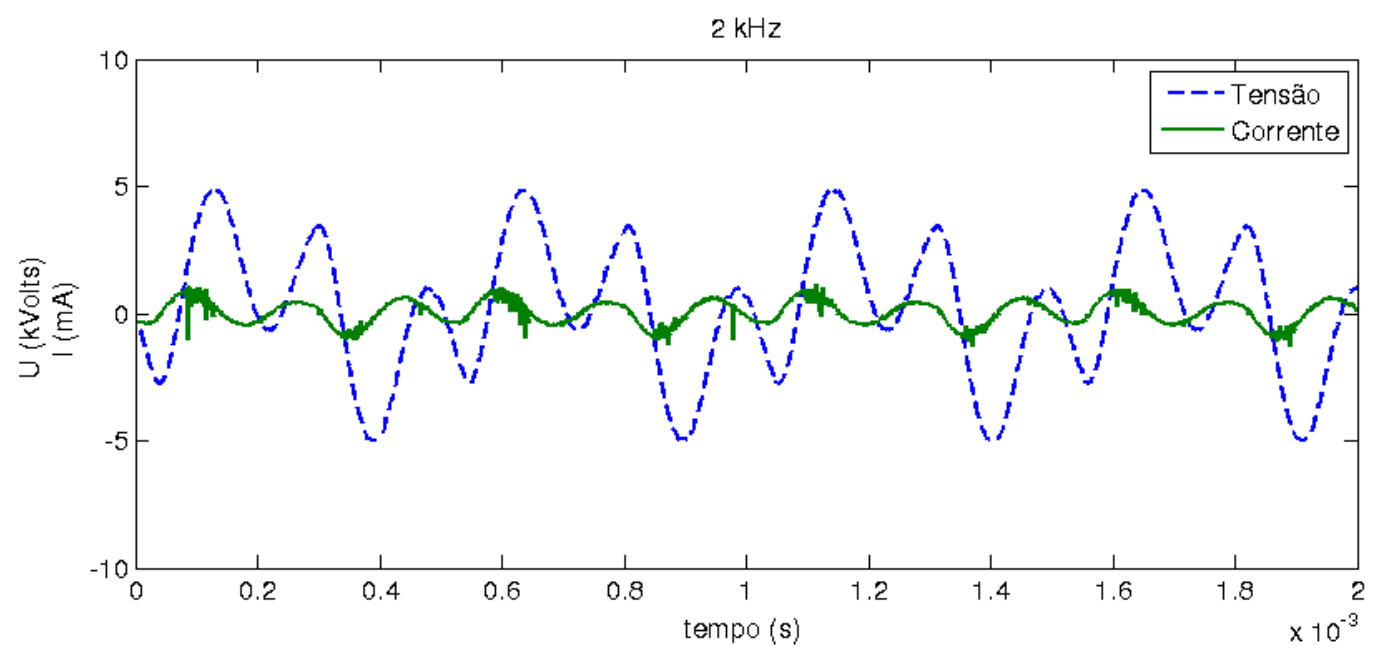

Figura 6.14 - Dados de tensão e corrente para a frequência de $2 \mathrm{kHz}$. 
Na sequência, a Figura 6.15 é o primeiro estágio desta etapa experimental que apresenta claras evidências de uma significativa alteração do escoamento ao redor do modelo. Nesta etapa a frequência de alimentação da descarga elétrica foi aumentada para um valor ao redor de $3 \mathrm{kHz}$. Pode-se ver claramente na Figura que as linhas de fumaça centrais, logo a frente do modelo, são atraídas na direção ao ponto de estagnação do modelo. A esteira do modelo também apresenta uma significativa diminuição em seu tamanho. Na Figura 6.16 pode-se observar que a tensão elétrica começa apresentar uma forma de onda mais adequado para a formação de descarga por barreira dielétrica uniforme.

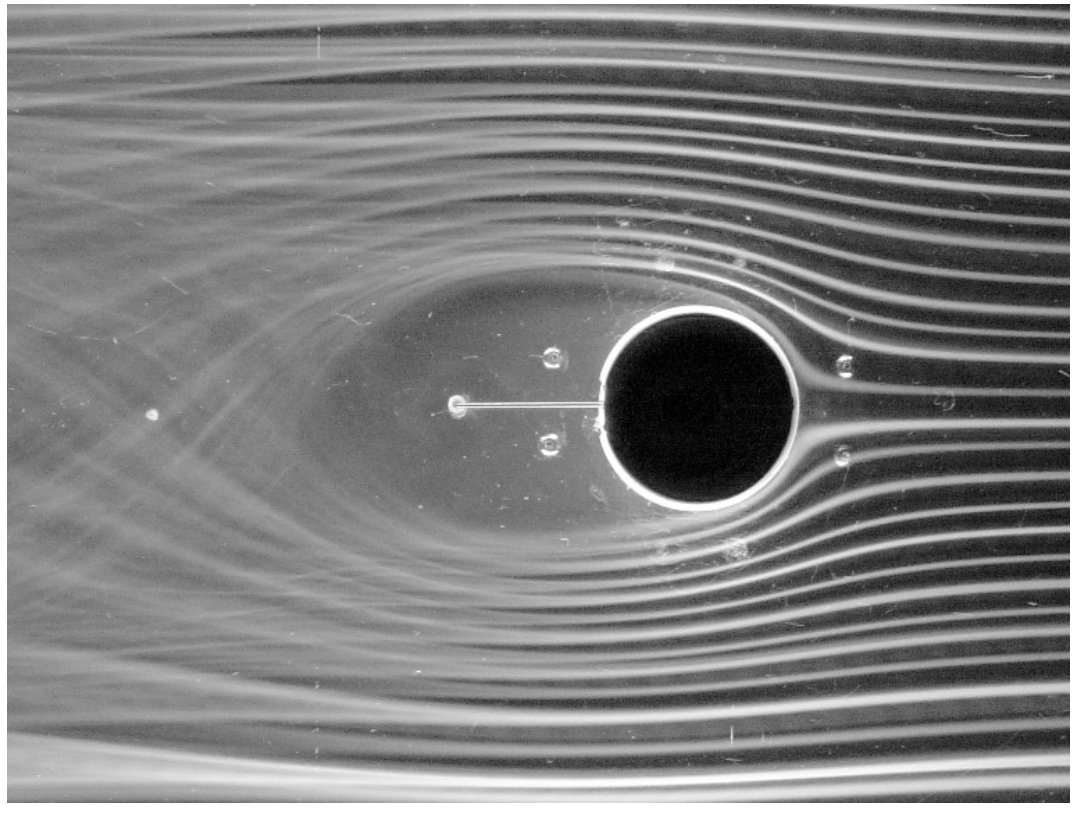

Figura 6.15 - Escoamento ao redor do Cilindro - Descarga Ligada - Frequência de $3 \mathrm{kHz}$.

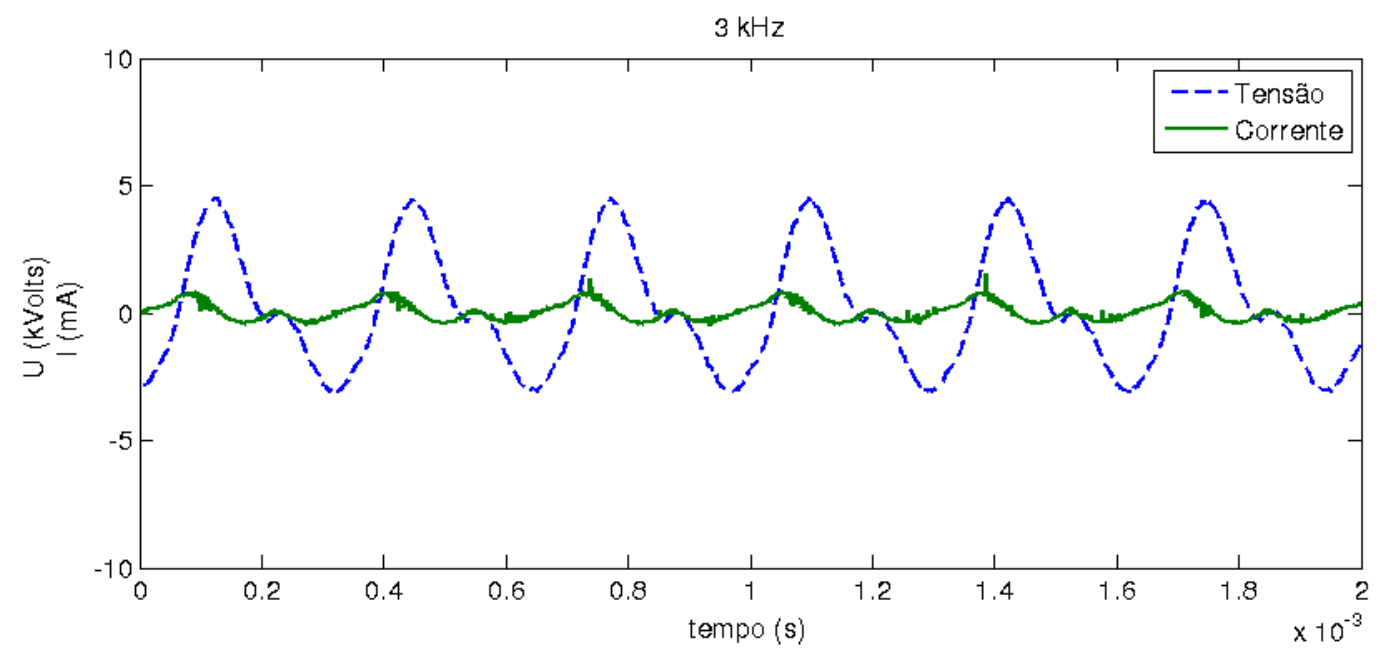

Figura 6.16 - Dados de tensão e corrente para a frequência de $3 \mathrm{kHz}$. 
A Figuras 6.17 apresenta a imagem para a descarga ajustada na frequência de $4 \mathrm{kHz}$. Pode-se observar que houveram grandes alterações em relação ao resultado apresentando na Figura 6.15. Isto pode ser devido ao fato de que as velocidades induzidas nesta etapa não diferem muito em magnitude da etapa anterior. Entretanto, esta é a primeira etapa em que a frequência da fonte de alimentação produziu uma descarga em regime uniforme (ver Figura 6.18).

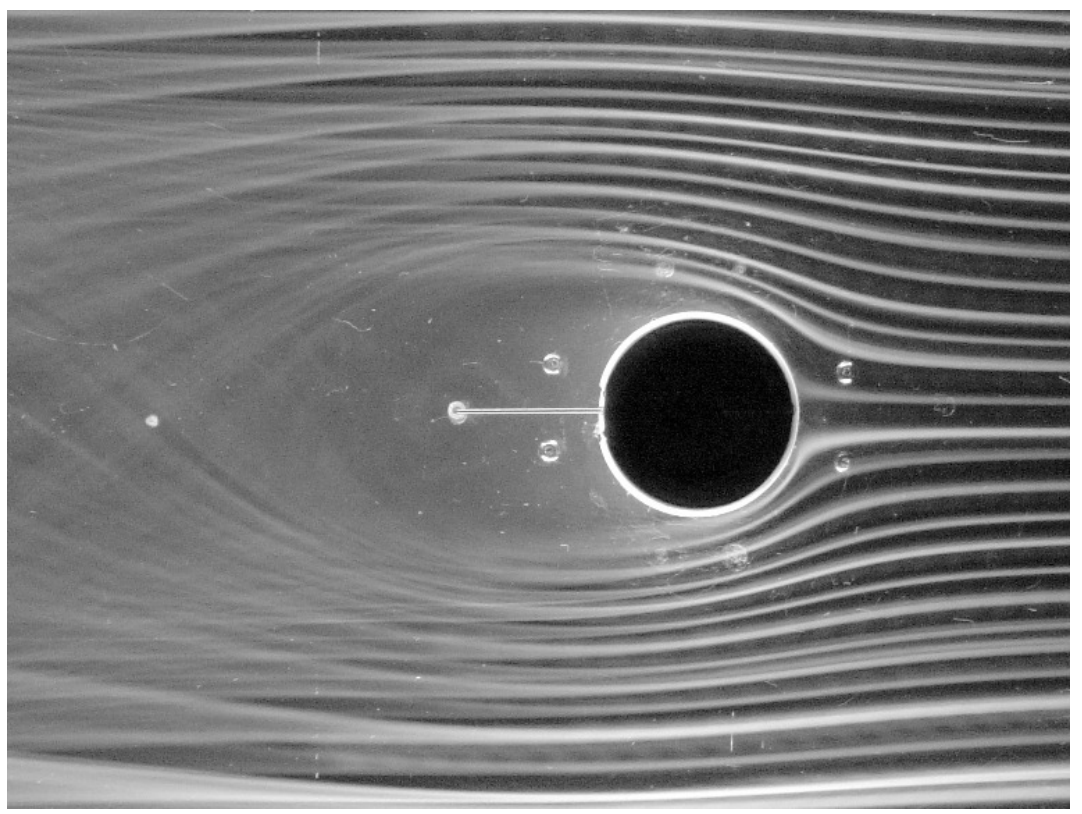

Figura 6.17 - Escoamento ao redor do Cilindro - Descarga Ligada - Frequência de 4 kHz.

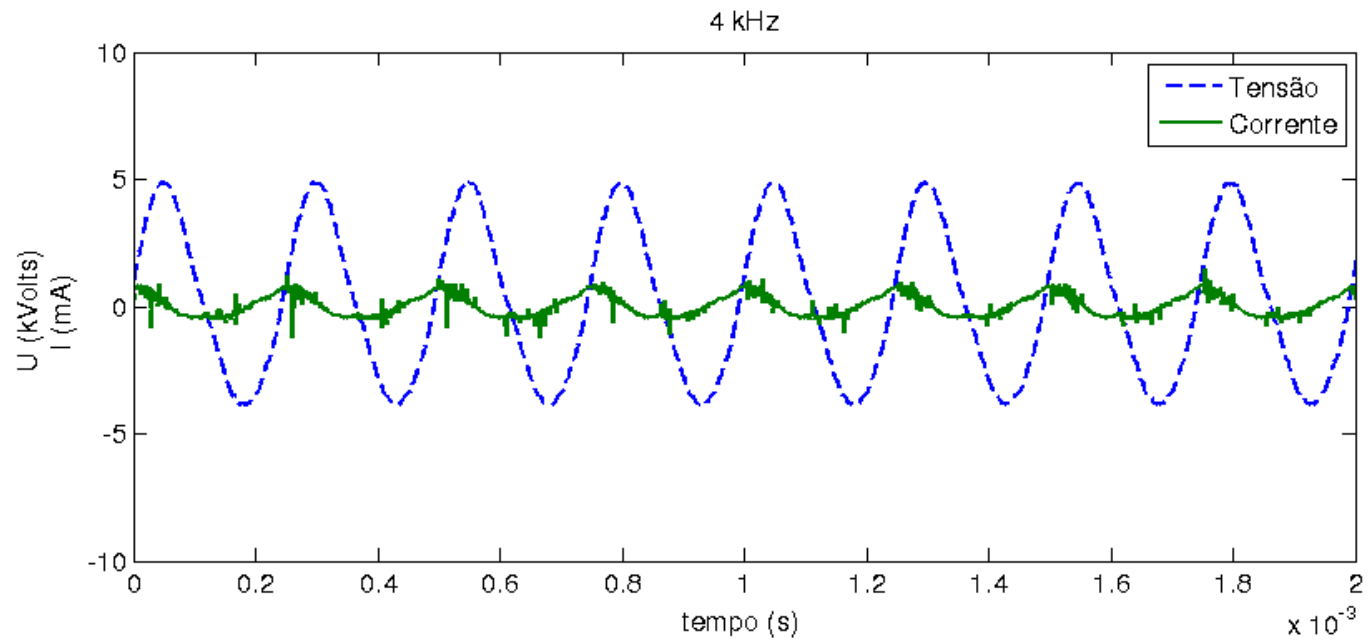

Figura 6.18 - Dados de tensão e corrente para a frequência de 4 kHz. 
Já na Figura 6.19 é apresentada a imagem do escoamento quando a frequência da descarga elétrica foi ajustada para $5 \mathrm{kHz}$. Nesta etapa a alteração das características do escoamento ao redor do modelo é intensa. A Figura 6.20 apresenta os dados da tensão e da corrente elétrica para esta etapa, mostrando que a tensão atingiu um valor máximo de aproximadamente $8 \mathrm{kVots}$ e que a corrente se apresenta na forma usual para uma descarga por barreira dielétrica. Pode-se afirmar que nesta etapa se atingiu a eficiência máxima da descarga elétrica, pois observa-se um aumento significativo na corrente elétrica fornecida à descarga elétrica.

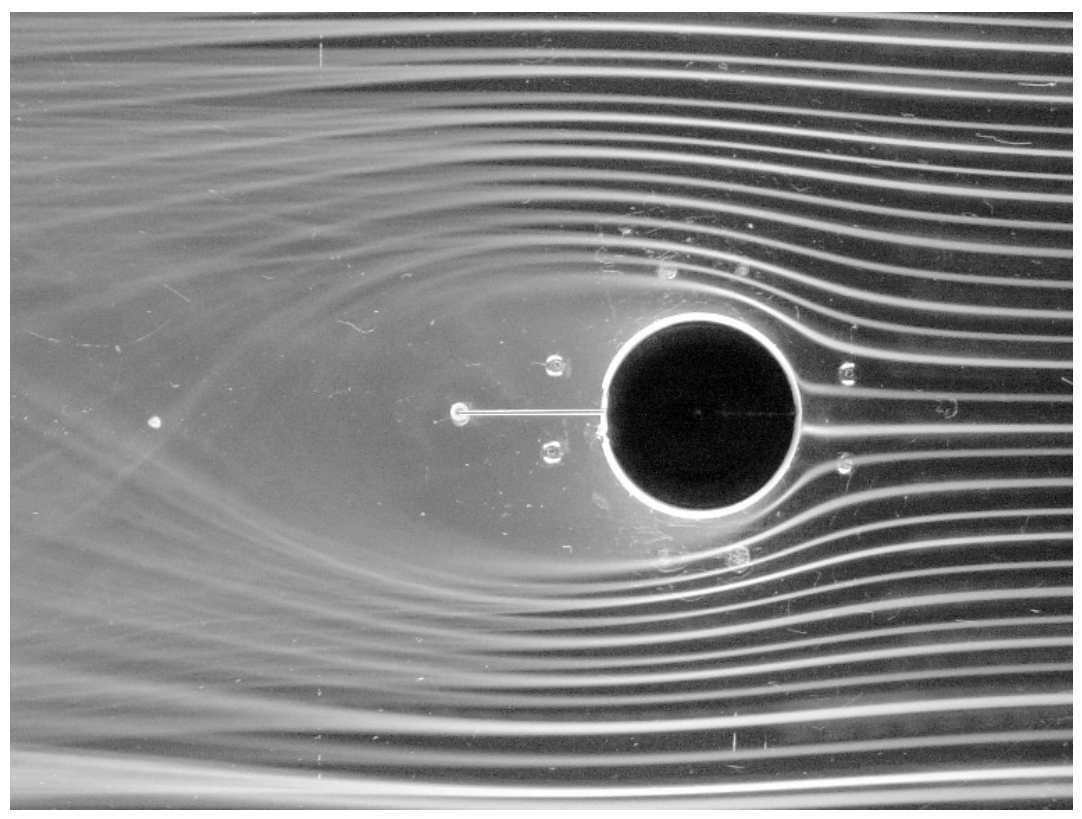

Figura 6.19 - Escoamento ao redor do Cilindro - Descarga Ligada - Frequência de 5 kHz.

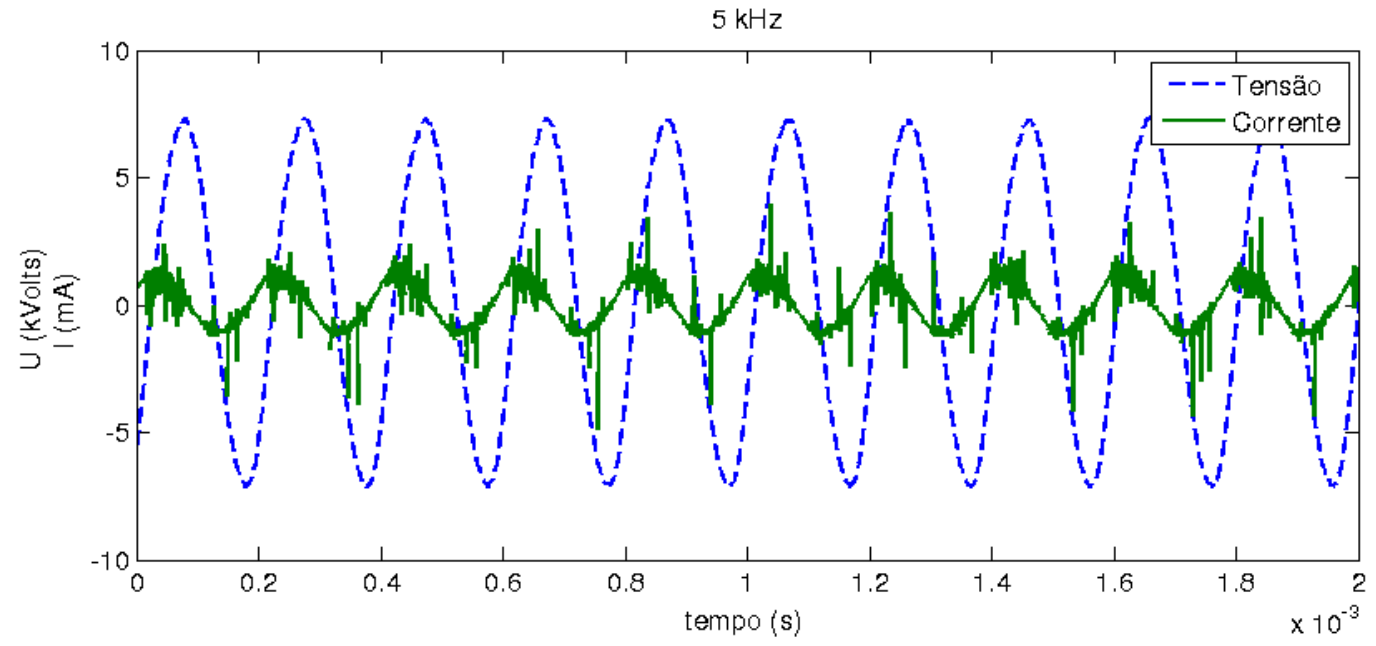

Figura 6.20 - Dados de tensão e corrente para a frequência de 5 kHz. 
A Figuras 6.21 apresenta a imagem para a descarga ajustada na frequência de 6 kHz. Ainda se verifica uma alteração significativa do escoamento ao redor do ponto de estagnação do modelo, com as linhas de fumaça sendo intensamente atraídas em direção a esta região, como na etapa anterior. A Figura 6.22 apresenta os dados da tensão e da corrente elétrica para esta etapa, mostrando que a tensão elétrica reduziu de valor em relação aos dados apresentados para a descarga em $5 \mathrm{kHz}$, mas a corrente ainda apresenta a forma usual para uma descarga por barreira dielétrica.

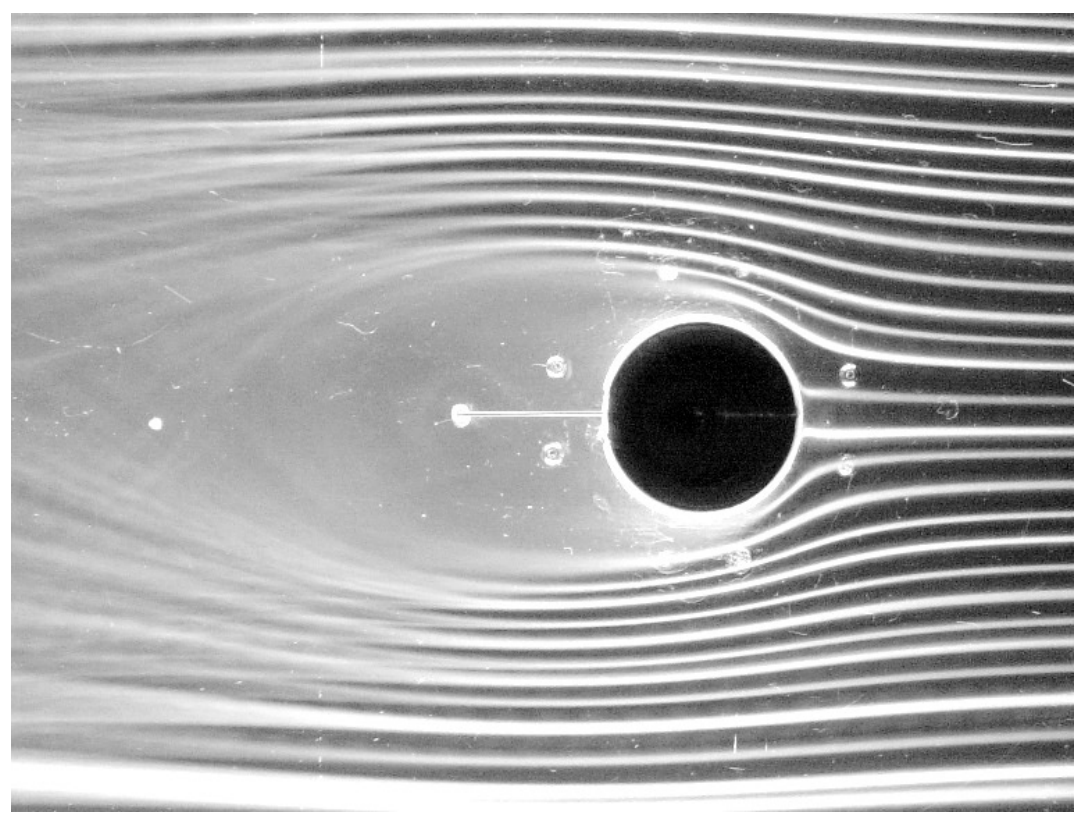

Figura 6.21 - Escoamento ao redor do Cilindro - Descarga Ligada - Frequência de 6 kHz.

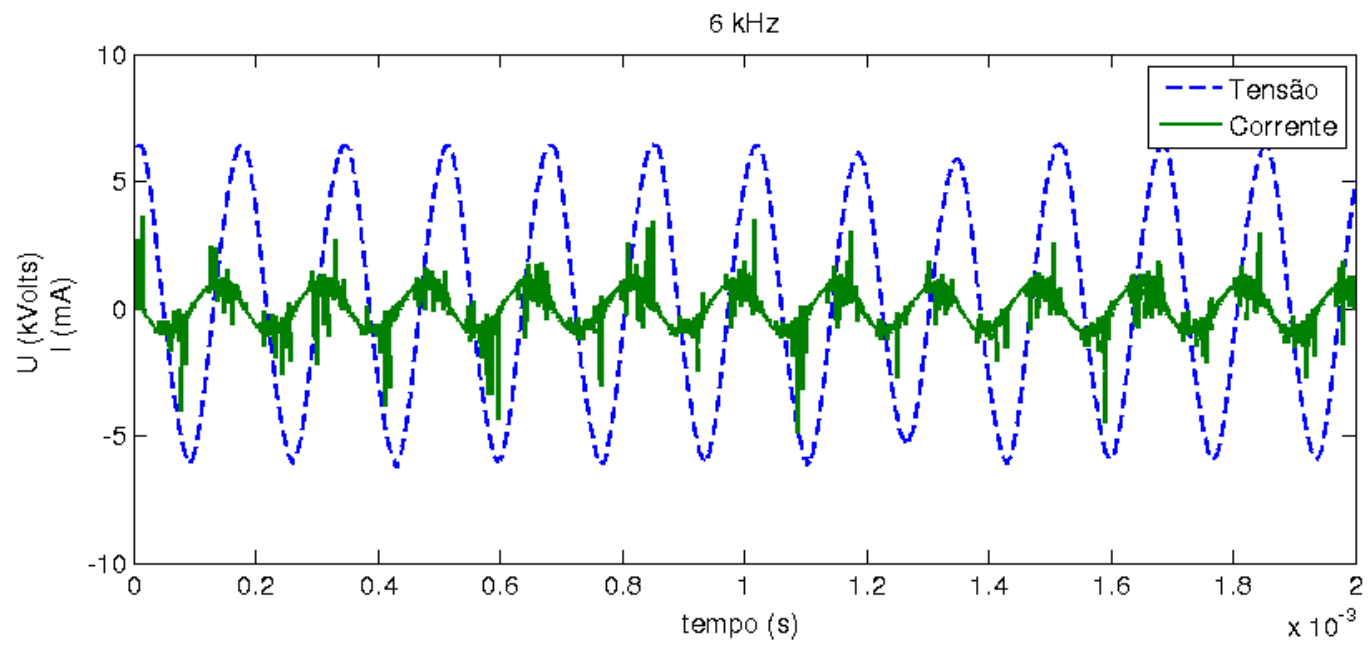

Figura 6.22 - Dados de tensão e corrente para a frequência de $6 \mathrm{kHz}$. 
Já na Figura 6.23 é apresentada a imagem do escoamento quando a frequência da descarga elétrica foi ajustada para $7 \mathrm{kHz}$. Nesta etapa existe uma aparente redução da alteração do escoamento ao redor do modelo, embora pouco significativa. Isto pode ser devido a uma redução na eficiência da produção da descarga elétrica. A Figura 6.24 apresenta os dados da tensão e da corrente elétrica para esta etapa, mostrando uma significativa redução do valor da tensão elétrica.

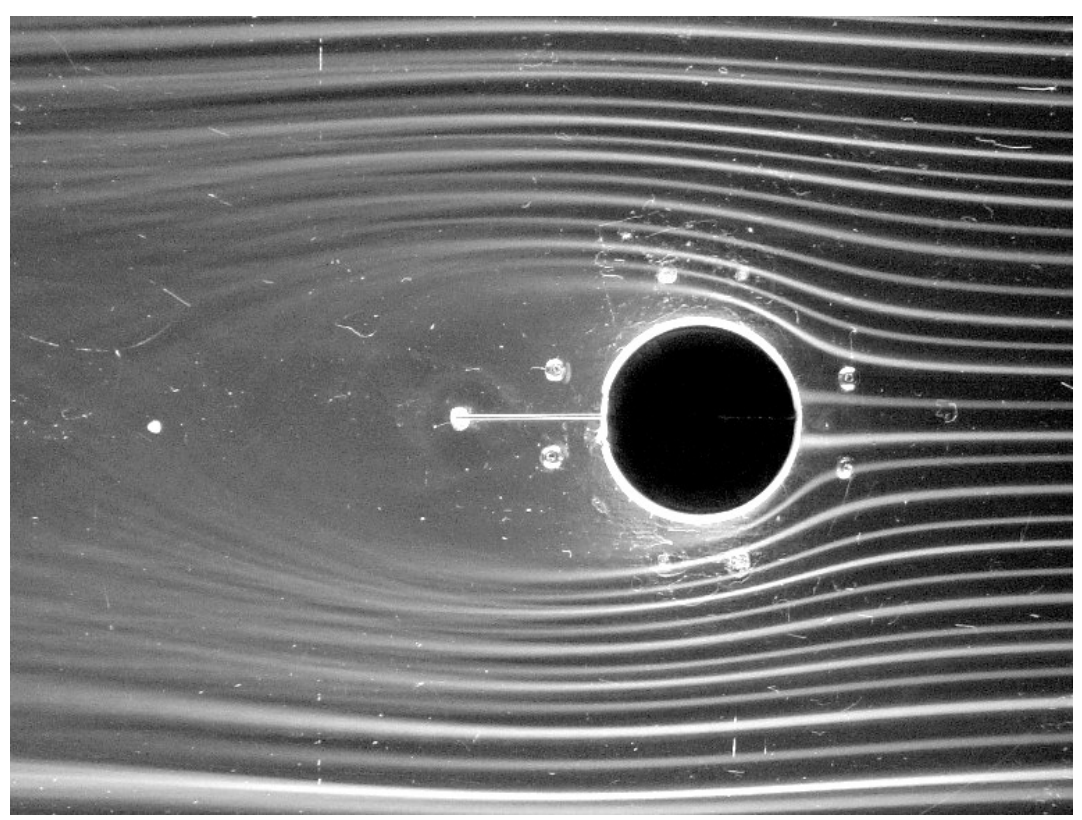

Figura 6.23 - Escoamento ao redor do Cilindro - Descarga Ligada - Frequência de 7 kHz.

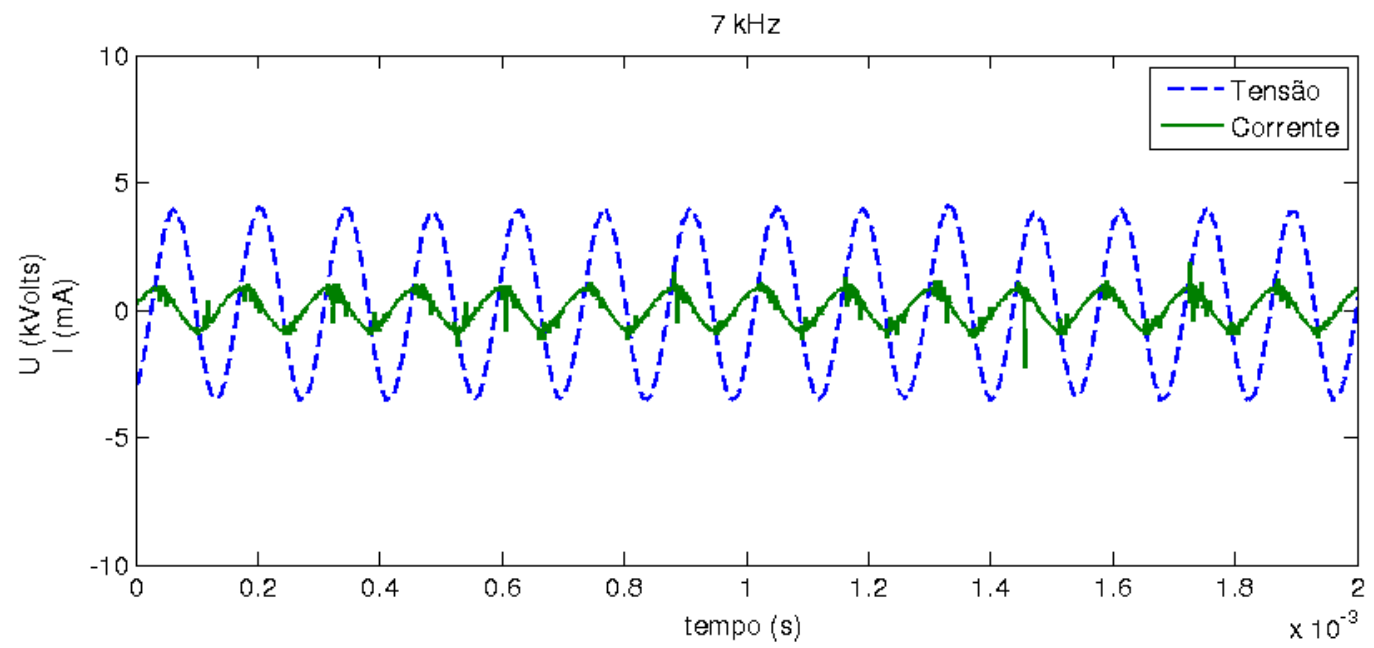

Figura 6.24 - Dados de tensão e corrente para a frequência de $7 \mathrm{kHz}$. 
A Figura 6.25 mostra a imagem do escoamento ao redor do modelo quando a frequência foi ajustada para $8 \mathrm{kHz}$. Pode-se verificar uma redução na intensidade da influência da descarga elétrica na alteração das características do escoamento, notadamente na região de estagnação do modelo. Na Figura 6.26 verifica-se uma redução acentuada do valor da tensão elétrica suprida para a descarga, o que leva, consequentemente, a uma redução de sua intensidade.

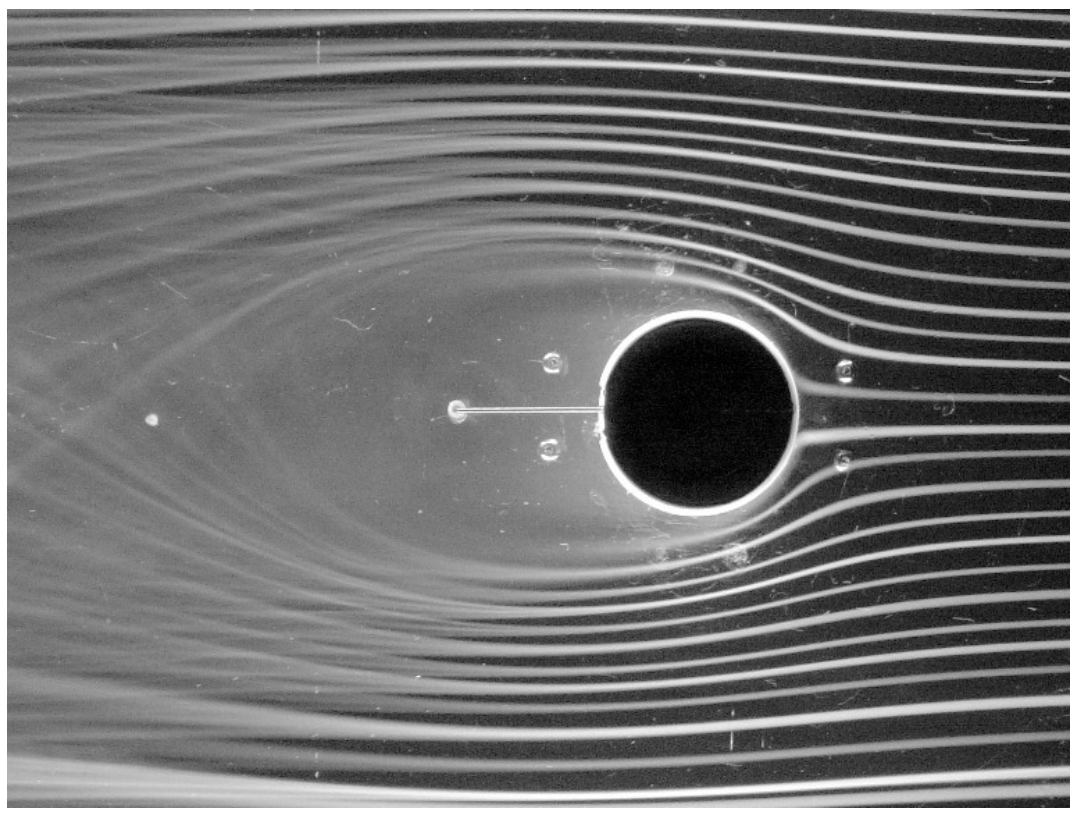

Figura 6.25 - Escoamento ao redor do Cilindro - Descarga Ligada - Frequência de 8 kHz.

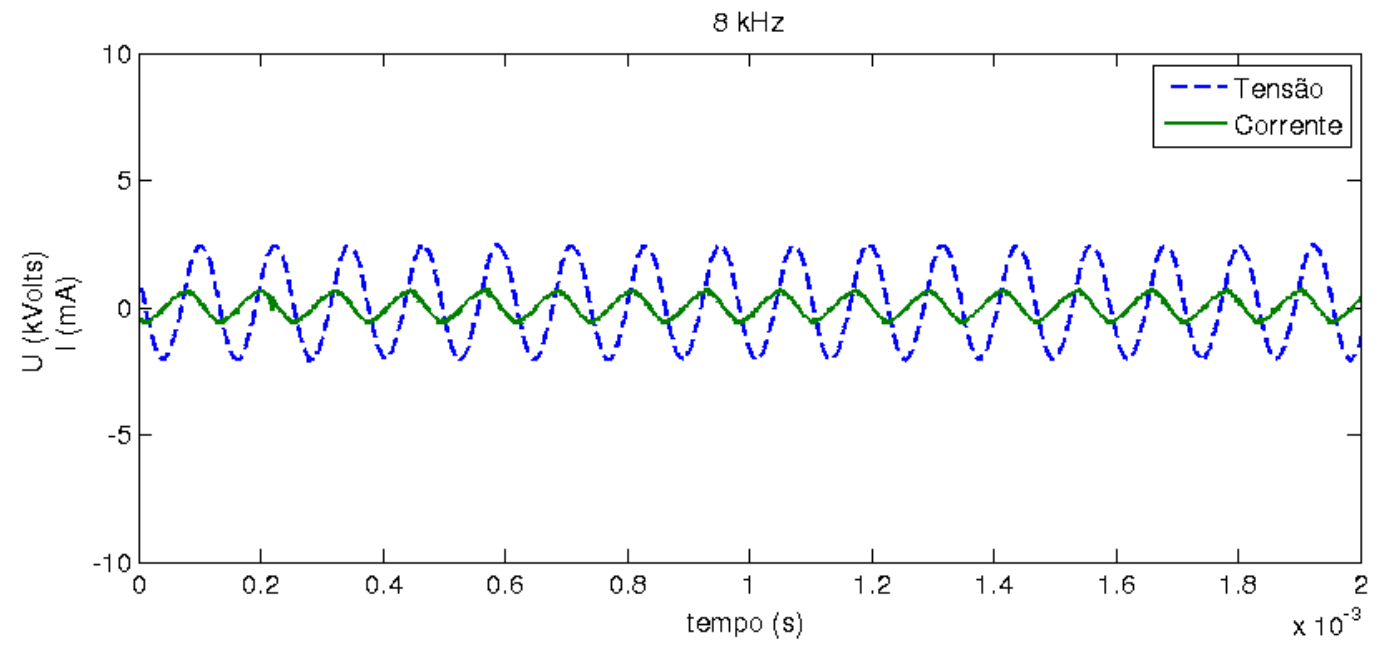

Figura 6.26 - Dados de tensão e corrente para a frequência de $8 \mathrm{kHz}$. 
A intensidade do efeito da descarga elétrica se reduz ainda mais quando a frequência foi ajustada para $9 \mathrm{kHz}$ (ver Figura 6.27). Pode-se observar que as linhas de fumaça na região de estagnação do cilindro não são mais atraídas como nas etapas anteriores. Isto pode ser evidência que a partir deste ponto a descarga não é mais tão intensamente produzida e, consequentemente, a velocidade induzida se reduz. Na Figura 6.28 verifica-se uma acentuada queda do valor da tensão elétrica.

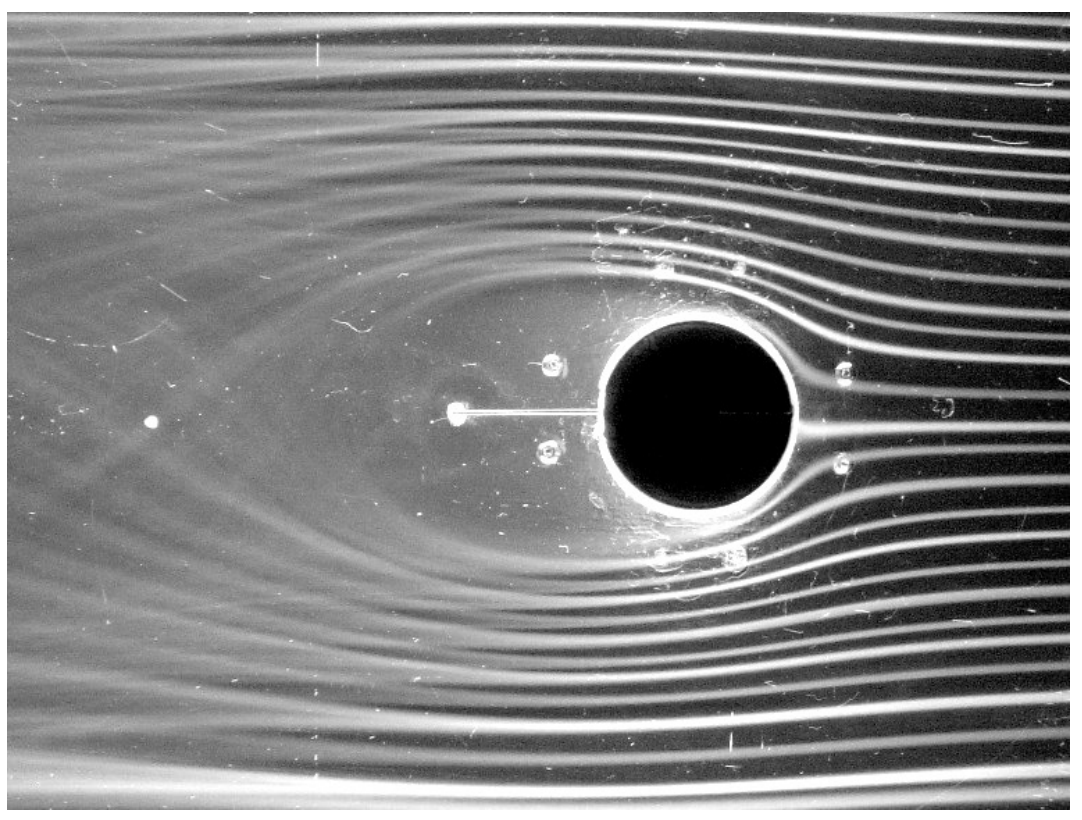

Figura 6.27 - Escoamento ao redor do Cilindro - Descarga Ligada - Frequência de 9 kHz.

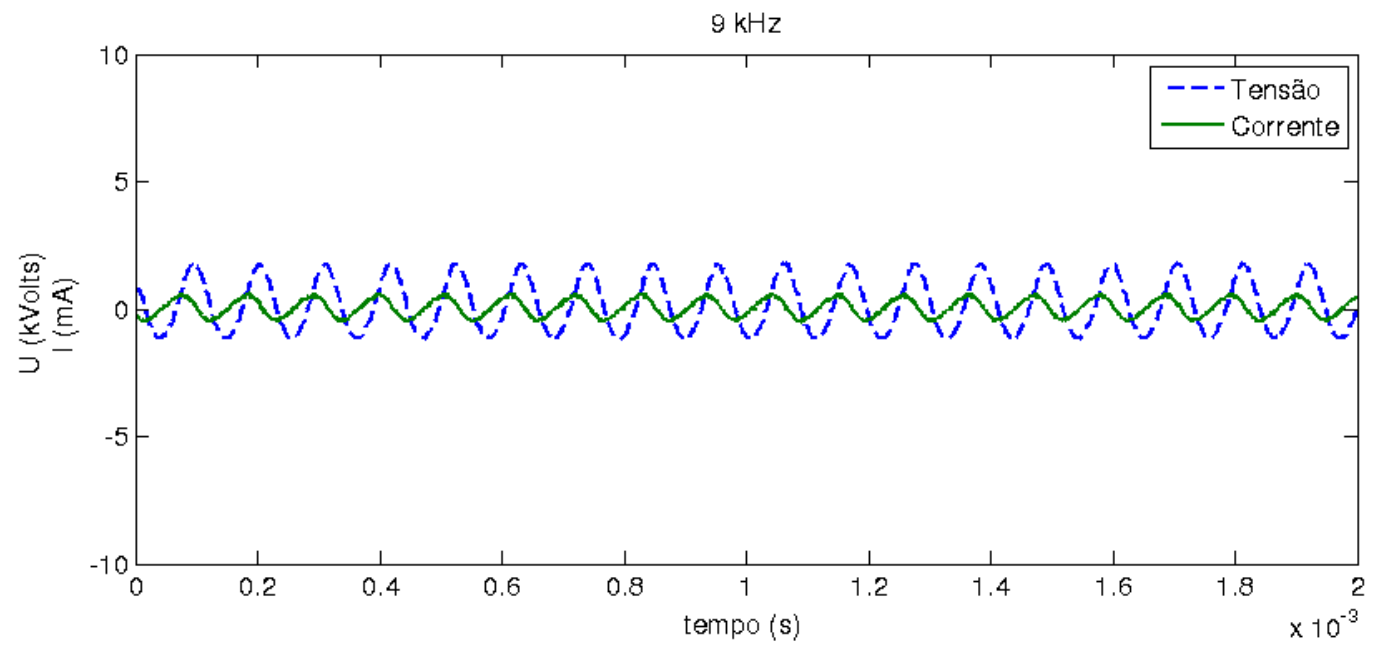

Figura 6.28 - Dados de tensão e corrente para a frequência de 9 kHz. 
Finalizando esta avaliação experimental, é apresentado na Figura 6.29 a imagem tirada quando a fonte de alimentação estava com a frequência ajustada para o valor de $10 \mathrm{kHz}$. Nesta etapa se evidencia de forma mais acentuada a redução do efeito da descarga elétrica na alteração do escoamento ao redor do modelo, principalmente na região do ponto de estagnação do modelo. Pode-se afirmar que nesta frequência a descarga elétrica não é mais eficiente em produzir um escoamento, pois verifica-se uma diminuição na corrente elétrica consumida.

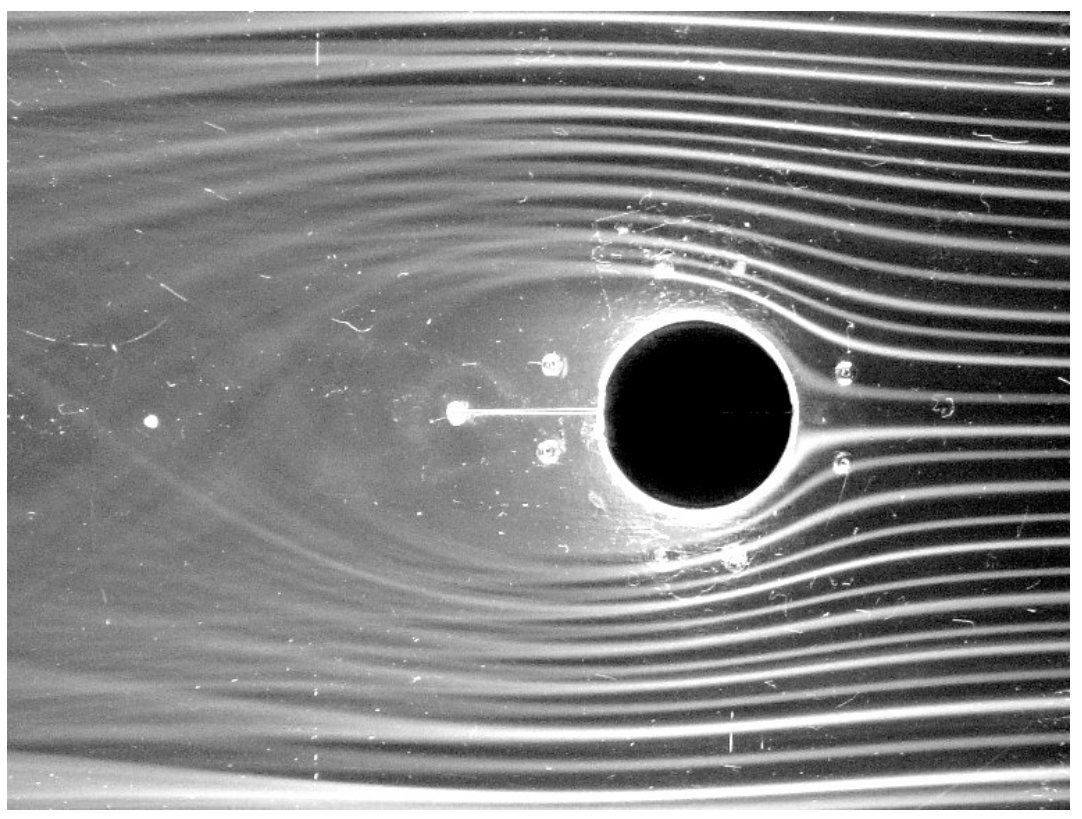

Figura 6.29 - Escoamento ao redor do Cilindro - Descarga Ligada - Frequência de $10 \mathrm{kHz}$.

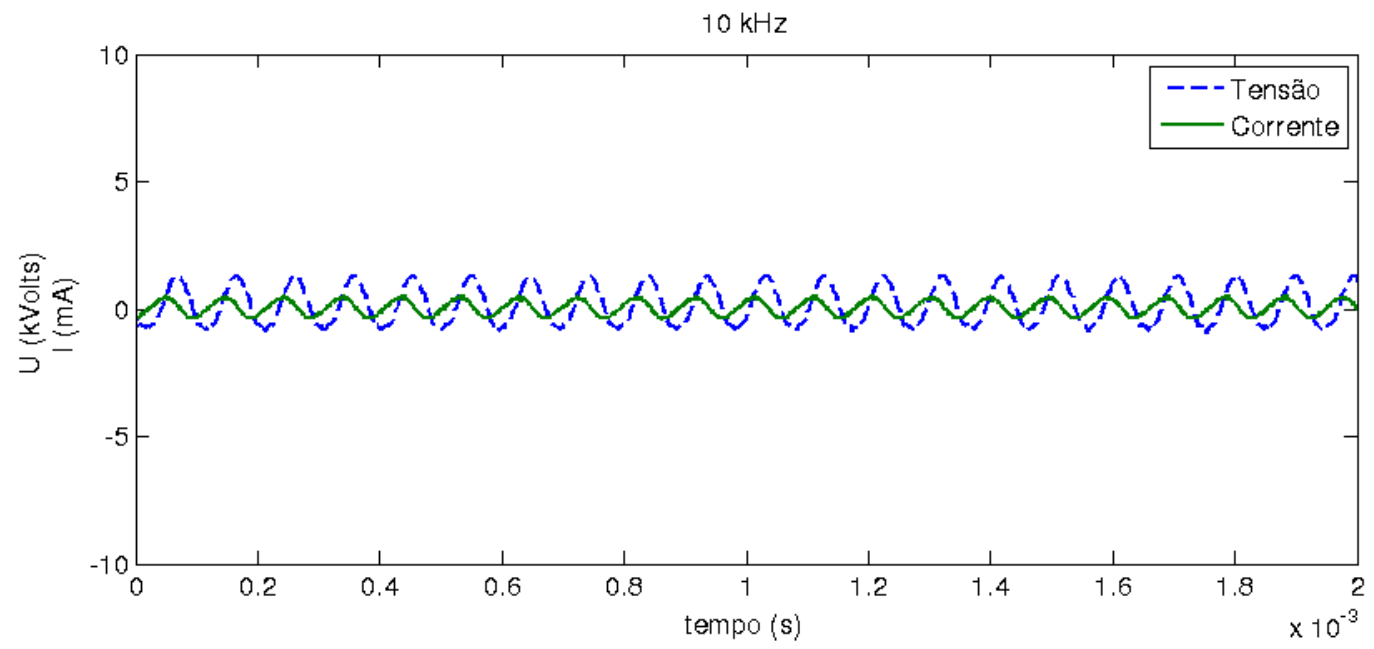

Figura 6.30 - Dados de tensão e corrente para a frequência de $10 \mathrm{kHz}$. 
Esta etapa experimental indica que a melhor eficiência na produção de escoamentos na configuração estudada ocorre na faixa de frequências entre $5 \mathrm{kHz}$ e $6 \mathrm{kHz}$. A Figura 6.31 apresenta os dados das potências elétricas utilizadas na produção das descargas elétricas em cada valor de frequência analisada. Isto está de acordo com a literatura, pois na maior parte dos trabalhos sobre a utilização de descargas por barreira dielétrica no controle ou produção de escoamentos a frequência de alimentação da fonte encontra-se nesta faixa.

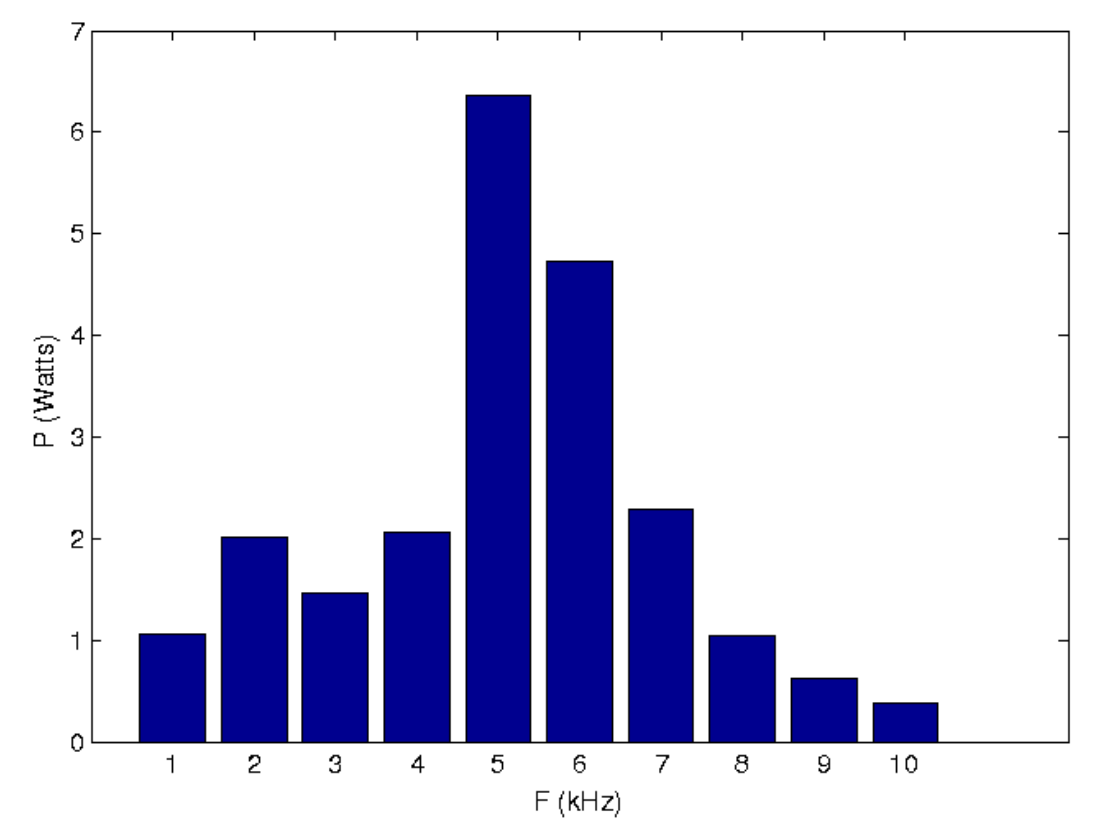

Figura 6.31 - Valores da potência elétrica para as frequências analisadas.

\subsubsection{Variação da Tensão Aplicada}

Nesta etapa experimental determinou-se o comportamento do escoamento ao redor do modelo com a variação da tensão aplicada aos eletrodos. O modelo foi montado na câmara de ensaio do túnel de vento com o eletrodo externo orientado ortogonalmente ao escoamento. A velocidade do escoamento livre na câmara de ensaio foi mantida em aproximadamente $1,5 \mathrm{~m} / \mathrm{s}$ em todos as etapas. A frequência da descarga foi ajustada para um valor considerado ótimo para a configuração de eletrodos utilizada, ou seja, f $=5,0$ kHz. Este valor foi determinado através do ponto de máxima corrente induzida no sistema, medida diretamente na saída da fonte de alimentação. O procedimento foi iniciado com a aquisição de uma imagem do escoamento ao redor do modelo sem a presença da descarga elétrica, como pode ser visto na Figura 6.32. 


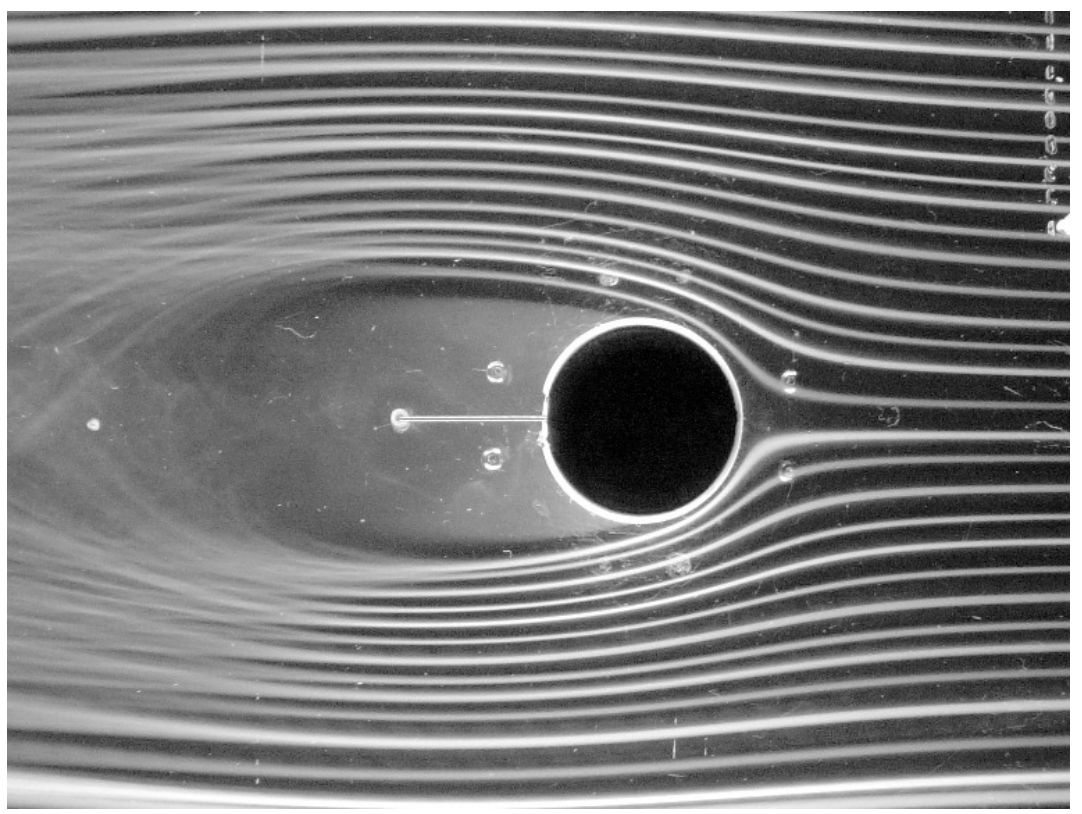

Figura 6.32 - Escoamento ao redor do Cilindro - Descarga Desligada.

Quando foi aplicada uma tensão de 5,0 kVolts já foi possível perceber uma pequena, mais significativa alteração no escoamento ao redor do cilindro. A Figura 6.33 apresenta a imagem desta etapa experimental. É possível identificar uma redução no comprimento da esteira formada atrás do cilindro. Nota-se, também, uma pequena alteração do escoamento próximo a região de estagnação do cilindro, com a linhas de fumaça sendo "atraídas"para a superfície do cilindro.

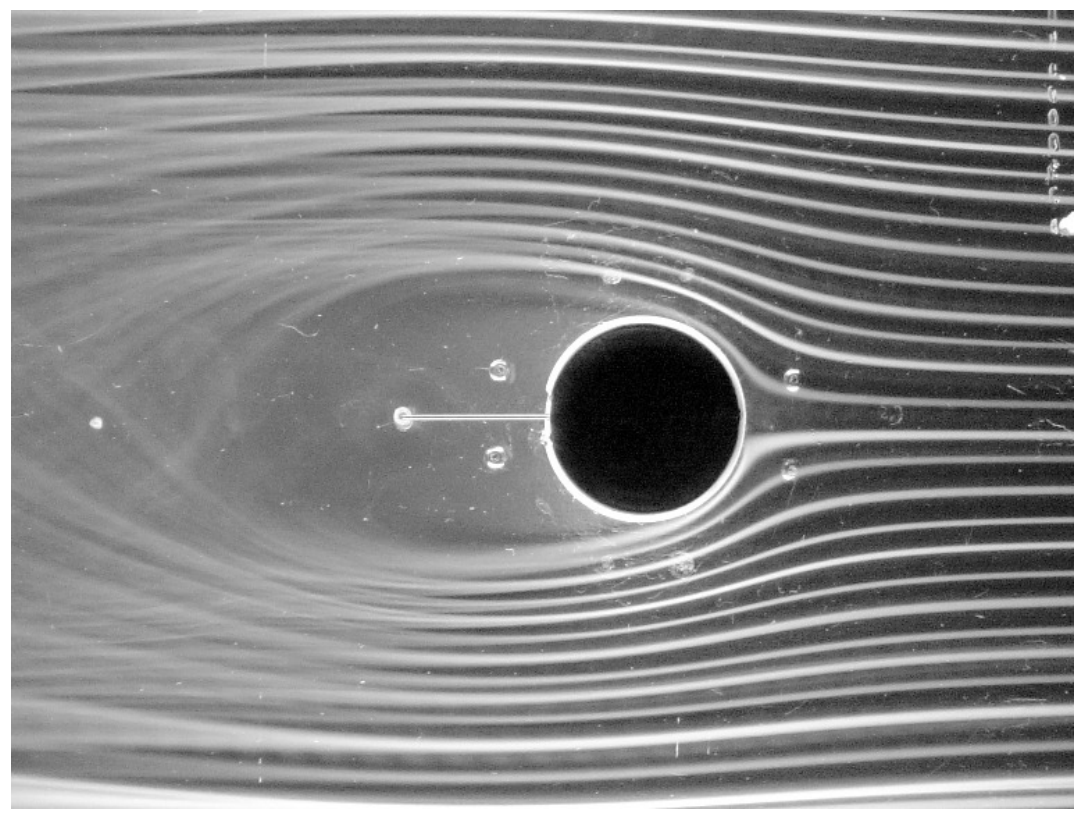

Figura 6.33 - Escoamento ao redor do Cilindro - Descarga Ligada - 5,0 kVolts. 
Com o aumento da tensão de alimentação (para 6 kVolts) ocorre uma alteração mais significativa do escoamento ao redor do cilindro. A esteira é significativamente reduzida em relação a etapa anterior. As linhas de fumaça próximo a região de estagnação são mais intensamente influenciadas. A Figura 6.34 apresenta a imagem desta etapa experimental.

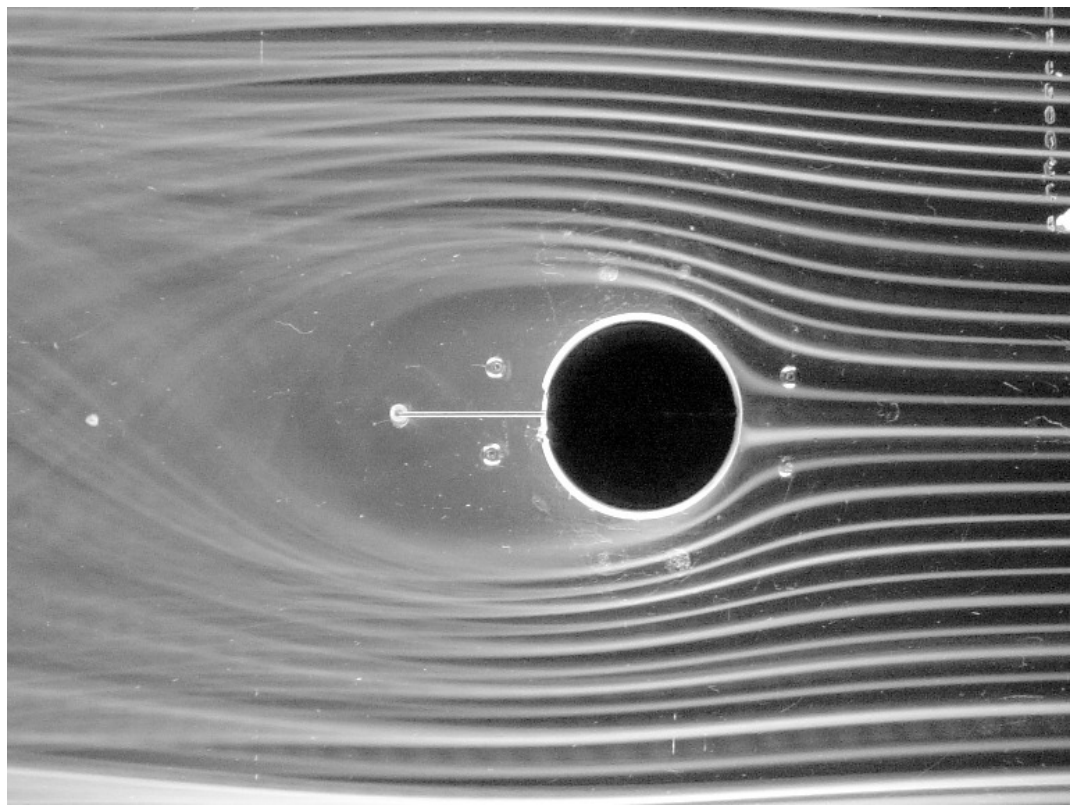

Figura 6.34 - Escoamento ao redor do Cilindro - Descarga Ligada - 6,0 kVolts.

Dando sequência a esta investigação experimental, a tensão de alimentação dos eletrodos foi aumentada para 7,0 kVolts. Isto produziu uma alteração no escoamento ao redor do cilindro ainda mais intensa, levando a uma redução no comprimento da esteira atrás do cilindro ainda significativamente maior do que na etapa anterior. Entretanto, foi na região de estagnação do cilindro que a alteração foi mais significativa. A Figura 6.35 apresenta a imagem desta etapa experimental.

Com um aumento para 8,0 kVolts da tensão de alimentação dos eletrodos, novamente pode-se verificar uma maior alteração no escoamento ao redor do cilindro. Entretanto, nesta etapa não se evidencia uma redução no comprimento da esteira atrás do modelo. Por outro lado, na região de estagnação do cilindro as linhas de fumaça são mais intensamente "atraídas" em direção a esta região do que na etapa anterior, estando estas linhas agora alinhadas ortogonalmente em relação a superfície do modelo. Isto é caracterizado novamente por um aumento da velocidade induzida pelo eletrodo nesta região. A Figura 6.36 apresenta a imagem desta etapa experimental. 


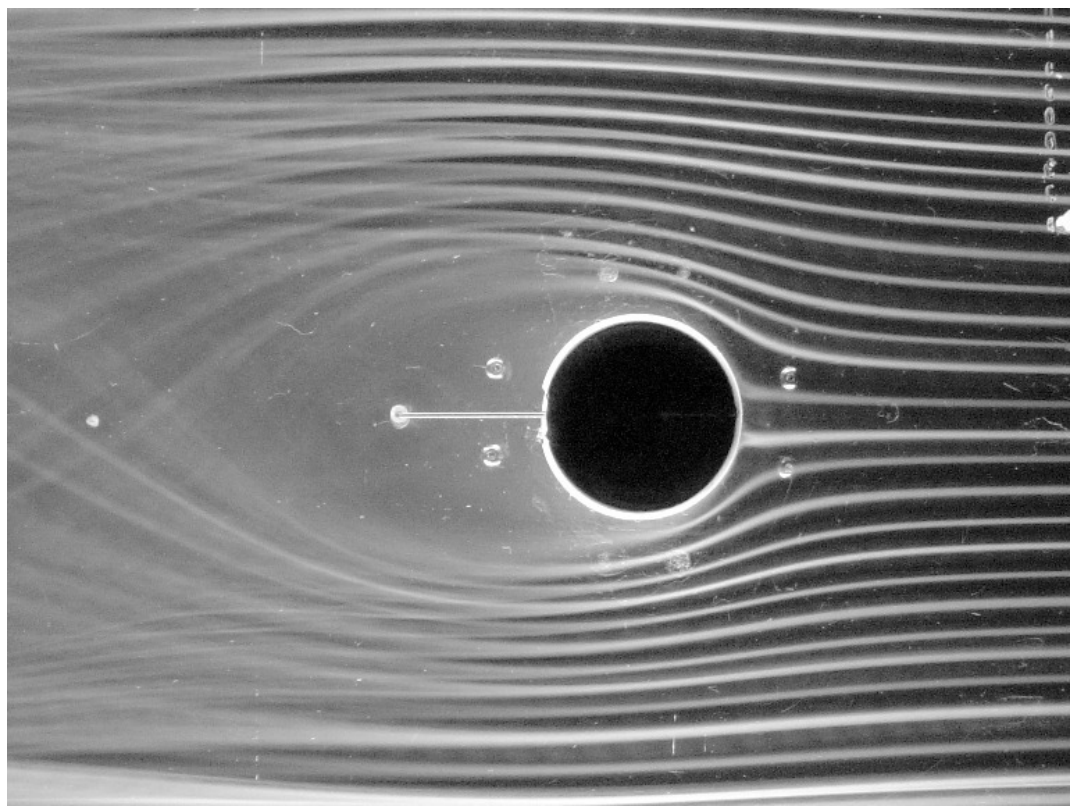

Figura 6.35 - Escoamento ao redor do Cilindro - Descarga Ligada - 7,0 kVolts.

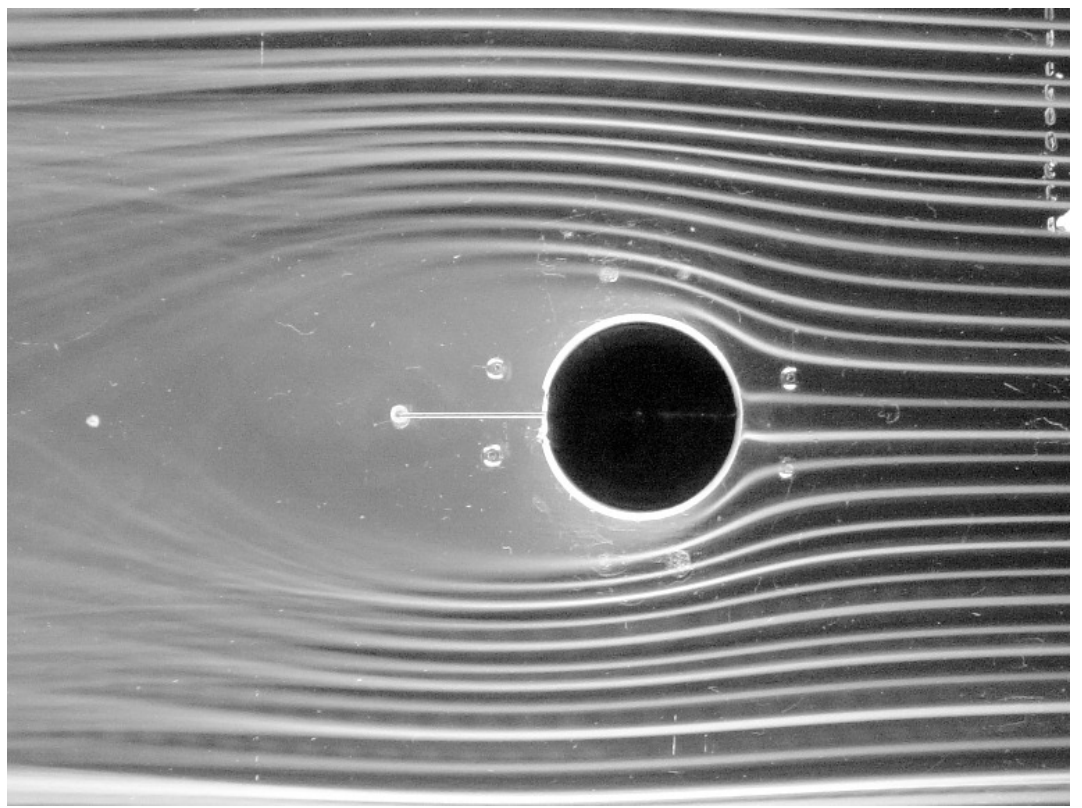

Figura 6.36 - Escoamento ao redor do Cilindro - Descarga Ligada - 8,0 kVolts.

Todos estes casos apresentados demonstram que, além da capacidade de indução de um escoamento, é possível alterar (ou controlar) sua intensidade de forma desejada. Ou seja, o escoamento induzido pode ser dimensionado para ter uma intensidade adequada a uma situação específica. Isto comprova, mesmo que de forma circunstancial, a habilidade do efeito eletro-hidrodinâmico na indução de escoamentos sobre superfícies. 


\subsection{Produção de Escoamentos sobre superfícies}

A produção de escoamentos por meio do efeito eletro-hidrodinâmico, utilizando a descarga por barreira dielétrica, consiste em uma arranjo especial de dois eletrodos, separados por um meio dielétrico, alimentados por uma alta tensão de corrente alternada com frequência elevada. A Figura 6.37 mostra de forma esquemática este tipo de dispositivo. Quando a tensão elétrica é aplicada ao dispositivo ocorre o surgimento de uma descarga elétrica ao longo do eletrodo externo. Nesta região o fluido encontra-se parcialmente ionizado e, desta forma, se move na direção do campo elétrico. Assim, é induzido um escoamento a partir da região da descarga elétrica que se desenvolve como um jato de parede mais à frente. Fica evidente a presença de três regiões distintas. Logo antes da descarga elétrica o fluido é succionado em direção a região da descarga elétrica (região de sucção), na região da descarga elétrica o fluido é acelerado e logo à frente ele é vertido para formar um jato de parede (região de recalque).
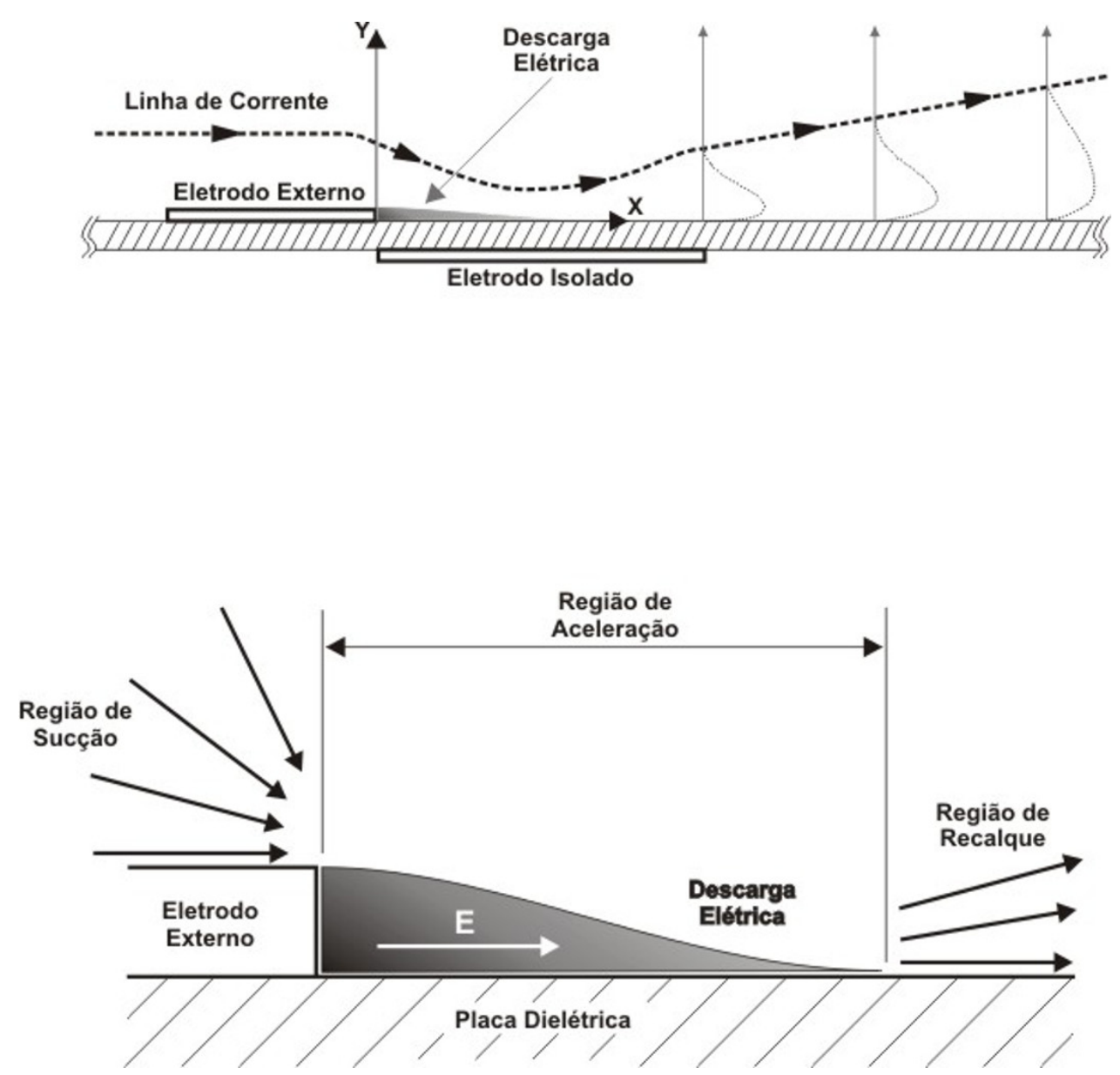

Figura 6.37 - Esquema da indução de um jato de parede através de um dispositivo eletro-hidrodinâmico por barreira dielétrica 
Desta forma, foi realizado um experimento com a intensão de visualizar o escoamento produzido por um dispositivo eletro-hidrodinâmico sobre superfícies planas. Para que isto fosse realizado a chave foi a possibilidade de se iluminar uma faixa de pequenas dimensões do escoamento, já traçado pela fumaça. Isto foi obtido através da focagem de uma fonte de luz de alta intensidade que passava através de uma pequena fenda. No início pretendeu-se que a espessura desta faixa de luz fosse a mínima possível, para que desta forma se capturasse os eventos o mais próximos possíveis de um mesmo plano. Ao longo do desenvolvimento do experimento, ficou evidente que a câmera digital utilizada tinha uma sensibilidade não tão alta, o que levou ao espessamento desta faixa. Assim, a dimensão final da espessura da faixa de luz utilizada ficou ao redor de $0,5 \mathrm{~cm}$. A priori pode parecer que esta dimensão é muita espessa para os fins deste experimento. No entanto, como será melhor evidenciado a seguir, assumiu-se como sendo satisfatória para os objetivos propostos.

A metodologia utilizada para a aquisição das imagens consistiu em se filmar o escoamento durante um certo intervalo de tempo. Desta forma, esperava-se obter uma quantidade razoável de imagens consecutivas para o tratamento posterior. Desta forma, a escolha da câmera recaiu em uma pequena câmera digital conectada diretamente a um computador. A Figura 6.38 apresenta o arranjo deste experimento.

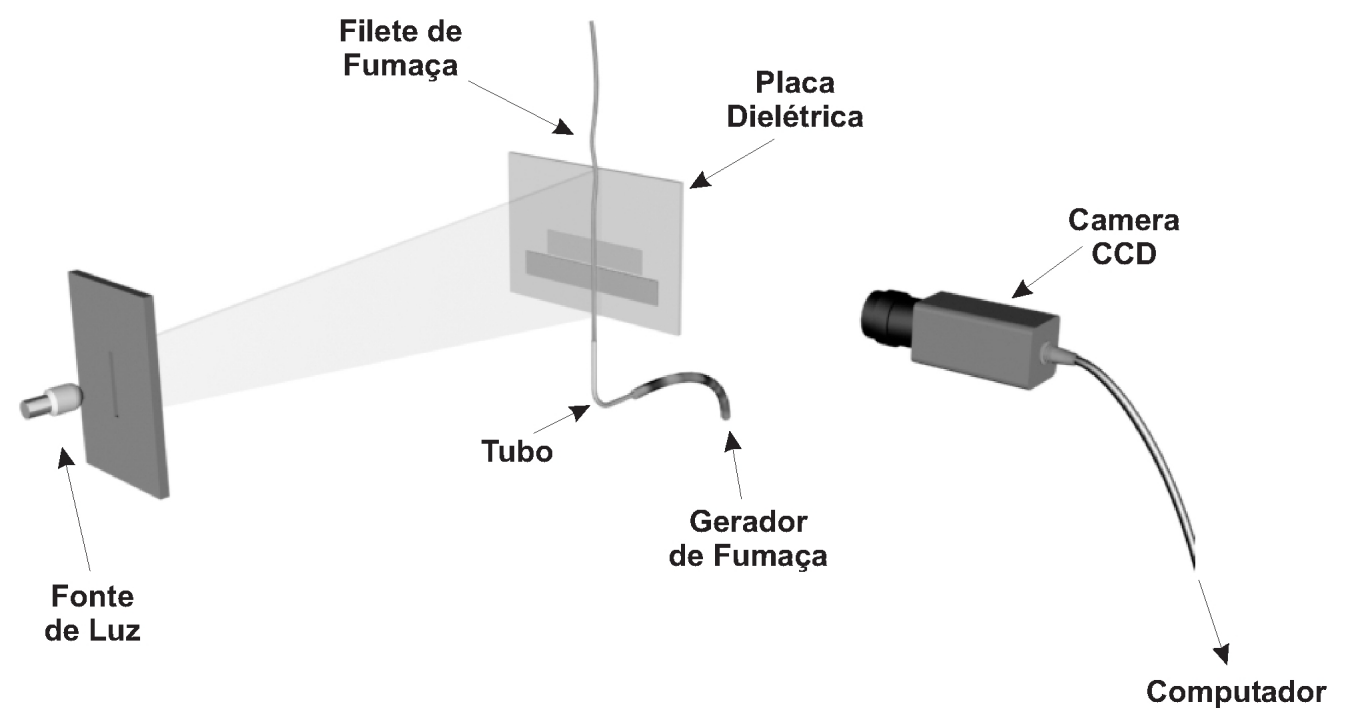

Figura 6.38 - Arranjo esquemático da visualização do escoamento produzido sobre superfícies.

A tensão de alimentação do sistema de produção da descarga elétrica foi mantida em seu máximo valor igual a 8 kVolts. A frequência da descarga foi ajustada para um valor considerado ótimo para a configuração de eletrodos utilizada, ou seja, $\mathrm{f}=5,5 \mathrm{kHz}$. Este 
valor foi determinado através do ponto de máxima corrente induzida no sistema, medida diretamente na saída da fonte de alimentação.

A Figura 6.39 apresenta uma sequência de imagens da visualização por fumaça do jato induzido sobre uma placa plana por uma configuração de eletrodos plano-plano. Podese ver nestas imagens a evidência do jato induzido ao longo da placa. São claramente mostradas as características descritas na Figura 6.37.

Tempo $=0$ segundos

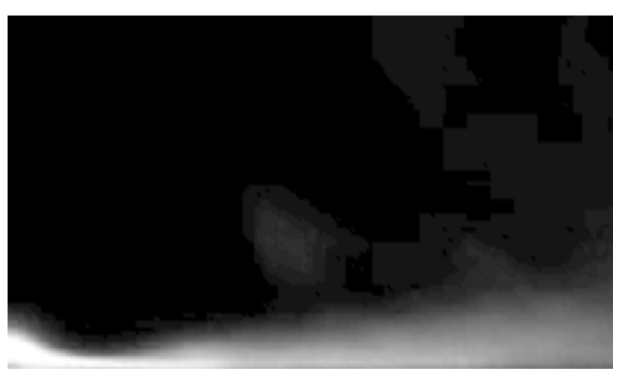

Tempo $=0,066$ segundos

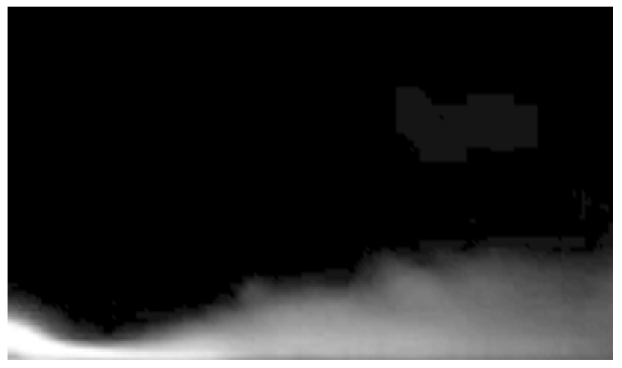

Tempo $=0,132$ segundos

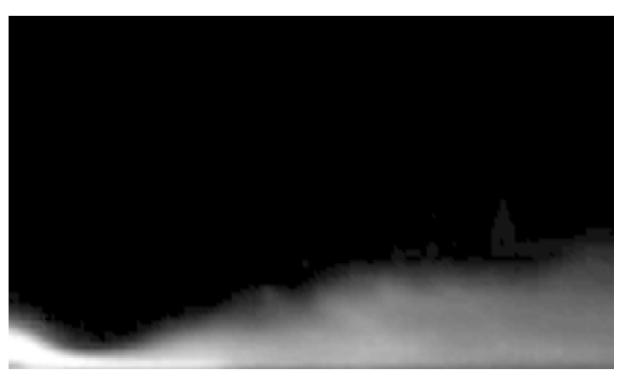

Tempo $=0,198$ segundos

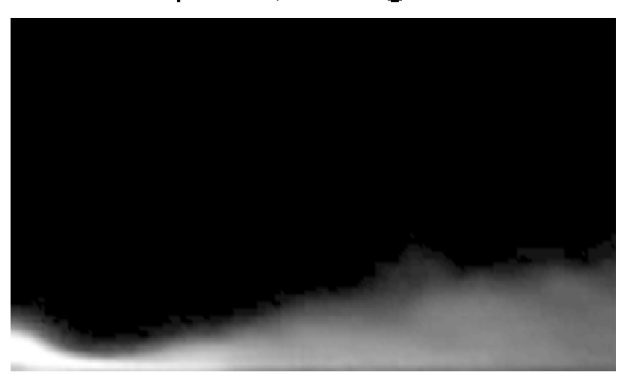

Tempo $=0,033$ segundos

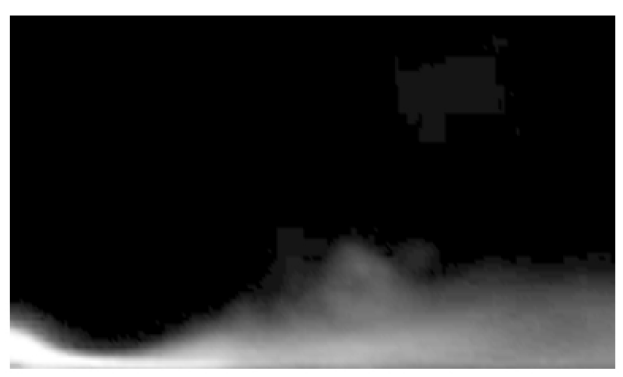

Tempo $=0,099$ segundos

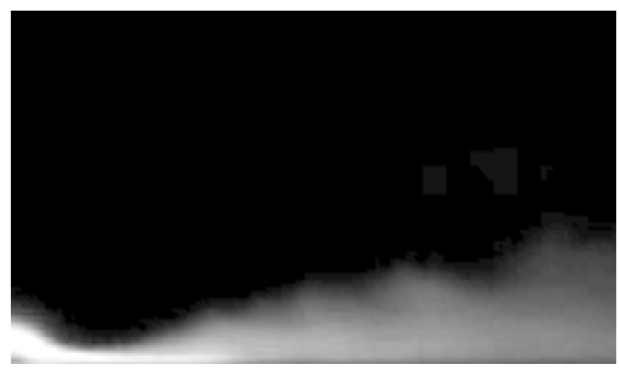

Tempo $=0,165$ segundos

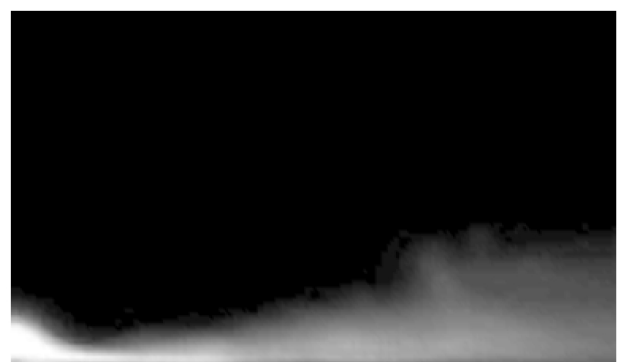

Tempo $=0,231$ segundos

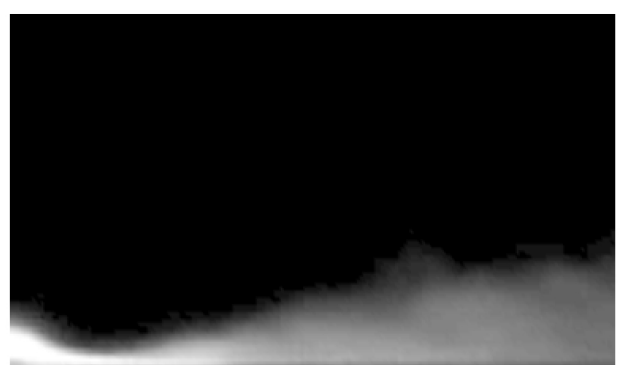

Figura 6.39 - Sequência de Visualização do Escoamento Induzido. 
Na Figura 6.40 é apresentada uma sequência de imagens a partir do ponto em que a descarga elétrica é ligada. Pode-se ver a indução do vórtice inicial, indicando o início da produção do escoamento junto a parede.

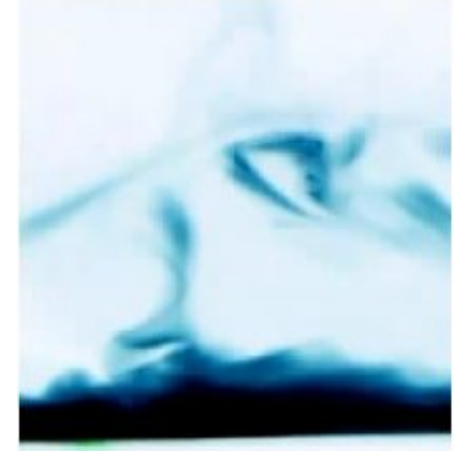

$\mathrm{t}=0,00 \mathrm{~s}$

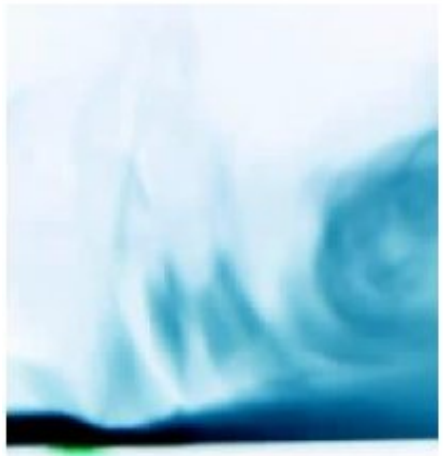

$\mathrm{t}=0,12 \mathrm{~s}$

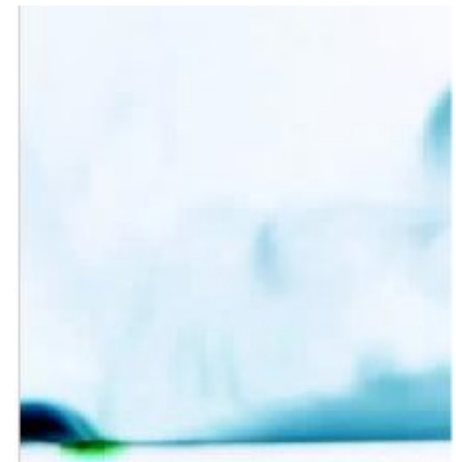

$\mathrm{t}=0,24 \mathrm{~s}$

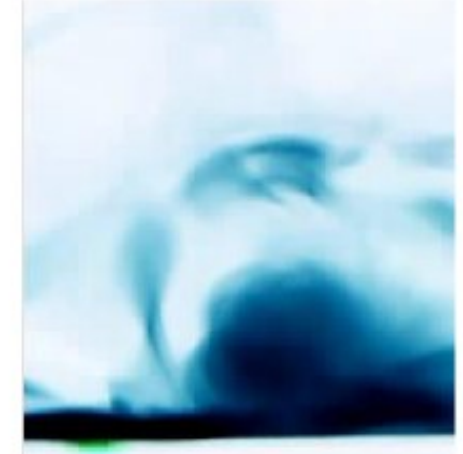

$\mathrm{t}=0,04 \mathrm{~s}$

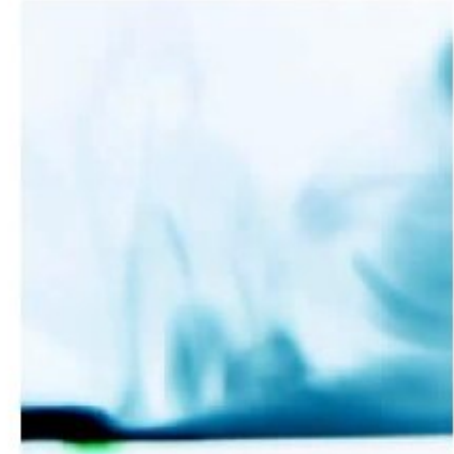

$\mathrm{t}=0,16 \mathrm{~s}$

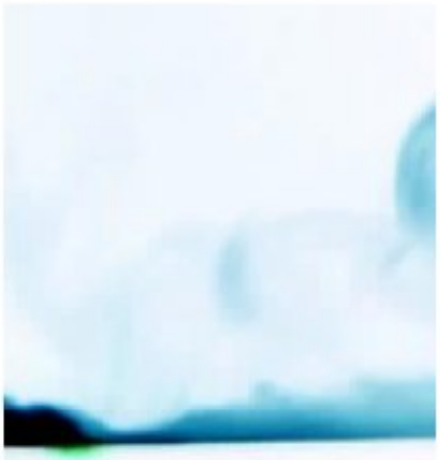

$\mathrm{t}=0,28 \mathrm{~s}$

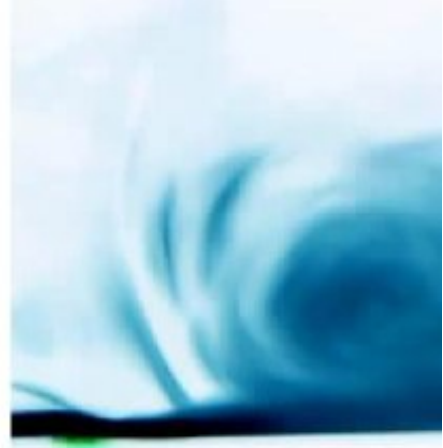

$\mathrm{t}=0,08 \mathrm{~s}$

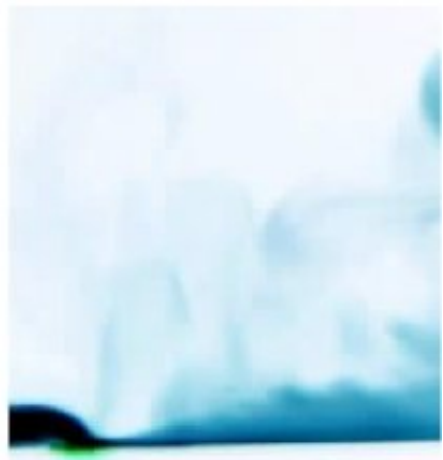

$\mathrm{t}=0,20 \mathrm{~s}$

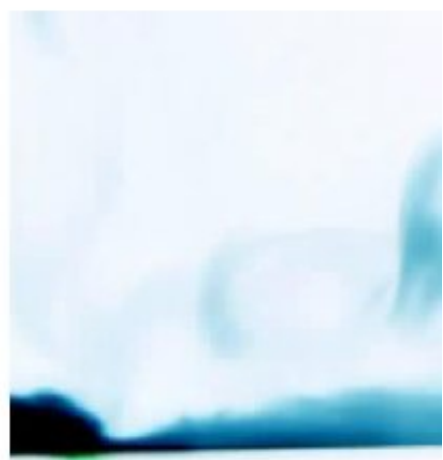

$\mathrm{t}=0,30 \mathrm{~s}$

Figura 6.40 - Sequência de imagens apresentando o vórtice inicial. 


\section{Capítulo 7}

\section{Efeitos Geométricos nos Dispositivos} EHD

\subsection{Introdução}

Esta análise experimental demonstrou que com uma escolha apropriada da geometria dos eletrodos é possível aumentar significativamente a eficiência de um dispositivo eletro-hidrodinâmico. Vários estudos foram realizados nos últimos anos com a intenção de demonstrar a aplicabilidade dos dispositivos eletro-hidrodinâmicos na produção e alteração de escoamentos formados sobre superfícies. Entretanto, pouco ainda foi realizado na análise de diferentes configurações geométricas dos eletrodos, ficando a maior parte dos trabalhos restritos a investigação de configurações comuns. Pode-se citar inicialmente Enloe et al. (2004), como tendo realizado uma primeira investigação sobre como as características geométricas dos eletrodos influenciam o desempenho dos dispositivos eletro-hidrodinâmicos. Mais recentemente Durscher e Roy (2011) apresentaram a análise de uma série de geometrias em forma de "serpentina" para os eletrodos com a qual obtiveram um comportamento bem distinto do escoamento induzido em relação as geometrias mais convencionais.

O ponto de partida desta análise consistiu no trabalho realizado por Enloe et al. (2004) que analisou e comparou duas configurações de dispositivo eletro-hidrodinâmicos, que tiveram a dimensão de um dos eletrodos, o eletrodo externo, variando o diâmetro para o eletrodo fio e espessura para o eletrodo plano. Os modelos utilizados consistem de um eletrodo exposto e de um eletrodo isolado, clássica configuração de um dispositivo que 


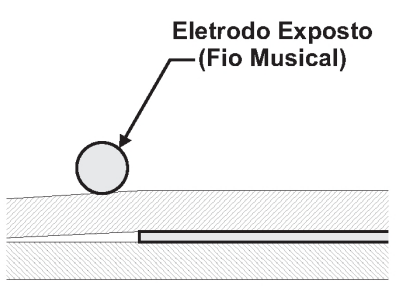

(a)

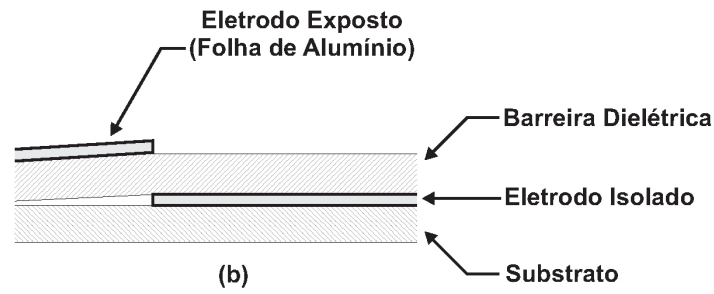

(b)

Figura 7.1 - Esquema dos dispositivos estudados por Enloe et al. (2004).

utiliza a descarga por barreira dielétrica. Neste caso, o eletrodo exposto apresentou duas geometrias diferentes, um eletrodo fio e um eletrodo plano. O primeiro teve seu diâmetro variado entre 0,36 a $0,98 \mathrm{~mm}$ enquanto que o eletrodo plano teve sua espessura estudada na faixa entre 0,08 a $0,64 \mathrm{~mm}$. Para ambas as configurações o eletrodo isolado utilizado foi uma folha de alumínio com espessura de 0,08 $\mathrm{mm}$ e encapsulado por uma fita dielétrica de poliamida. Os resultados produzidos demonstraram um aumento significativo do jato de parede produzido pela configuração que utilizou o eletrodo em forma de fio, inclusive com um aumento expressivo na velocidade máxima do jato de parede.

Para tentar investigar a influência da geometria dos eletrodos envolvidos na produção do escoamento eletro-hidrodinâmico, foi montado um experimento para a medição do jato de parede produzido sobre uma placa plana por três geometrias distintas de eletrodos. Duas geometrias foram escolhidas tomando-se por base outros trabalhos sobre o mesmo assunto realizados por outros autores. Estas geometrias já foram bem estudadas, principalmente a geometria de eletrodos planos simples. Outra geometria que foi utilizada consiste em um eletrodo fio fino (fio metálico) e um eletrodo plano. Esta geometria é mais promissora para aplicações práticas, pois produz uma descarga elétrica mais intensa e consequentemente induz um jato de parede mais forte quando comparada com a configuração de eletrodos planos simples. A proposta fundamental da análise da variação de geometria da borda ativa dos eletrodos externos consiste em se determinar o incremento (ou decremento) da intensidade de indução de escoamentos. Sabendo-se da tendência à formação de descargas elétricas em pontas, espera-se que com a geometria certa chegar-se a uma melhor eficiência com relação a quantidade de movimento injetada no fluido. Muito cuidado foi tomado com as escolhas das geometrias da borda ativa dos eletrodos externos para que as características da descarga brilhante uniforme sejam mantidas. Desta forma, foram descartadas certas configurações, como a geometria da borda triangular pois a descarga elétrica formada tende ao regime filamentar, o que, em princípio, pode prejudicar 


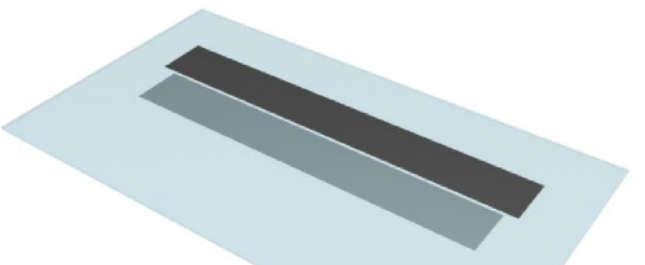

(A)

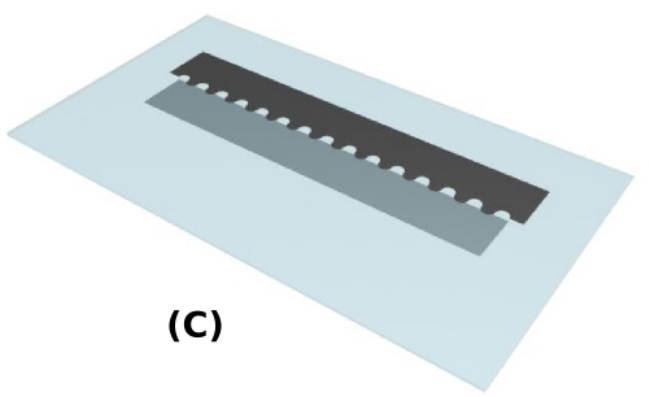

Figura 7.2 - Tipos de Configurações dos Eletrodos: (A) Plano-Plano; (B) Fio-Plano; (C) SerrilhadoPlano; (D) Serrilhado Triangular-Plano.

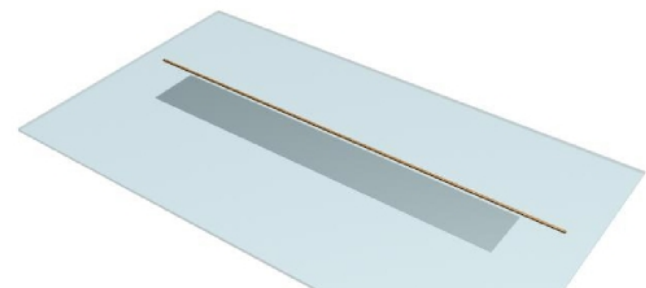

(B)

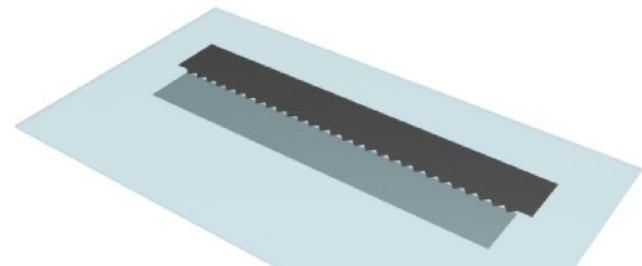

(D)

a eficiência da indução de movimento. A Figura 7.2 apresenta configurações possíveis da disposição dos eletrodos.

Desta forma, será utilizada uma geometria especial para o eletrodo que induz o escoamento em um formato similar ao estudado por Durscher e Roy (2011), mas com duas alterações significativas. Primeiro, as dimensões utilizadas para o formato do perfil serrilhado deste eletrodo serão reduzidas. Enquanto o raio do eletrodo superior estudado por Durscher e Roy (2011) foi de $6 \mathrm{~mm}$, neste experimento este mesmo raio será de $1 \mathrm{~mm}$. Espera-se com isso fazer com que o escoamento produzido tenha um predominância no sentido principal do escoamento, ou seja, descarregue o jato preferencialmente no sentido normal ao eletrodo. Outra alteração será a utilização de um eletrodo plano, sem detalhes, na confecção do eletrodo isolado. Espera-se com isso aumentar o efeito da intensidade do gradiente do campo elétrico, pois a distorção das linhas de campo serão maiores neste caso, o que pode intensificar a descarga elétrica produzida. Para efeito de comparação, serão analisados também as duas geometrias utilizadas por Enloe et al. (2004), ou seja, um conjunto de eletrodos na configuração plano-plano e o outro na configuração fio-plano. Espera-se com isso demonstrar qual destas geometrias produz um efeito mais significativo, com potencial para aplicações reais. 


\subsection{Descrição do Experimento}

Fundamentalmente, os experimentos realizados consistiram na medição do perfil de velocidades presentes em um jato de parede induzido sobre uma placa plana. Este perfil de velocidades foi medido através de uma sonda tipo Tubo de Pitot utilizada na medição do perfil de velocidades em camada limite, ou seja, com a entrada do tubo voltada para o escoamento achatada, no formato oblongo. A geometria da entrada tinha uma largura de $2 \mathrm{~mm}$ e altura interna de $0,1 \mathrm{~mm}$. A saída do tubo foi conectada em uma das entradas de um sensor de pressão, sendo que desta forma foi possível medir a pressão total presente na entrada do tubo. Uma tomada estática foi providenciada através de um simples tubo plástico montado a uma distância de 30 centímetros da região onde o escoamento era induzido pelo dispositivo eletro-hidrodinâmico. Isso foi feito de forma a produzir uma medição de pressão estática em uma região não perturbada pelo escoamento induzido. Da mesma forma que para o tubo de Pitot, a saída deste tubo foi conectada na outra entrada do sensor de pressão. Desta forma, foi possível inferir a pressão dinâmica a partir da diferença de pressões lidas pelo sensor.

Para um preciso levantamento do perfil de velocidades do jato induzido foi construído especialmente para este fim um posicionador eletromecânico, com a habilidade de produzir deslocamentos precisos e com boa repetição. Este dispositivo foi feito com a utilização de um mecanismo utilizado em CD-ROM, movimentado por um motor de passo controlado por microcontrolador PIC16F628. Especificamente, o firmware do microcontrolador foi feito de tal forma a controlar o motor de passo no modo half-step, o que, em conjunto com a redução por engrenagens do mecanismo, produzia deslocamentos da ordem de 0,01 mm. Este equipamento foi construído para poder receber comandos remotos digitais em um nível de tensão apropriado para ser controlado por saídas digitais encontradas em placas de aquisição de dados da National Instruments ${ }^{\circledR}$.

Todo o conjunto foi montado em um suporte de madeira, que por sua vez foi fixado em um base de madeira. Esta base foi utilizada também como ponto de montagem dos modelos que foram ensaiados. Uma haste metálica conectava o mecanismo de posicionamento a uma barra de madeira na qual foi fixado o tubo de Pitot. Na fixação do tubo de Pitot foi utilizado um parafuso borboleta para ser possível movimentar o tubo toda vez que fosse necessário ajustar o ponto inicial da medição, ou seja, fazer com que a ponta 


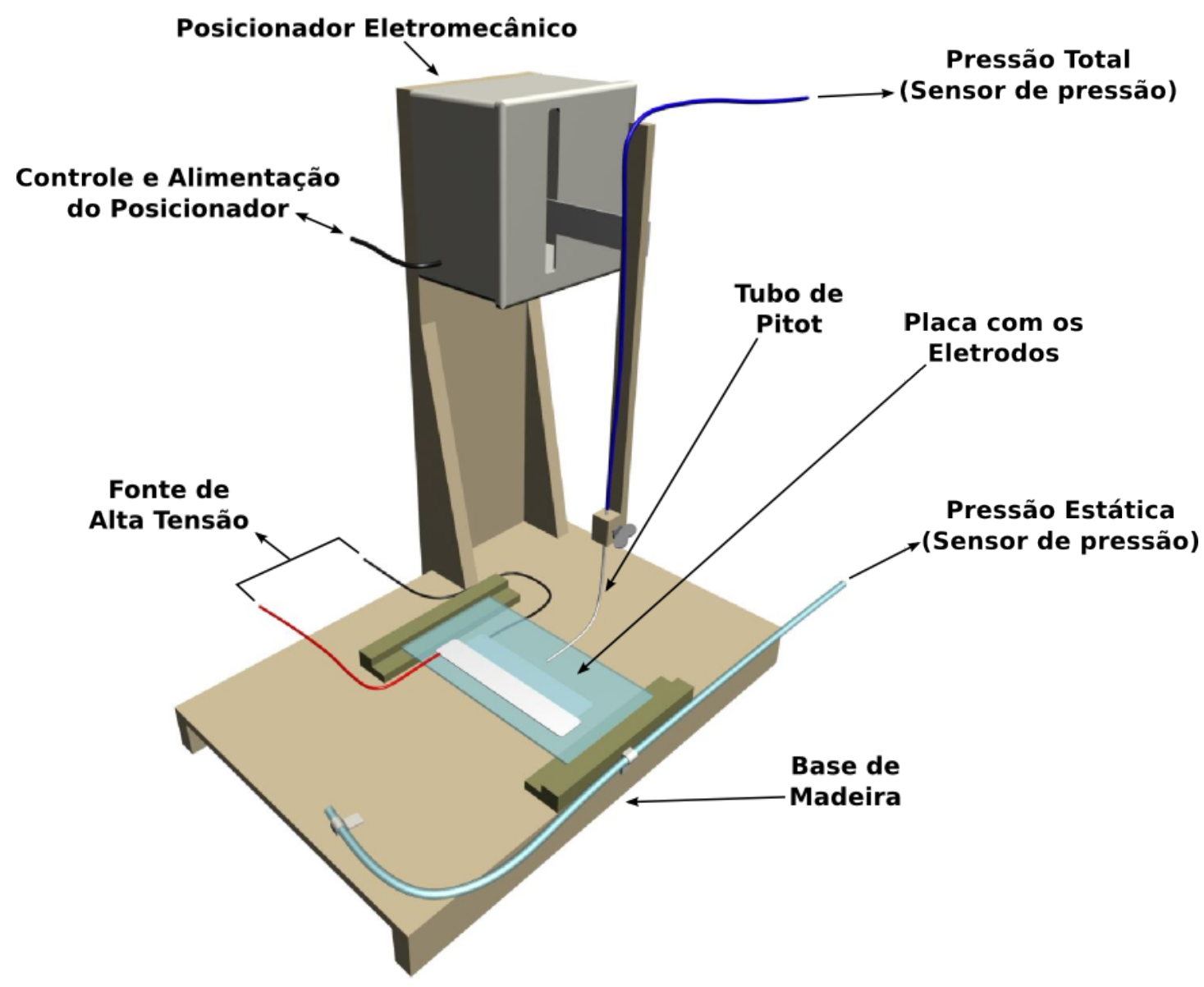

Figura 7.3 - Aspecto geral do equipamento construído.

do tubo tocasse a placa. A Figura 7.3 mostra um desenho esquemático dos equipamentos descritos acima.

O instrumento utilizado para medição de pressão foi um micromanômetro eletrônico de precisão modelo Baratron - tipo 77 fabricado pela $M K S$ Instruments ${ }^{\circledR}$. Este instrumento tem capacidade de atuar como um micromanômetro eletrônico, pois, dependendo da sonda de pressão empregada, pode medir diferenças de pressão na faixa de $0,0003 \mathrm{mmHg}$. No entanto, sua faixa total de medição pode ir de $1 \times 10^{-4}$ até $10 \mathrm{mmHg}$ com a utilização de sondas de pressão diferentes. Este equipamento produz um sinal de saída na faixa de 0 a 10 Volts, diretamente proporcional a pressão medida. A Figura 7.4 apresenta uma foto deste equipamento tendo a sua direita uma sonda de pressão. A sonda de pressão utilizada nos experimentos foi o modelo 77H-3. Esta sonda é composta de um sensor de pressão capacitivo integrado com um circuito em ponte conectado a um pré-amplificador. Este sensor tem oito faixas de pressão em escala total de $3,1,0,3,0,1,0,01,0,03,0,003$, 


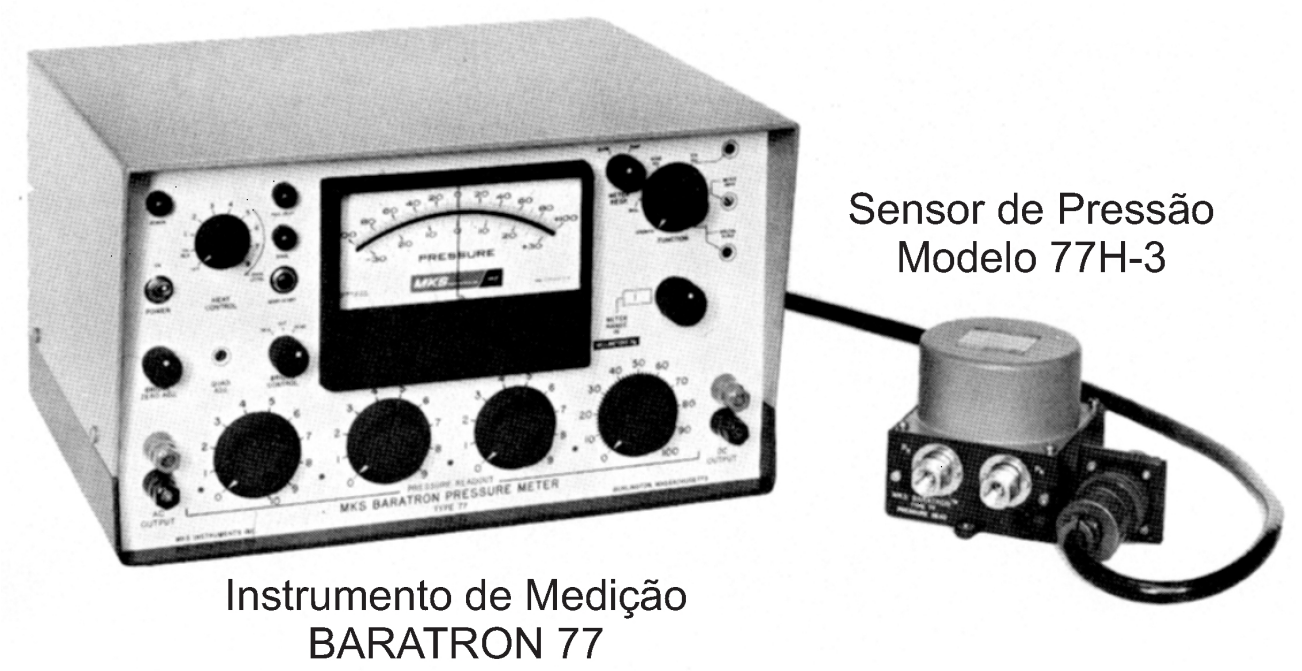

Figura 7.4 - Sistema Eletrônico de Medição de Pressão.

e 0,001 $\mathrm{mm}$ de $\mathrm{Hg}$. A escala de $0,1 \mathrm{mmHg}$ foi utilizada neste estudo. A medição da pressão é realizada de forma diferencial, ou seja, existem duas tomadas de pressão na sonda para a medição da diferença de pressão entre elas. A precisão do Baratron é de aproximadamente $0,1 \%$ da escala completa, o que significa que a incerteza nas leituras de pressão para o sensor utilizado foi de aproximadamente $1 \times 10^{-4} \mathrm{mmHg}$.

Os dados medidos pelo sensor de pressão foram lidos em uma placa de aquisição de dados das National Instruments ${ }^{\circledR}$, com auxilio de um computador. Como o instrumento de medição de pressão produzia um sinal elétrico amplificado de amplitude adequada, foi possível conectá-lo diretamente em uma das entradas analógicas da placa de aquisição. O sinal medido nesta entrada era convertido para um valor digital de 16 bits, o que produz uma resolução mais do que adequada para os valores medidos. Para uma completa automatização do processo de medição foi feito um programa em LabView ${ }^{\circledR}$. Este programa exercia as funções de ler os dados na entrada analógica da placa de aquisição, condicionálos e fazer o armazenamento, além de controlar o posicionador eletromecânico, ou seja, fazia uma leitura em determinada posição e procedia, então, a movimentar o tubo de Pitot para a próxima posição. Isto se repetia até que todas as leituras fossem realizadas e posteriormente armazenada em arquivo. A Figura 7.5 mostra a tela principal do programa. 


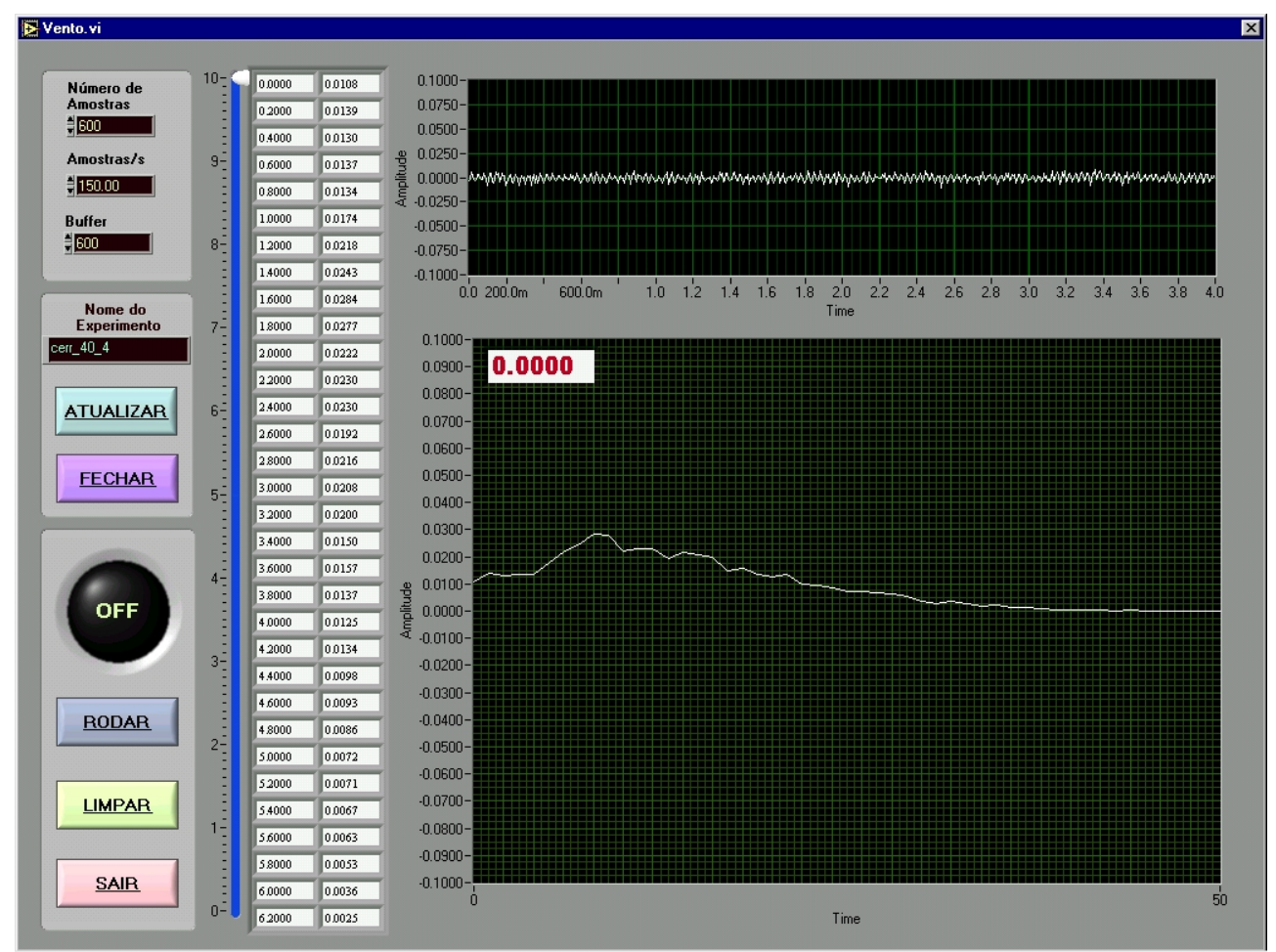

Figura 7.5 - Tela do programa utilizada nas medições.

\subsection{Análise dos Resultados}

Os dados foram medidos pelo sistema de aquisição de dados a uma taxa de 150 amostras/s, sendo que em cada tomada foram lidas 600 amostras, totalizando 4 segundos para cada tomada. Nas avaliações prévias, utilizadas para validar o sistema experimental, verificou que uma taxa de amostragem menor seria preferível, pois não sofria tanto os efeitos de varições temporais nos valores medidos. Por outro lado, valores menores do que 100 amostras por segundo faziam com que cada levantamento do perfil do jato demorasse um tempo tal que fazia com que os eletrodos e todo o sistema elétrico utilizado na produção da descarga elétrica esquentasse o suficiente para comprometer a eficiência deste sistema durante o tempo que levava cada levantamento. Isto produzia uma varição considerável nos valores de pressão medidos, o que comprometia uma adequada avaliação do efeito de produção do jato.

Cada levantamento completo foi realizado entre 0 e $10 \mathrm{~mm}$ de altura a partir da superfície da placa e com $0,2 \mathrm{~mm}$ entre cada passo. Para a medição do desenvolvimento do jato de parede induzido pela descarga, as medições do perfis de velocidade foram realizadas em três distâncias a partir da broda ativa do eletrodo que produzia a descarga. Estas distâncias foram mantidas para todos os experimentos realizados nos valores de 30 


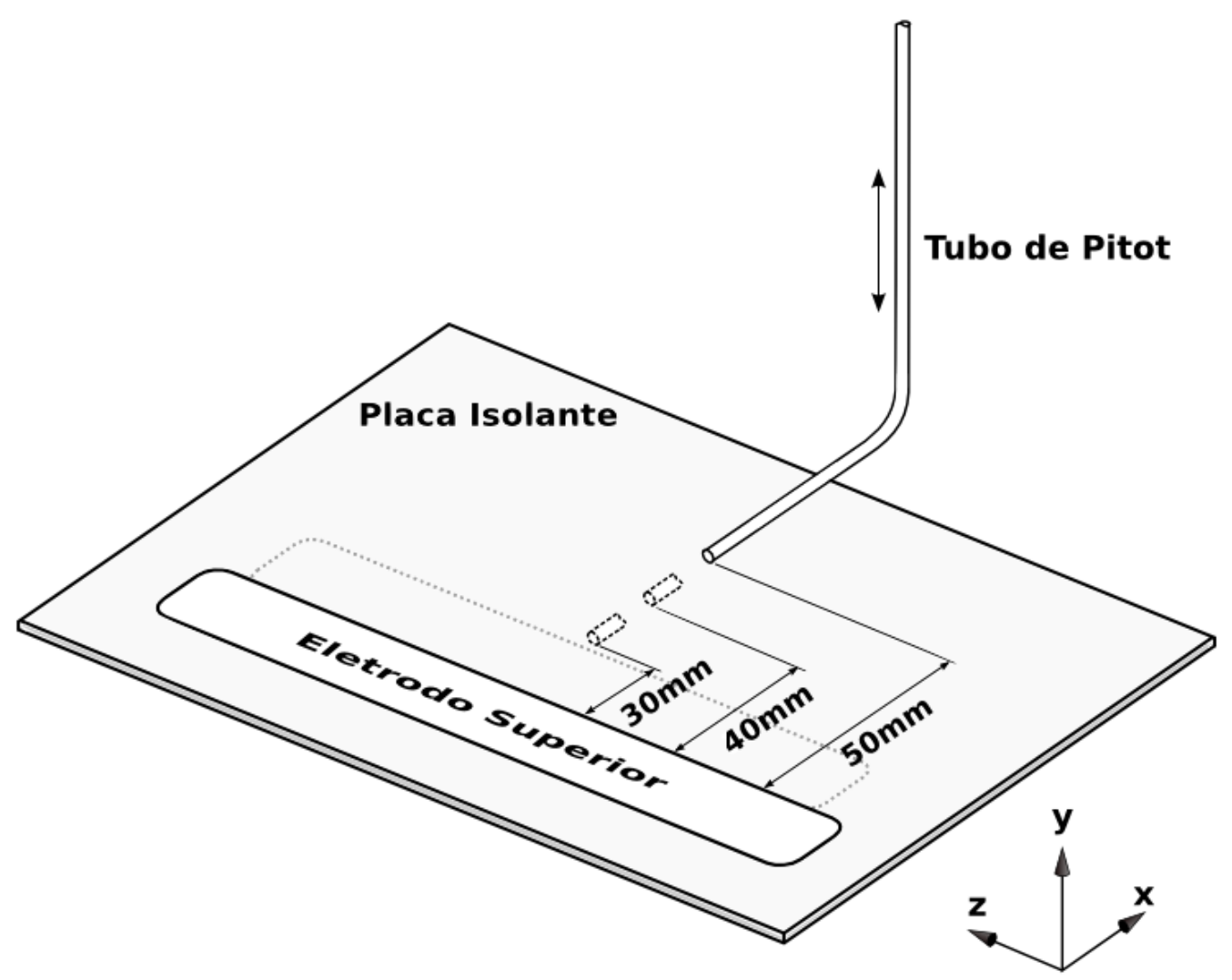

Figura 7.6 - Procedimento utilizado para medição dos perfis de velocidade

mm, $40 \mathrm{~mm}$ e $50 \mathrm{~mm}$. A Figura 7.6 mostra de forma esquemática este procedimento. Os dados coletados pelo sistema de aquisição, na forma de tensão elétrica proporcional ao valor da diferença de pressão, foram tratados pelo programa de aquisição para serem transformados em valores de metros de coluna de mercúrio, para posterior armazenamento no computador. Os dados coletados foram posteriormente tratados por uma série de scripts feitos em Matlab ${ }^{\circledR}$.

Os dados obtidos pelo sistema de aquisição de dados foram gravados em valores de pressão, com unidade de milímetros de mercúrio $(\mathrm{mmHg})$. Isto foi possível devido ao fato de que o equipamento de medição de pressão gera sinais elétricos em tensão proporcionais nesta unidade de medição de pressão. Os arquivos gerados foram processados por scripts específicos. Primeiramente, os valores foram convertidos para gerar valores de pressão em Pascal (Pa) através da seguinte relação.

$$
P[P a]=133,32237 P[m m H g]
$$


Como citado anteriormente, a pressão medida representa a diferença de pressão entre as duas tomadas do sensor. Devido ao arranjo utilizado nesta investigação experimental, uma tomada de pressão está conectada a um tubo de Pitot total, enquanto a outra está aberta para a pressão atmosférica. Desta forma, mede-se a pressão dinâmica $\left(P_{d}\right)$ que está, por sua vez, relacionada com a velocidade através da seguinte relação:

$$
V=\sqrt{\frac{2 P_{d}}{\rho_{a r}}} \quad[m / s]
$$

Sendo a massa específica do ar, $\rho_{a r}$, calculado em cada etapa experimental através da medição da temperatura e da pressão atmosférica no local dos ensaios e, finalmente, avaliada pela equação dos gases perfeitos, ou seja:

$$
\rho_{a r}=\frac{P_{a t m}}{R_{a r} T_{a m b}} \quad\left[k g / m^{3}\right]
$$

Substituindo a equação 7.3 na equação 7.2 obtém-se:

$$
V=C \sqrt{\frac{2 P_{d} R_{a r} T_{a m b}}{P_{a t m}}}
$$

Sendo $C$ um fator de calibração do tubo de Pitot. Para a medição da pressão atmosférica local foi utilizado um barômetro de mercúrio, cuja precisão básica é da ordem 0,5 mmHg. Para a medição da temperatura ambiente foi utilizado um termômetro de líquido, com precisão da ordem de $0,5^{\circ} \mathrm{C}$. A constante do gás, $\mathrm{R}$, foi assumida com seu valor padrão, ou seja, $R_{a r}=287,04 \mathrm{~kg} / \mathrm{Km}$. Com estes dados, foi possível estimar a incerteza na medição das velocidades através da seguinte relação:

$$
\frac{U_{V}^{2}}{V^{2}}=\frac{U_{C}^{2}}{C^{2}}+\frac{1}{4} \frac{U_{P_{d}}^{2}}{P_{d}^{2}}+\frac{1}{4} \frac{U_{T_{a m b}}^{2}}{T_{a m b}^{2}}+\frac{1}{4} \frac{U_{P_{a t m}}^{2}}{P_{a t m}^{2}}
$$

Sendo $U_{V}$ a incerteza na medição da velocidade, $C$ o valor de calibração do tubo de Pitot, $U_{C}$ as incertezas associadas com a calibração, $U_{P_{d}}$ as incertezas com relação a 
medição da diferença de pressão pelo sensor, $U_{T_{a m b}}$ as incertezas associadas a medição da temperatura ambiente e $U_{P_{a t m}}$ as incertezas na medição da pressão atmosférica.

A Equação 7.5 foi utilizada na determinação da incerteza dos valores de velocidade medidos nos experimentos. Para tanto, a incerteza na medição da diferença pressão foi de $\pm 0,001 \mathrm{~Pa}$, para o modelo de sensor utilizado. Como os experimentos foram realizados em ambiente controlado e sem nenhum efeito de compressibilidade e os escoamentos medidos foram de baixa intensidade, o valor da constante de calibração foi mantida em $C=1.0$. Entretanto, o valor da incerteza associada a calibração foi mantido em $U_{C}=0,01$, pois, desta forma, levam-se em conta prováveis, embora pequenos, desalinhamentos da entrada do tubo de Pitot em relação ao escoamento.

Os dados de velocidade medidos foram comparados com curvas teóricas, principalmente, na caracterização dos perfis de velocidade medidos como jatos de parede. Para tanto, utilizou-se a relação obtida por Verhoff (1970) para o cálculo da curva teórica do perfil de velocidades de um jato de parede livre. Esta relação é apresentada a seguir.

$$
\frac{U}{U_{m}}=1,48\left(\frac{y}{y_{1 / 2}}\right)^{1 / 7}\left(1-\operatorname{erf}\left(0.68\left(\frac{y}{y_{1 / 2}}\right)\right)\right)
$$

A Figura 7.7 apresenta um gráfico com a curva teórica calculada pela relação de Verhoff (1970). O eixo ordenado do gráfico apresenta a distância a partir da superfície na qual o jato é teoricamente imposto, mas com valores adimensionalizados na forma $y / y_{\frac{1}{2}} U_{\max }$, enquanto o eixo das abíssicas apresenta a velocidade adimensionalizada na forma $U / U_{\max }$ Pode-se ver, que um jato de parede é caracterizado por uma típica distribuição de velocidades, a qual tem características bem definidas, como, por exemplo, o valor de $U / U_{\max }$ $=0,5$ é encontrado na metade da altura, ou seja, quando $y / y_{\frac{1}{2} U_{\max }}=1$.

Para a medição da tensão de alimentação dos eletrodos foi utilizada uma sonda de alta tensão especialmente construída para esta investigação. Este equipamento tem a característica fundamental de reduzir a tensão de entrada a uma razão de 1000:1, ou seja, apresenta em sua saída uma tensão 1000 vezes menor do que a de entrada. Maiores detalhes sobre este equipamento podem ser obtidos no Apêndice B. A medição da corrente fornecida aos eletrodos foi utilizando um transformador de corrente modelo TA12-100. Este componente tem a característica de medir a corrente induzida ao longo de um fio 


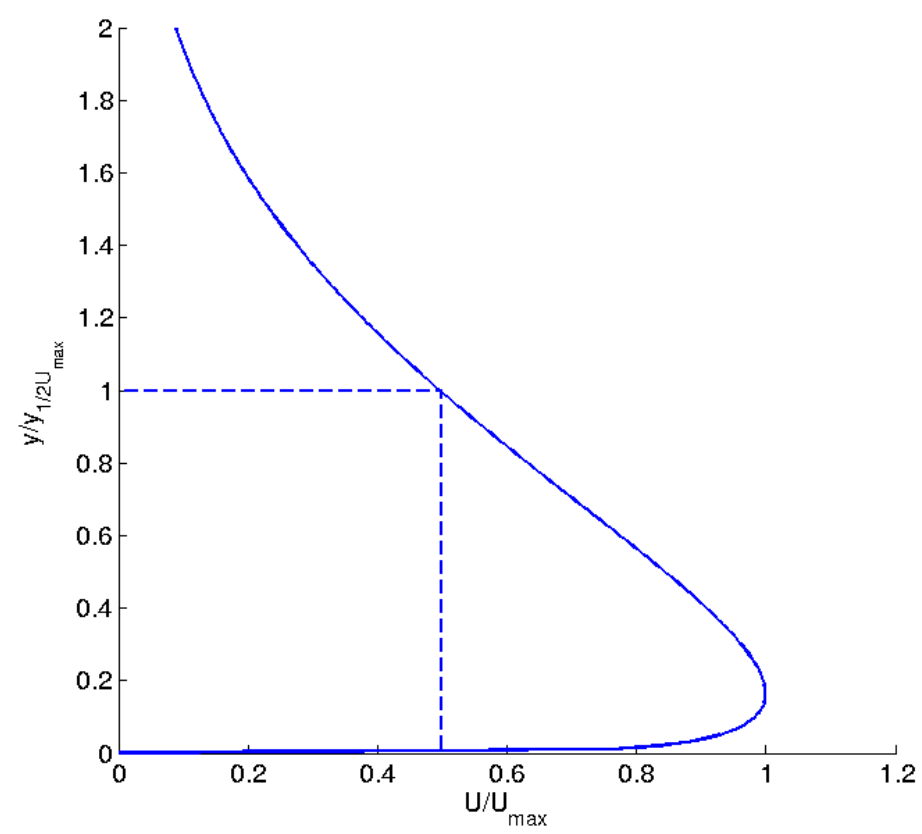

Figura 7.7 - Perfil de Velocidades Adimensionais Teórico para um Jato de Parede.

condutor e fornecer uma saída em tensão proporcional a corrente medida. Ou seja, é um componente que mede do forma não invasiva a corrente que flui por um condutor. Isto é extremamente adequado para a medição de correntes que fluem por condutores submetidos a elevadas tensões. Suas principais características são: faixa de corrente de entrada de 0 a 5 A, razão de 1000:1 na tensão proporcional de saída e capacidade de medir corrente por 1 minuto quando o condutor está submetido a uma tensão de corrente alternada de 6,0 kVolts. A Figura 7.8 apresenta uma amostra dos dados de tensão e corrente medidos através deste procedimento.

A potência elétrica que foi consumida por cada configuração foi calculada através da somatória do produto entre a tensão instantânea $\left(U_{i}\right)$ e a corrente instantânea $\left(I_{i}\right)$ e dividindo-se o resultado pelo número total de períodos de tempo $(N)$. A Equação 7.7 mostra este procedimento.

$$
\text { Pot }=\frac{1}{N} \sum_{i=1}^{N} U_{i} \cdot I_{i} \quad[W]
$$




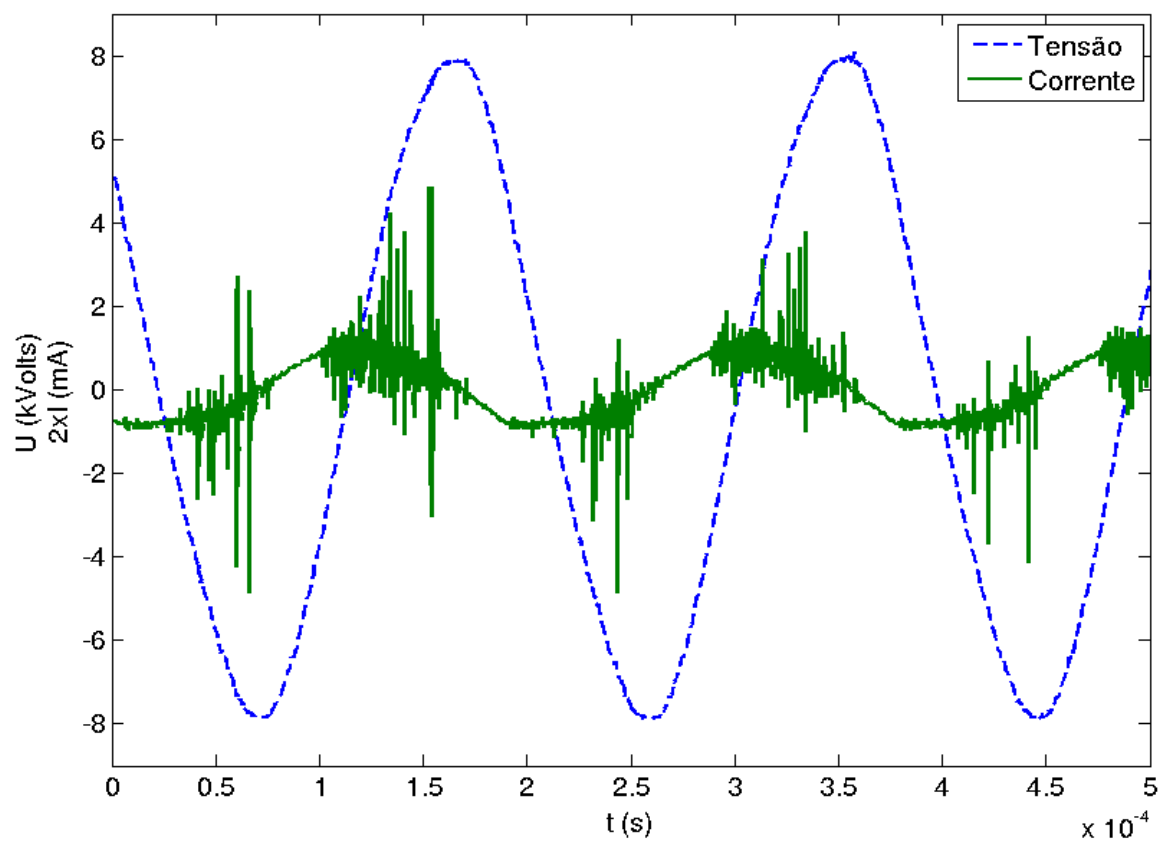

Figura 7.8 - Dados típicos de tensão e corrente elétrica medidos.

\subsection{Resultados Experimentais}

\subsubsection{Avaliação da Configuração Plano-Plano}

O atuador era composto de dois eletrodos planos, feitos com folhas de alumínio fino com espessura de 0,05 mm. O eletrodo externo (o que induzia o escoamento medido) tinha dimensões de $17 \mathrm{~cm}$ de comprimento, 1,8 cm de largura e o eletrodo isolado (do outro lado do substrato isolante) tinha $15 \mathrm{~cm}$ de comprimento e 1,8 $\mathrm{cm}$ de largura. Os eletrodos foram fixados, com a utilização de uma fita adesiva de dupla face, sobre uma placa de acrílico com dimensões de $15 \mathrm{~cm}$ de comprimento, $25 \mathrm{~cm}$ de largura e $3 \mathrm{~mm}$ de espessura. Duas pequenas extensões dos eletrodos foram feitas de forma a servirem de barras de alimentação, sendo que chegavam até as bordas da placa, onde os cabos de alimentação da fonte de tensão eram conectados por meio de garras jacaré. A Figura 7.9 apresenta o o desenho aproximado deste modelo.

Todos os experimentos foram realizados nas mesmas condições atmosféricas, com a temperatura ambiente igual a $25,5^{\circ} \mathrm{C}$ e a pressão atmosférica igual a $668 \mathrm{mmHg}$. Foram realizadas três etapas para a medição do perfil de velocidades do jato induzido, com a primeira sendo realizada $30 \mathrm{~mm}$ a jusante do eletrodo externo, a segunda a $40 \mathrm{~mm}$ e a terceira a $50 \mathrm{~mm}$. 


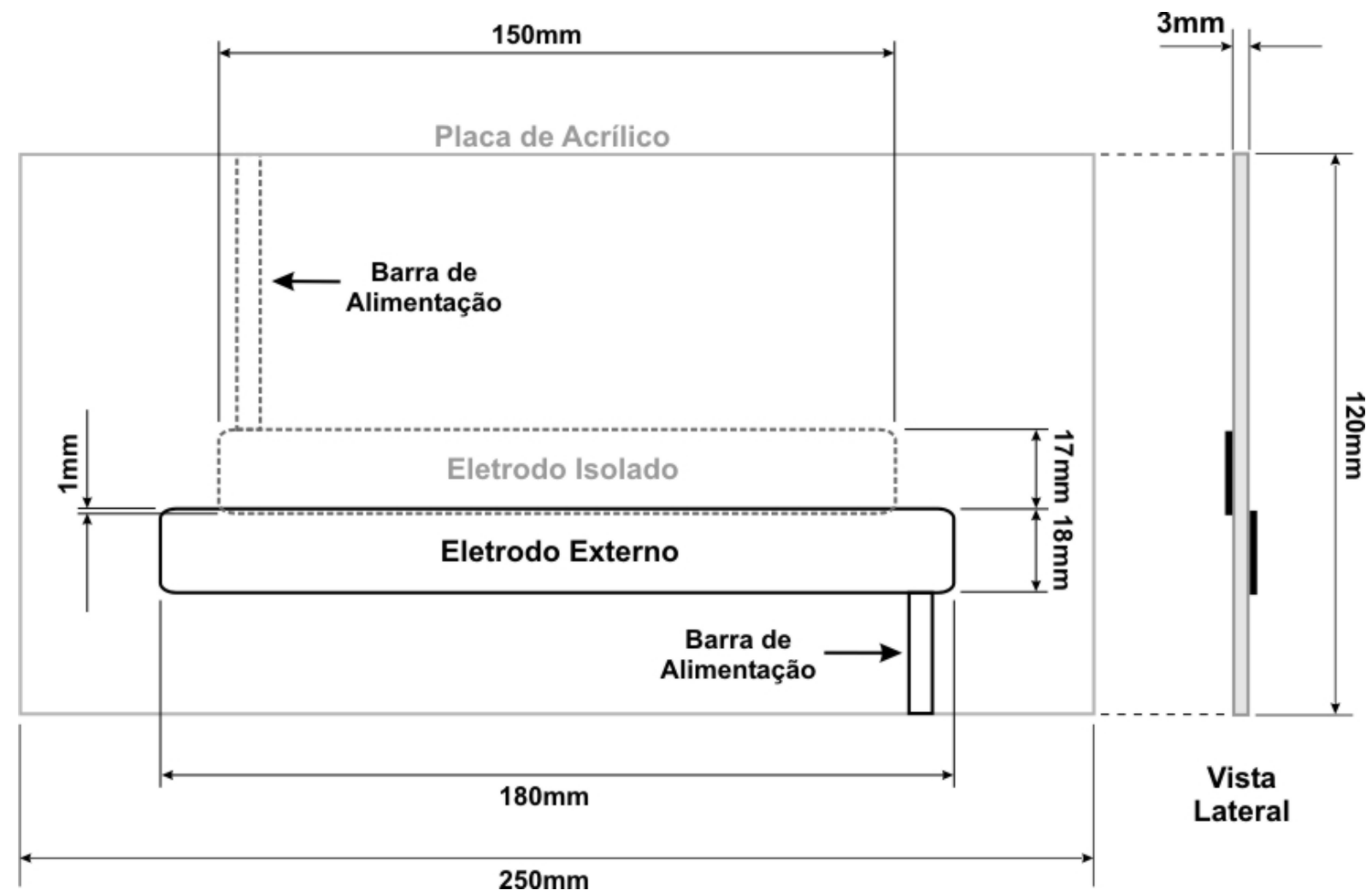

Figura 7.9 - Modelo com Eletrodo Externo Plano.

Em todas estas etapas a sonda foi movimentada verticalmente em intervalos de 0,2 mm até atingir $10 \mathrm{~mm}$ da posição inicial. Foram realizadas três tomadas completas de dados, para efeito de aumento da confiabilidade. A tensão de alimentação foi mantida em 8,0 k Volts com a frequência de alimentação igual a 5,5 kHz. O sistema de medição de pressão foi o micromanômetro Baratrom com a Sonda de Pressão de 3 mmHg, sendo os valores de pressão medidos lidos por meio do sistema de aquisição. A Figura 7.10 apresenta os resultados desta etapa experimental, mostrando todos os perfis de velocidades medidos. Já a Figura 7.11 mostra uma comparação dos perfis médios de velocidade na forma adimensional com os perfis de velocidade teóricos na forma normalmente utilizada para representar um jato de parede. 

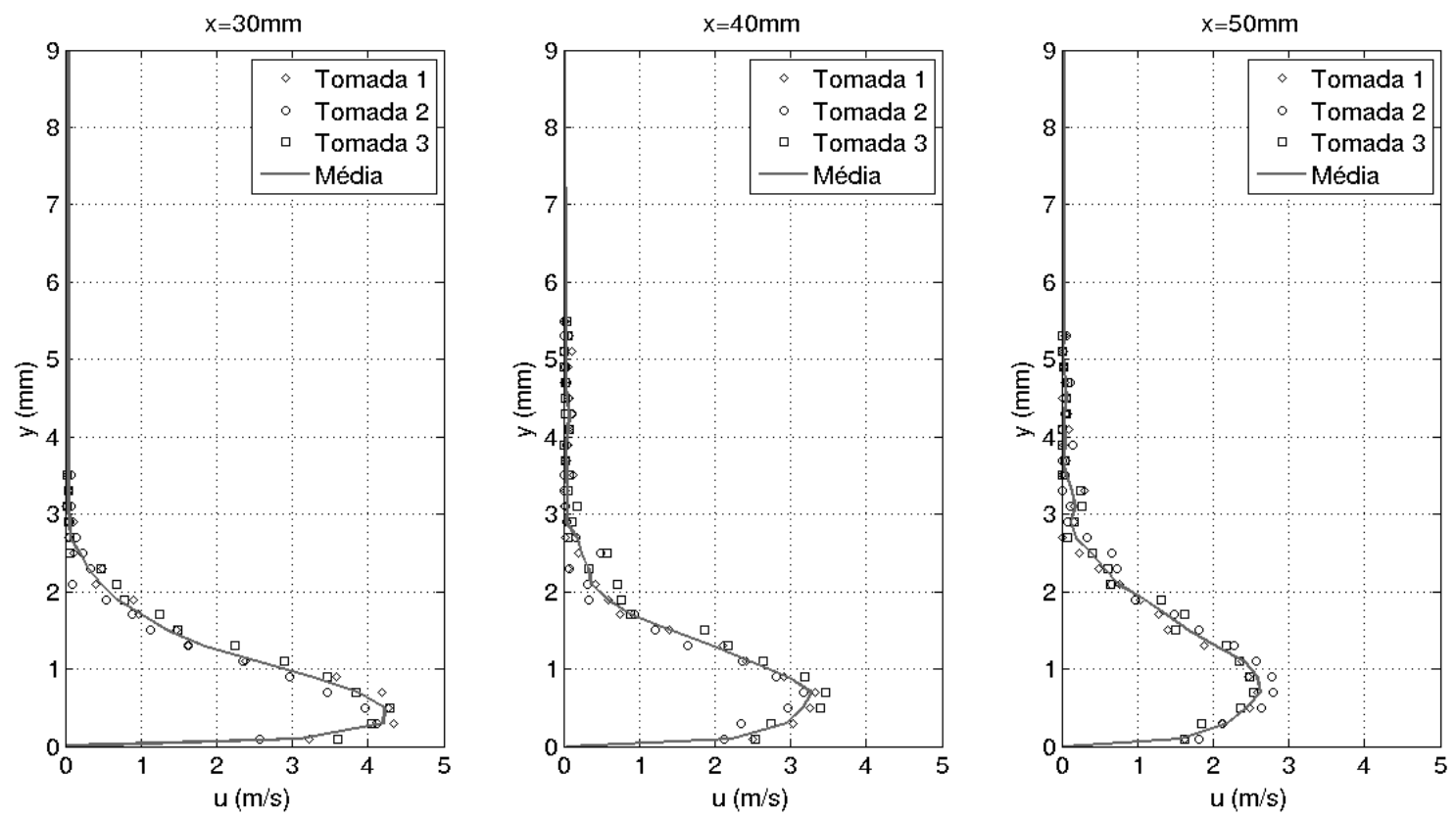

Figura 7.10 - Perfis de Velocidades produzidos pela configuração plano-plano.
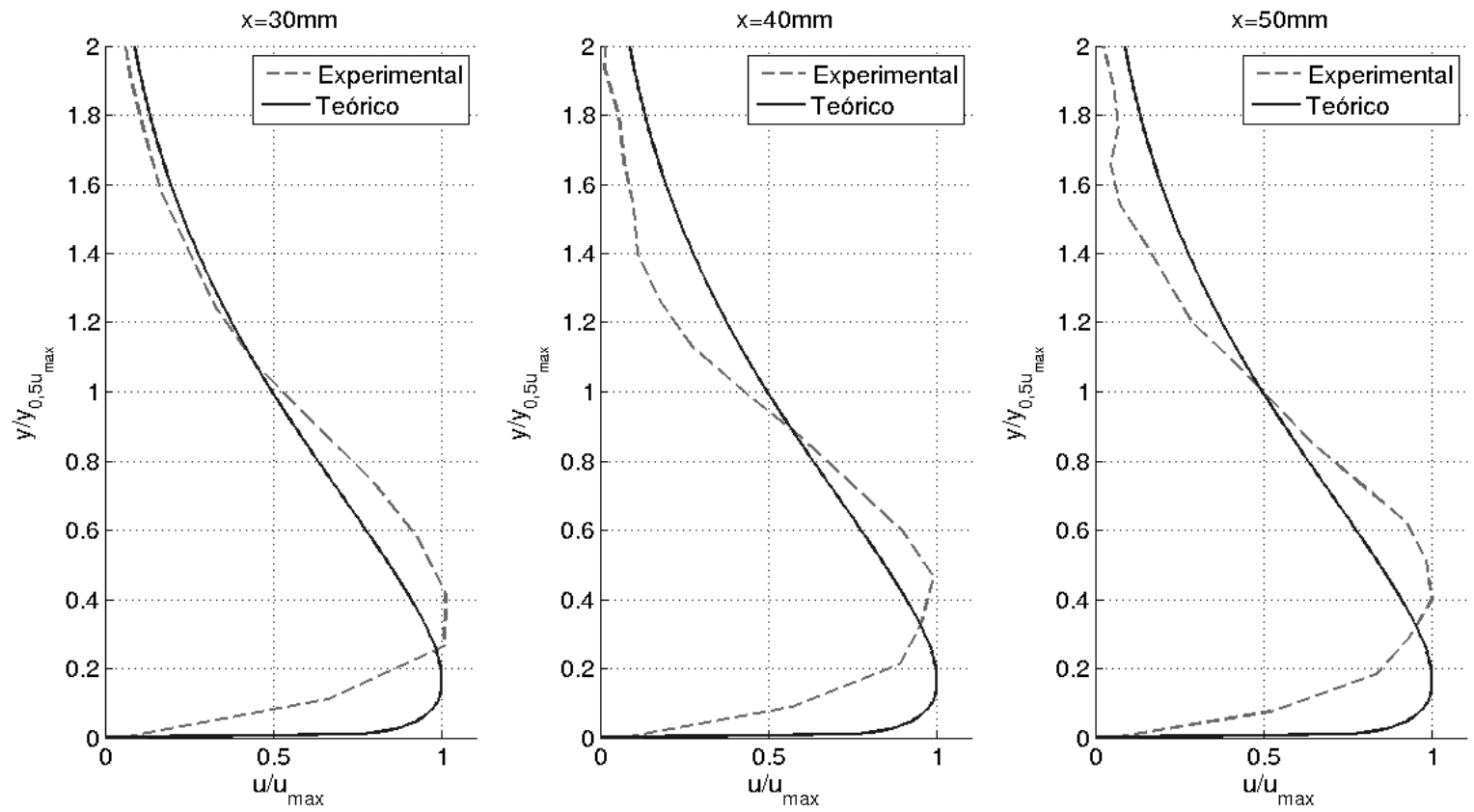

Figura 7.11 - Perfis médios da configuração plano-plano.

\subsubsection{Avaliação da Configuração Fio-Plano}

O atuador era composto por um eletrodo plano, montado na parte inferior da placa, feito com folha de alumínio fino de dimensões de $17 \mathrm{~cm}$ de comprimento e 1,8 $\mathrm{cm}$ de largura. O eletrodo superior (que induzia o escoamento) foi feito a partir de um fio de cobre, com diâmetro de 0,644 mm (AWG 22), colado com cola epóxi sobre a superfície. O 
eletrodo inferior foi fixado com a utilização de uma fita adesiva de dupla face. Foi utilizada uma placa de acrílico com dimensões de $15 \mathrm{~cm}$ de comprimento, $25 \mathrm{~cm}$ de largura e $3 \mathrm{~mm}$ de espessura. Uma pequena extensão do eletrodo inferior serviu de barras de alimentação, enquanto que uma das pontas do eletrodo superior foi estendida para ser utilizada como ponto de alimentação. Os cabos de alimentação da fonte de tensão eram conectados por meio de garras jacaré. A Figura 7.12 apresenta o desenho aproximado deste modelo.

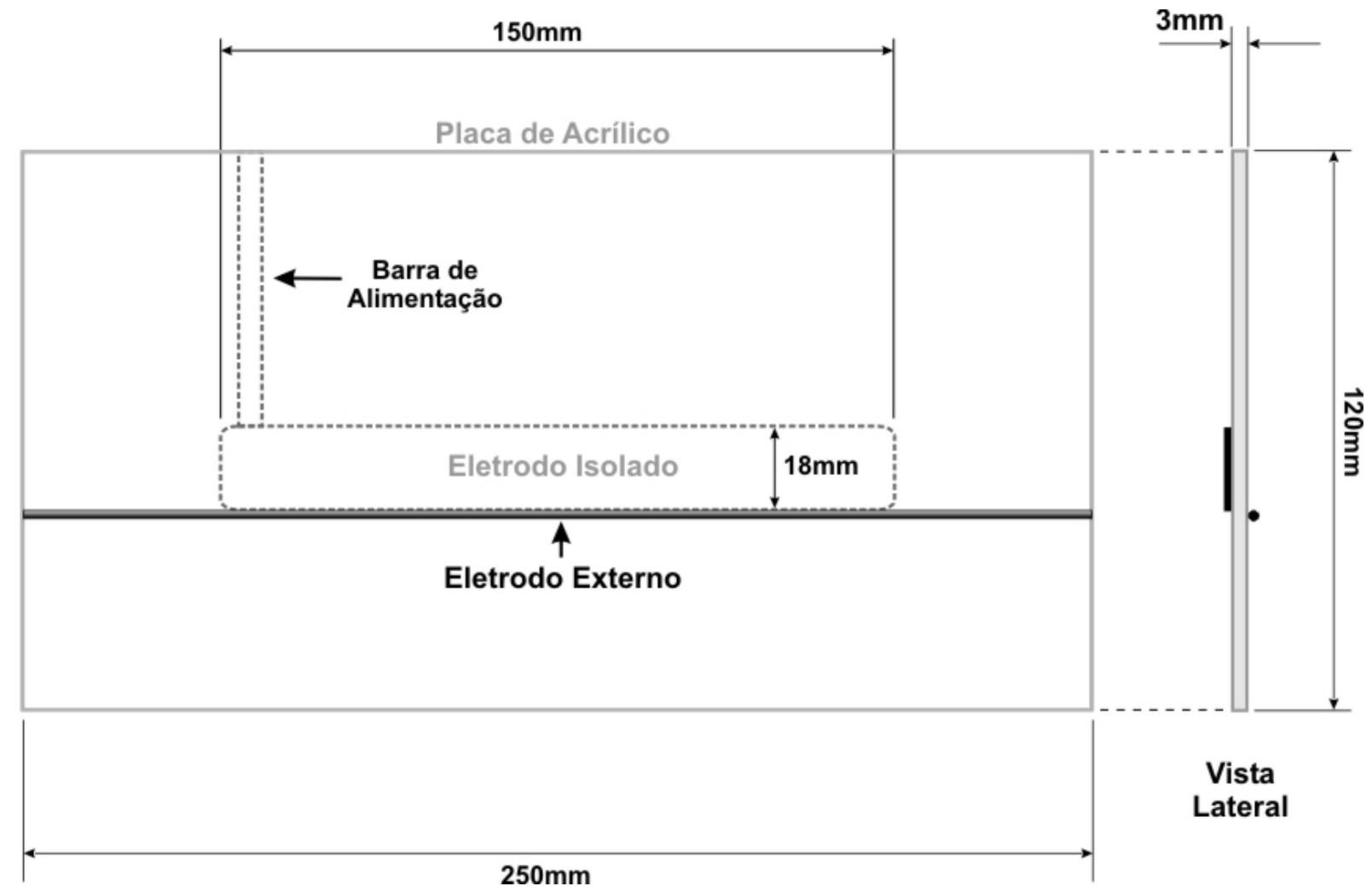

Figura 7.12 - Modelo com Eletrodo Externo Fio.

Todos os experimentos foram realizados nas mesmas condições atmosféricas com a temperatura ambiente igual a $28^{\circ} \mathrm{C}$ e a pressão atmosférica igual a $694 \mathrm{mmHg}$. Foram realizados três levantamentos do perfil de velocidades induzido pelo jato, com a primeira tomada sendo realizada $30 \mathrm{~mm}$ a jusante do eletrodo externo, a segunda a $40 \mathrm{~mm}$ e a terceira a $50 \mathrm{~mm}$. Em todas as etapas a sonda foi movimentada verticalmente em intervalos de 0,2 $\mathrm{mm}$ até atingir $10 \mathrm{~mm}$ de deslocamento total. A tensão de alimentação foi mantida em 8,0 kVolts e a frequência de alimentação igual a $5,5 \mathrm{kHz}$. O sistema de medição de pressão mais uma vez foi o micromanômetro Baratrom com a Sonda de Pressão de $3 \mathrm{mmHg}$, sendo os valores de pressão medidos lidos por meio do sistema de aquisição. Foram realizadas três tomadas completas de dados, para efeito de aumento da confiabilidade. A Figura 7.13 apresenta os resultados desta etapa experimental, mostrando todos 
os perfis de velocidades medidos. Já a Figura 7.14 mostra uma comparação dos perfis médios de velocidade na forma adimensional com os perfis de velocidade teóricos na forma normalmente utilizada para representar um jato de parede.
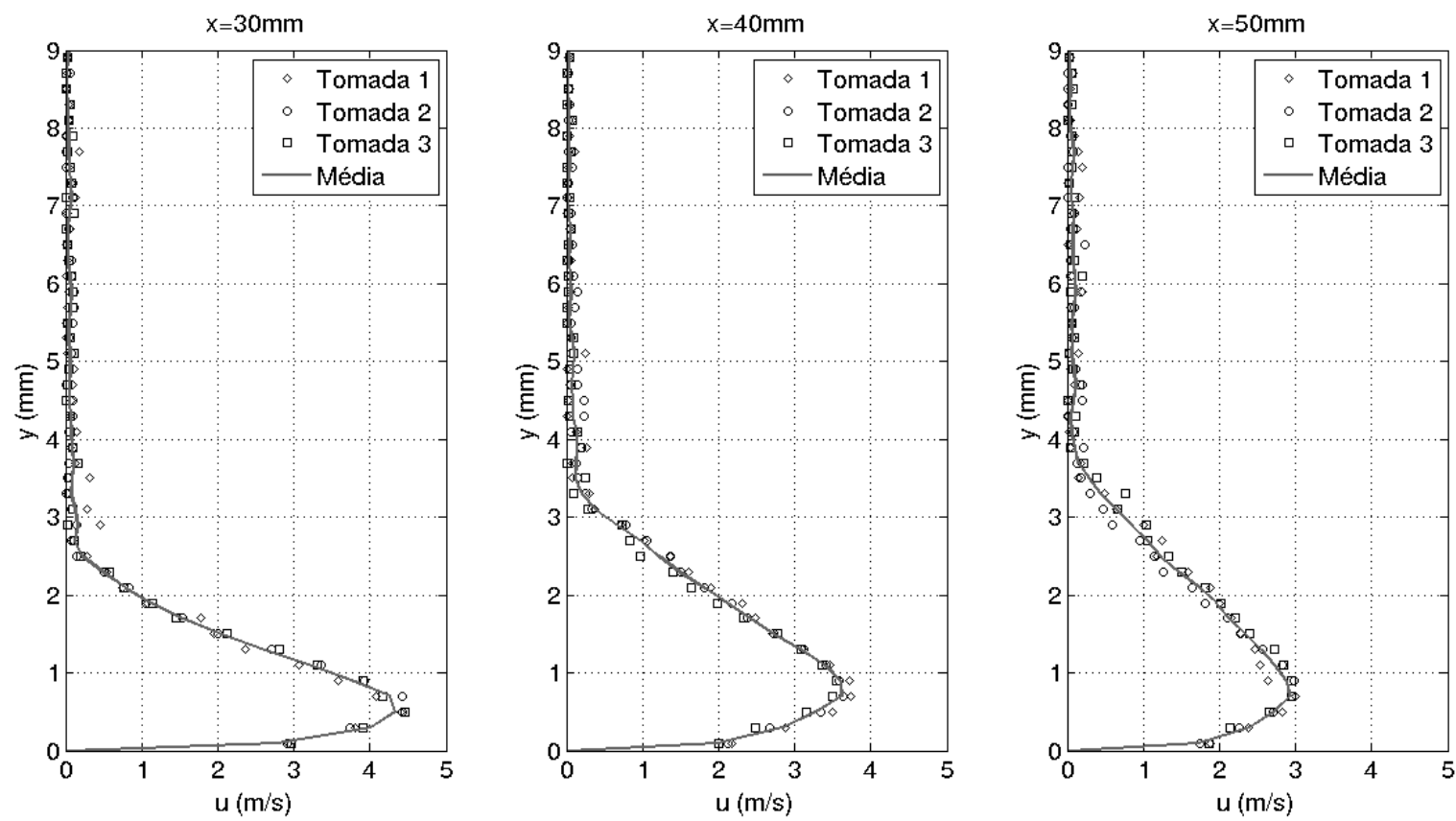

Figura 7.13 - Perfis de Velocidades produzidos pela configuração cilindrico-plano.
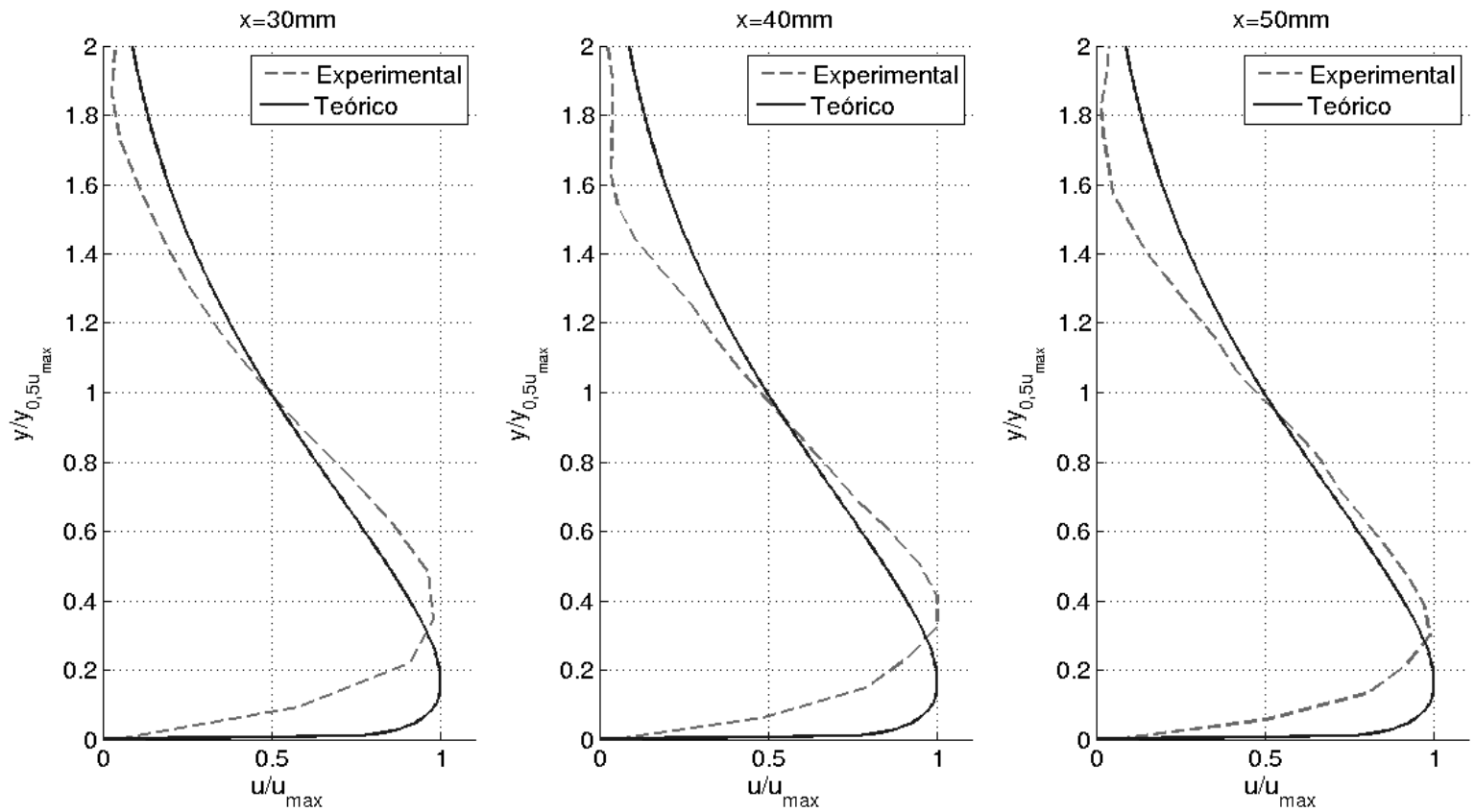

Figura 7.14 - Perfis médios da configuração Fio-plano. 


\subsubsection{Avaliação da Configuração Serrilhado-Plano}

O atuador era composto de dois eletrodos planos, feitos com folhas de alumínio fino, sendo o eletrodo externo (o que induzia o escoamento medido) com dimensões de $17 \mathrm{~cm}$ de comprimento e 1,4 cm de largura e com a borda ativa recortada no formato serrilhado (ver Figura 7.15). O eletrodo isolado (do outro lado do substrato isolante) tinha dimensões de $15 \mathrm{~cm}$ de comprimento e $1,8 \mathrm{~cm}$ de largura. Os eletrodos foram afixados com a utilização de uma fita adesiva de dupla face sobre uma placa de acrílico com dimensões de $15 \mathrm{~cm}$ de comprimento, $25 \mathrm{~cm}$ de largura e $3 \mathrm{~mm}$ de espessura. Duas pequenas extensões dos eletrodos foram feitas de forma a servirem de barras de alimentação, sendo que chegavam até as bordas da placa, onde os cabos de alimentação da fonte de tensão eram conectados por meio de garras jacaré. A Figura 7.15 apresenta o o desenho aproximado deste modelo.

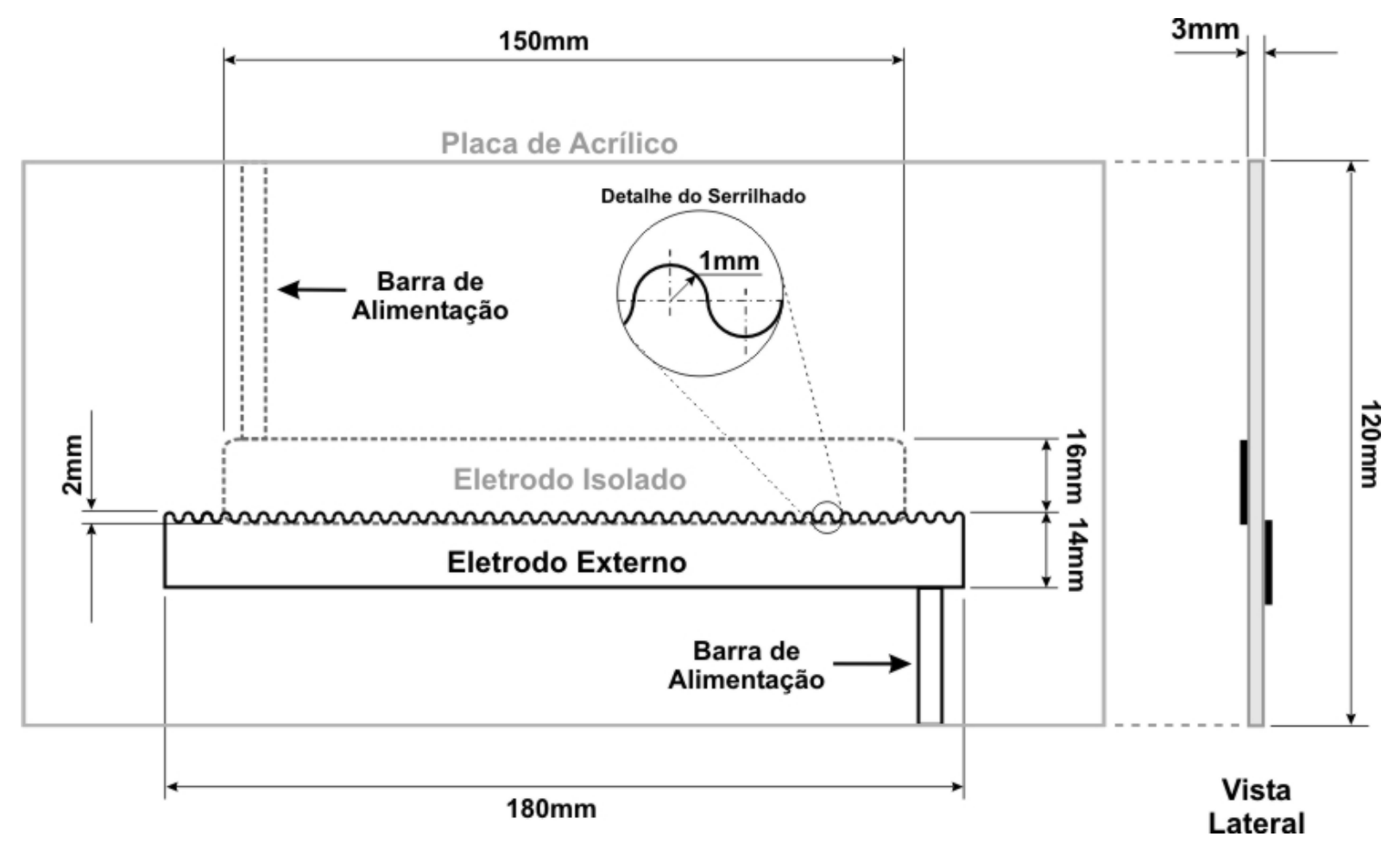

Figura 7.15 - Modelo com Eletrodo Externo Serrilhado.

Todos os experimentos foram realizados nas mesmas condições atmosféricas com a temperatura ambiente igual a $26^{\circ} \mathrm{C}$ e a pressão atmosférica igual a $692 \mathrm{mmHg}$. Foram realizados três levantamentos do perfil de velocidades induzido pelo jato, com a primeira tomada sendo realizada $30 \mathrm{~mm}$ a jusante do eletrodo externo, a segunda a $40 \mathrm{~mm}$ e a terceira a $50 \mathrm{~mm}$. Foram realizadas três tomadas completas de dados, para efeito de 
aumento da confiabilidade. Em todas as etapas a sonda foi movimentada verticalmente em intervalos de 0,2 mm até atingir $10 \mathrm{~mm}$ de deslocamento total. A tensão de alimentação foi mantida em $8,0 \mathrm{kVolts}$ e a frequência de alimentação igual a $5,5 \mathrm{kHz}$.

O sistema de medição de pressão mais uma vez foi o micromanômetro Baratrom com a Sonda de Pressão de $10 \mathrm{mmHg}$, sendo os valores de pressão medidos lidos por meio do sistema de aquisição. A Figura 7.16 apresenta os resultados desta etapa experimental, mostrando todos os perfis de velocidades medidos. Já a Figura 7.17 mostra uma comparação dos perfis médios de velocidade na forma adimensional com os perfis de velocidade teóricos na forma normalmente utilizada para representar um jato de parede.
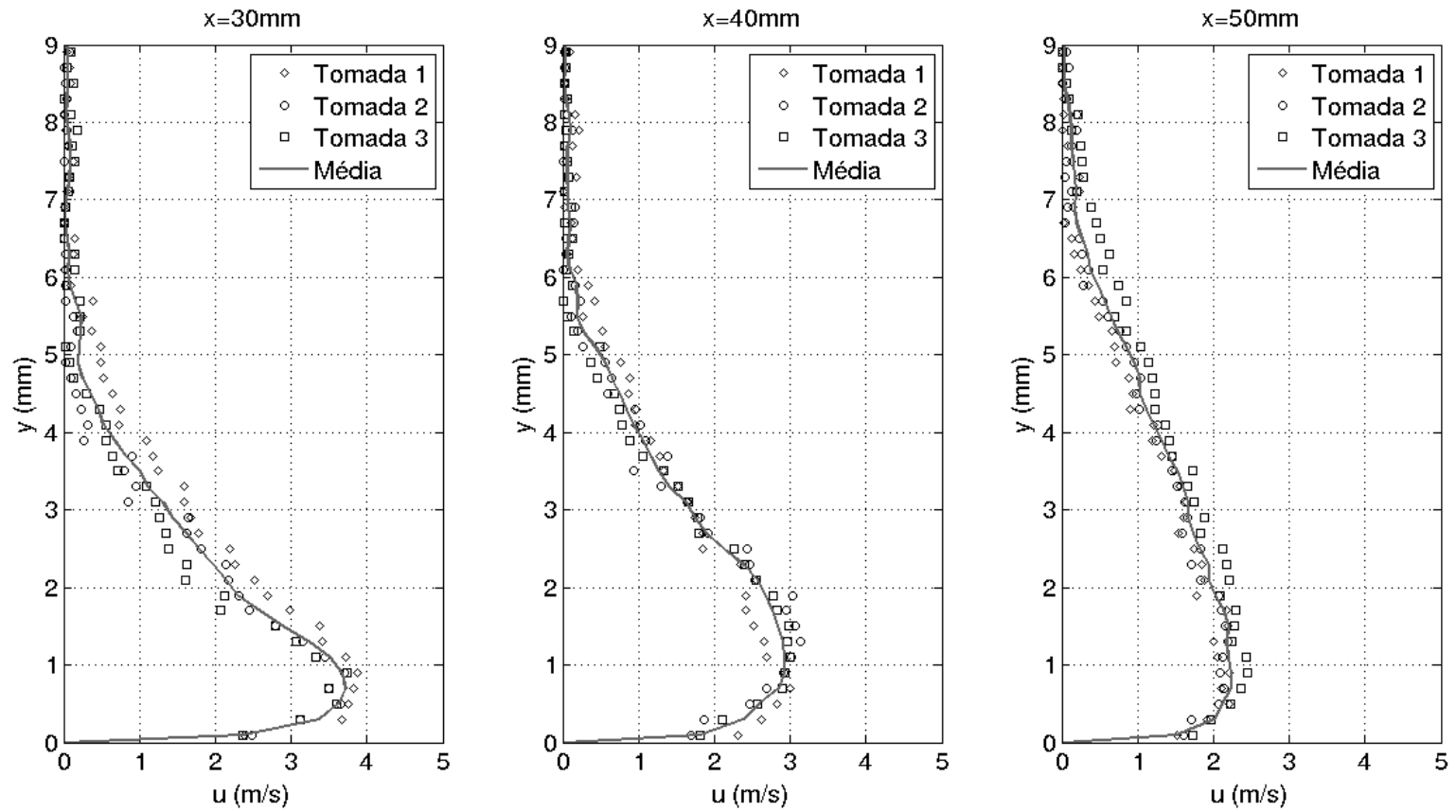

Figura 7.16 - Perfis de Velocidades produzidos pela configuração serrilhado-plano. 

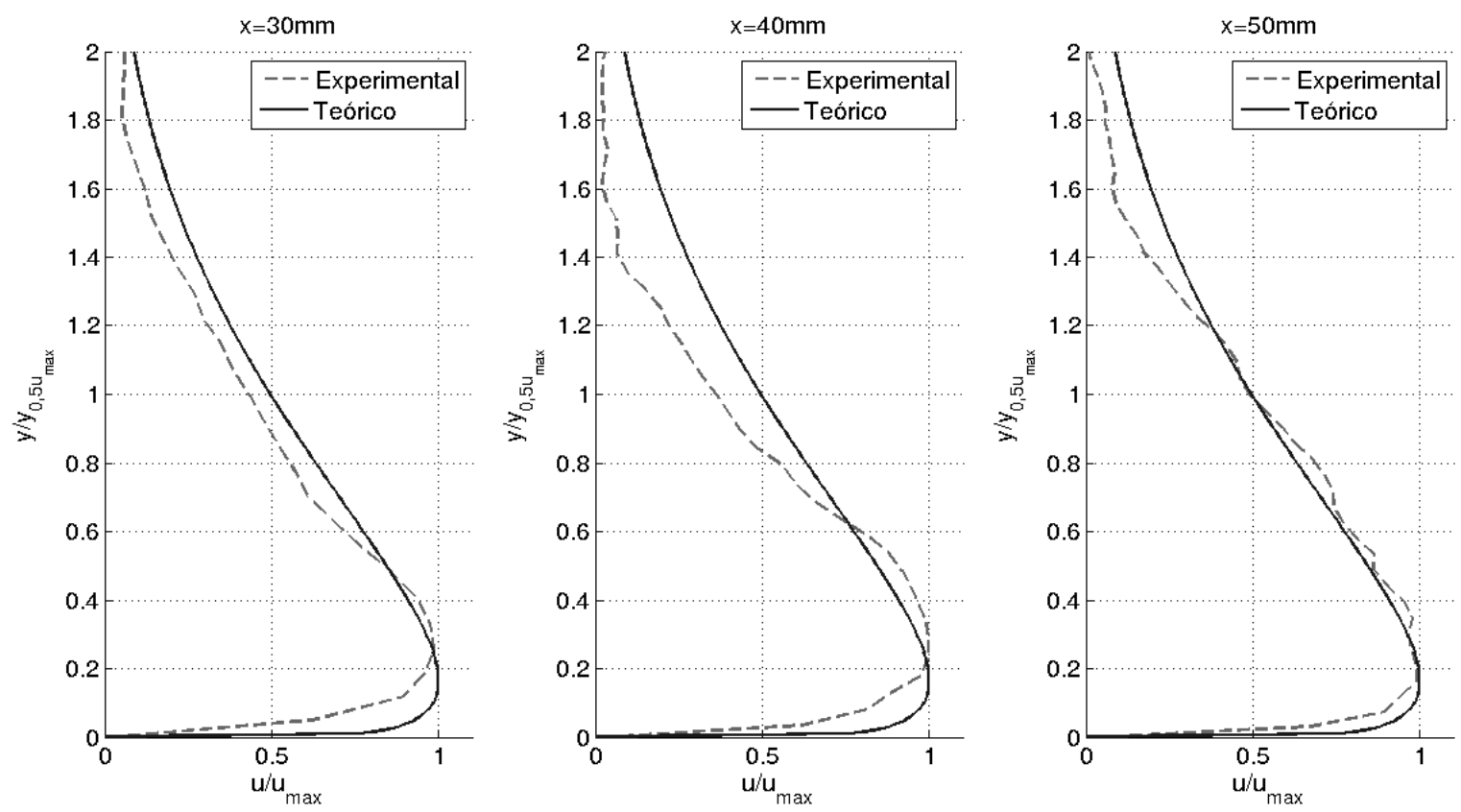

Figura 7.17 - Perfis médios da configuração serrilhado-plano.

\subsubsection{Análise e Comparação dos Casos Estudados}

A Figura 7.18 apresenta a comparação entre os perfis de velocidades médios de todos os casos estudados. É notável a grande diferença na distribuição de velocidades do jato induzido pelo eletrodo serrilhado quando comparado com os outros. Pode-se ver que este caso específico apresenta um desenvolvimento mais espesso do jato, mesmo não sendo o que produz o maior valor de velocidade. Neste caso, a maior velocidade $\left(V_{\max }=4,43 \mathrm{~m} / \mathrm{s}\right)$ foi produzida a $30 \mathrm{~mm}$ do eletrodo fio. Da mesma forma, as velocidades máximas foram todas observadas a $30 \mathrm{~mm}$ do eletrodo serrilhado $\left(V_{\max }=3,77 \mathrm{~m} / \mathrm{s}\right)$ e do eletrodo plano $\left(V_{\max }=\right.$ $4,17 \mathrm{~m} / \mathrm{s}$ ). Isto é consistente com o desenvolvimento tridimensional de um jato induzido, ou seja, se entranha com o fluido circundante tanto verticalmente quanto lateralmente, sendo limitado apenas pela superfície na qual é produzido. Não se optou por limitar seu desenvolvimento lateral, pois temia-se que isso poderia influenciar o comportamento do experimento.

A Figura 7.19 mostra os valores das velocidades máximas de cada configuração, enquanto a Tabela 7.1 mostra os valores numéricos das velocidades máximas com a incerteza associadas de seus valores. Pode-se verificar que a configuração de eletrodos fio-plano apresenta o valor máximo de velocidade induzida para todas as etapas, consistente com os dados encontrados na literatura. Outro ponto interessante é que a configuração de 

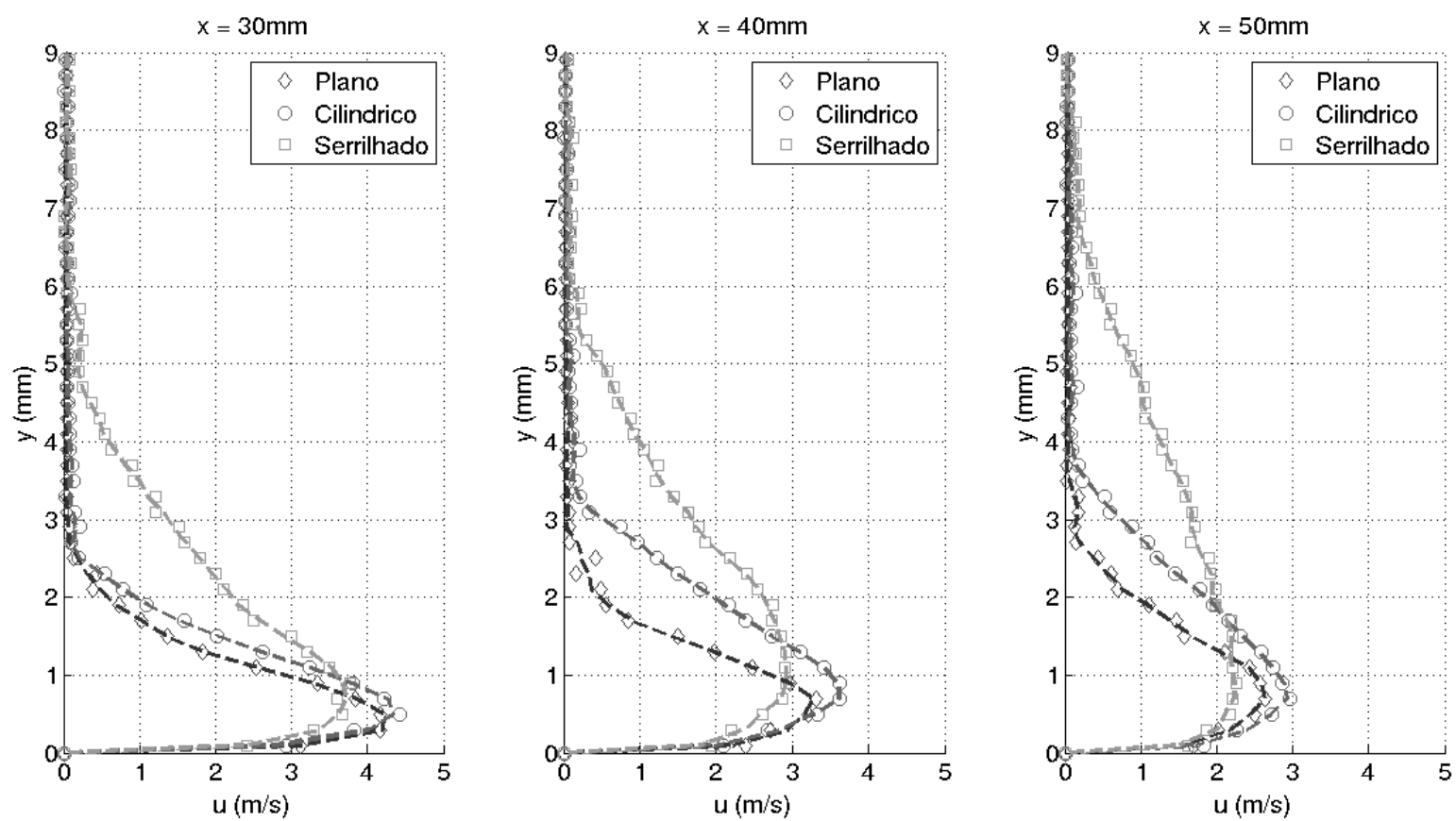

Figura 7.18 - Velocidades máximas de cada configuração nas três etapas de medição.

eletrodos serrilhado-plano apresenta valores inferiores em todas as etapas, mesmo sendo a que produz um perfil de velocidades mais intenso ao longo da espessura do jato.

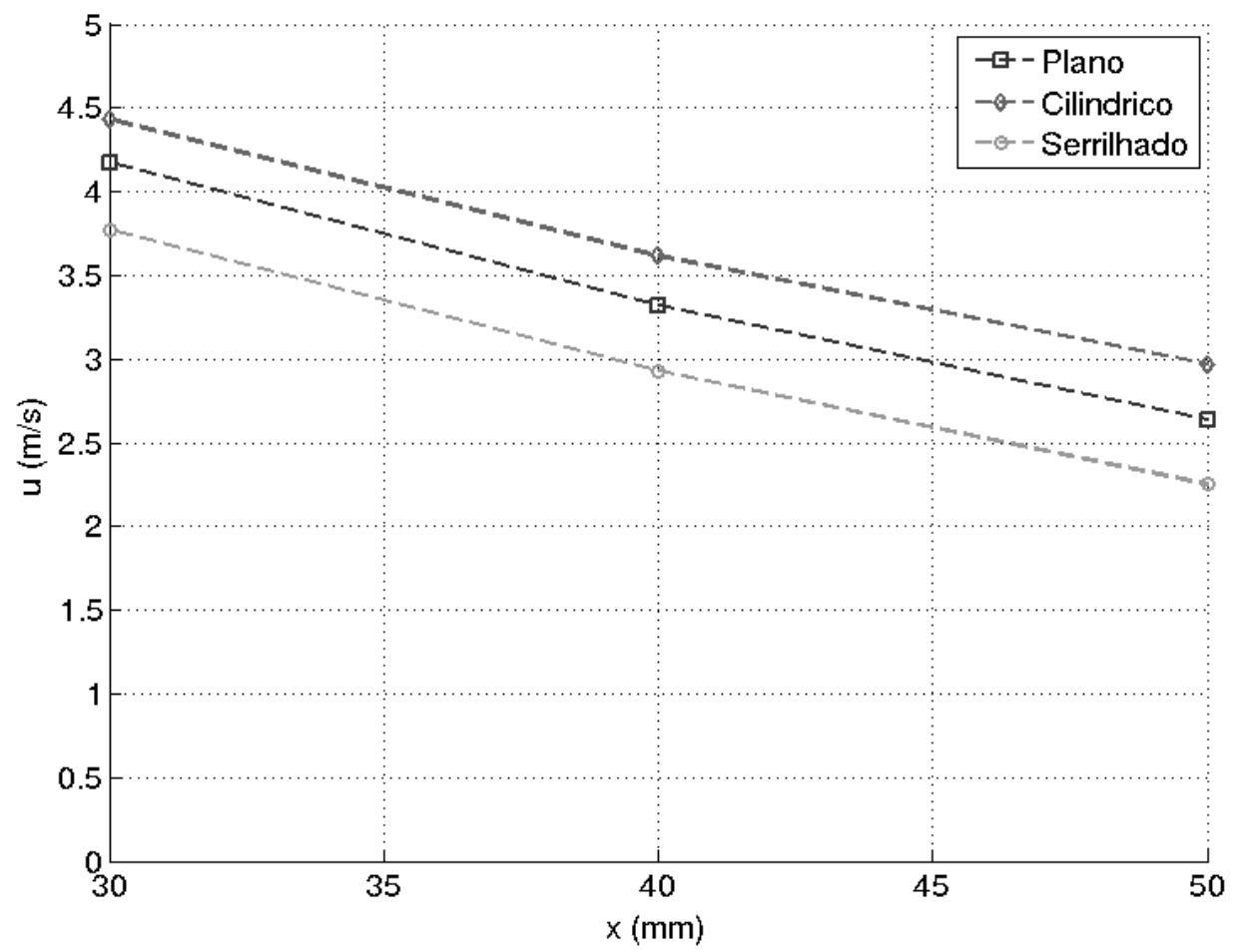

Figura 7.19 - Valores das velocidades máximas das configurações estudadas.

A Figura 7.20 apresenta os dados da localização de cada velocidade máxima a partir 
Tabela 7.1 - Valores máximos de velocidades ao longo da borda dos eletrodos estudados.

\begin{tabular}{cccc}
\hline & $\begin{array}{c}\text { Plano } \\
\mathrm{u}_{\max }(\mathrm{m} / \mathrm{s})\end{array}$ & $\begin{array}{c}\text { Fio } \\
\mathrm{u}_{\max }(\mathrm{m} / \mathrm{s})\end{array}$ & $\begin{array}{c}\text { Serrilhado } \\
\mathrm{u}_{\max }(\mathrm{m} / \mathrm{s})\end{array}$ \\
\hline $\mathrm{x}=30 \mathrm{~mm}$ & $4.17 \pm 0.04$ & $4.43 \pm 0.04$ & $3.77 \pm 0.04$ \\
$\mathrm{x}=40 \mathrm{~mm}$ & $3.32 \pm 0.03$ & $3.62 \pm 0.04$ & $2.93 \pm 0.03$ \\
$\mathrm{x}=50 \mathrm{~mm}$ & $2.63 \pm 0.02$ & $2.96 \pm 0.03$ & $2.25 \pm 0.02$ \\
\hline
\end{tabular}

da superfície da placa de eletrodos. Pode-se ver claramente a tendência de crescimento desta posição a partir da região no qual os jatos são induzidos. Esta Figura mostra a tendência de maior "espessamento" do jato produzido pela configuração serrilhado-plano em relação as demais, pois em todas as etapas as velocidades máximas são encontradas em uma posição acima.

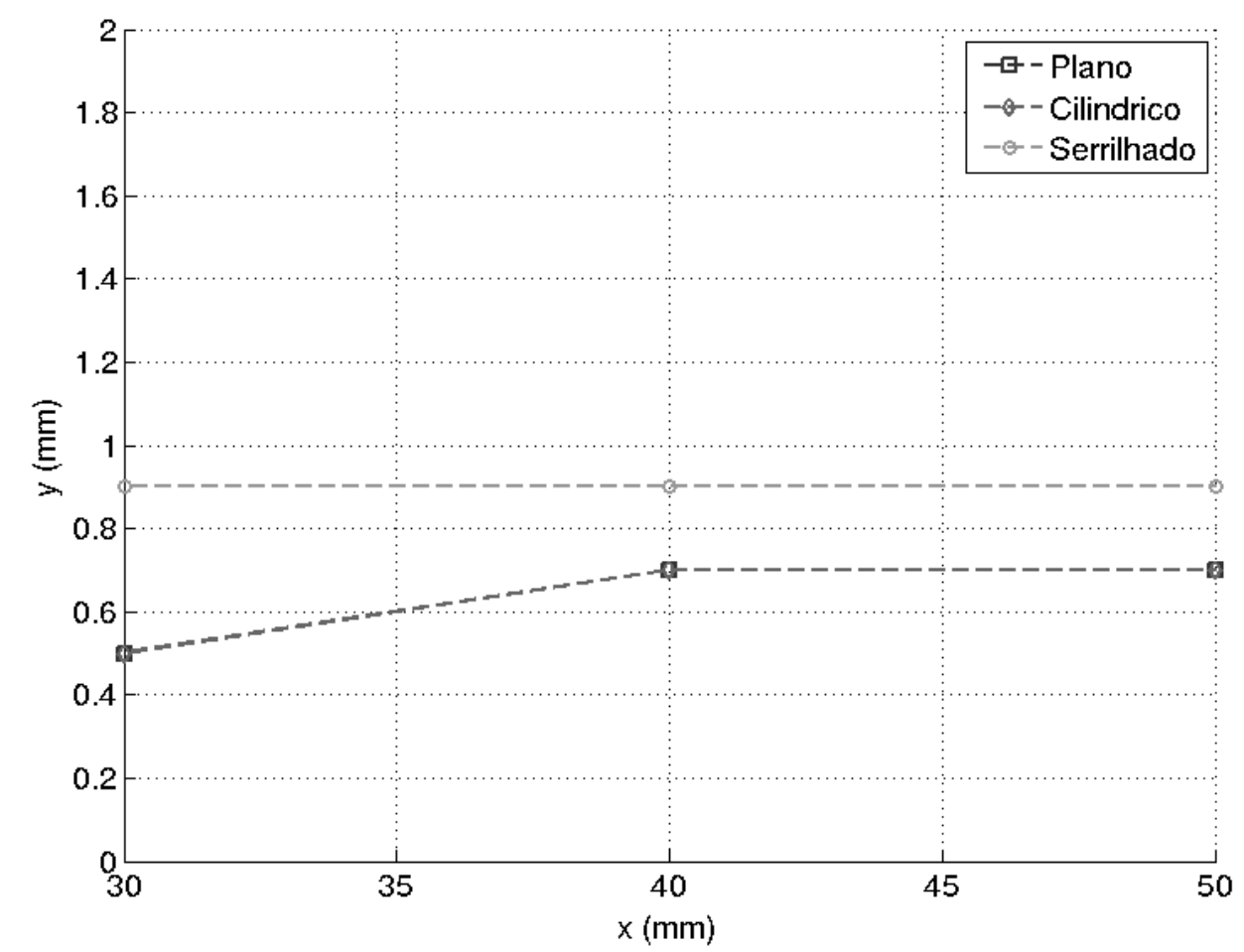

Figura 7.20 - Posição das velocidades máximas das configurações estudadas.

Já a Figura 7.21 apresenta as espessuras dos jatos para todas as configurações estudadas. A espessura foi determinada a partir dos dados experimentais como sendo correspondente ao ponto em que a velocidade era inferior a $0,5 \%$ do valor da velocidade máxima medida em cada configuração. Estes dados mostram a significativa diferença entre a espessura para a configuração serrilhado-plano em relação as demais. Pode-se notar claramente o desenvolvimento mais acentuado da configuração serrilhado-plano. 


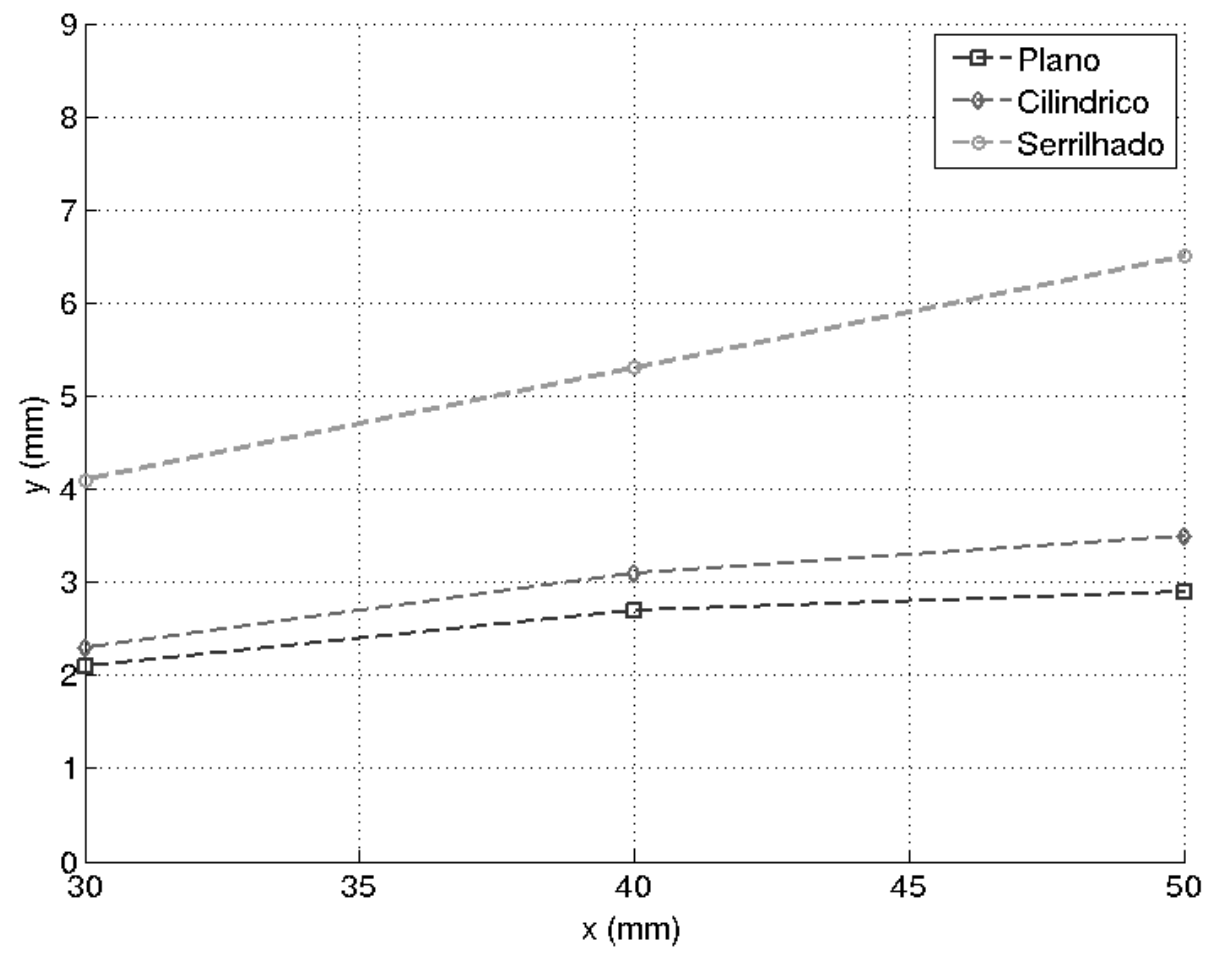

Figura 7.21 - Comparação entre as espessuras dos jatos para todas as configurações estudadas.

Para uma melhor comparação dos casos estudados foi realizado uma análise do fluxo de quantidade de movimento produzido pelos jatos. Entretanto, teve-se que assumir um valor constante do desenvolvimento lateral dos jatos induzidos para a determinação da área da superfície de controle, ou seja, para $A=L . \delta$, sendo $\delta$ a espessura do jato e $L$ a largura do jato. Assumindo escoamento incompressível e que este não variava ao longo do comprimento do eletrodo, pode-se reduzir a equação acima ao caso bidimensional:

$$
M=\rho L \int_{0}^{\delta} u^{2} d y
$$

A Figura 7.22 apresenta os resultados dos valores de quantidade de movimento calculados para todas as etapas de medição realizadas. Pode-se observar que a configuração serrilhado-plano apresenta um valor maior em todas as etapas, chegando a um valor máximo de aproximadamente 0,16 N. Isto é uma indicação que esta configuração é mais eficiente em injetar energia mecânica no meio circundante para a produção de escoamentos. 


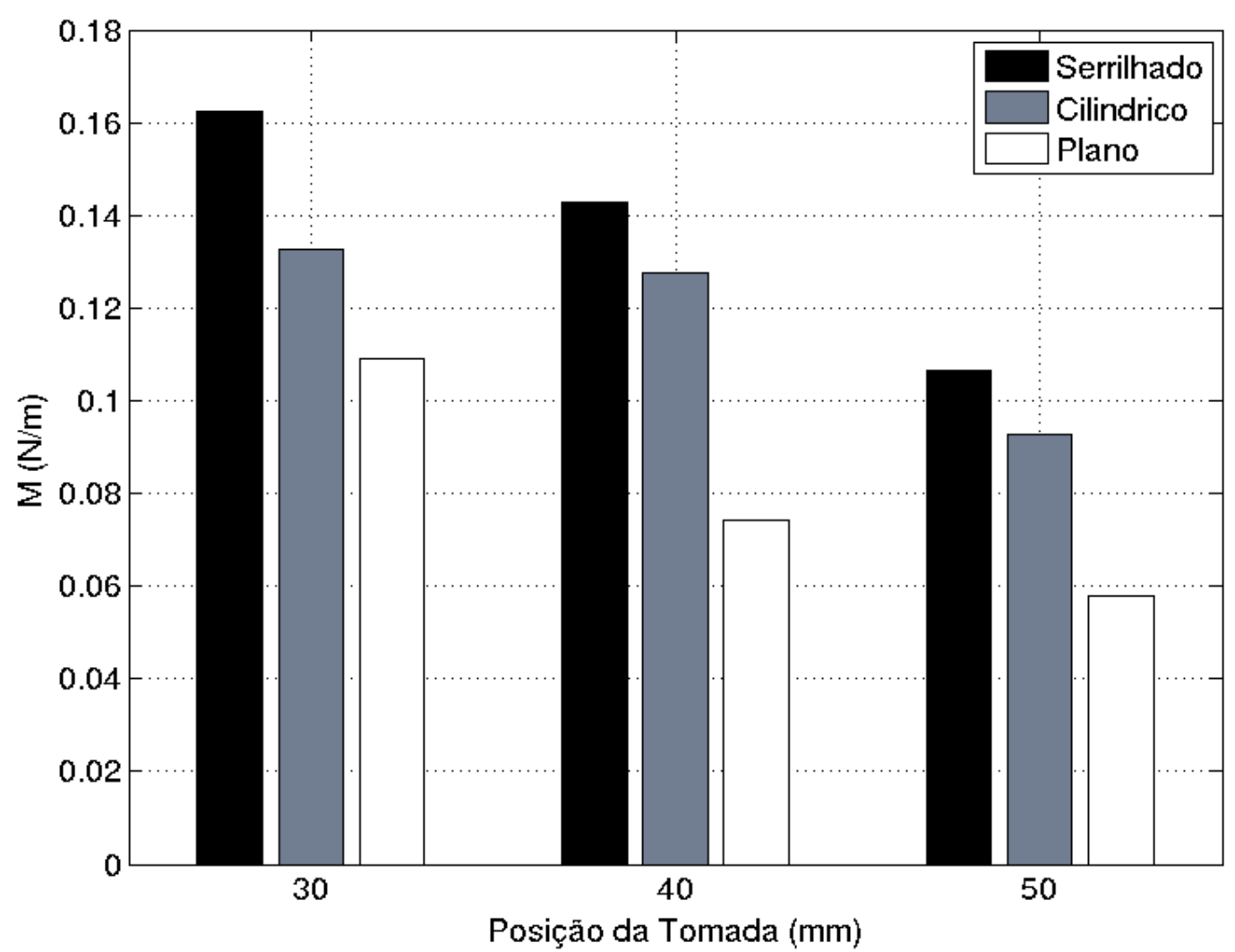

Figura 7.22 - Valores do fluxo da quantidade de movimento calculado para todas as etapas de medição realizadas.

\subsection{Medição lateral do jato induzido}

Ficou muito evidente a significativa diferença entre o comportamento do jato induzido pela configuração serrilhado-plano em relação as demais. A comparação apresentada na Figura 7.18 mostra um desenvolvimento mais acentuado na espessura do jato para esta configuração. Isto pode ser devido ao fato de que o jato produzido pela configuração serrilhado-plano apresenta um perfil de velocidades não uniforme ao longo da borda do eletrodo devido a sua geometria. Ou seja, deve ocorrer a concentração na produção de maiores velocidades na região das "pontas"e menores nos "vales". Assim, é produzida uma intensa perturbação na indução do escoamento logo após a descarga elétrica, que não deve ser encontrada nas outras configurações. Com a intenção de investigar este comportamento da configuração de eletrodos serrilhado-plano, foi realizado um experimento para a medição do comportamento ao longo do eletrodo exposto. A Figura 7.23 mostra as posições nas quais foram realizadas as medições. 


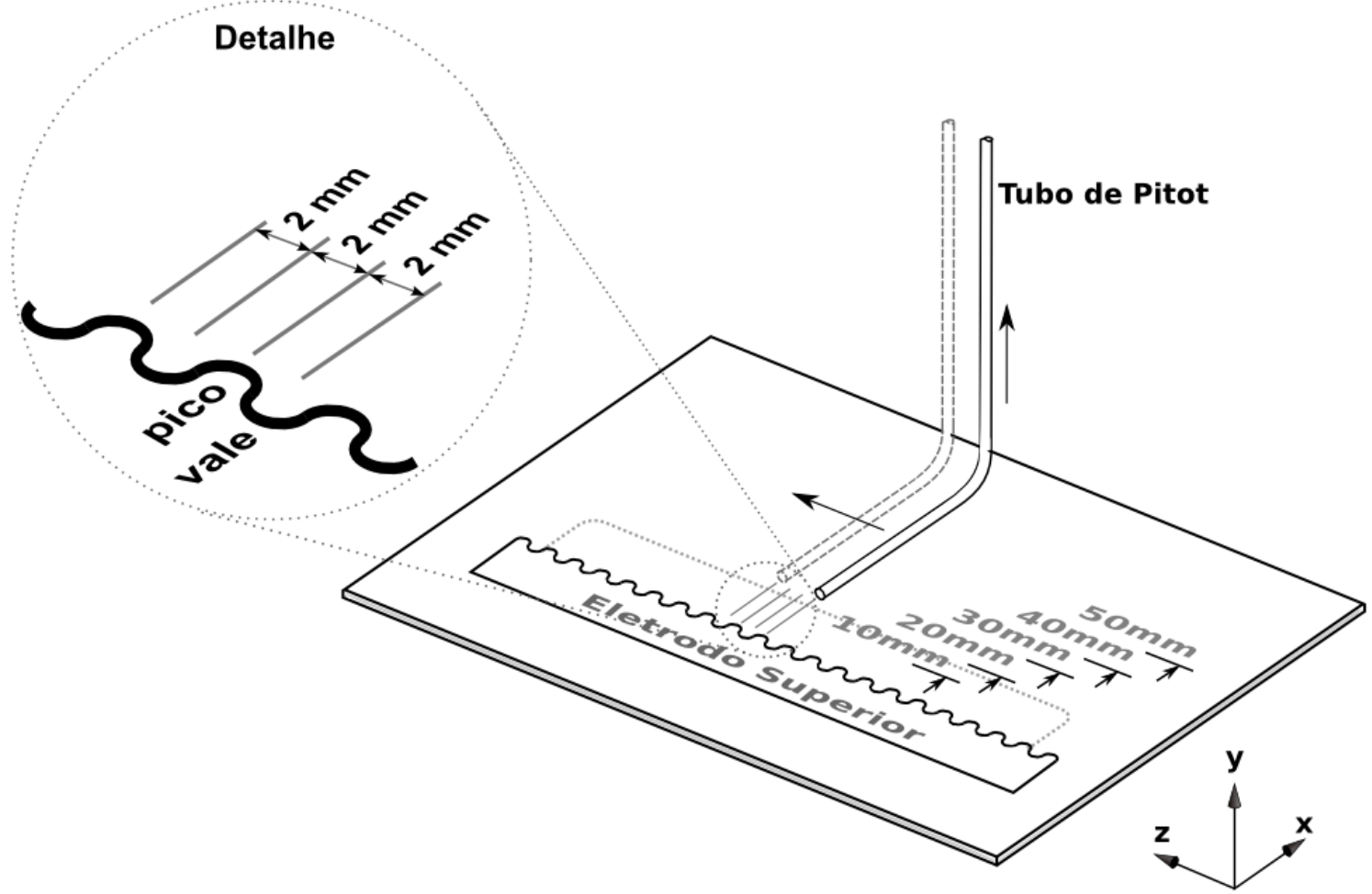

Figura 7.23 - Esquema do experimento de medição ao longo da borda do eletrodo.

Esta etapa experimental consistiu no levantamento dos perfis de velocidade dos jatos induzidos em quatro posições distintas ao longo do bordo do eletrodo serrilhado. Estas posições foram escolhidas em referência ao contorno do eletrodo serrilhado, ou seja, uma tomada completa em frente ao "vale' do contorno e outra em frente ao "pico" do contorno. Estas quatro medições foram repetidas em cinco distâncias diferentes a partir da borda ativa do eletrodo serrilhado, ou seja, $x=10 \mathrm{~mm}, \mathrm{x}=20 \mathrm{~mm}, \mathrm{x}=30 \mathrm{~mm}, \mathrm{x}=40 \mathrm{~mm}$ e $\mathrm{x}=50 \mathrm{~mm}$.

Nesta etapa a sonda foi movimentada no sentido da espessura dos jatos em passos de 0,4 mm até o valor máximo de 7,8 $\mathrm{mm}$. O tubo de Pitot utilizado também diferiu do utilizado nos experimentos iniciais. Foi utilizado um tubo de Pitot com a extremidade voltada para o escoamento no formato oblongo, mas com largura de $1 \mathrm{~mm}$ e espessura de $0,1 \mathrm{~mm}$. Os dados coletados foram processados de forma similar aos procedimentos adotando na seção 7.3. Ou seja, os dados forma primeiramente medidos através do sensor de pressão, com uma conexão ligada ao tubo de Pitot e a outra aberta para a o ambiente. Os dados lidos por este sensor foram transformados em valores de pressão na escala de Pascal e as velocidades calculadas. 
A Figura 7.24 apresenta os resultados com as medidas sendo realizadas a $10 \mathrm{~mm}$ de distância da borda do eletrodo serrilhado. Já fica evidenciada a diferença entre os perfis de velocidade avaliados em distintas posições relativas ao contorno do eletrodo. Os perfis de velocidade localizados nas posições $\mathrm{z}=0 \mathrm{~mm}$ e $\mathrm{z}=4 \mathrm{~mm}$ apresentam os valores medidos em frente dos "vales" do contorno do eletrodo. Já os perfis localizados nas posições z = $2 \mathrm{~mm}$ e $\mathrm{z}=6 \mathrm{~mm}$ apresentam os valores medidos em frente dos "picos" do contorno do eletrodo. É notável a diferença entre os dois conjuntos de de dados. Pode-se observar que as máximas velocidades são obtidas nas posições $\mathrm{z}=2 \mathrm{~mm}$ e z $=6 \mathrm{~mm}$, ou seja, em frente dos "picos" do contorno do eletrodo.

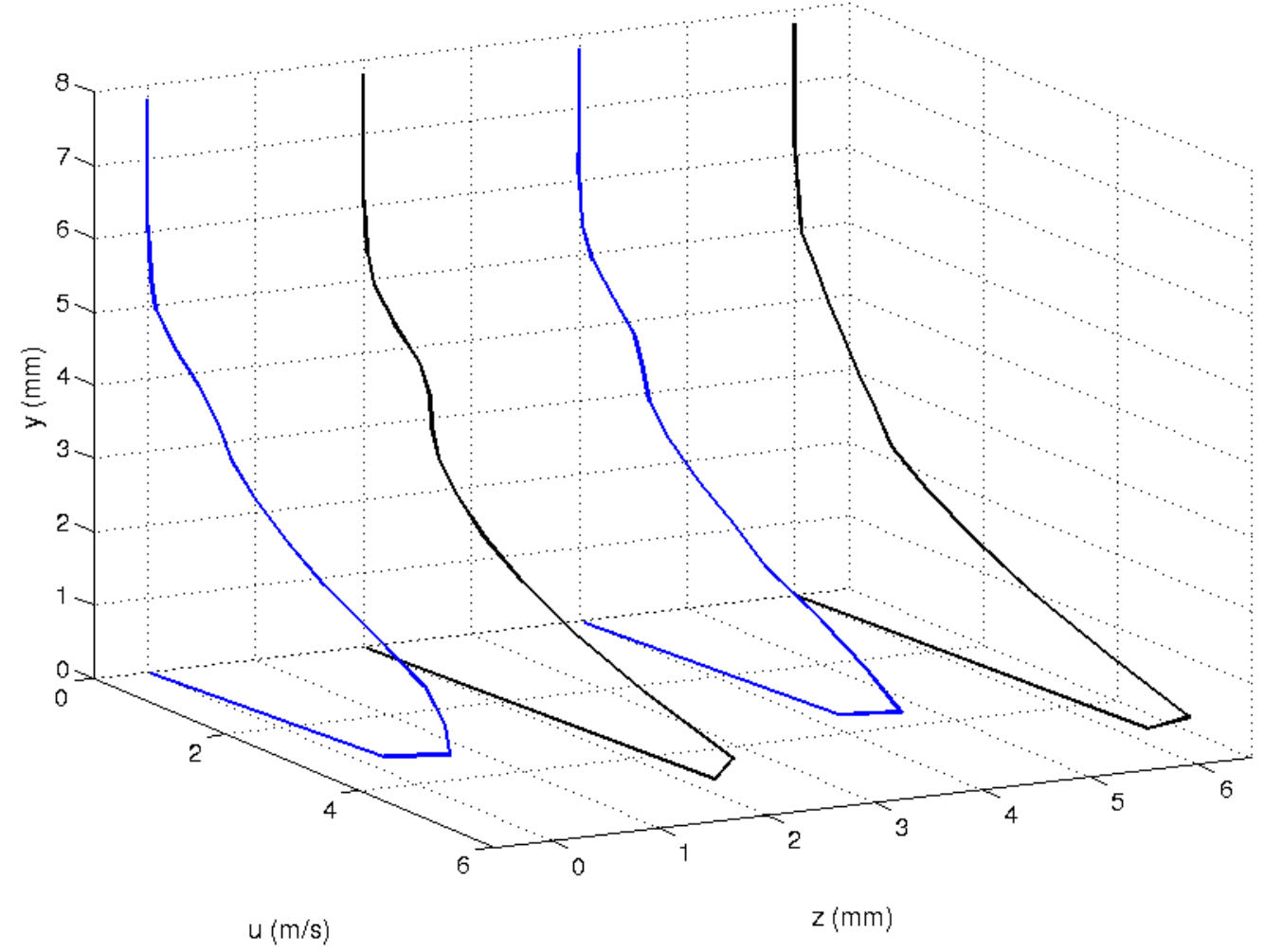

Figura 7.24 - Perfis de velocidades medidos ao longo do eletrodo serrilhado a $10 \mathrm{~mm}$ de distância da borda do eletrodo. 
A Figura 7.25 apresenta os resultados para todos os perfis de velocidade. Nesta Figura é claramente evidenciado a tendência de formação dos maiores valores de velocidade a partir dos "picos" da borda ativa de eletrodo serrilhado. Em relação aos contornos de distribuição de velocidade pouca diferença foi encontrada, embora exista uma aparente tendência a um maior espessamento dos jatos produzidos a partir dos "vales".

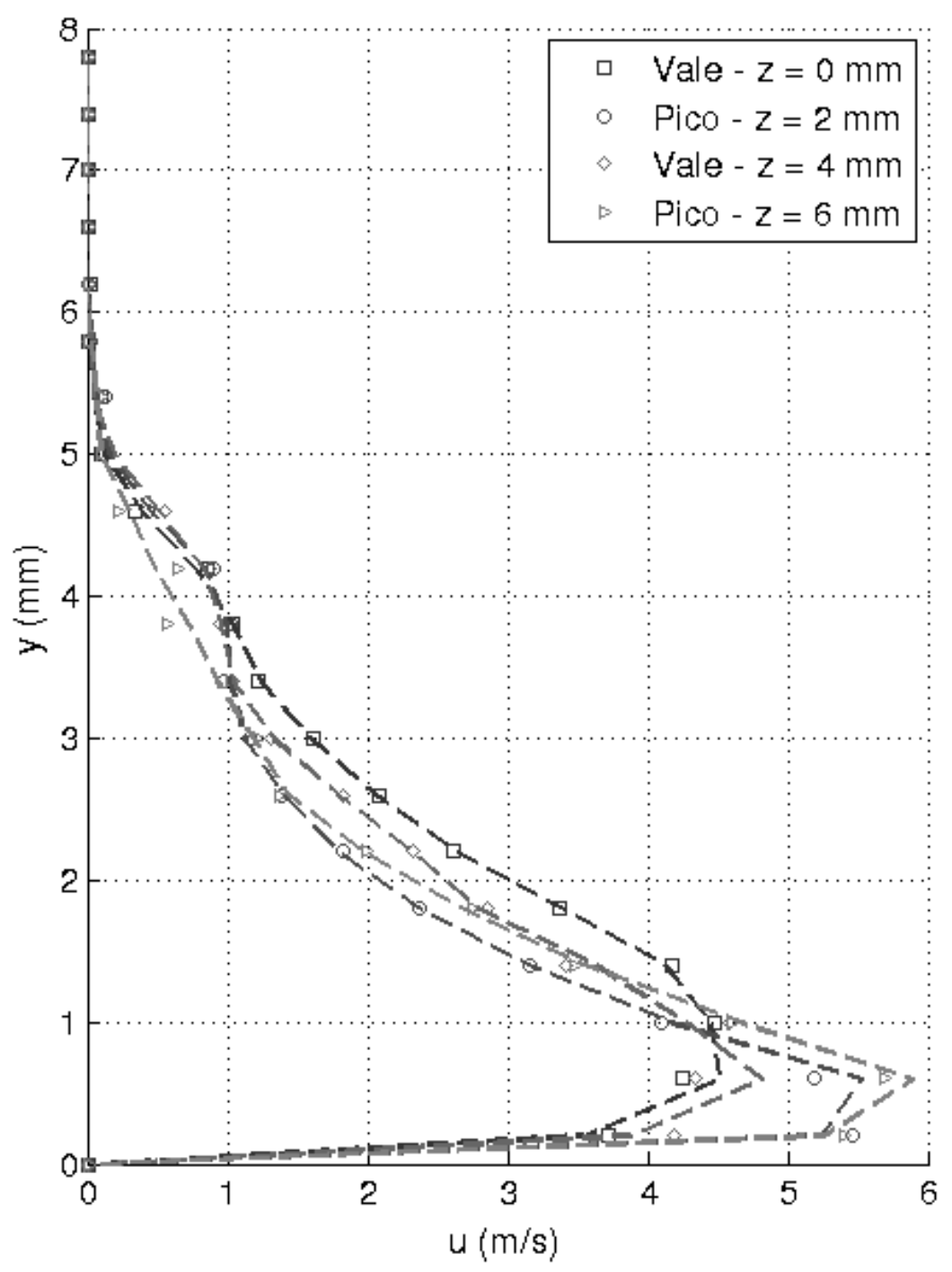

Figura 7.25 - Perfis de velocidades medidos ao longo do eletrodo serrilhado a $10 \mathrm{~mm}$ de distância da borda do eletrodo. 
A Figura 7.26 apresenta os resultados com as medidas sendo realizadas a $20 \mathrm{~mm}$ de distância da borda do eletrodo serrilhado. Novamente, verifica-se uma significativa diferença entre os perfis de velocidade avaliados nas distintas posições relativas ao contorno do eletrodo. Os perfis de velocidade localizados nas posições $\mathrm{z}=0 \mathrm{~mm} \mathrm{e} \mathrm{z}=4 \mathrm{~mm}$ apresentam os valores medidos em frente dos "vales" do contorno do eletrodo. Já os perfis localizados nas posições $\mathrm{z}=2 \mathrm{~mm}$ e $\mathrm{z}=6 \mathrm{~mm}$ apresentam os valores medidos em frente dos "picos" do contorno do eletrodo. O mais notável nesta etapa é o aumento da espessura dos perfis medidos a partir dos "vales" em relação aos medidos a partir dos "picos".

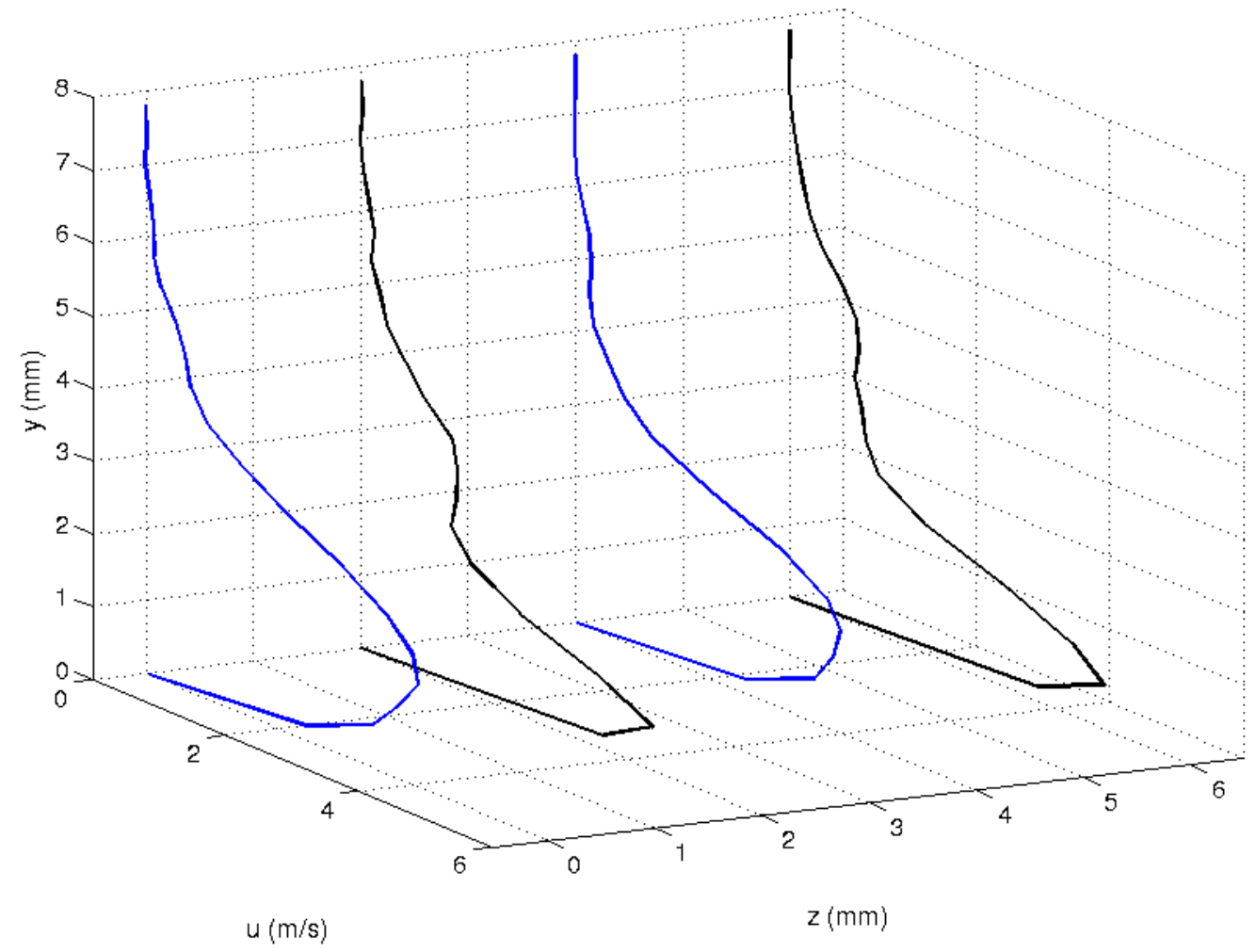

Figura 7.26 - Perfis de velocidades medidos ao longo do eletrodo serrilhado a $20 \mathrm{~mm}$ de distância da borda do eletrodo. 
A Figura 7.27 apresenta os resultados para todos os perfis de velocidade. Nesta Figura percebe-se claramente uma grande diferença nos contornos dos perfis de velocidade. Entretanto, existe a evidente tendência de contorno dos perfis de velocidade mais desenvolvidos na direção "y"para os jatos produzidos a partir dos "vales"em relação aos produzidos a partir dos "picos".

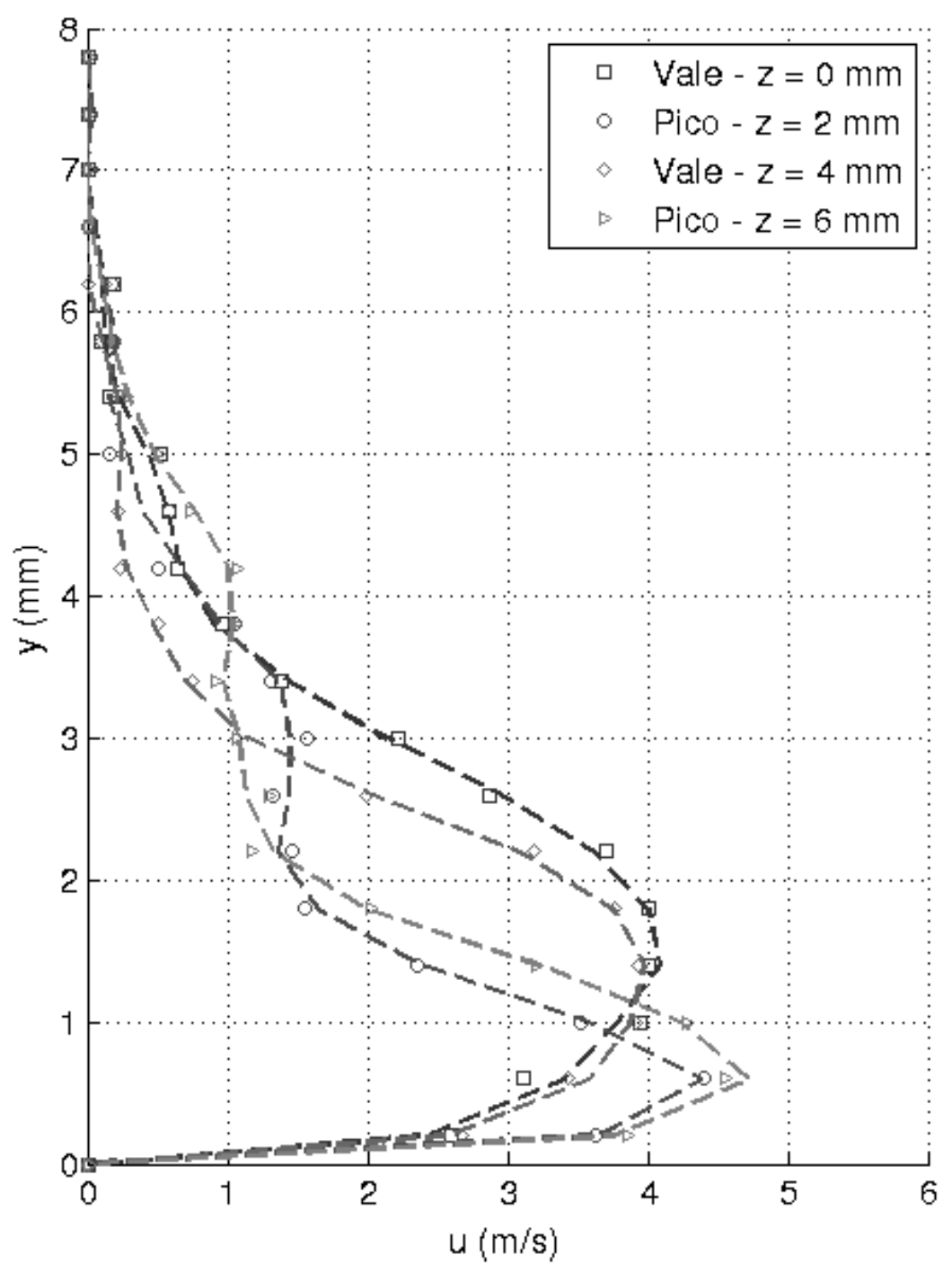

Figura 7.27 - Perfis de velocidades medidos ao longo do eletrodo serrilhado a $20 \mathrm{~mm}$ de distância da borda do eletrodo. 
Na Figura 7.28 são apresentados os resultados para as medidas realizadas a $30 \mathrm{~mm}$ de distância da borda ativa do eletrodo serrilhado. Pode-se ver que existe ainda uma significativa diferença entre os perfis de velocidade medidos em frente aos "picos"e os medidos em frente aos "vales". Entretanto, esta diferença aparece de forma menos intensa, pois, além do contorno dos perfis serem menos distintos, as velocidades máximas são pouco diferentes.

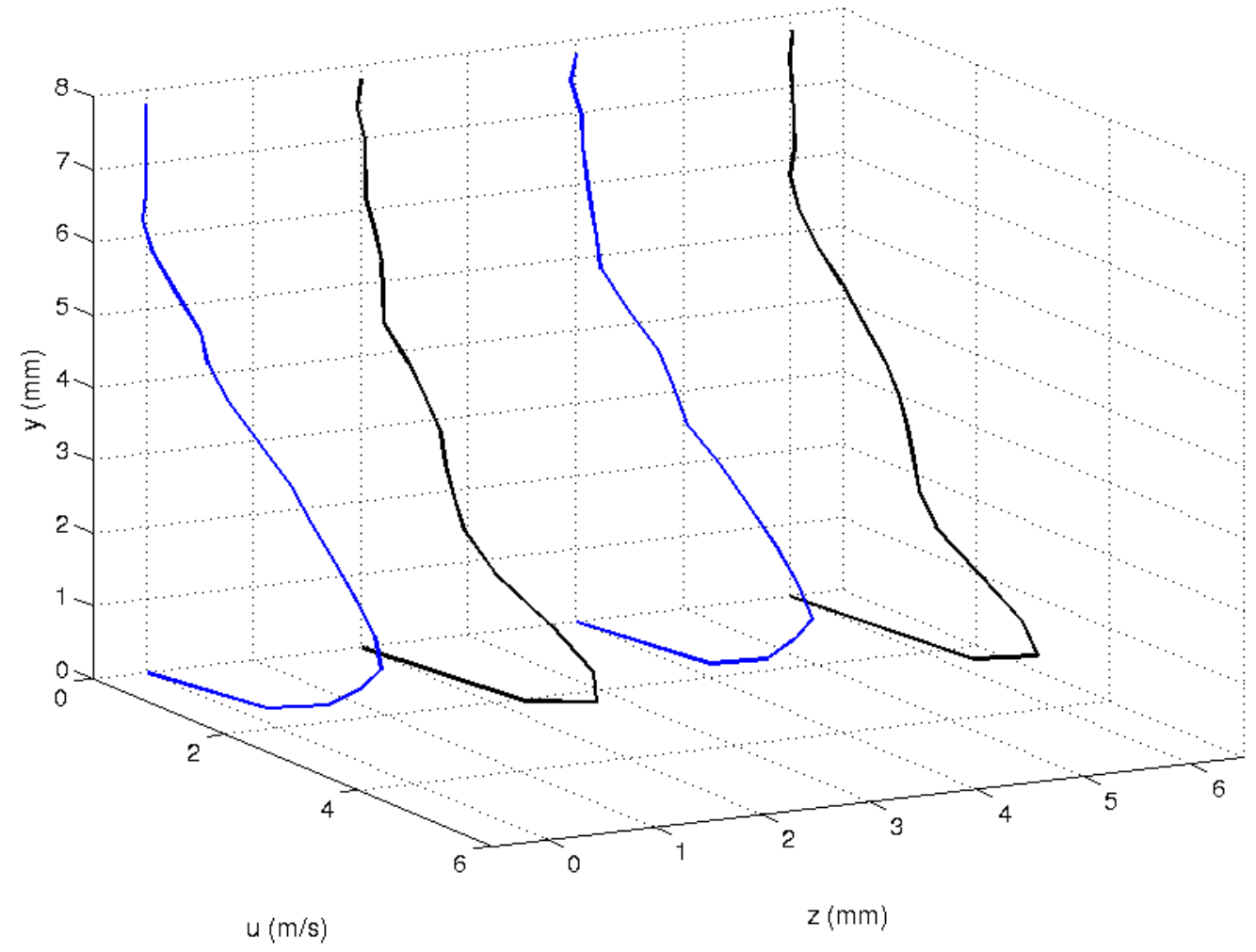

Figura 7.28 - Perfis de velocidades medidos ao longo do eletrodo serrilhado a $30 \mathrm{~mm}$ de distância da borda do eletrodo. 
A Figura 7.29 apresenta os resultados para todos os perfis de velocidade medidos em $\mathrm{x}=30 \mathrm{~mm}$. Nesta Figura percebe-se novamente uma grande diferença nos contornos dos perfis de velocidade. Existe uma evidente tendência de contorno dos perfis de velocidade mais desenvolvidos na direção "y" para os jatos produzidos a partir dos "vales" em relação aos produzidos a partir dos "picos". Entretanto, nesta etapa ficou evidenciada uma significativa redução na diferença entre as máximas velocidades produzidas ao longo da borda do eletrodo.

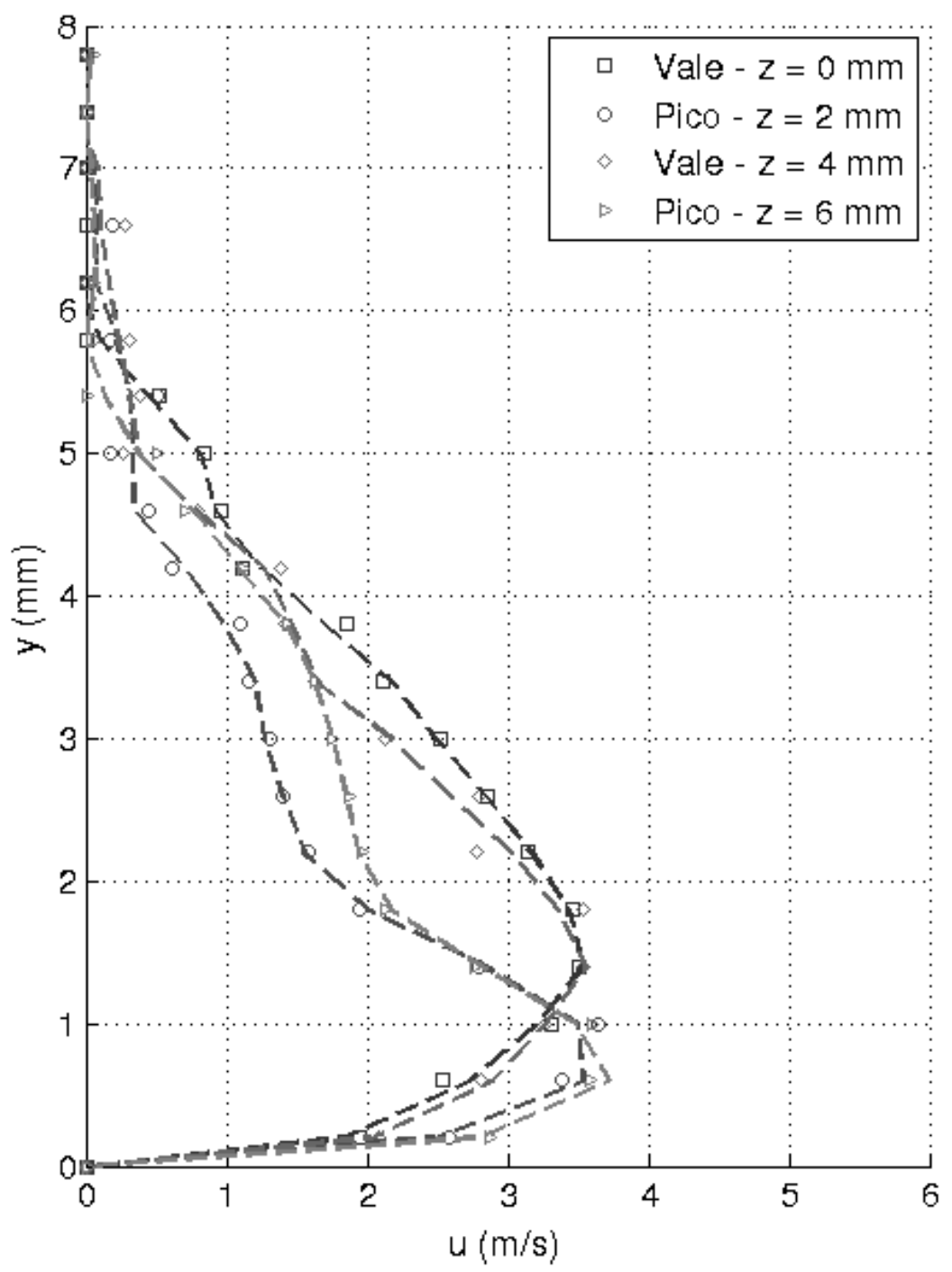

Figura 7.29 - Perfis de velocidades medidos ao longo do eletrodo serrilhado a $30 \mathrm{~mm}$ de distância da borda do eletrodo. 
Na Figura 7.30 são apresentados os perfis de velocidade dos jatos distantes $40 \mathrm{~mm}$ da borda do eletrodo ativos. Nesta etapa verificou-se a tendência de convergência das distribuições de velocidade para todos os perfis medidos, ou seja, tanto nos "vales" quanto nos "picos". Existe ainda uma significativa diferença localizada entre as alturas y $=1 \mathrm{~mm}$ e y $=4 \mathrm{~mm}$. Entretanto, esta diferença não se manifestou de forma tão intensa quanto nas etapas anteriores.

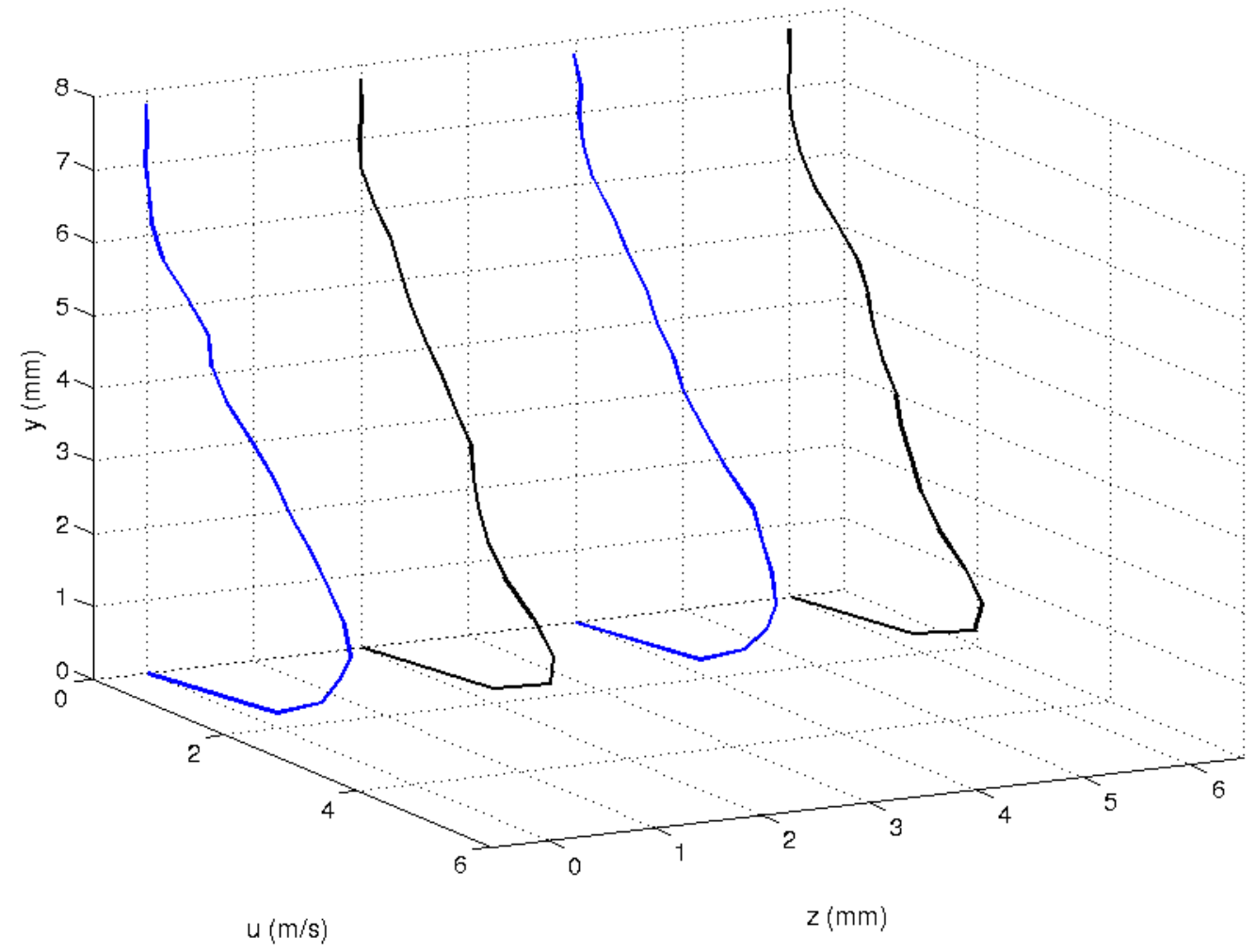

Figura 7.30 - Perfis de velocidades medidos ao longo do eletrodo serrilhado a $40 \mathrm{~mm}$ de distância da borda do eletrodo. 
A Figura 7.31 apresenta os resultados para todos os perfis de velocidade medidos em $\mathrm{x}=40 \mathrm{~mm}$. Agora, percebe-se uma grande redução na diferença nos contornos dos perfis de velocidade. Existe ainda uma evidente tendência de contorno dos perfis de velocidade mais desenvolvidos na direção "y" para os jatos produzidos a partir dos "vales" em relação aos produzidos a partir dos "picos". Entretanto, pode-se verificar que ocorreu a tendência de uniformização do escoamento para todos os casos medidos.

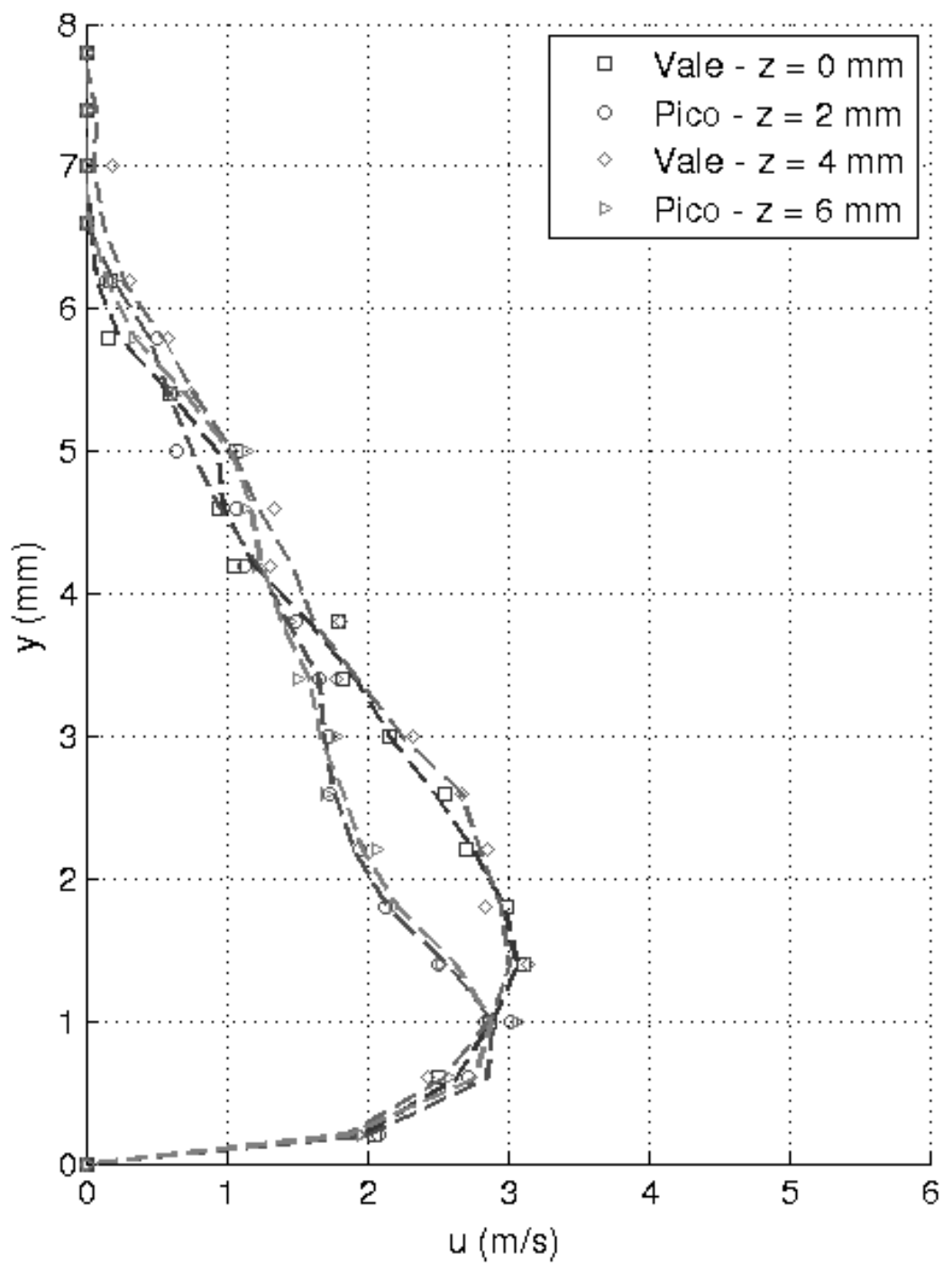

Figura 7.31 - Perfis de velocidades medidos ao longo do eletrodo serrilhado a $40 \mathrm{~mm}$ de distância da borda do eletrodo. 
A seguir são apresentados, na Figura 7.32, os resultados dos perfis de velocidade dos jatos distantes $50 \mathrm{~mm}$ da borda do eletrodo ativos. Novamente, verificou-se uma tendência de convergência das distribuições de velocidade para todos os perfis medidos, mas agora com uma intensidade muito grande. Pode-se ver na Figura 7.32 que existe uma mínima diferença entre os perfis de velocidade e não encontra-se mais um comportamento bem distinto para as medidas tomadas em frente as "vales" quando compradas com as medidas tomadas em frete aos "picos".

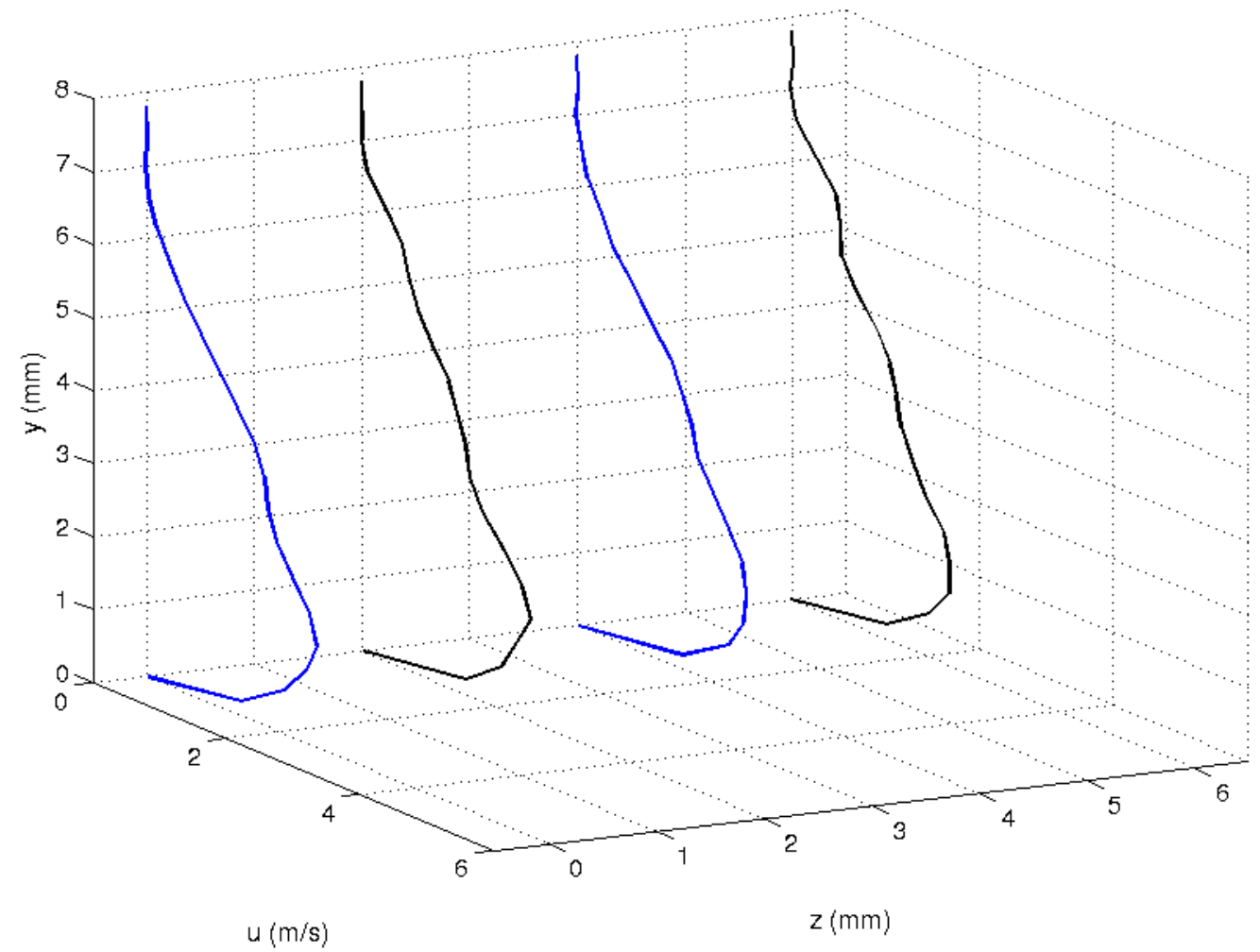

Figura 7.32 - Perfis de velocidades medidos ao longo do eletrodo serrilhado a $50 \mathrm{~mm}$ de distância da borda do eletrodo. 
A Figura 7.33 apresenta os resultados para todos os perfis de velocidade medidos em $\mathrm{x}$ $=50 \mathrm{~mm}$. Pode-se verificar que ocorreu a tendência de uniformização do escoamento para todos os casos medidos. Agora, percebe-se uma grande redução na diferença nos contornos dos perfis de velocidade, todos apresentam distribuições de velocidades praticamente idênticas.

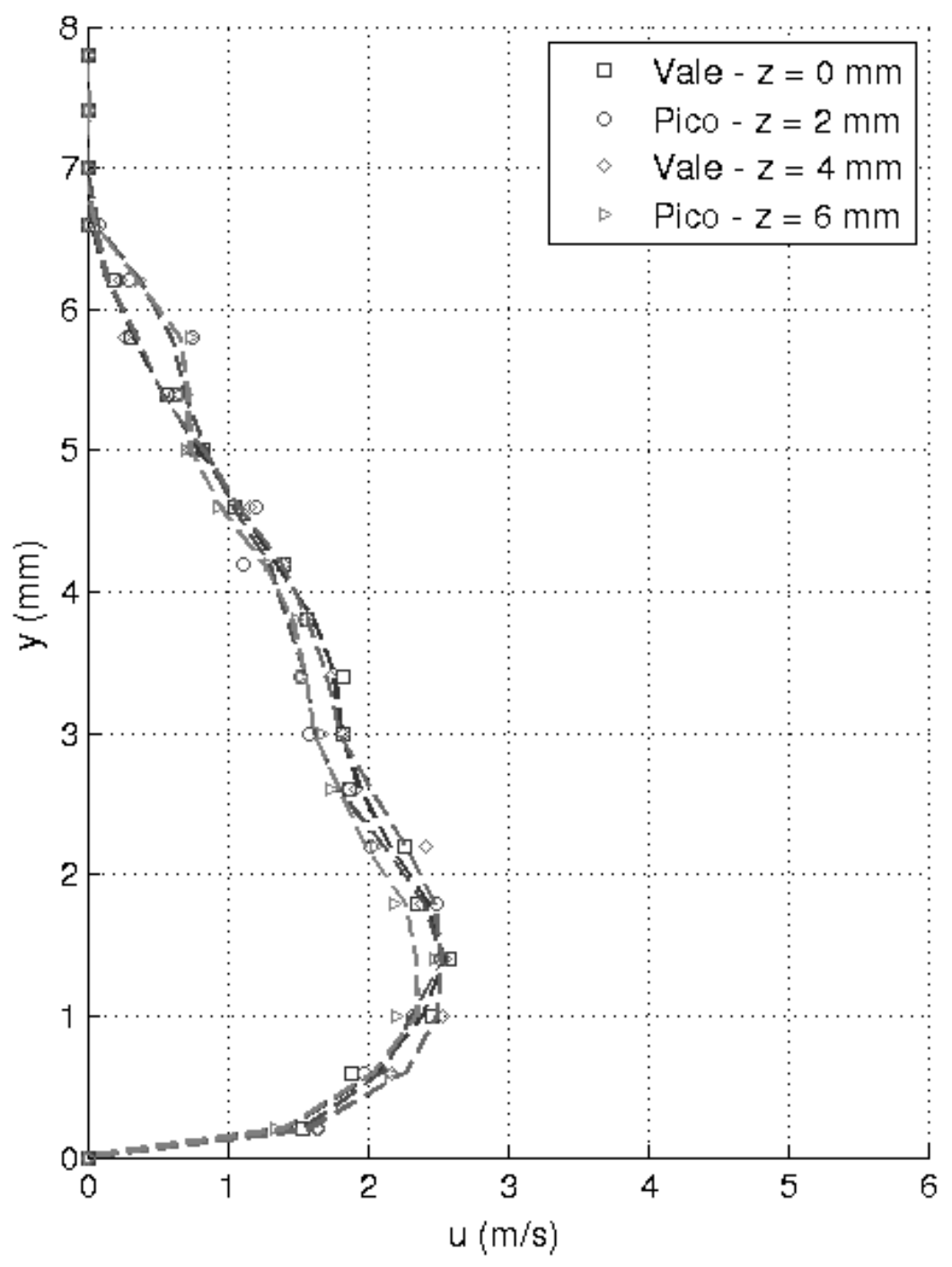

Figura 7.33 - Perfis de velocidades medidos ao longo do eletrodo serrilhado a $50 \mathrm{~mm}$ de distância da borda do eletrodo. 


\subsection{Discussão dos Resultados}

A descarga elétrica produzida pelo eletrodo serrilhado é mais eficiente para injetar energia mecânica no fluido para a produção de escoamentos. Isto é evidenciado pelo rápido crescimento vertical do jato induzido por esta configuração. As primeiras pistas para elucidar isto podem estar na forma como esta descarga é produzida por esta configuração. A Figura 7.34 apresenta uma imagem obtida através de uma câmera digital mostrando um mapa de intensidade luminosa da descarga produzida pelo eletrodo serrilhado. Podese ver que a descarga elétrica é concentrada ao redor dos picos do serrilhado, enquanto diminui de intensidade nos vales. Este comportamento pode ser explicado pelo simples efeito das pontas na intensidade de uma descarga elétrica, ou seja, ocorre o acumulo de cargas elétricas nesta região em comparação com as demais. Isto faz com que a energia elétrica seja liberada mais intensamente nesta região para a ionização do meio.

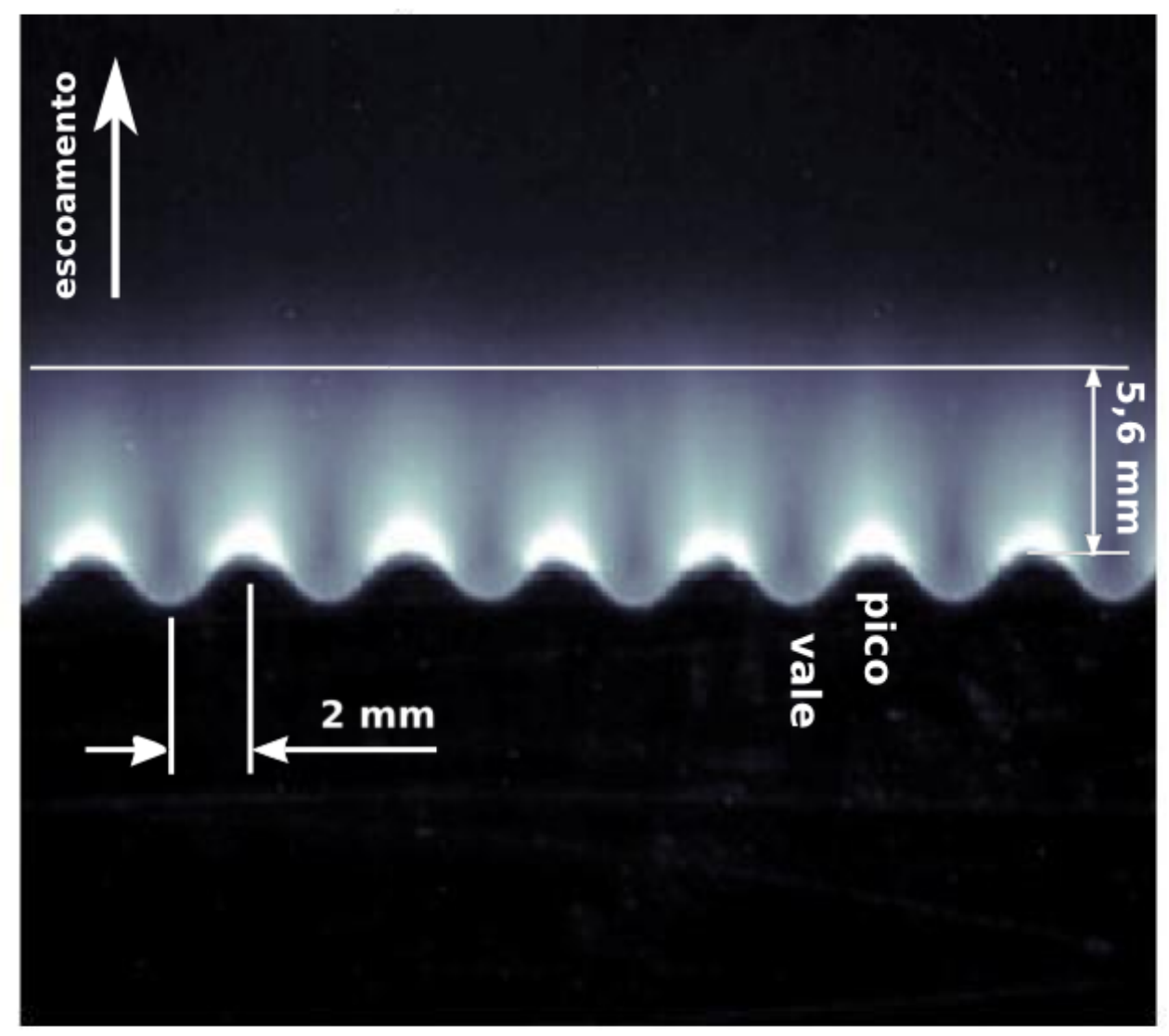

Figura 7.34 - Aspecto da descarga elétrica do eletrodo serrilhado. 
Consequentemente, isto faz com que o escoamento não seja induzido uniformemente ao longo do eletrodo. Ou seja, existe preferencialmente a indução de maiores velocidades a partir dos picos do serrilhado em comparação com as induzida nos vales. A Tabela 7.2 apesenta os valores das velocidades máximas ao longo da borda do eletrodo serrilhado e nas cinco localizações de medição distantes do eletrodo. Isto é consistente com o observado nos experimentos realizados. Na Figura 7.35 são mostradas as máximas velocidades com relação a posição em se localizam na direção da espessura do jato, ou seja, na direção "y".

Tabela 7.2 - Valores máximos de velocidades ao longo da borda do eletrodo serrilhado.

\begin{tabular}{ccccc}
\hline & $\begin{array}{c}\mathrm{u}_{\max }(\mathrm{m} / \mathrm{s}) \\
\text { vale }\end{array}$ & $\begin{array}{c}\mathrm{u}_{\max }(\mathrm{m} / \mathrm{s}) \\
\text { pico }\end{array}$ & $\begin{array}{c}\mathrm{u}_{\max }(\mathrm{m} / \mathrm{s}) \\
\text { vale }\end{array}$ & $\begin{array}{c}\mathrm{u}_{\max }(\mathrm{m} / \mathrm{s}) \\
\text { pico }\end{array}$ \\
\hline $\mathrm{x}=10 \mathrm{~mm}$ & $4,48 \pm 0,04$ & $5,47 \pm 0,06$ & $4,57 \pm 0,04$ & $5,69 \pm 0,06$ \\
$\mathrm{x}=20 \mathrm{~mm}$ & $4,01 \pm 0,04$ & $4,41 \pm 0,04$ & $3,93 \pm 0,04$ & $4,56 \pm 0,06$ \\
$\mathrm{x}=30 \mathrm{~mm}$ & $3,51 \pm 0,03$ & $3,65 \pm 0,04$ & $3,55 \pm 0,03$ & $3,59 \pm 0,04$ \\
$\mathrm{x}=40 \mathrm{~mm}$ & $3,11 \pm 0,03$ & $3,02 \pm 0,03$ & $3,14 \pm 0,03$ & $3,07 \pm 0,03$ \\
$\mathrm{x}=50 \mathrm{~mm}$ & $2,59 \pm 0,03$ & $2,52 \pm 0,03$ & $2,55 \pm 0,03$ & $2,48 \pm 0,02$ \\
\hline
\end{tabular}

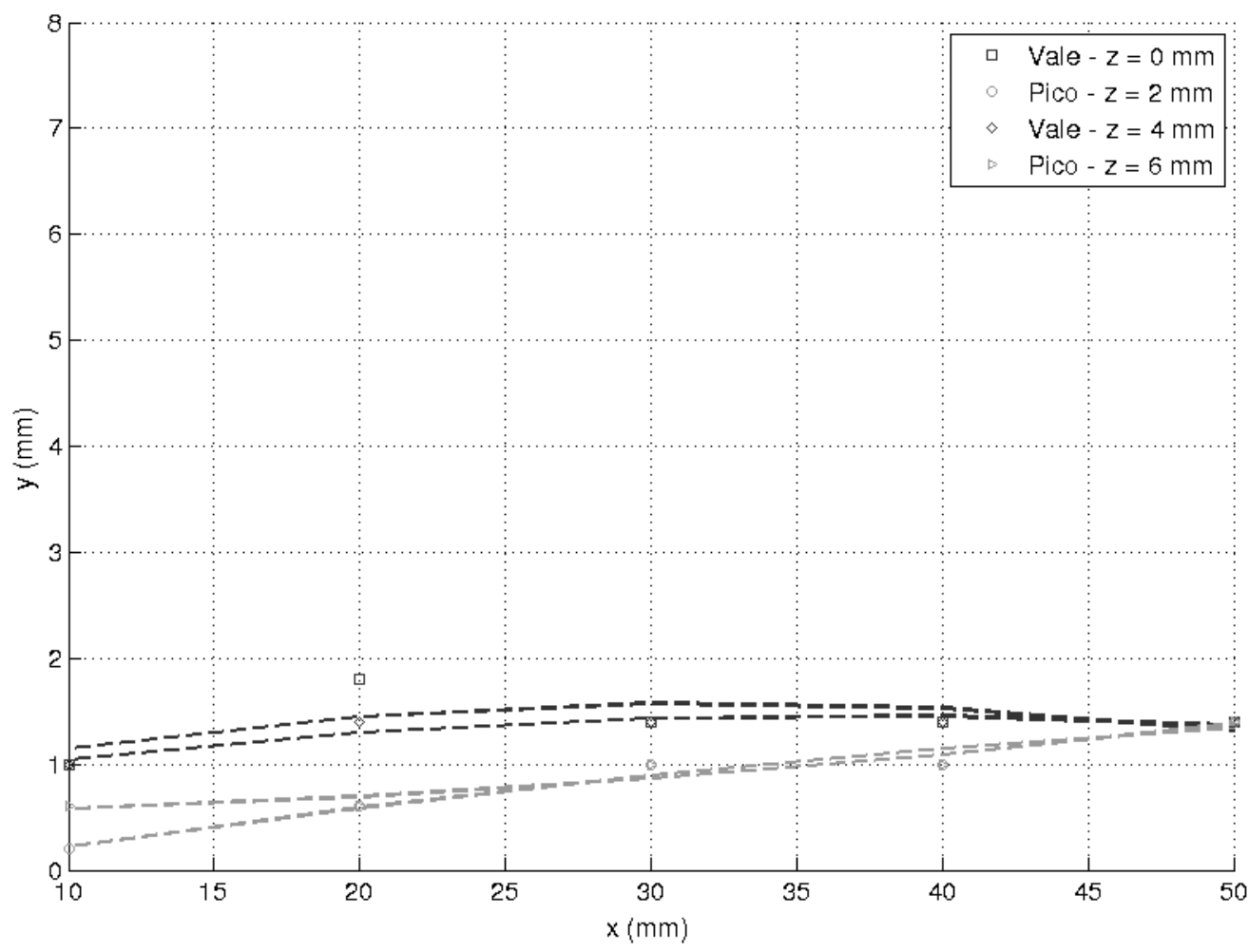

Figura 7.35 - Posição dos maiores valores de velocidade induzida ao longo da borda do eletrodo serrilhado. 
Além deste fato, a velocidade induzida tende a seguir o contorno do eletrodo, ou seja, uma parte da velocidade é induzida lateralmente. Pode-se afirmar que esta configuração induz um jato de parede de forma parcialmente similar a configuração utilizada por Durscher e Roy (2012), na qual eles estudaram uma configuração em forma de "serpentina" para os dois eletrodos que compõe o dispositivo eletro-hidrodinâmica. Entretanto, a configuração por eles estudada produzia uma tendência mais acentuada na imposição de um escoamento lateral, que tendia a se manter por uma distância maior. Na configuração estudada neste trabalho obteve-se uma tendência maior da convergência do jato induzido para uma distribuição de velocidades mais uniforme, mas com o benefício do rápido espessamento do jato devido ao exposto acima. A Figura 7.36 apresenta de forma esquemática a indução de velocidade sugerida no eletrodo serrilhado. Como a velocidade induzida tende a acompanhar o contorno do eletrodo, uma parte é injetada no sentido lateral o que leva ao encontro parcial das velocidades induzidas nesta região em angulo contrário, logo após a borda do eletrodo ativo. Supõe-se que parte do escoamento que sai da região do vale seja injetado com uma componente de velocidade maior na direção da espessura, em relação ao usualmente encontrada em um jato de parede comum. Assim, a espessura do jato nesta configuração tende a crescer de forma mais acentuada do que as produzidas pelas outras configurações estudadas. Desta forma, é possível o surgimento de grandes estruturas em forma de vórtices que produzem o rápido espessamento do jato induzido (quando comparado com outras configurações).

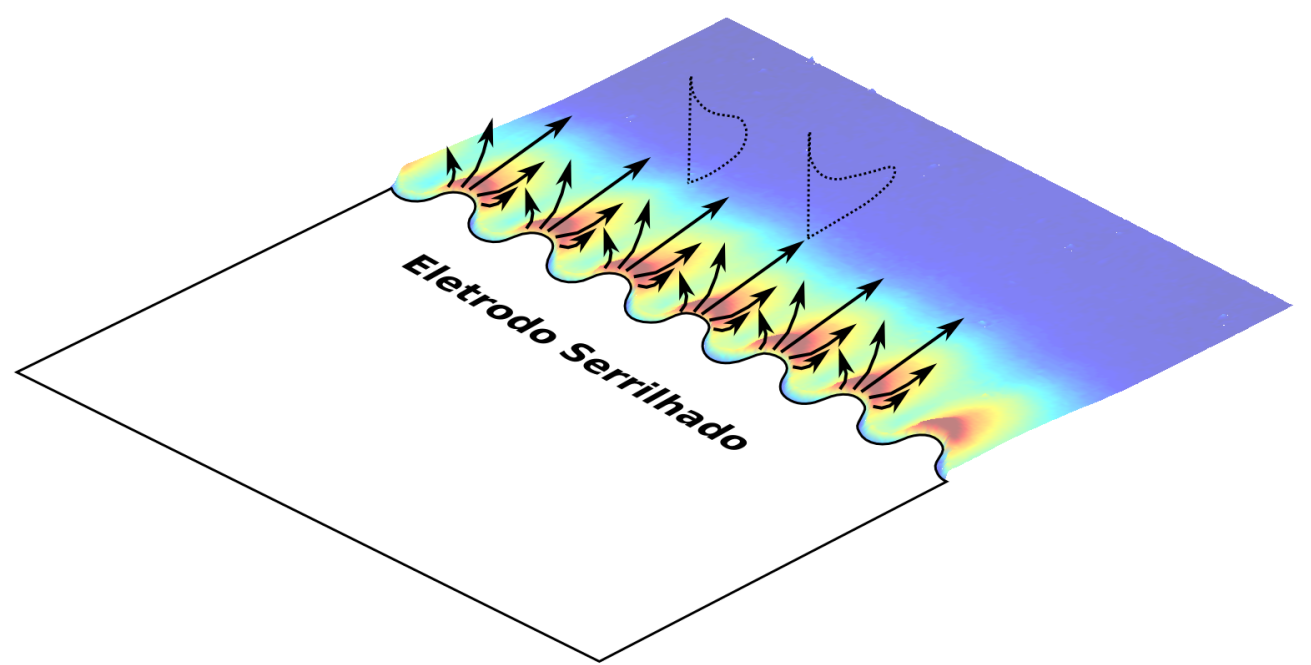

Figura 7.36 - Indução de velocidades ao longo do eletrodo serrilhado. 
Outro fato de importância significativa é que a descarga elétrica produzida pela configuração serrilhado-plano consome uma potência elétrica pouco superior a da configuração plano-plano. Além disso, consome bem menos do que a potência utilizada pela descarga da configuração fio-plano, mesmo fazendo a ressalva que esta configuração apresenta a formação de descarga elétrica nos dois lados do eletrodo fio (ver Figura D.3, Anexo D). A Tabela 7.3 apresenta os valores das potências consumidas pelas diversas configuração. Apresenta, também, o valor da potência por unidade de comprimento.

Tabela 7.3 - Valores das potências elétricas das descargas.

\begin{tabular}{lcc}
\hline & $\begin{array}{c}\text { Potência } \\
\text { (Watts) }\end{array}$ & $\begin{array}{c}\text { Potência/l } \\
\text { (Watts/m) }\end{array}$ \\
\hline Plano & 3,85 & 25,6 \\
Fio & 5,49 & 36,6 \\
Serrilhado & 4,12 & 27,4 \\
\hline
\end{tabular}




\section{Capítulo 8}

\section{Conclusões}

Os experimentos realizados comprovam a eficiência da descarga por barreira dielétrica como um instrumento para a produção e manipulação de escoamentos. Os resultados apresentados no Capitulo 6 mostram como os parâmetros de frequência e tensão podem ser ajustados para se produzir uma alteração intensa de um escoamento de baixas velocidades ao redor de um cilindro. Pôde-se verificar o comportamento clássico desta descarga elétrica, ou seja, ela atinge um ponto máximo de eficiência em função das características do meio em que é formada. Os dados de potência elétrica utilizada pela descarga nas diversa faixas de frequência medidas, mostram claramente que a descarga atinge um regime de máxima intensidade no seu estabelecimento.

No Capitulo 7, três dispositivos eletro-hidrodinâmicos diferentes, com base na geometria da borda do eletrodo ativo, foram testados e comparados no que diz respeito aos jatos de parede gerados. A tensão e a frequência da fonte de alimentação foram mantidas no mesmo valor para todos os experimentos. Estes parâmetros foram ajustados em função do ponto máximo em que descarga injetava energia no meio. O primeiro fato a ser evidenciado consiste na capacidade de produção de um escoamento mais desenvolvido em termos de espessura da configuração de eletrodo serrilhado-plano em comparação com as demais.

Embora a velocidade mais elevada foi obtida com a configuração de eletrodo fio, a configuração com o eletrodo serrilhado era mais capaz de produzir um fluxo de massa mais intenso. Conclui-se, com base nos dados medidos, que a descarga elétrica produzida pelo eletrodo serrilhado é mais eficiente para injetar a energia mecânica no fluido para produzir escoamento. Isso é claramente evidenciado pelo rápido crescimento vertical do 
jato de parede induzido por esta configuração. Um dos fatos fundamentais para elucidar esta tendência é a forma em que a descarga elétrica é produzida por esta configuração.

Esta descarga elétrica está concentrada em torno dos picos serrilhados, diminuindo em intensidade nos vales. Este comportamento pode ser explicado pelo simples efeito das pontas na intensidade de uma descarga elétrica, ou seja, há um acúmulo de cargas elétricas nesta região em comparação com as outras. Isso faz com que a energia elétrica seja lançado de forma mais intensa nesta região para a ionização do meio. Consequentemente, isso produz um escoamento não uniforme ao longo do eletrodo. Ou seja, há a preferência de velocidades mais elevada a partir dos picos serrilhados em comparação com as velocidades induzidas nos vales. Como a velocidade induzida tende a acompanhar o contorno do eletrodo, uma parte é injetada no sentido lateral o que leva ao encontro parcial das velocidades induzidas nesta região em angulo contrário, logo após a borda do eletrodo ativo. Isto produz uma tendência de parte do escoamento que sai da região do vale ser injetado com uma componente de velocidade maior na direção da espessura, em relação ao usualmente encontrada em um jato de parede comum. Assim, a espessura do jato nesta configuração tende a crescer de forma mais acentuada do que as produzidas pelas outras configurações estudadas. Somando os dois efeitos, maiores velocidades a partir dos picos com a tendência de uma componente vertical a partis dos vales, esta configuração produz um jato de parede mais intenso do que as outras configurações estudadas.

Por outro lado, a configuração utilizada neste trabalho se mostrou mais capaz de induzir escoamento com velocidades maiores do que a utilizada por Durscher e Roy (2012). No trabalho citado eles obtiveram velocidades inferiores, mas apresentaram um modelo que tinha mais influência na espessura. Isto pode ser devido a escala menor da geometria do eletrodo utilizado, ou seja, devido ao menor raio do contorno da borda do eletrodo serrilhado. Isto pode ser determinante no estabelecimento mais rápido de um jato de parede com características adequadas para aplicações reais.

Outro fato interessante, consiste na eficiência elétrica do eletrodo serrilhado não ser muito maior do que para a configuração plano-plano. Enquanto a potência elétrica da configuração plano-plano foi de aproximadamente 25,6 Watts/m, a da configuração serrilhado-plano foi de 27,4 Watts/m. Além, de mais eficiente quando comparada com a descarga produzida pela configuração fio-plano $(\mathrm{P}=36,6 \mathrm{Watts} / \mathrm{m})$. Isto é uma evidência das características mais adequadas desta configuração na indução de escoamentos. 
Os resultados mostram melhores características da configuração serrilhado-plano para ser utilizada na produção de escoamento mais intensos. Desta forma, conclui-se que a geometria de eletrodos serrilhado-plano apresenta características mais adequada para o controle e indução de escoamentos em aplicações reais. 


\section{Referências}

AHN, S. H.; KIM, Y. K. Fabrication and experiment of a planar micro ion drag pump. Sensors and Actuators, n. 70, p. 1-5, 1998.

AKYUZ, M. Positive streamer discharges in air and along insulating surfaces: experiment and simulation. Acta Universitatis Upsaliensis, 2002.

ARTANA, G.; AL et. Flow control with electrohydrodynamics actuators. AIAA Journal, v. 40, n. 9, p. 1773-9, sep 2002.

ARTANA, G.; DIPRIMO, G. Electrohydrodynamic actuators on a subsonic air flow around a circular cylinder. AIAA Plasmadynamic and Lasers Conference and Weakly Ionized Gases Workshop, n. 70, p. 1-5, 2001.

BAUGHN, J. et al. Momentum transfer for an aerodynamic plasma actuator with an imposed boundary layer. 44th AIAA Aerospace Sciences Meeting and Exhibit. Reno, NV: AIAA, 2006.

BRAND, F. Plasma physics. 1997. Notas de aula.

BUSHNELL, D. M. Application frontiers of 'designer fluid mechanics'-visions versus reality or an attempt to answer the perennial question 'why isn't it used?'. 28th AIAA Fluid Dynamics Conference, n. AIAA Paper 97-2110, 1997.

CARR, A. K. Increase in the surface energy of metal and polymeric surfaces using the one atmosphere uniform glow discharge plasma. Dissertação (Mestrado) - University of Tennessee, 1997.

DURSCHER, R.; ROY, S. Induced flow from serpentine plasma actuators acting in quiescent air. 49th AIAA Aerospace Sciences Meeting, n. AIAA 2011-957, 2011.

DURSCHER, R.; ROY, S. Three-dimensional flow measurements induced from serpentine plasma actuators in quiescent air. Journal of Physics D: Applied Physics, v. 45 , p. $9,2012$.

EL-KHABIRY, S.; COLVER, G. M. Drag reduction by dc corona discharge along an electrically conductive flat plate for small reynolds number flow. Physics of Fluids, v. 9, n. 3, mar 1997.

ENGEL, A. Ionized Gases. [S.1.]: Oxford Press, 1965.

ENLOE, C. L. et al. Mechanisms and responses of a single dielectric barrier plasma actuator: Geometric effects. AIAA Journal, v. 42, n. 3, p. 595-604, 2004. 
FANTEL, H. Major de seversky's ion-propelled aircraft. Popular Mechanics, v. 122, n. 2, p. 58-61, ago 1964.

FORTE, M. et al. Optimization of a dielectric barrier discharge actuator by stationary and non-stationary measurements of the induced flow velocity: application to airflow control. Experiments in fluids, n. 43, p. 917-928, 2007.

GHERARDI, N.; MASSINES, F. Mechanisms controlling the transition from glow silent discharge to streamer discharge in nitrogen. IEEE Transactions on Plasma Science, v. 29, n. 3, p. 536-44, jun 2001.

GOLDMAN, M.; SIGMOND, R. S. Corona and insulation. IEEE Transaction on Electrical Insulation, E-17, n. 2, p. 90-105, mar 1982.

HYUN, K. T.; CHUN, C. H. he wake flow control behind a circular cylinder using ion wind. Experiments in Fluids, v. 30, p. 541-552, 2003.

JAYARAMAN, B.; THAKUR, S.; SHYY, W. Modeling of fluid dynamics and heat transfer induced by dielectric barrier plasma actuator. Journal of Heat Transfer, v. 129, p. 517-525, 2007.

LACHOWICZ, J. T.; AL. et. Instabilities introduced by a point source on a conical body at mach 6: Stability analysis and experimental implementation. In Transition, Turbulence and Combustion, v. 3, p. 63-76, 1994.

LIEBERMAN, M. A.; LICHTENBERG, A. J. Principles of plasma discharges and materials processing. MRS Bulletin, Cambridge Univ Press, v. 30, p. 899-901, 1994.

MALIK, M. R.; AL. et. Ion wind drag reduction. AIAA Paper, n. 83-0231, 1983.

MASSINES, F. et al. Experimental and theoretical study of a glow discharge at atmospheric pressure controlled by dielectric barrier. Journal of Applied Physics, AIP Publishing, v. 83, n. 6, p. 2950-2957, 1998.

MOHAN, M. R. C. Boundary layer flow acceleration by paraelectric and peristaltic EHD effects of aerodynamic plasma actuators. Dissertação (Mestrado) - University of Tennessee, Knoxville, 2004.

PORTE, C. O. et al. Temporal force measurements on an aerodynamic plasma actuator. 44th AIAA Aerospace Sciences Meeting and Exhibit. Reno, NV: AIAA, 2006.

ROTH, J. R. Industrial Plasma Engineering - Volume 1: Principles. Londres: Insitute of Physics Publishing, 1995.

ROTH, J. R. Electrohydrodynamically induced air flow in a one atmosphere uniform glow discharge surface plasma. $25^{\text {th }}$ IEEE International Conference on Plasmas Science, 1998.

ROTH, J. R. Industrial Plasma Engineering: Volume 2 - Applications to Nonthermal Plasma Processing. [S.l.]: Taylor \& Francis, 2001. (Industrial Plasma Engineering).

ROTH, J. R. Aerodynamic flow acceleration using paraelectric and peristaltic electrohydrodynamic effects of a one atmosphere uniform glow discharge plasma. Physics of Plasmas, v. 10, n. 5, p. 2117-26, mai 2003. 
ROTH, J. R.; SHERMAN, D. M.; WILKINSON, S. P. Boundary layer flow control with a one-atmosphere uniform glow discharge surface plasma. AIAA 98-0328, 1998.

ROTH, J. R.; SHERMAN, D. M.; WILKINSON, S. P. Electrohydrodynamics flow control with a glow-discharge surface plasma. AIAA Journal, v. 38, n. 7, p. 1166-72, jan 2000 .

SCHOPPA, A.; HUSSAIN, F. A large-scale control strategy for drag reduction in turbulent boundary layers. Physics of Fluids, v. 10, n. 1049, 1998.

SHERMAN, D. M. Manipulating aerodynamic boundary layers: using an electrohydrodynamic effect generated by a One Atmosphere Uniform Glow Discharge Plasma. Dissertação (Mestrado) — University of Tennessee, Knoxville, 1998.

SIN, H. A Polyphase Power Supply and Peristaltic Flow Accelerator Using a One Atmosphere Uniform Glow Discharge Plasma. Dissertação (Mestrado) - University of Tennessee., Knoxville, 2002.

SOLDATI, A.; MARCHIOLI, C. Prospects for modulation of turbulent boundary layer by ehd flows. In: In Turbulence Structure and Modulation. [S.l.]: Springer-Verlag, 2001. p. 119-160.

STUETZER, O. M. Ion drag pressure. Journal of Applied Physics, v. 30, n. 7, 1959.

VERHOFF, A. Steady and pulsating two-dimensional turbulent wall jets in a uniform stream. [S.l.], 1970.

WÅHLIN, L. Atmospheric electrostatics. [S.l.]: JOHN WILEY and SONS INC, England, 1989.

WIER, T. Boundary layer control by means of electromagnetic forces. ERCOFTAC Bulletin, n. 44, p. 36-40, 2000.

WILKINSON, S. P. Interactive wall turbulence control. In Viscous Drag Reduction in Boundary Layers. [S.l.]: AIAA, 1990.

ZHANG, P. Atmospheric pressure dielectric barrier glow discharge and its numerical simulation. 2004. 


\section{Apêndice A}

\section{Fonte de Alta Tensão e Alta Frequência}

\section{A.1 Projeto e Construção da Fonte}

Como já foi claramente especificado, para a produção da descarga por barreira dielétrica é necessário a aplicação de uma tensão de corrente alternada de vários quilovolts de intensidade e com uma frequência acima de $1 \mathrm{kHz}$. Não é usual encontrar uma fonte de tensão com estas características. Desta forma, desenvolveu-se para este estudo uma fonte de tensão com características adequadas para o emprego na geração de uma descarga por barreira dielétrica. A Tabela A.1 apresenta as principais características desta fonte de tensão, evidenciando claramente a particularidade deste dispositivo.

Tabela A.1 - Características Fundamentais da Fonte de Alimentação.

\begin{tabular}{cc}
\hline Tensão de Saída & $8 k$ Volts $($ C.A. $)$ \\
Corrente de Saída & $20 m A_{\max }$ \\
Frequência & $1 \mathrm{kHz}$ a $10 \mathrm{kHz}$ \\
Tensão de Entrada & $30 V_{\max }$ (C.C.) \\
Corrente de Entrada & $5 A_{\max }$ \\
\hline
\end{tabular}

Para alcançar o desempenho desejado, a fonte de tensão foi construída levando-se em conta não a otimização elétrica do circuito (ou seja, projeto dimensionado no limite), mas sim teve como ponto principal de projeto o fato de poder fornecer a potência requerida para a geração da descarga por barreira dielétrica durante longos períodos e sem perda de 
desempenho. Para tanto, alguns componentes do sistema, principalmente os de potência elevada, foram até certo ponto super dimensionados. Além disso, quando foi possível, equipamentos comerciais padronizados foram utilizados no sistema.

O projeto final consistiu, então, no cálculo e confecção de determinados itens e no dimensionamento e aquisição de outros. Para tanto, a fonte de tensão foi dividida em três módulos, sendo o dimensionamento de um módulo levando ao dimensionamento dos outros. Este processo interativo foi repetido até que o sistema foi projetado com o máximo de dispositivos padronizados. A Figura A.1 apresenta um esquema geral da fonte de tensão projetada, discretizando especificamente cada módulo e a Figura A.2 apresenta a fonte de tensão construída.

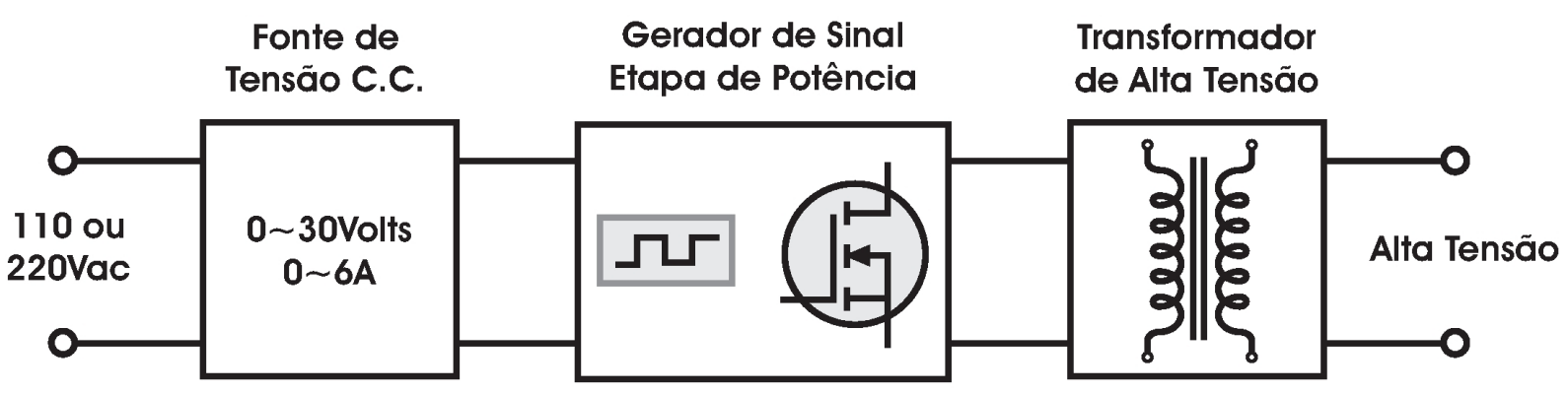

Figura A.1 - Circuito Esquemático da Fonte de Alimentação.

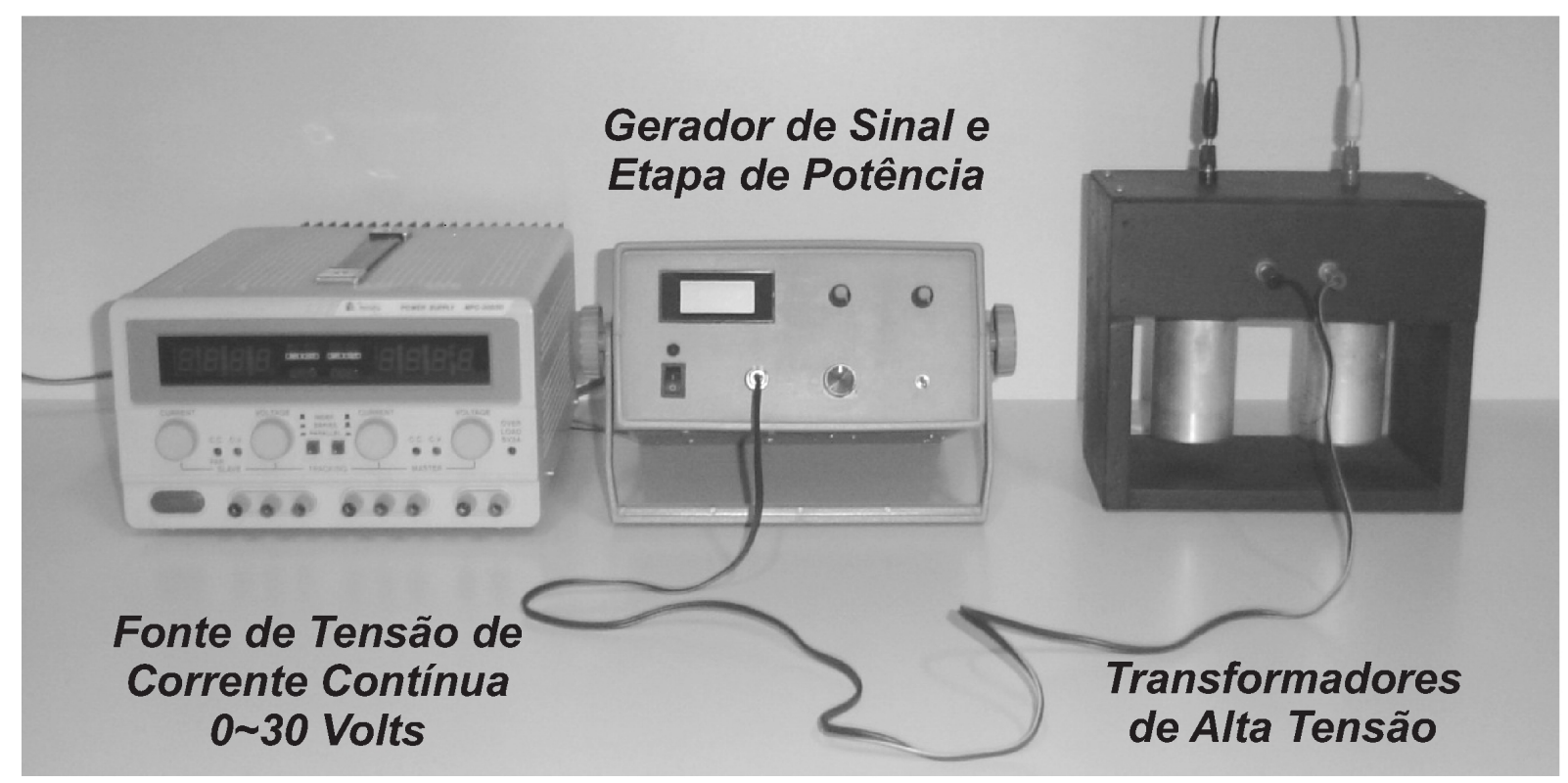

Figura A.2 - Fonte de Alimentação. 


\section{A.2 Fonte de Tensão C.C.}

Inicialmente optou-se pelo projeto e construção de uma fonte de alimentação de corrente contínua para a alimentação do sistema. No entanto, dado à elevada necessidade de corrente de saída requerida pelo sistema, o que tornaria crítico a construção deste equipamento, a escolha recaiu na utilização de um equipamento comercial padronizado. Desta forma, para este módulo utilizou-se uma fonte de tensão C.C da Minipa, modelo MPC-3006D. A Figura A.3 mostra uma foto deste equipamento.

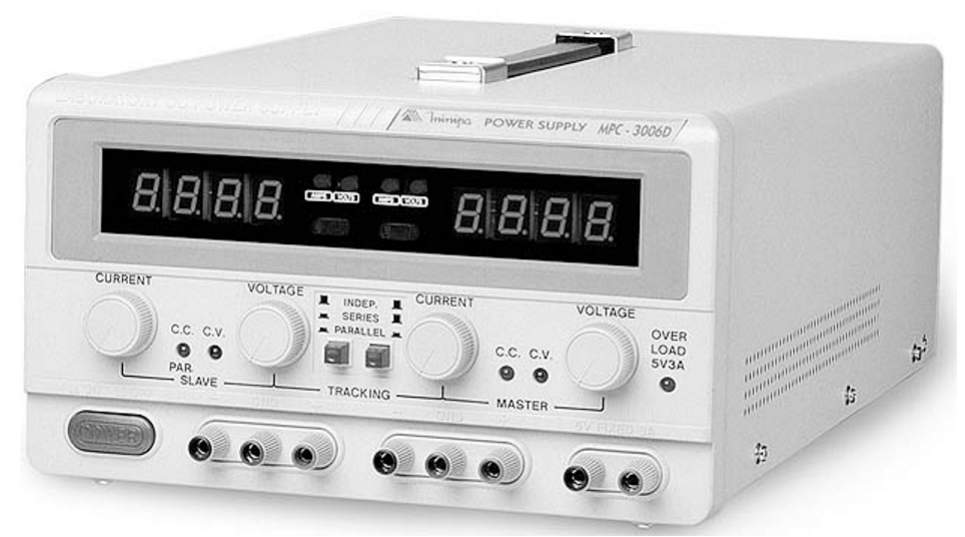

Figura A.3 - Fonte de Alimentação C.C. Minipa.

Este equipamento apresentou qualidades adequadas para fornecer a tensão de alimentação das etapas de alta tensão da fonte. Dentre suas principais características podese citar a capacidade de controle preciso da tensão de saída, com uma precisão da ordem de 0,1 Volts. Além deste fato, um outro ponto determinante na escolha deste equipamento consistiu na sua grande capacidade de fornecimento de corrente elétrica. O valor máximo de trabalho está na ordem de $6 \mathrm{~A}$ de corrente elétrica. Este valor foi adequado para a alimentação das etapas posteriores da fonte de alta tensão. Sumarizando, a Tabela A.2 apresenta as principais características deste equipamento.

Tabela A.2 - Características Gerais da Fonte de Alimentação.

\begin{tabular}{ll}
\hline Modelo & MinipaMPC $-3006 D$ \\
\hline Tensão de Saída & 0 a 30 Volts $($ C.C. $)$ \\
Corrente de Saída & 0 a 6 Amperes \\
\hline
\end{tabular}




\section{A.3 Gerador de Sinal}

A fonte de alta tensão e de alta frequência é o elemento principal da fonte. Esta etapa consiste basicamente em um inversor ressonante paralelo, ou seja, um circuito eletrônico que converte uma tensão de corrente contínua pulsada em uma tensão de corrente alternada. Ela é composta basicamente de uma etapa que produz o sinal adequado e de uma etapa de potência. O circuito que produz o sinal retangular utiliza um componente especial para este fim. Este componente é o circuito integrado XR-2206, fabricado pela EXAR, e que consiste basicamente em um gerador de funções com capacidade de operar na faixa de frequência que vai de $1 \mathrm{~Hz}$ até $100 \mathrm{kHz}$. A Figura A.4 mostra o circuito específico da etapa geradora do sinal, configurada especificamente para produzir um sinal retangular, com amplitude de saída de 3 Volts, em duas faixas de frequência, de $1 \mathrm{kHz}$ e de $10 \mathrm{kHz}$, selecionadas através do seletor $S 1$ mostrado no circuito. Para o ajuste da frequência de saída utiliza-se o potenciômetro P1. Com este componente pode-se ajustar a frequência de saída entre $1 \mathrm{~Hz}$ à $1 \mathrm{kHz}$ e $1 \mathrm{kHz}$ à $10 \mathrm{kHz}$.

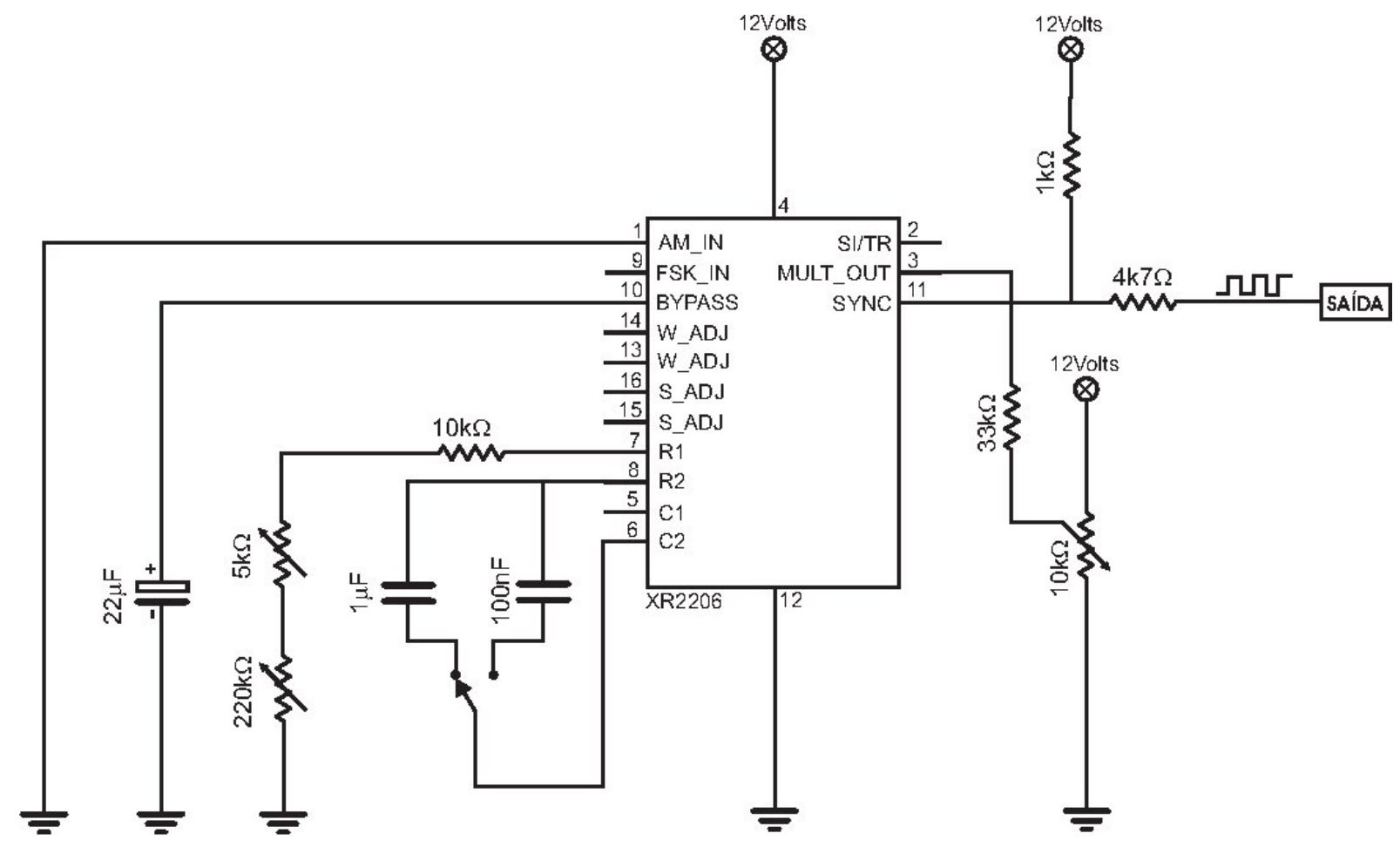

Figura A.4 - Etapa de geração e controle do sinal.

Logo após o estágio de geração do sinal é colocado uma etapa para amplificar o sinal de saída. Desta forma, o sinal gerado pode ser utilizado para o próximo estágio que 
necessita de uma potência maior do sinal do que o que é gerado pelo circuito. No circuito construído, mostrado na Figura A.5, existe a possibilidade de ajustar livremente o ganho do circuito integrado. No entanto, o circuito foi ajustado para amplificar o sinal de entrada, de valor igual à 3 Volts, para um valor de saída igual à 12 Volts. Desta forma, este sinal estará adequadamente condicionado para exitar a próxima etapa da fonte. $\mathrm{O}$ circuito integrado utilizado nesta etapa foi o amplificador operacional LM741, que está adequadamente dimensionado neste caso já que a aplicação não é crítica.

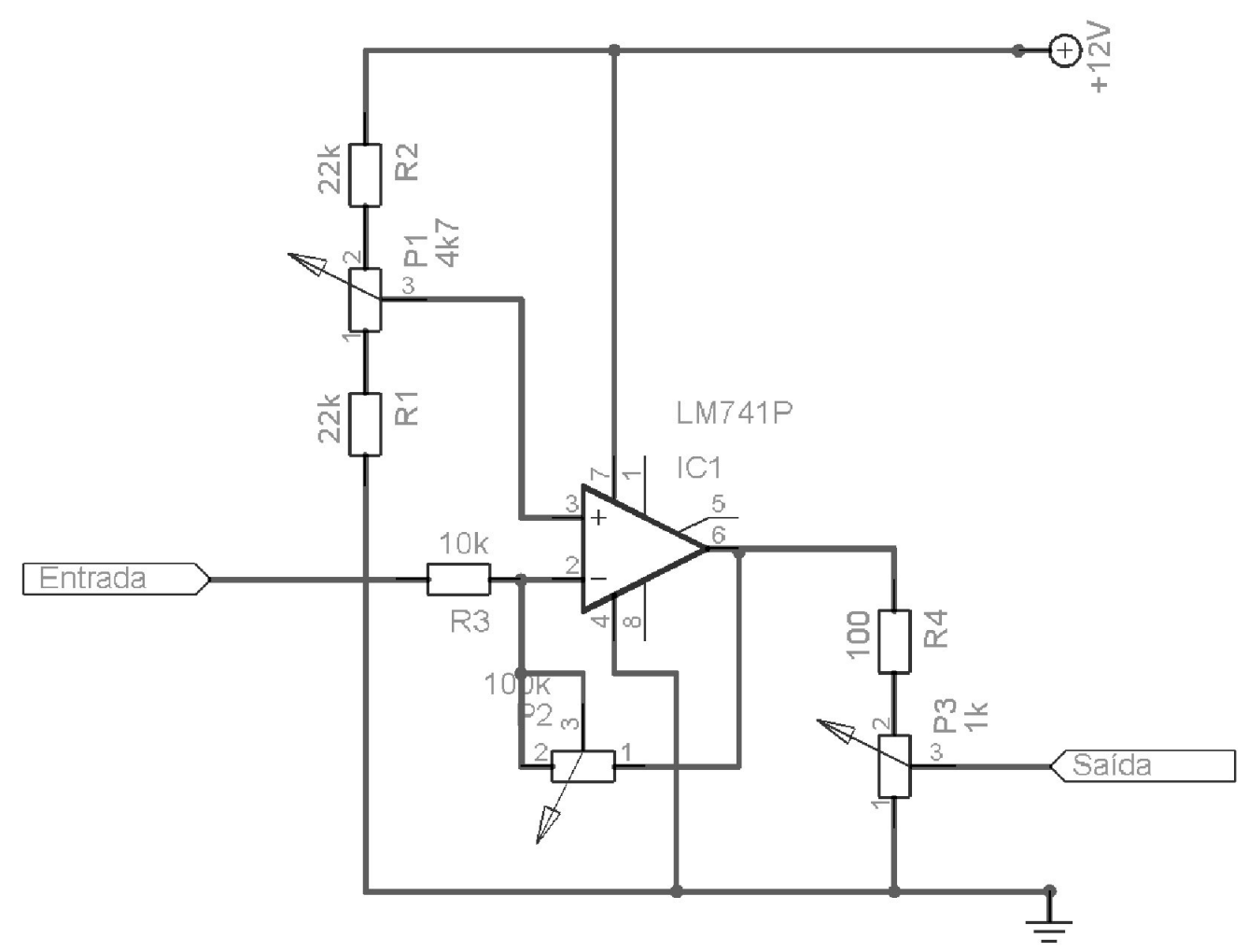

Figura A.5 - Etapa amplificadora do sinal gerado.

\section{A.4 Etapa de Potência}

A etapa de potência da fonte de alta tensão e de alta frequência é conectada na saída da etapa geradora do sinal retangular e aplica o sinal, de potência, diretamente em um transformador elevador de tensão, neste caso uma bobina de ignição utilizada em motores a combustão interna. Esta bobina tem por característica fundamental aumentar por um fator de até 1.500 a tensão elétrica aplicada em seu enrolamento primário. Para tanto, 
a bobina utilizada contém um enrolamento primário com 200 espiras e um enrolamento secundário com aproximadamente 100.000 espiras. Um componente é o responsável pela chaveamento do sinal de baixa potência para um sinal de alta potência. Este componente é IRFZ-48 que consiste em um HEXFET de potência fabricado pela International Rectifier (ver Figura A.6). Este componente tem por características principais suportar uma corrente de até 64 amperes em operação contínua. No entanto, este componente dissipa uma potência de aproximadamente 50 Watts, o que levou este componente ser montado em um grande dissipador de calor com ventilação forçada. A Figura A.7 apresenta o esquema elétrico da etapa de potência.
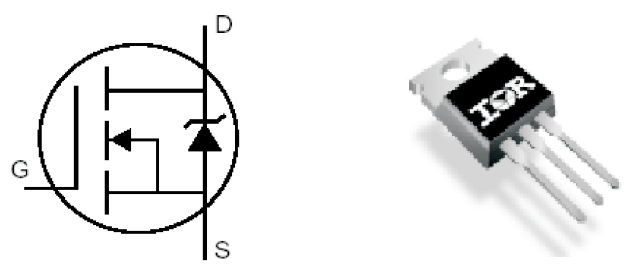

Figura A.6 - Etapa de Potência da Fonte de Alimentação.

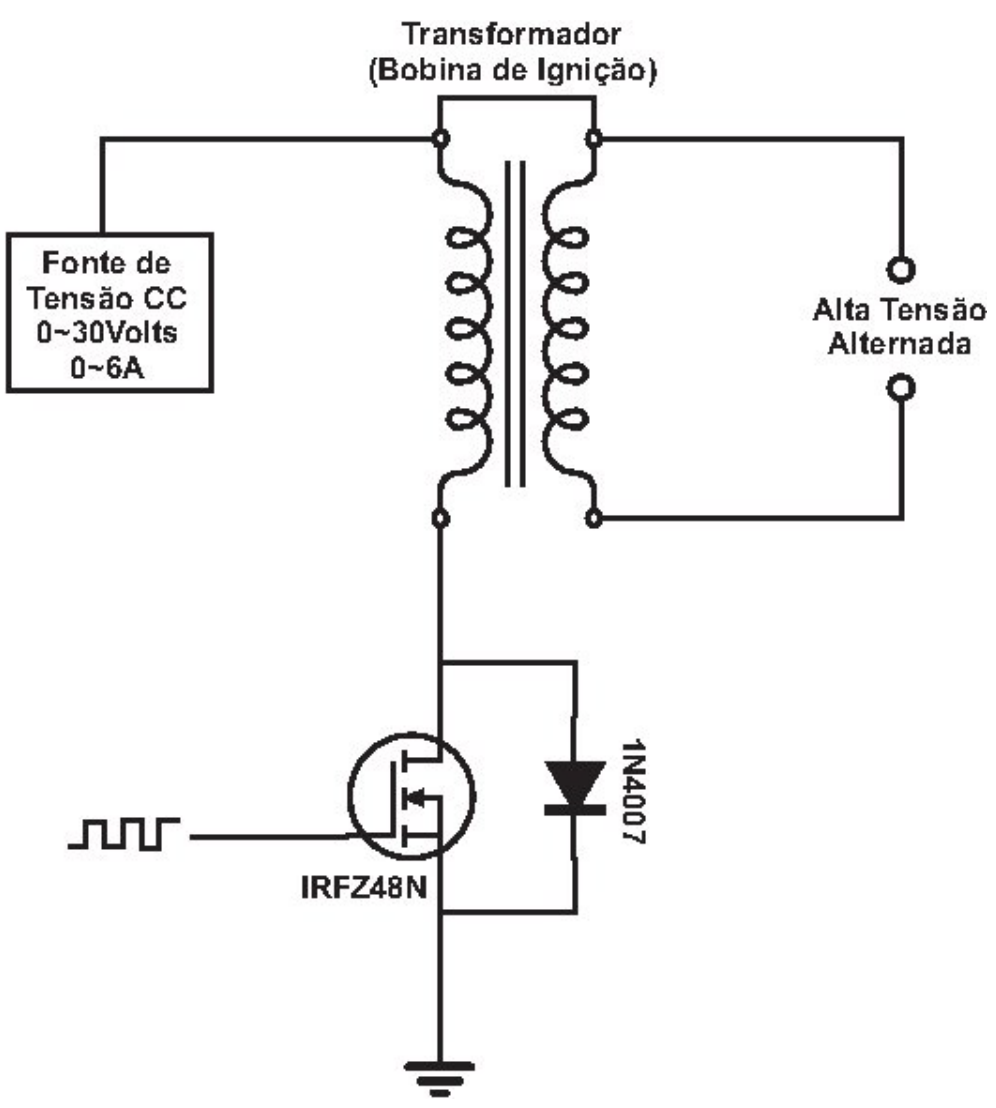

Figura A.7 - Etapa de Potência da Fonte de Alimentação.

Foram utilizados bobinas de ignição de motores para a etapa de elevação da tensão 
até a faixa dos kVolts. Estas bobinas apresentam uma boa resposta em frequência para a tensão de alimentação de seu primário, embora são mais indicadas para trabalharem com frequências menores. Para contornar isto e melhorar eficiência neste estágio, com um aumento na capacidade de suporte a corrente elétrica, estas bobinas foram montadas em paralelo. A Figura A.8 apresenta a forma como isto foi feito, enquanto a Figura A.9 mostra estas bobinas montadas em um suporte de madeira, indicando as respectivas entradas e saídas de tensão.
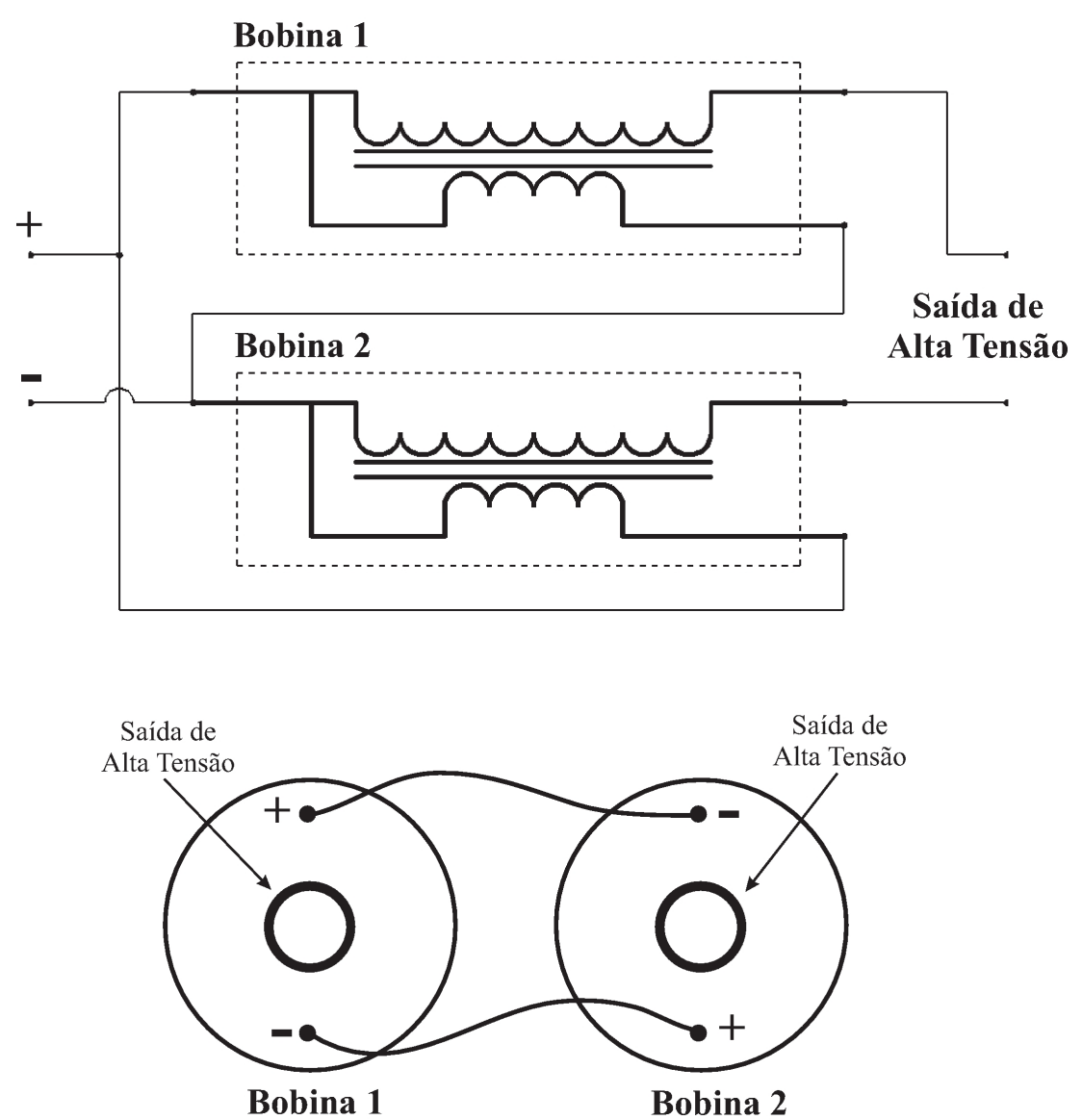

Figura A.8 - Esquema de ligação das duas bobinas de alta tensão

Para finalizar, foi construído um simples frequencímetro que foi, por sua vez, ligado junto a saída do de tensão do gerador de sinal. Desta forma, foi possível monitorar a frequência na qual a tensão de saída se encontrava através de um display de cristal líquido localizado no painel do equipamento. A Figura A.10 apresenta o circuito eletrônico deste equipamento. Já a Figura A.11 apresenta o equipamento gerador de sinal completamento, com os controles e o display de LCD no painel principal. 


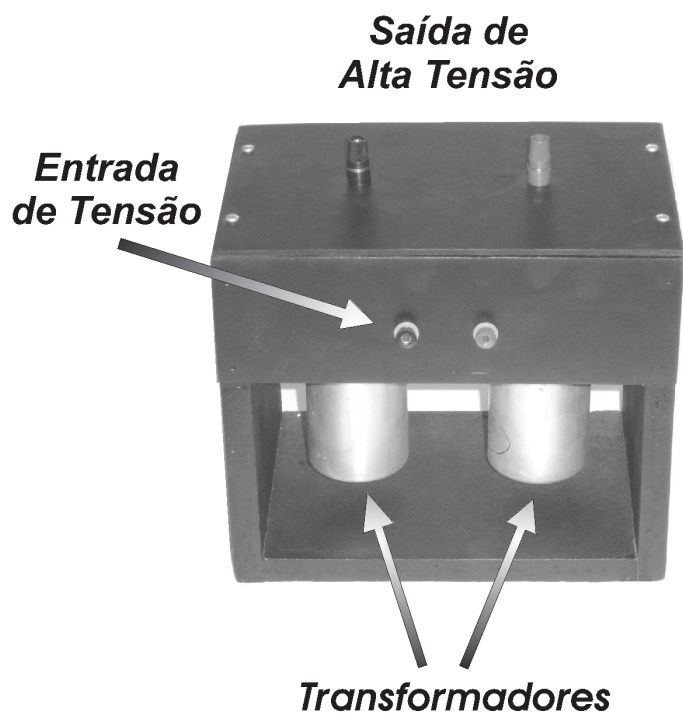

Figura A.9 - Equipamento Gerador do Sinal e Etapa de Potência

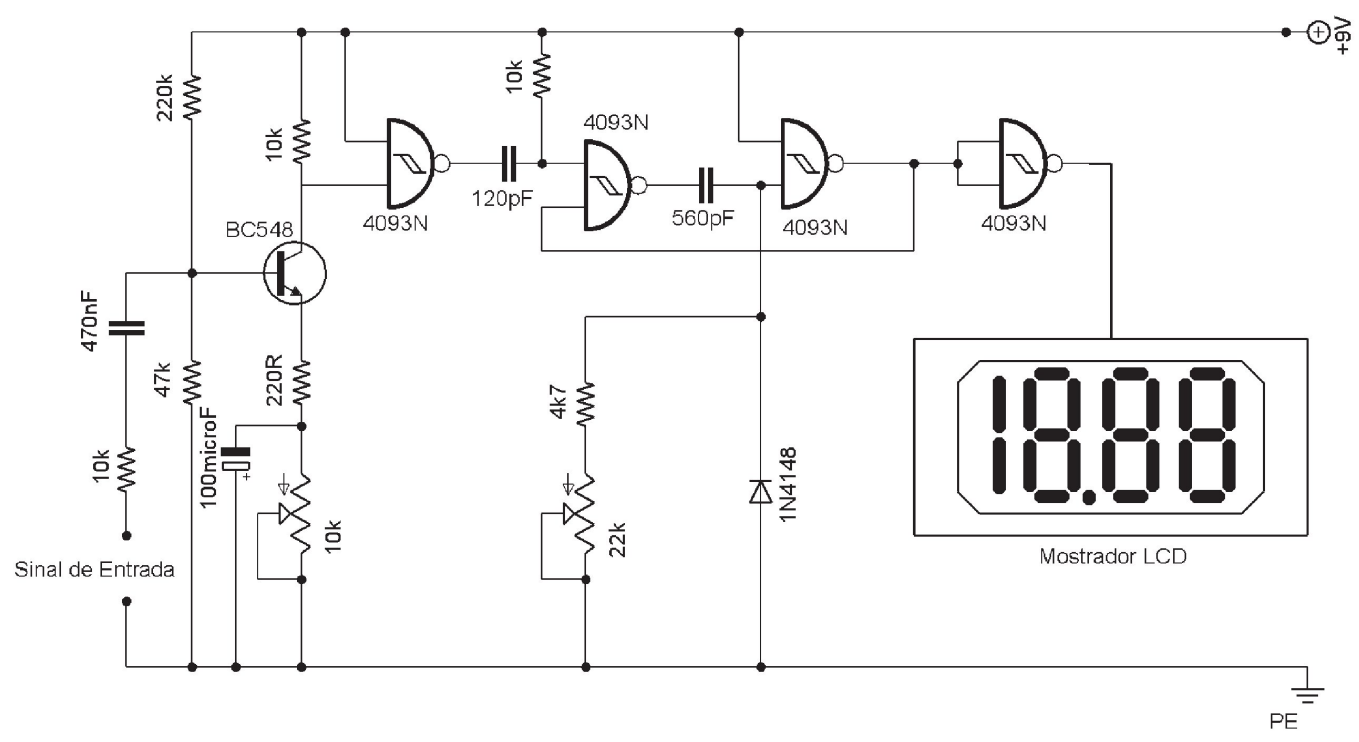

Figura A.10 - Etapa Indicadora da Frequência de Saída da Fonte

\section{A.5 Calibração e Ajustes}

Foi realizado um levantamento experimental para se obter a relação entre a tensão de entrada e a tensão de saída da fonte. Para tanto, a fonte foi ligada a um simples par de eletrodos planos feitos com folhas de alumínio, ambos com 150mm de comprimento e $15 \mathrm{~mm}$ de largura, separados por uma placa de acrílico de $3 \mathrm{~mm}$ de espessura. Um sonda de alta de tensão (ver Apêndice B) foi conectada em uma das saídas da fonte, para fornecer uma tensão reduzida que, por sua vez, foi levada até a uma das entradas de um osciloscópio digital. Desta forma, foi possível medir o valor de tensão da saída da fonte 


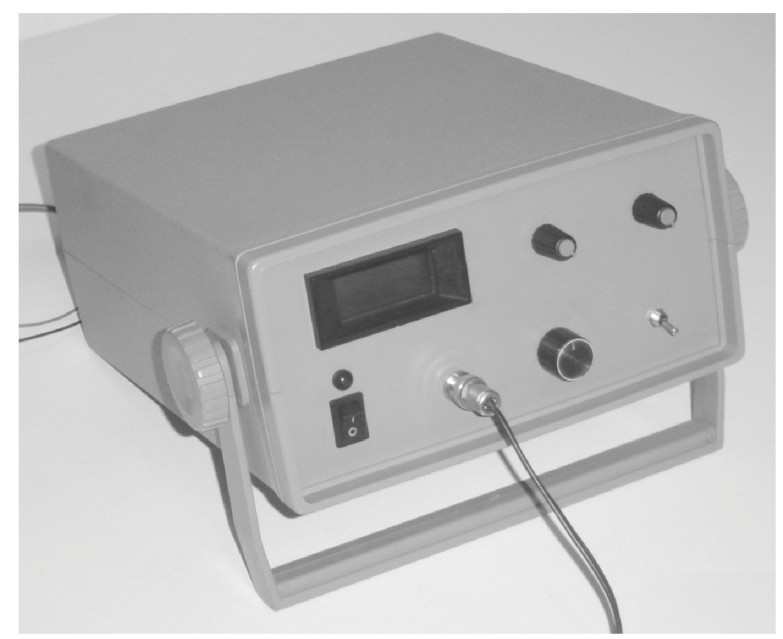

Figura A.11 - Equipamento Gerador do Sinal e Etapa de Potência

de alta tensão para diversos valores de tensão fornecidos pela fonte de alimentação. As Figuras A.12, A.13, A.14, A.15, A.16 e A.17 apresentam os resultados para os diversos casos estudados. Já a Figura A.18 apresenta de forma explícita a relação entre os valores de tensão de alimentação da fonte e a tensão de na saída dos transformadores. Esta relação pode ser melhor analisada segunda a seguinte equação.

$$
U_{\text {saida }}=1,0120+0,2399 U_{\text {entrada }}
$$

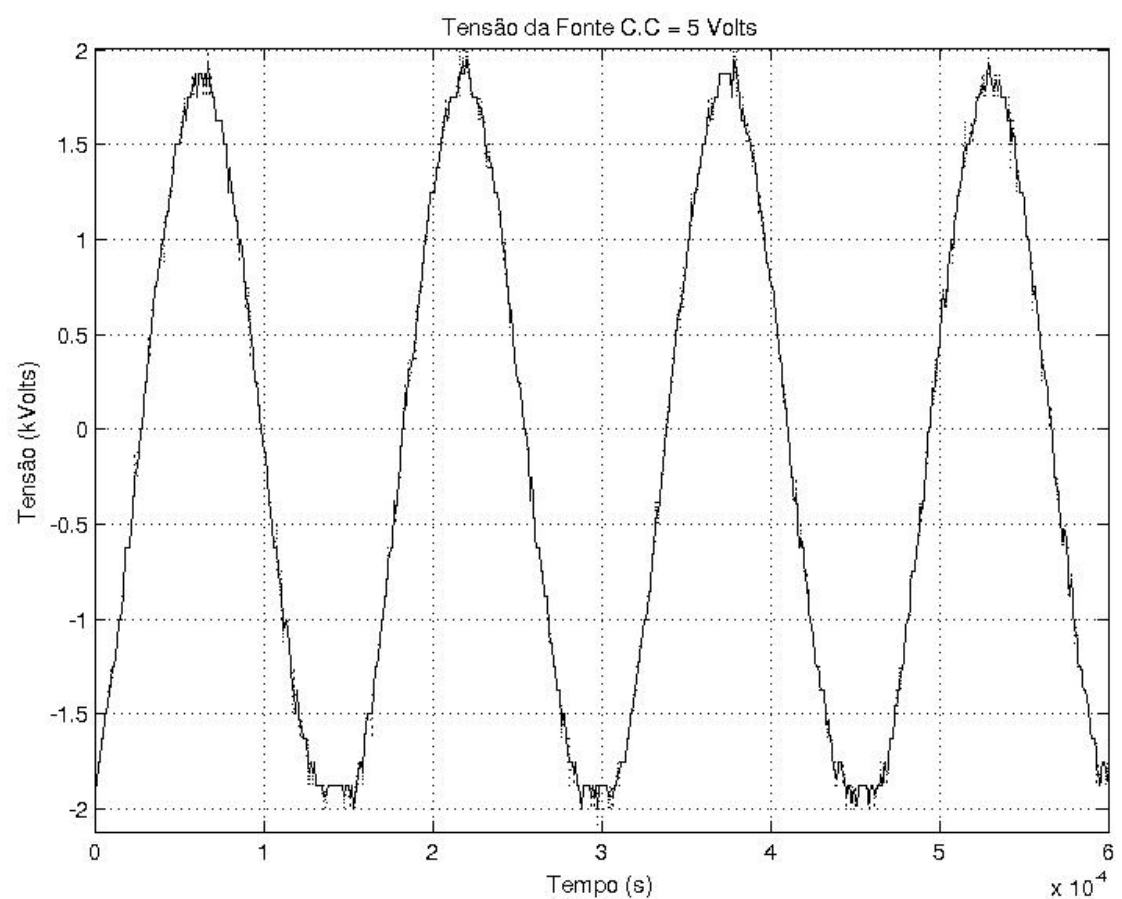

Figura A.12 - Tensão no eletrodo externo com tensão na fonte C.C. de 5 Volts. 


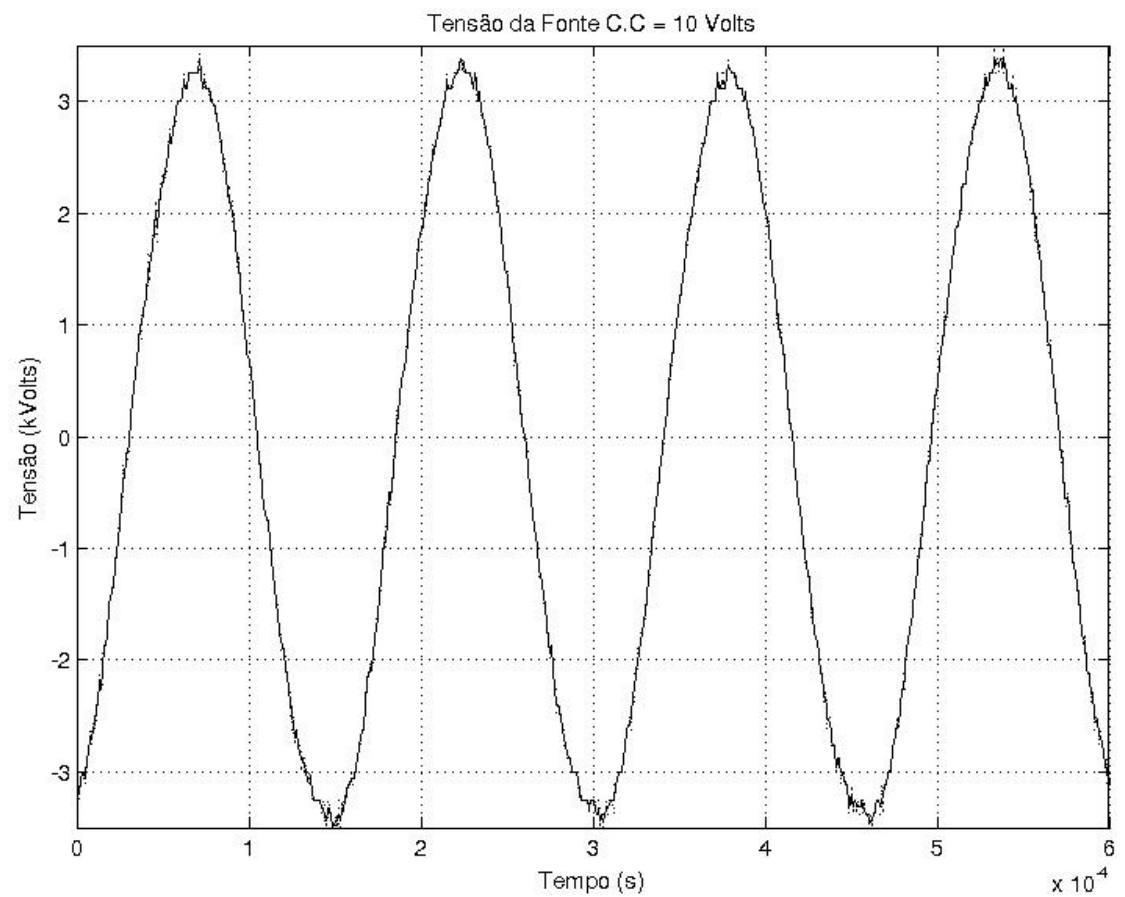

Figura A.13 - Tensão no eletrodo externo com tensão na fonte C.C. de 10 Volts.

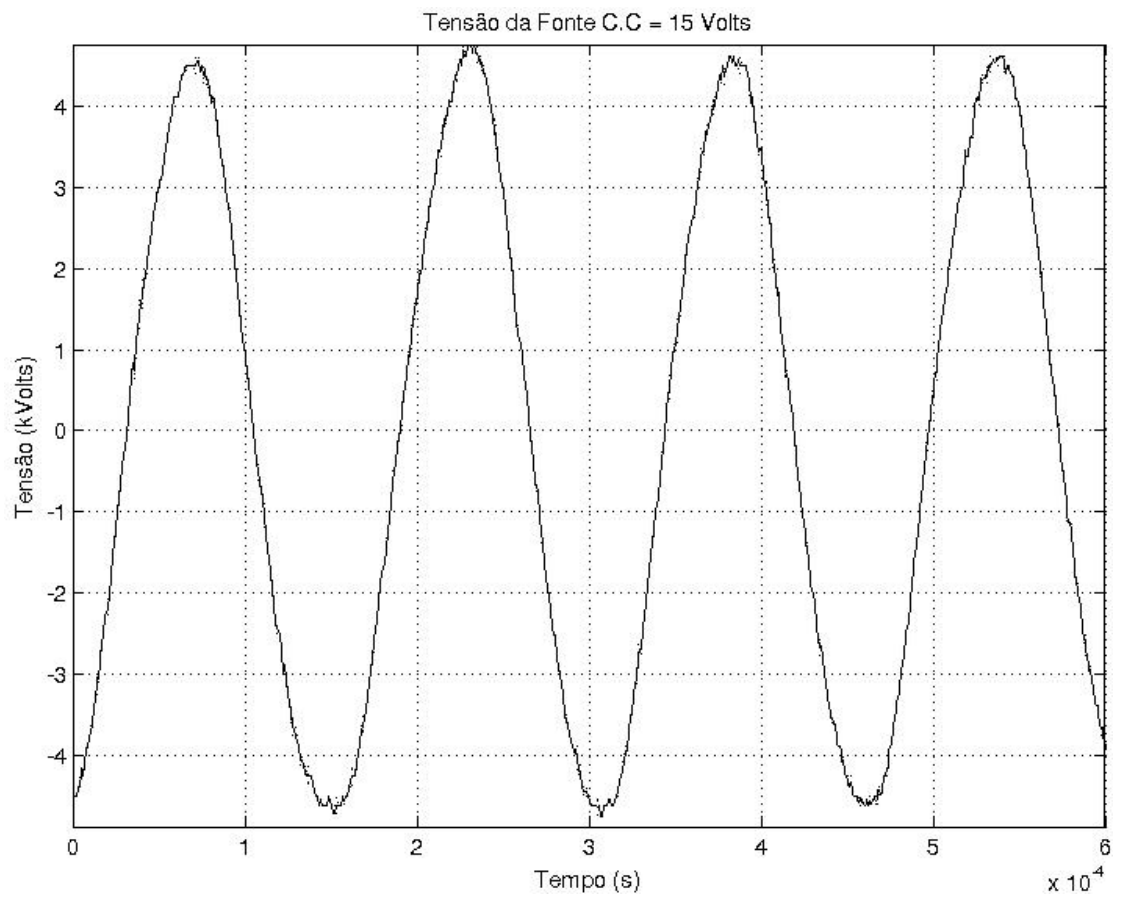

Figura A.14 - Tensão no eletrodo externo com tensão na fonte C.C. de 15 Volts. 


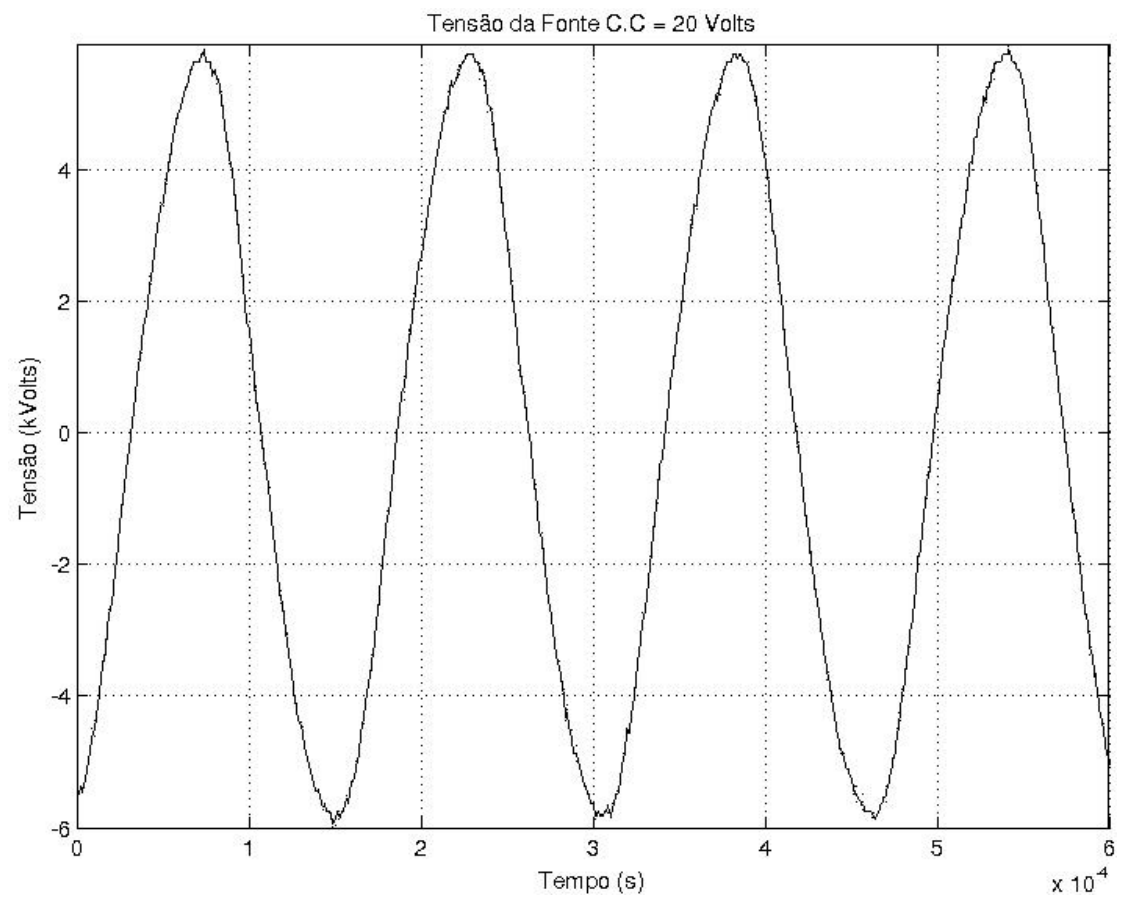

Figura A.15 - Tensão no eletrodo externo com tensão na fonte C.C. de 20 Volts.

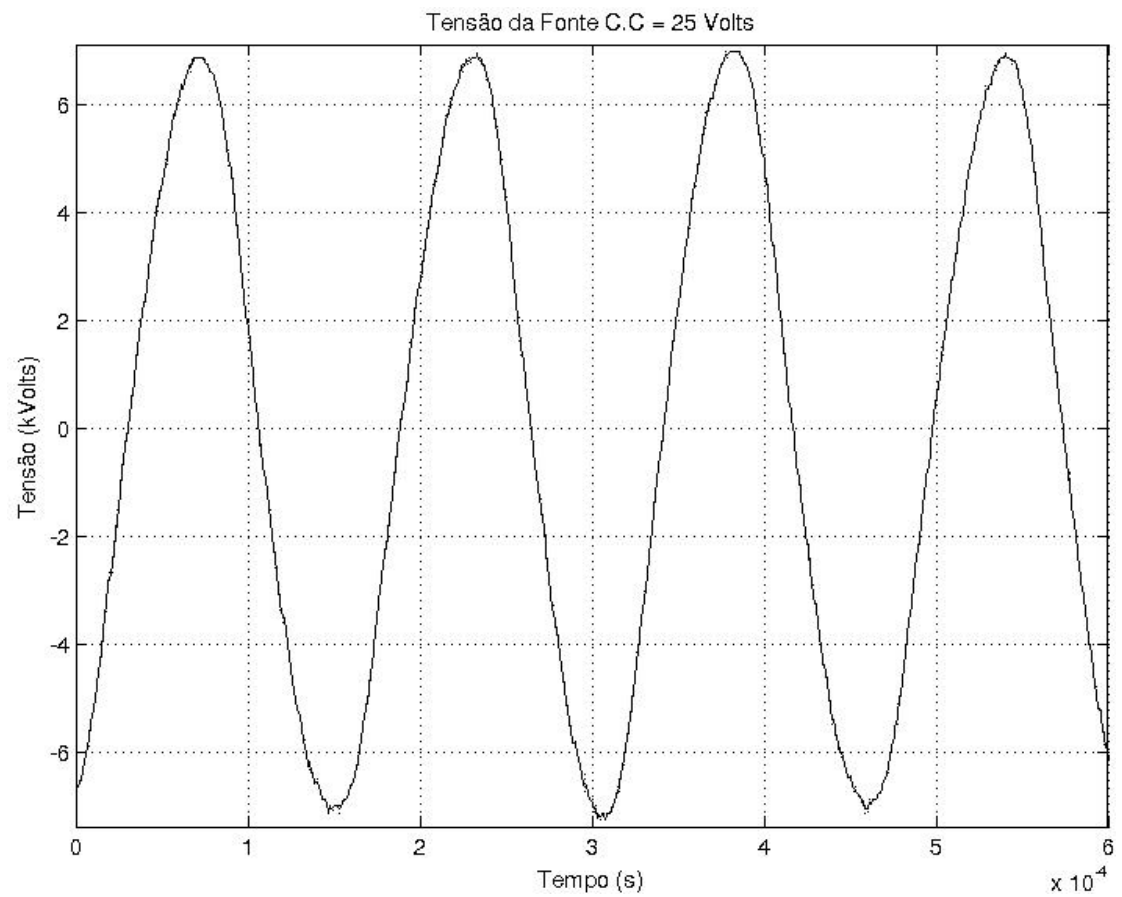

Figura A.16 - Tensão no eletrodo externo com tensão na fonte C.C. de 25 Volts. 


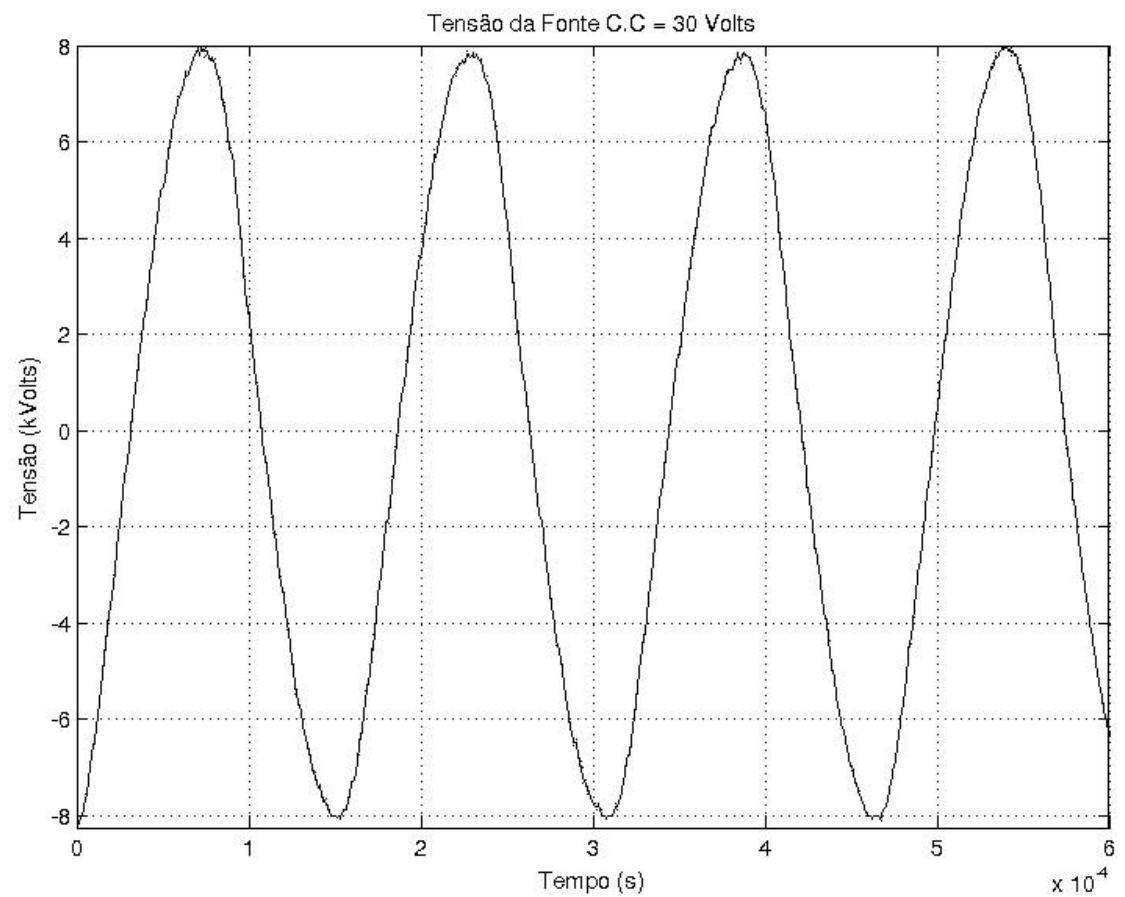

Figura A.17 - Tensão no eletrodo externo com tensão na fonte C.C. de 30 Volts.

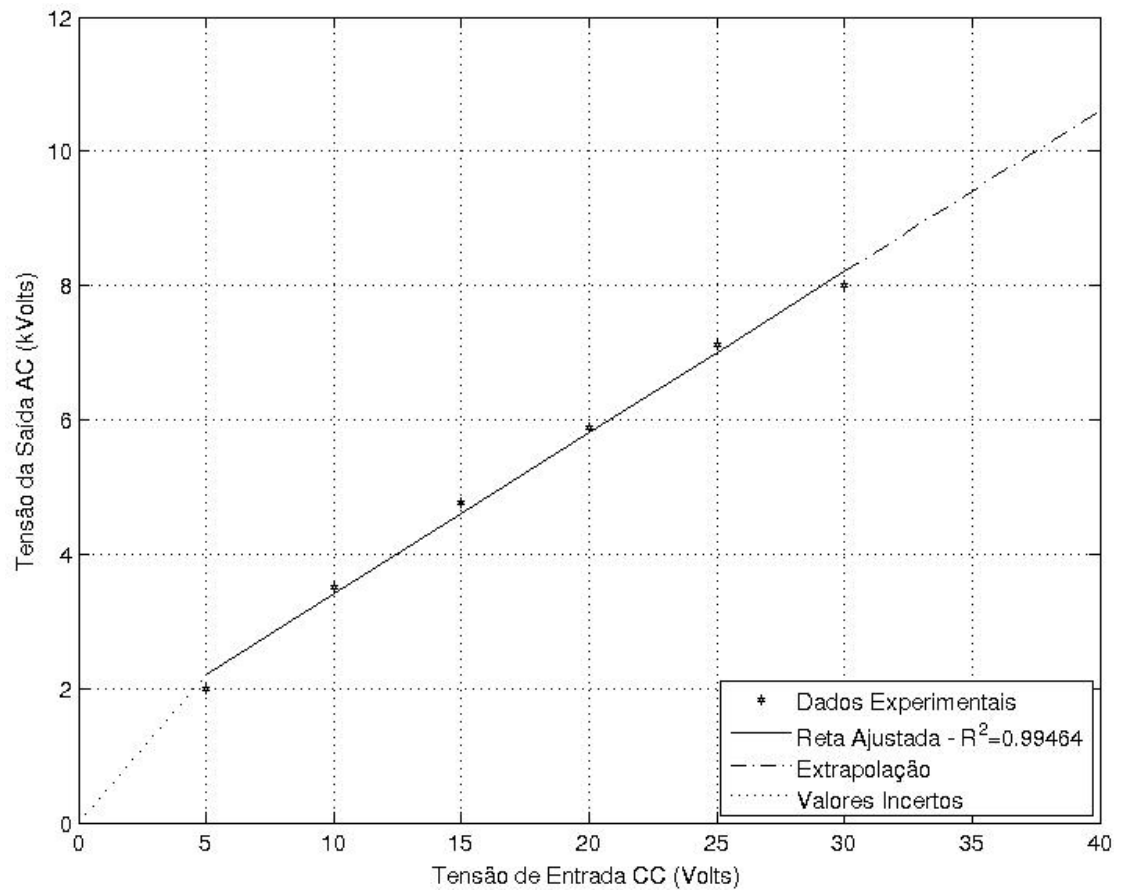

Figura A.18 - Relação entre a tensão da fonte C.C a a tensão no eletrodo externo. 


\section{Apêndice B}

\section{Sonda de Alta Tensão}

\section{B.1 Introdução}

A medição de altas tensões é um objetivo de apreciável dificuldade com os instrumentos normais encontrados em laboratório. No entanto, é, até certo ponto, fácil diminuir a intensidade de determinada fonte de alta tensão para, então, se proceder à sua medição dentro das faixas dos equipamentos padronizados. Por exemplo, um osciloscópio de boa qualidade tem sua faixa de medição limitado a não mais do que 1000 Volts C.C. (ou 750 Volts C.A.). No entanto, é comum a utilização de sondas redutoras de tensão, com fatores de atenuação de tensão da ordem de 1:1000, para a redução da intensidade da tensão em investigação para a adequação com as faixas do instrumento de medição. No entanto, devido as capacitâncias parasitas que existem entre os terminais do componentes da sonda e mesmo com o terra, a aplicação da técnica descrita acima fica limitada para sinais de tensão C.C. Mesmo em baixas frequências, por exemplo a tensão C.A. de 60 $\mathrm{Hz}$ da rede de alimentação normal, não seria possível se obter uma precisa medição da tensão com uma sonda puramente resistiva. Para se contornar este problema, a solução mais prática consiste em se utilizar uma sonda de alta tensão que tanto contenha um divisor resistivo quanto uma etapa divisora capacitiva. Desta forma, deixa-se as baixas frequências (menores do que $10 \mathrm{~Hz}$ ) para o divisor resistivo e para a faixa de frequência acima o sinal é processado de forma correta pelo divisor capacitivo.

Além do especificado acima, a presença de capacitância na impedância interna do instrumento faz com que a tensão medida dependa da frequência. Portanto, a forma de 
onda mostrada na tela do osciloscópio é deformada (no caso de um sinal não senoidal) e imprecisa (ou seja, de amplitude diferente daquela que teríamos se o circuito não estivesse ligado ao osciloscópio). Neste caso também se recomenda a utilização de uma ponta de prova (sonda) que consiste de um cabo de 1 a 2 metros com um resistor de precisão e um capacitor variável em paralelo com o resistor. Ajustando o valor do capacitor podese conseguir que a forma de onda no osciloscópio seja pouco distorcida. Geralmente, os osciloscópios têm um gerador interno para calibração que consiste de uma onda quadrada de $1 \mathrm{kHz}$ de alta precisão. Para o ajuste, liga-se a ponta de prova na saída do sinal de calibração e varia-se o capacitor até que a forma de onda observada seja quadrada. Uma ponta de prova ajustada deste modo é chamada uma ponta compensada. Se a ponta de prova não está devidamente ajustada, a onda quadrada aparecerá deformada.

Desta forma, é de vital importância que a sonda a ser utilizada nas medições de altas tensões em altas frequências deve atender os requisitos de manutenção dos valores de tensão e do contorno de onda do sinal. Assim, este trabalho utilizou uma sonda de alta tensão projetada e construída exclusivamente para medir a tensão de alimentação dos dispositivos eletro-hidrodinâmicos estudados. Dois fatores foram levados em conta para o projeto deste dispositivos: a elevada tensão de alimentação ( $>3 \mathrm{kVolts}$ ) e frequências do sinal na faixa de $1 \mathrm{kHz}$ à $10 \mathrm{kHz}$. Outro fator delimitante foi que o objetivo principal seria a utilização da sonda em conjunto com um osciloscópio. Por conta disto, as resistência e capacitância do equipamento de medição também foi levado em conta no projeto da sonda de alta tensão.

\section{B.2 Projeto e Construção}

Para que um sinal de alta tensão de alta frequência seja medido é necessário, então, a utilização de uma sonda que contenha um divisor de tensão resistivo, para lidar com o sinal C.C. e de baixa frequência e um divisor capacitivo para as faixas de tensão de frequência elevada. Desta forma, o dispositivo que se pretende é o de um divisor RC (resistivocapacitivo) efetivo. A Figura B.1 apresenta um esquema genérico deste dispositivo. 


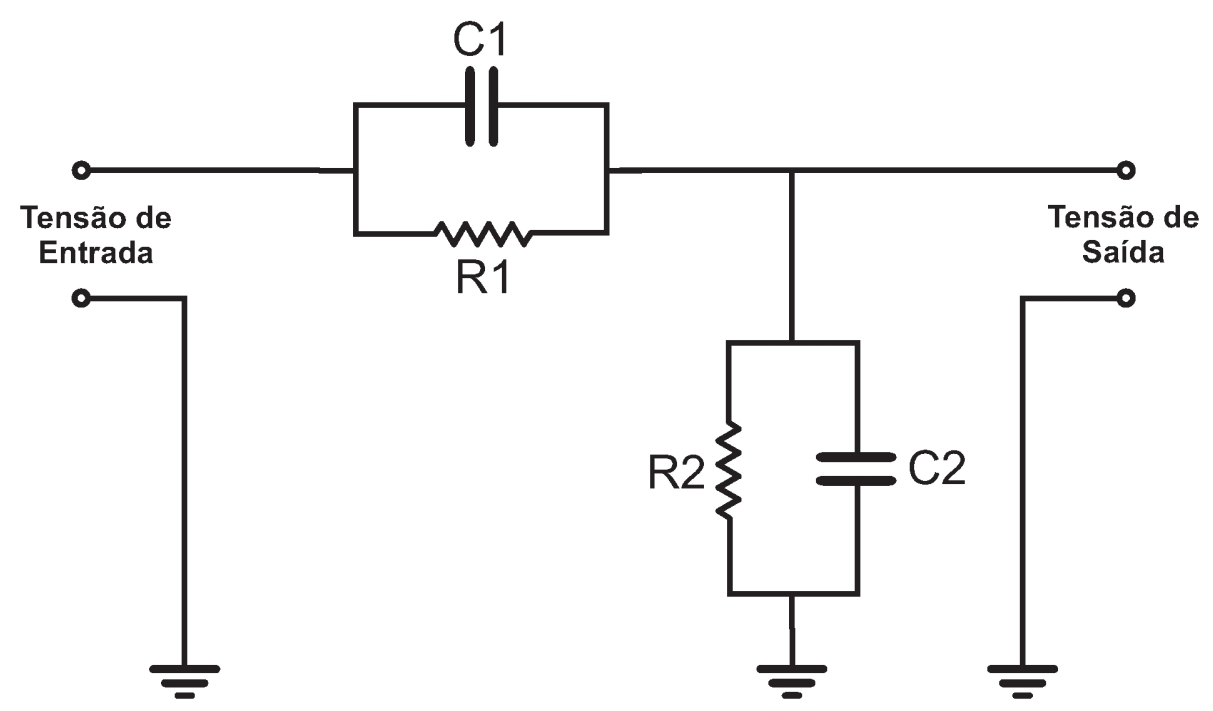

Figura B.1 - Esquema Elétrico de um Divisor de Tensão RC.

$$
\frac{V_{o}}{V_{e}}=\frac{Z_{1}}{Z_{2}+Z_{1}}=\frac{R_{2}}{R_{2}+R_{1} \frac{1+S C_{2} R_{2}}{1+S C_{1} R_{1}}}
$$

Onde:

$$
S=i 2 \pi \omega
$$

Tabela B.1 - Especificações do Resistor de Alta Tensão.

\begin{tabular}{ll}
\hline Modelo & HVR37 \\
\hline Resistência & $20 \mathrm{M} \Omega$ \\
Tolerância & $5 \%$ \\
Tensão Limite & $3500 \mathrm{~V}$ (C.C.) \\
& $2500 \mathrm{~V}$ (C.A.) \\
\hline
\end{tabular}

Tabela B.2 - Especificações do Capacitor de Alta Tensão.

\begin{tabular}{ll}
\hline Modelo & DE0910B221K6K \\
\hline Capacitância & $220 \mathrm{pF}$ \\
Tolerância & $10 \%$ \\
Tensão Limite & $6000 \mathrm{~V}($ C.C. $)$ \\
& $6000 \mathrm{~V}_{p p}$ (C.A.) \\
\hline
\end{tabular}




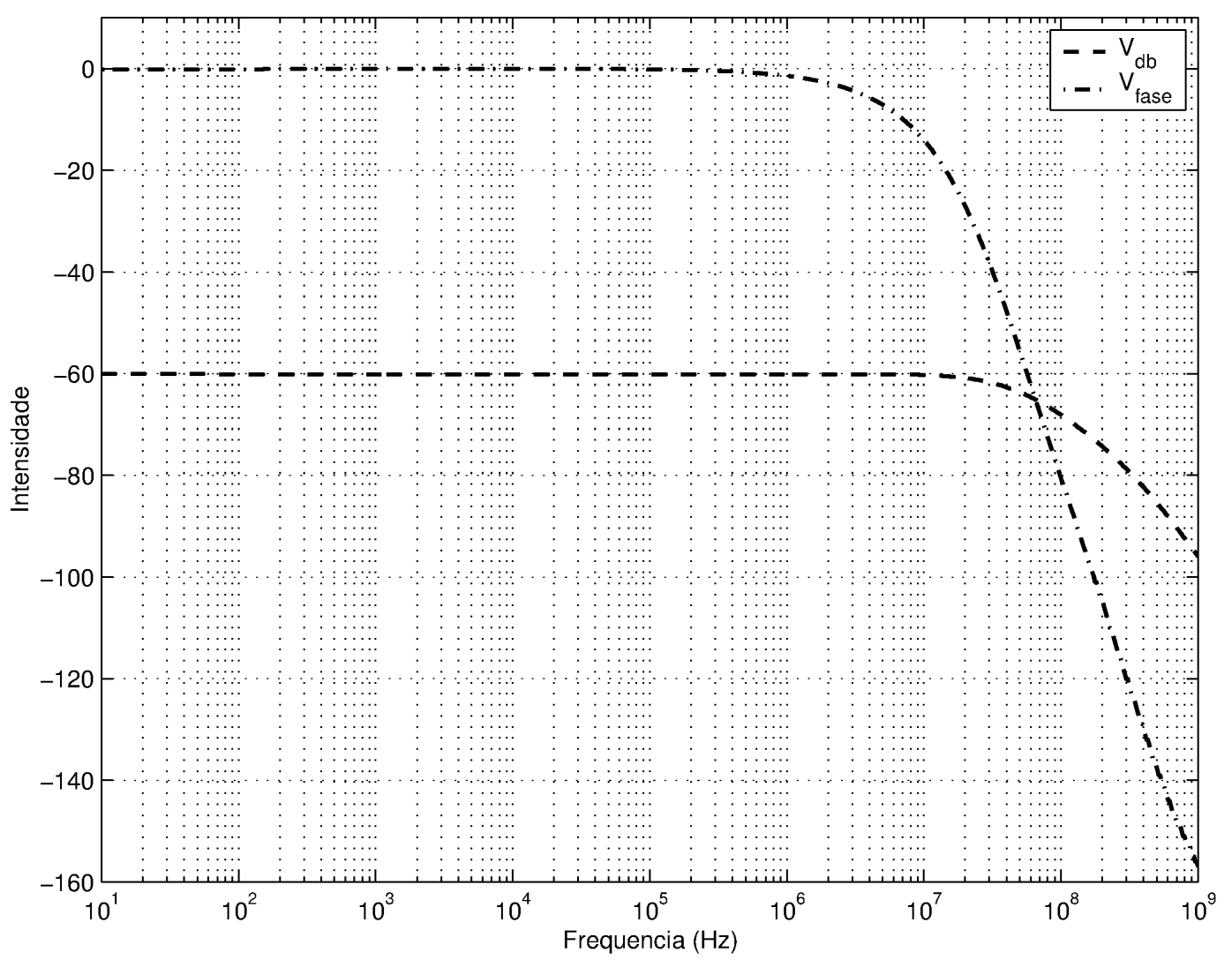

Figura B.2 - Resposta em frequência da sonda de alta tensão.

\section{B.3 Construção}

O circuito apresentado na Figura (B.11) foi divido em dois para a construção da sonda. Desta forma, foram confeccionadas duas placas de circuito impresso em fenolite com as trilhas de cobre sendo produzidas pela corrasão das placas em uma solução de percloreto de ferro. Uma placa consistiu no circuito que contém os capacitores e resistores de alta tensão. Em seu desenho foi levado em consideração uma separação mínima das trilhas sujeitas à altas tensões para que não ocorresse o aparecimento de arco elétrico. Esta ocorrência danificaria os componentes e comprometeria a medição da tensão. A Figura B.3 apresenta a máscara utilizada para a confecção da placa de circuito impresso desta etapa do circuito.

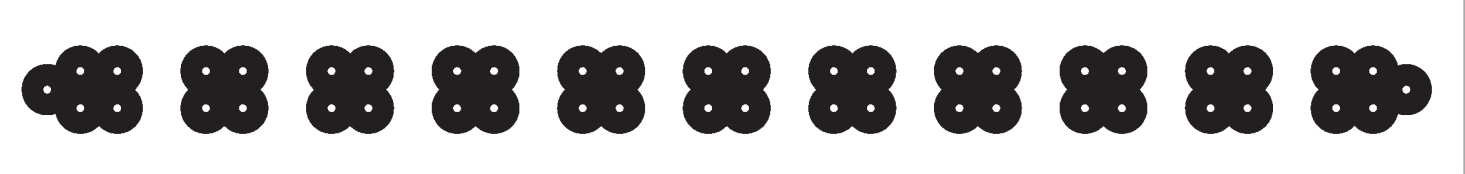

Figura B.3 - Esquema Elétrico da Sonda. 
A outra placa que compõe a sonda de alta tensão consiste na etapa de baixa tensão do divisor capacitivo-resistivo. Esta placa também foi confeccionada em uma placa de fenolite, utilizado o mesmo procedimento apresentado acima. Como nesta etapa não lida com altas tensões, o desenho das trilhas não foi crítico. Desta forma tem-se um projeto de placa de circuito impresso mais clássico. A Figura B.4 apresenta a mascara utilizada para a confecção desta placa.

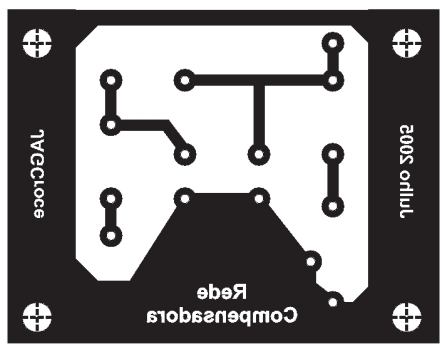

Figura B.4 - Esquema Elétrico da Sonda.

As placas foram montadas dentro de uma caixa de alumínio onde os conectores de entrada e saída foram fixados.

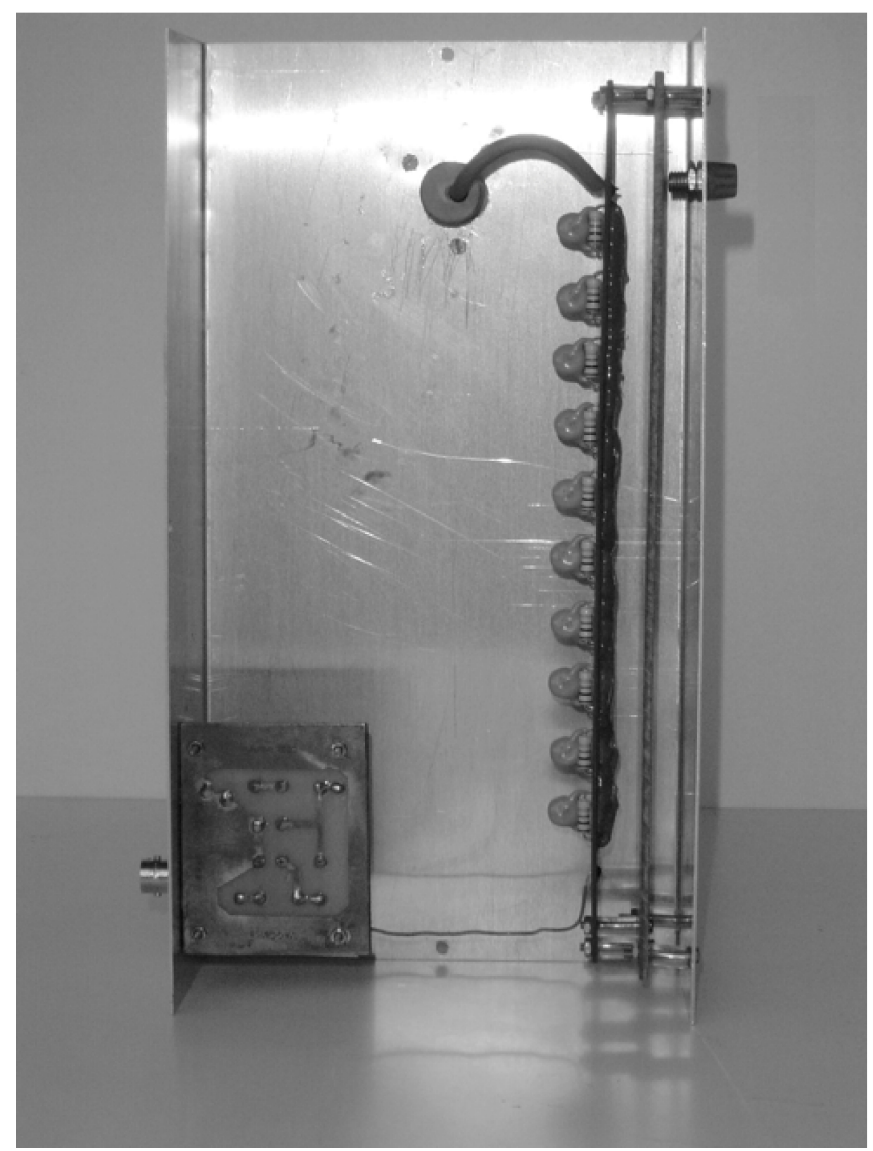

Figura B.5 - Esquema Elétrico da Sonda. 

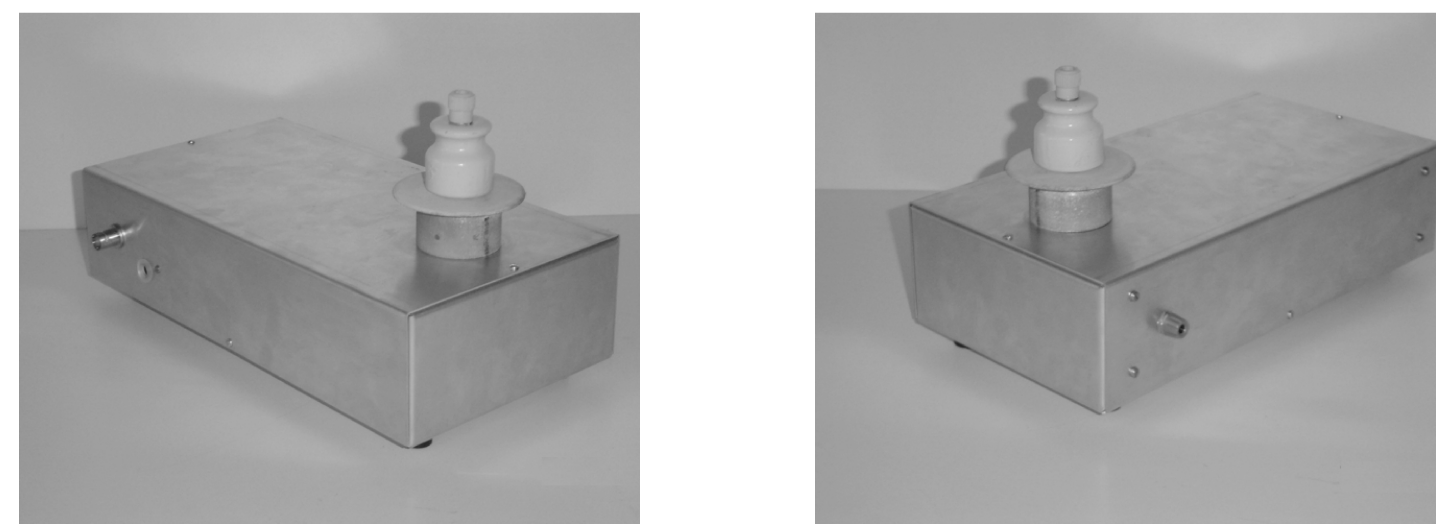

Figura B.6 - Sonda de alta tensão.

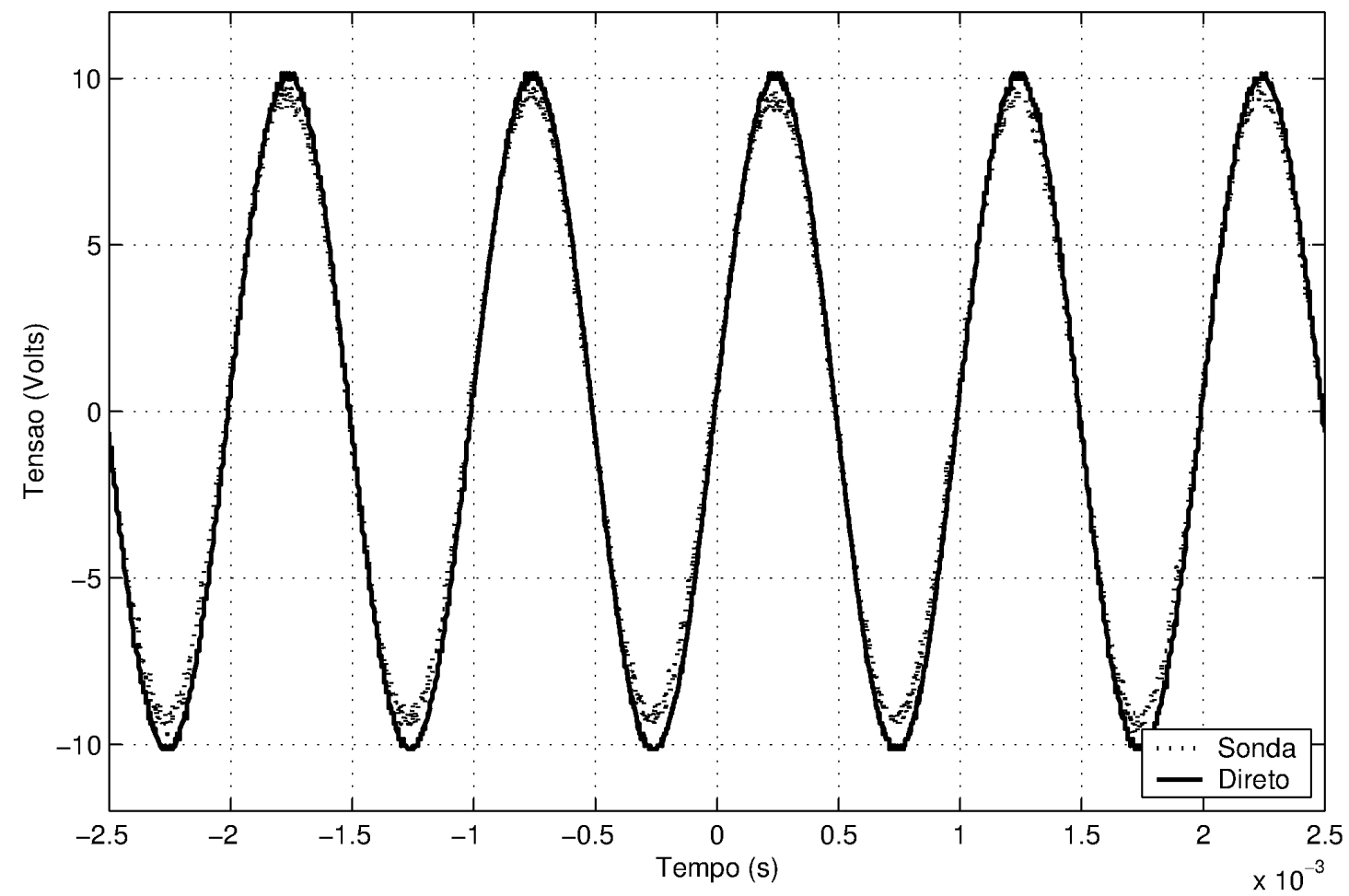

Figura B.7 - Sinal senoidal 1kHz medido pela sonda e diretamente pelo osciloscópio. 


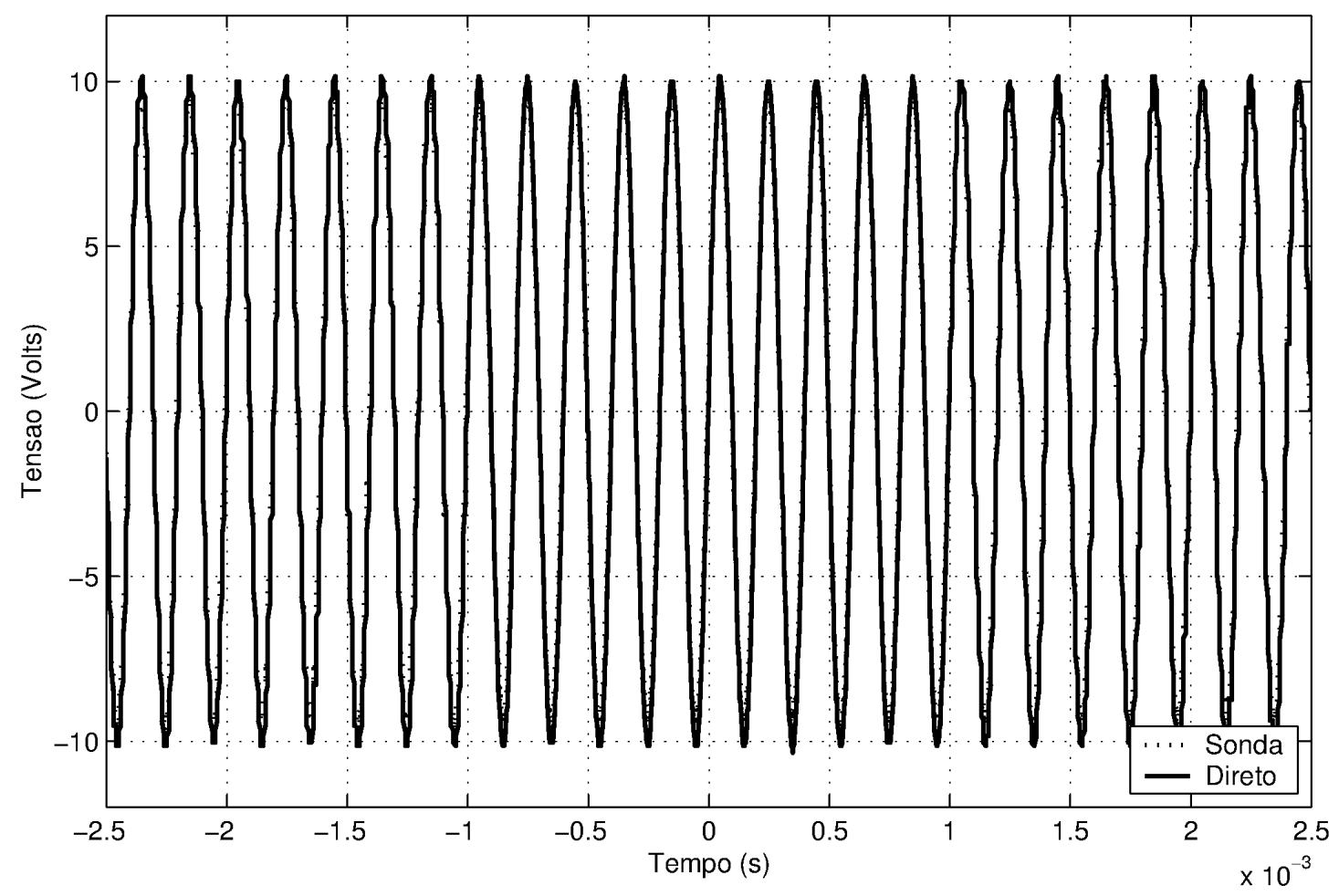

Figura B.8 - Sinal senoidal de 5kHz medido pela sonda e diretamente pelo osciloscópio.

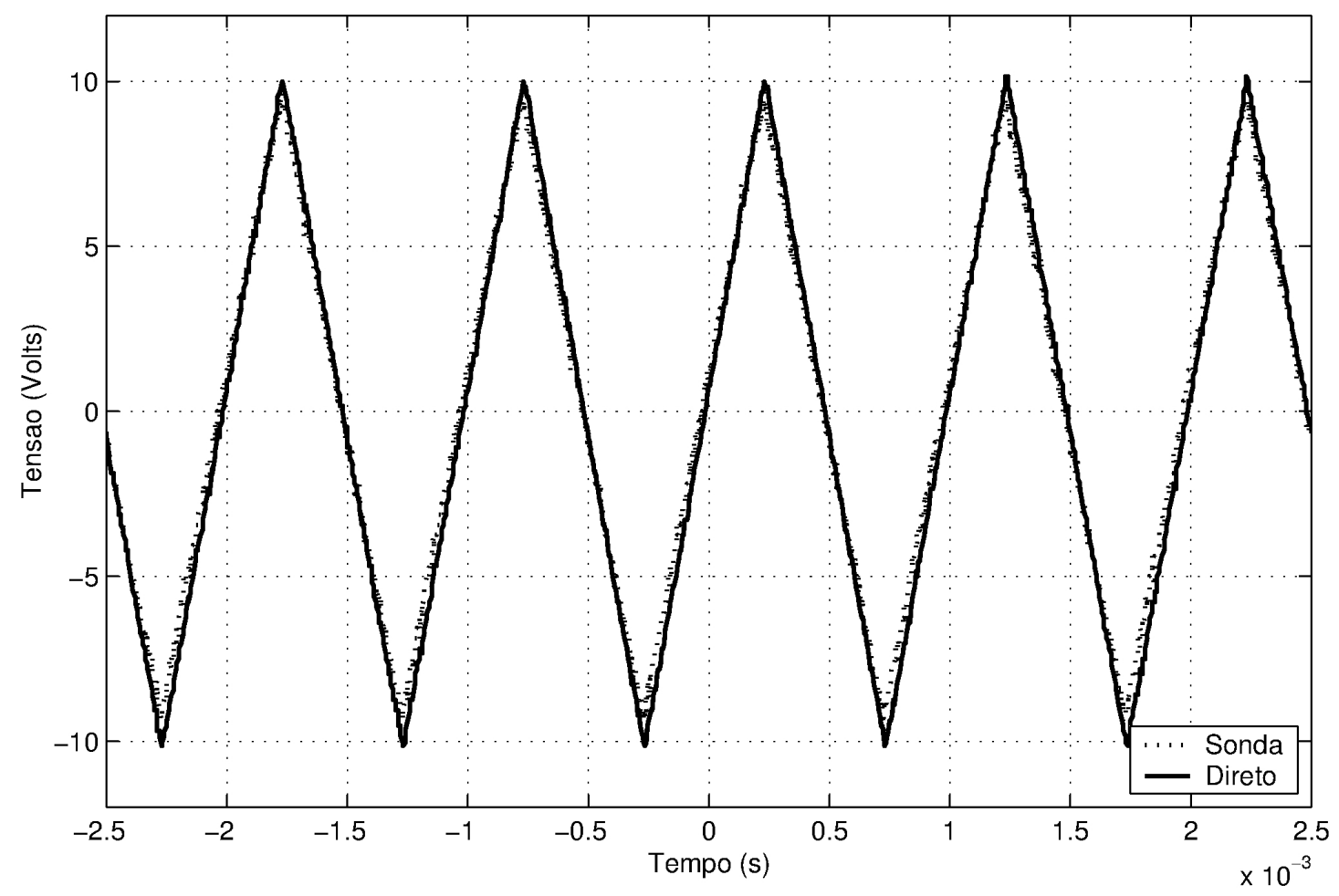

Figura B.9 - Sinal triangular 1kHz medido pela sonda e diretamente pelo osciloscópio. 


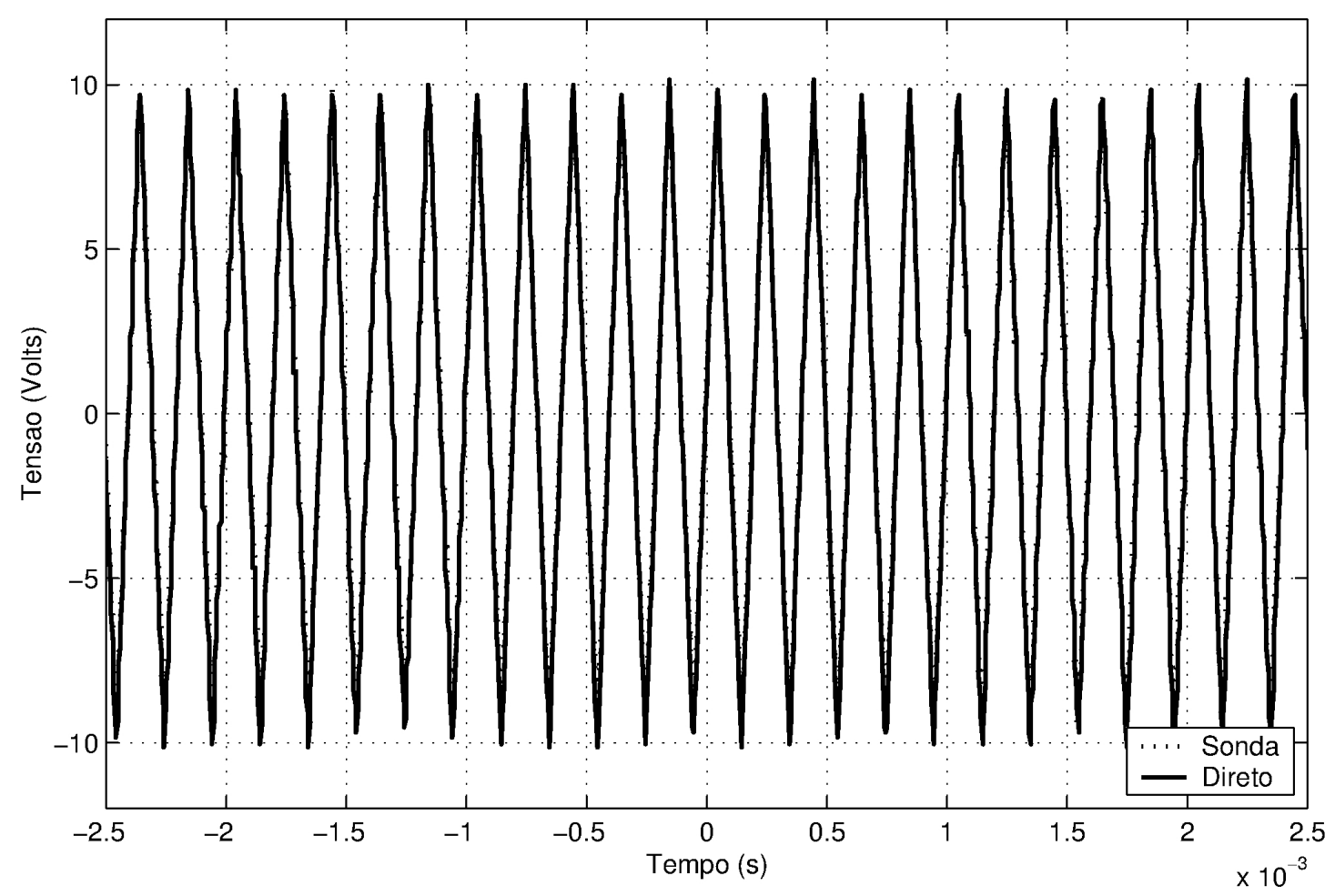

Figura B.10 - Sinal triangular de 5kHz medido pela sonda e diretamente pelo osciloscópio. 


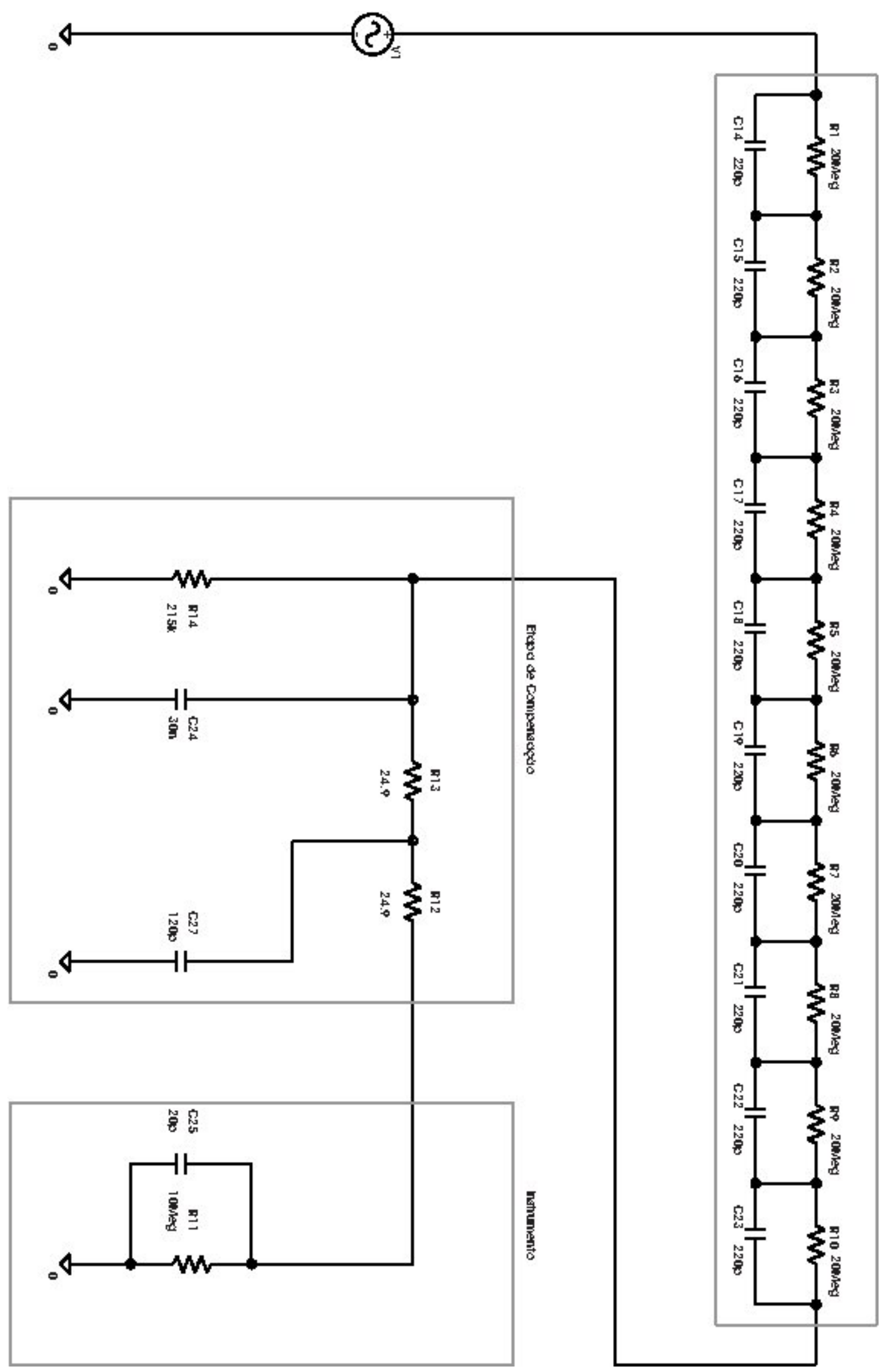

Figura B.11 - Esquema Elétrico da Sonda para Simulação. 


\section{Apêndice $\mathrm{C}$}

\section{Medição da Corrente de Alimentação}

A medição da corrente de alimentação dos dispositivos eletro-hidrodinâmicos do tipo barreira dielétrica apresentam um desafio significativo. Estes dispositivos devem ser obrigatoriamente alimentados por elevadas tensões de corrente alternada para serem eficientes na produção de escoamentos. Dois métodos podem ser citados. O primeiro e mais simples consiste em medir a queda de tensão ao longo de um resistor conetado entre o eletrodo que será aterrado e o nível terra. Este tipo medição é muito utilizada, pois oferece uma facilidade muito grande para sua implementação. Entretanto, consiste em um método invasivo e, provavelmente, sujeito a sofrer influências do sistema, além de não oferecer uma precisão alta.

Uma forma de medição da corrente fornecida aos eletrodos consiste na utilização de um transformador de corrente. Desta forma, foi utilizado um transformador de corrente do modelo TA 12-100. Este componente tem a característica de medir a corrente induzida ao longo de um fio condutor e fornecer uma saída em tensão proporcional a corrente medida. Ou seja, é um componente que mede de forma não invasiva a corrente que flui por um condutor. Isto é extremamente adequado para a medição de correntes que fluem por condutores submetidos a elevadas tensões. Suas principais características são: faixa de corrente de entrada de 0 a 5 A, razão de 1000:1 na tensão proporcional de saída, 0,3\% de precisão e capacidade de medir corrente por 1 minuto quando o condutor está submetido a uma tensão de corrente alternada de 6,0 kVolts. A Figura C.1 apresenta uma foto deste componente enquanto a Figura C.2 apresenta as dimensões e o esquema elétrico deste componente. 


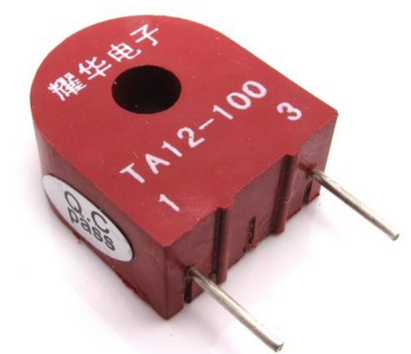

Figura C.1 - Imagem do transformador de corrente modelo TA12-100.

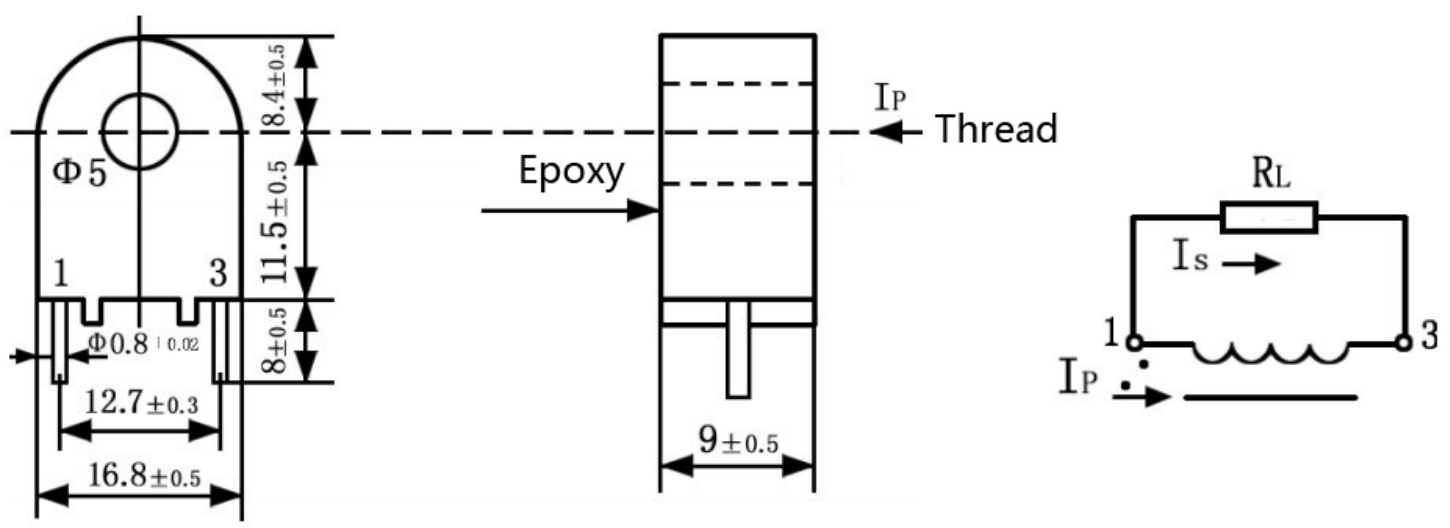

Front view

Side view

Figura C.2 - Esquema do transformador de corrente modelo TA12-100.

Para a medição da corrente, o transformador de corrente foi montado na saída do cabo de alimentação que saia do transformador de alta tensão e alimentava o eletrodo externo. Seus terminais elétricos foram conectados a um dos canais de medição de um osciloscópio digital. Os dados de corrente, medidos em tensão proporcional, eram lidos e armazenados pelo osciloscópio. A Figura C.3 apresenta o esquema elétrico da medição da corrente e da tensão, indicando ligação do transformador de corrente e da sonda de alta tensão.

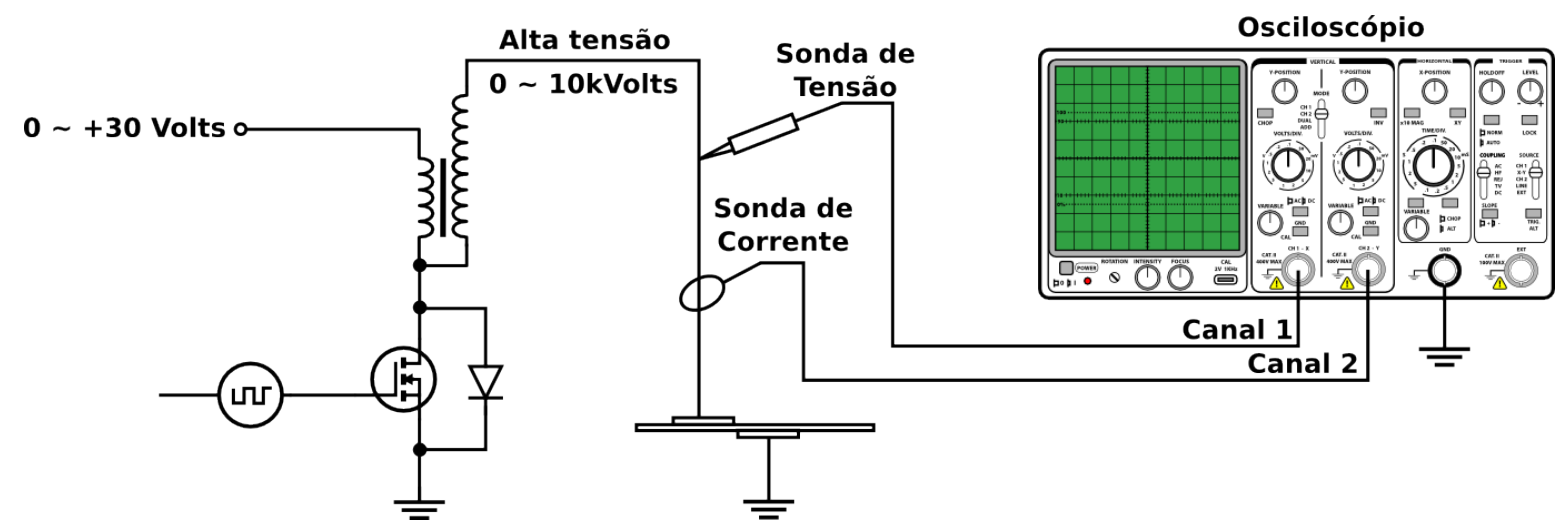

Figura C.3 - Esquema do procedimento de medição da corrente. 
Os valores lidos pelos osciloscópio (ver Figura C.4) foram processados por cálculos em computador para a apresentação adequada dos dados e para a determinação da potência dissipada pelo dispositivo eletro-hidrodinâmico. A potência elétrica que foi consumida por cada configuração foi calculada através da somatória do produto entre a tensão instantânea $\left(U_{i}\right)$ e a corrente instantânea $\left(I_{i}\right)$ e dividindo-se o resultado pelo número total de períodos de tempo $(N)$. A Equação C.1 mostra este procedimento.

$$
P o t=\frac{1}{N} \sum_{i=1}^{N} U_{i} \cdot I_{i} \quad[W]
$$

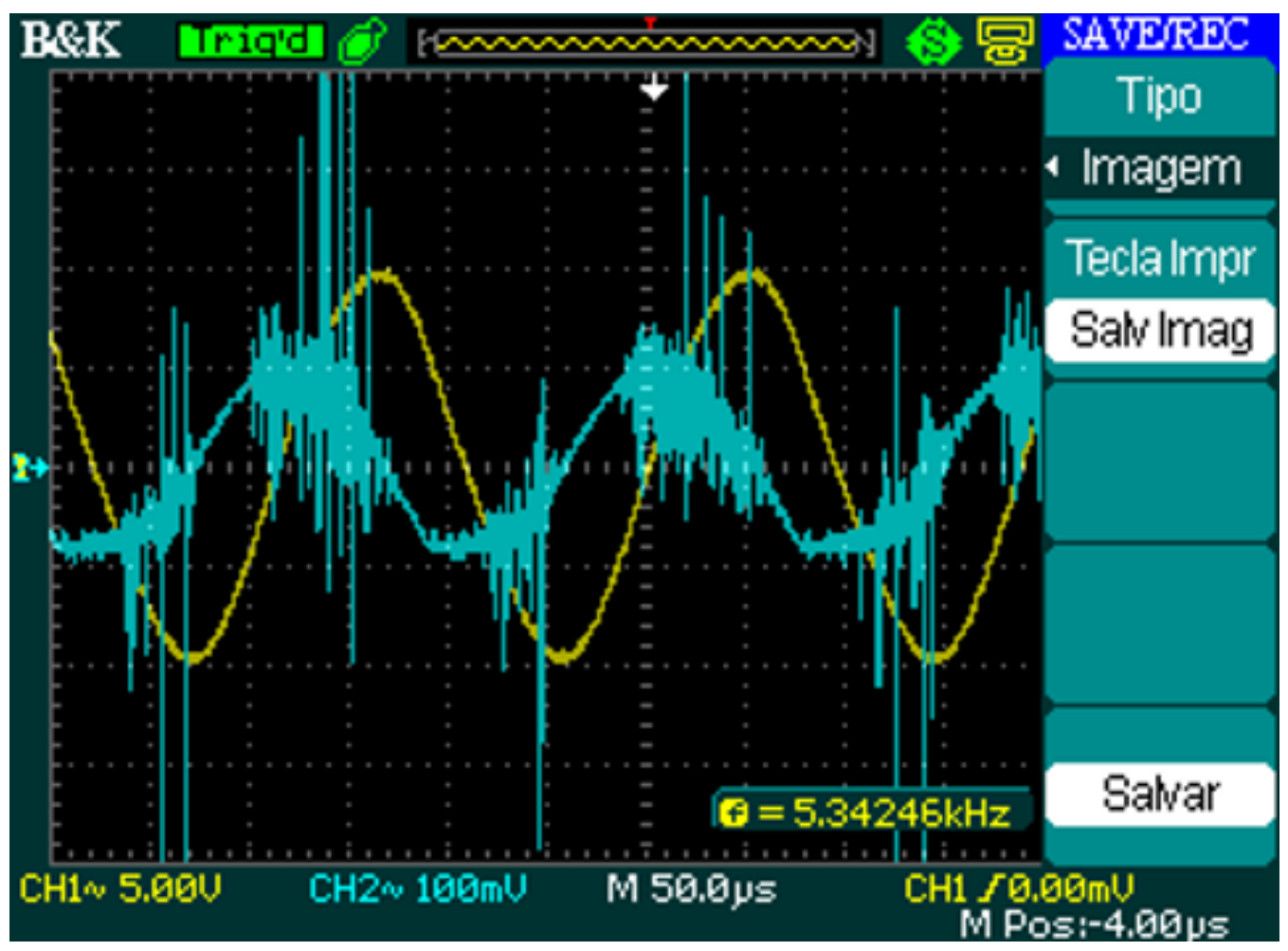

Figura C.4 - Imagem apresentando a tela do osciloscópio antes de salvar os dados.

A Figura C.5 apresenta uma série de dados de corrente e tensão medidos em um ensaio de um dispositivo eletro-hidrodinâmico da configuração serrilhado-plano. Nesta avaliação a tensão de alimentação foi variada de aproximadamente 1,0 kVolt até 8,0 kVolts. 

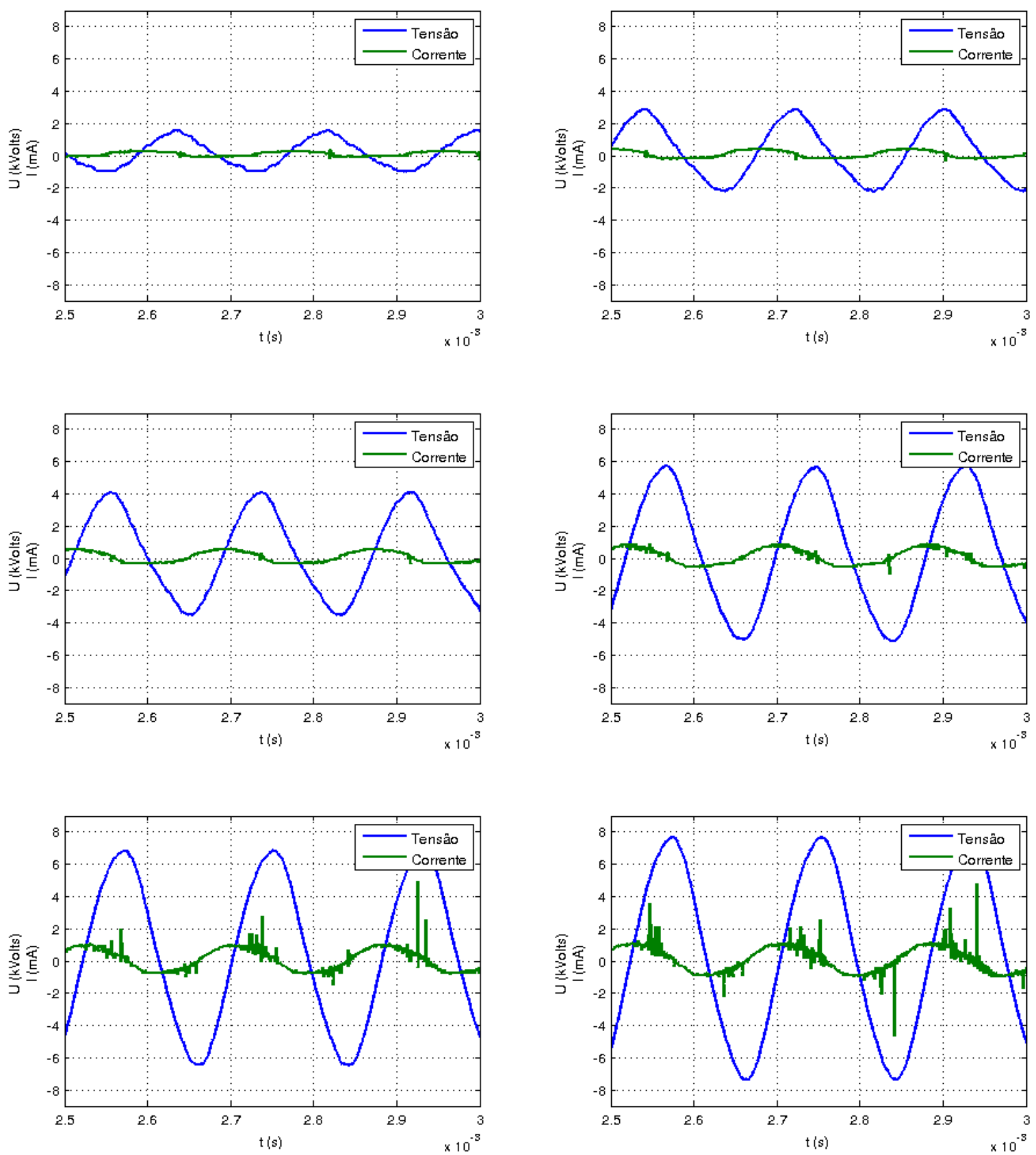

Figura C.5 - Esquema do transformador de corrente modelo TA12-100. 


\section{Apêndice D}

\section{Visualização da Descarga Elétrica}

\section{D.1 Introdução}

Com o objetivo de auxiliar na identificação do comportamento dos jatos induzidos pelas configurações experimentas neste trabalho foi realizado uma avaliação secundária para a aquisição de imagens das descargas elétricas. Isto foi feito, pois a geometria da configuração de eletrodos serrilhado-plano difere muito das outras, que têm bordas lineares em todos os eletrodos. Desta forma, identificou-se este comportamento através da visualização da descarga elétrica.

Esta avaliação experimental consistiu na simples aquisição de imagens digitais através de uma câmera CCD. Este câmera teve sua lente objetiva substituída por uma lente do tipo utilizada em máquinas fotográfica. Isto foi feito para se poder aproximar a região de interesse da descarga, sem aproximar a câmera CCD da região da descarga elétrica, onde o campo elétrico é intenso. A sequência de imagens obtidas em todos os levantamento foram processadas digitalmente para a obtenção de imagens médias do comportamento da descarga. A Figura D.1 mostra esquematicamente o experimento realizado. 

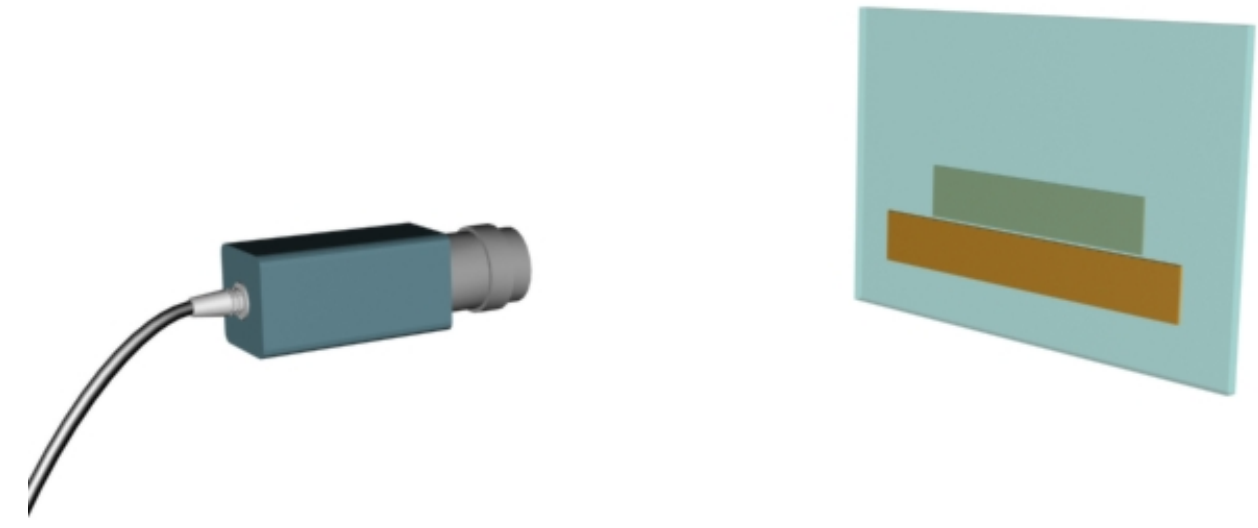

Figura D.1 - Esquema geral do experimento de visualização da descarga elétrica.

Descarga Elètrica do Eletrodo Plano

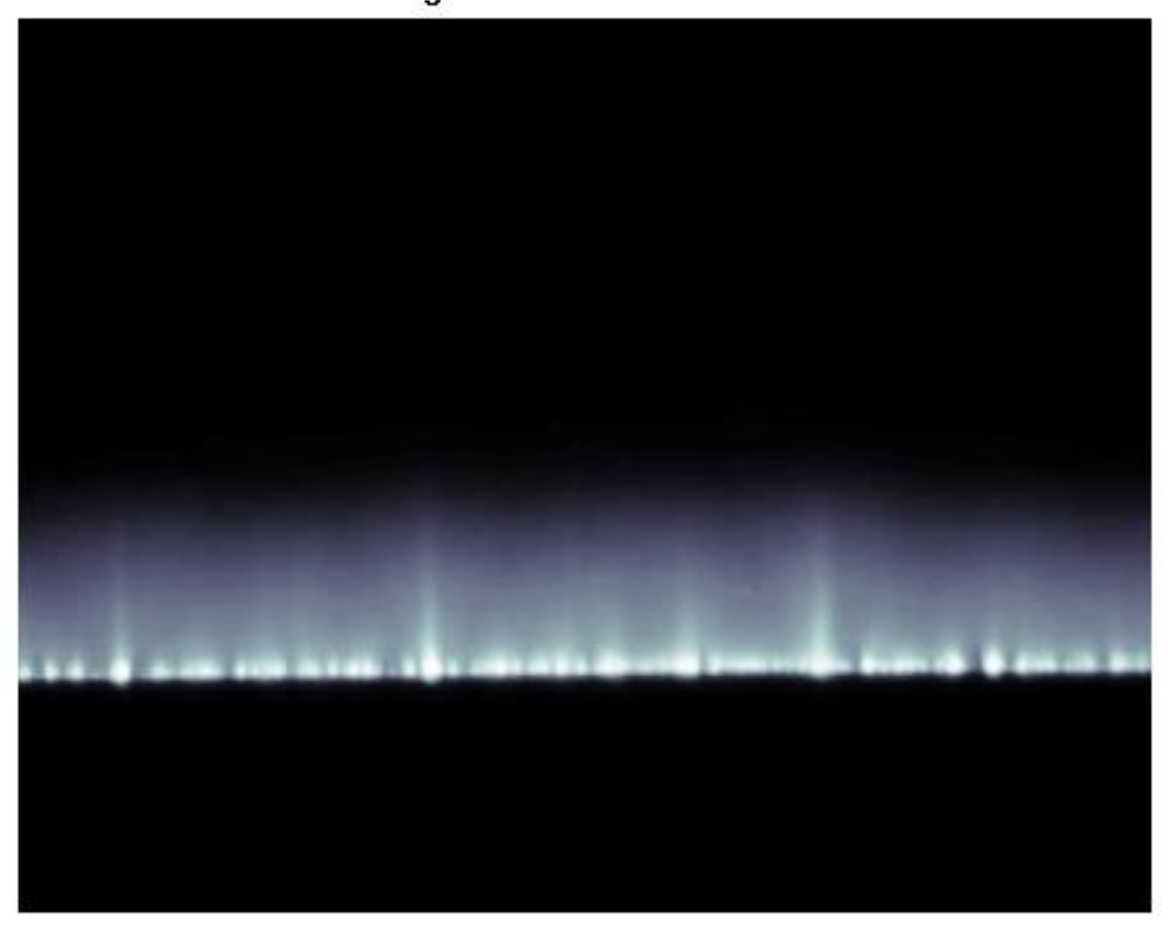

Figura D.2 - Visualização da descarga elétrica da configuração plano-plano. 


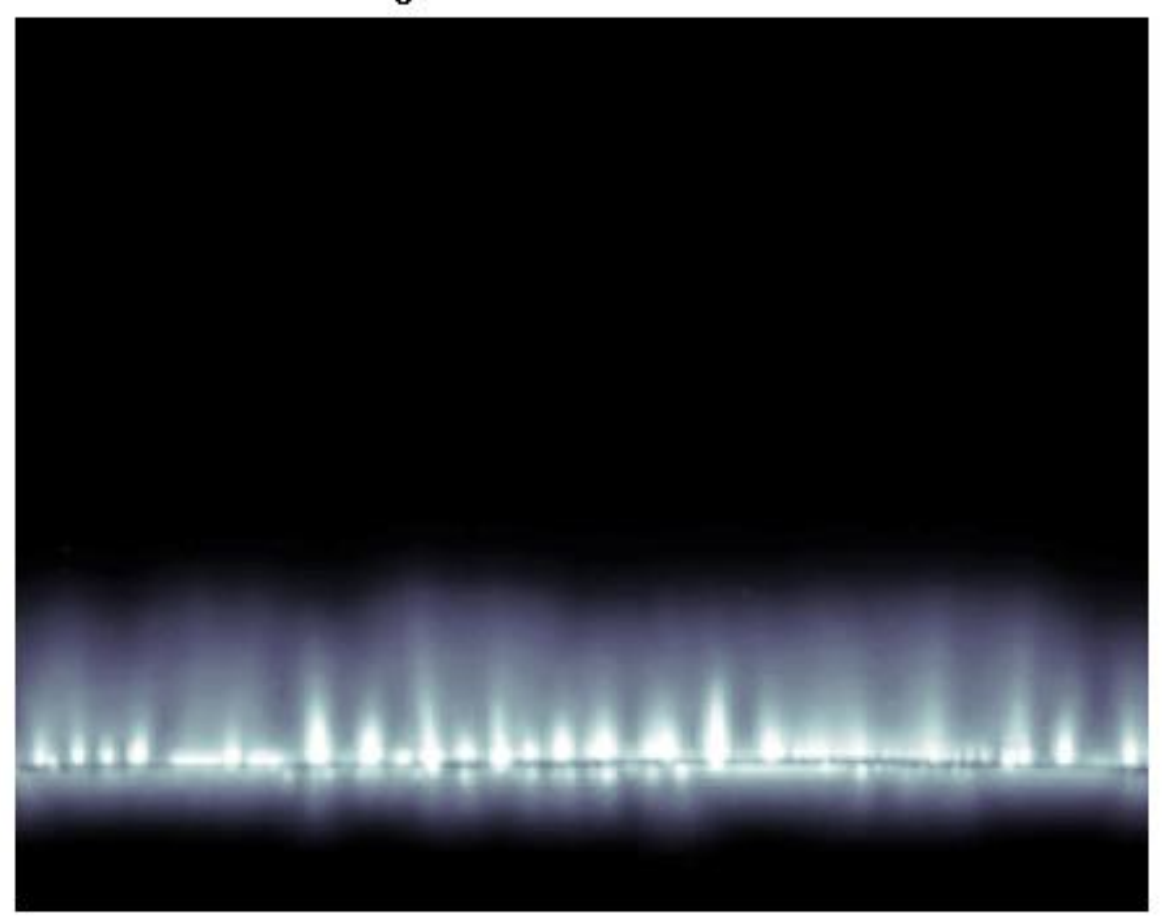

Figura D.3 - Visualização da descarga elétrica da configuração cilíndrico-plano.

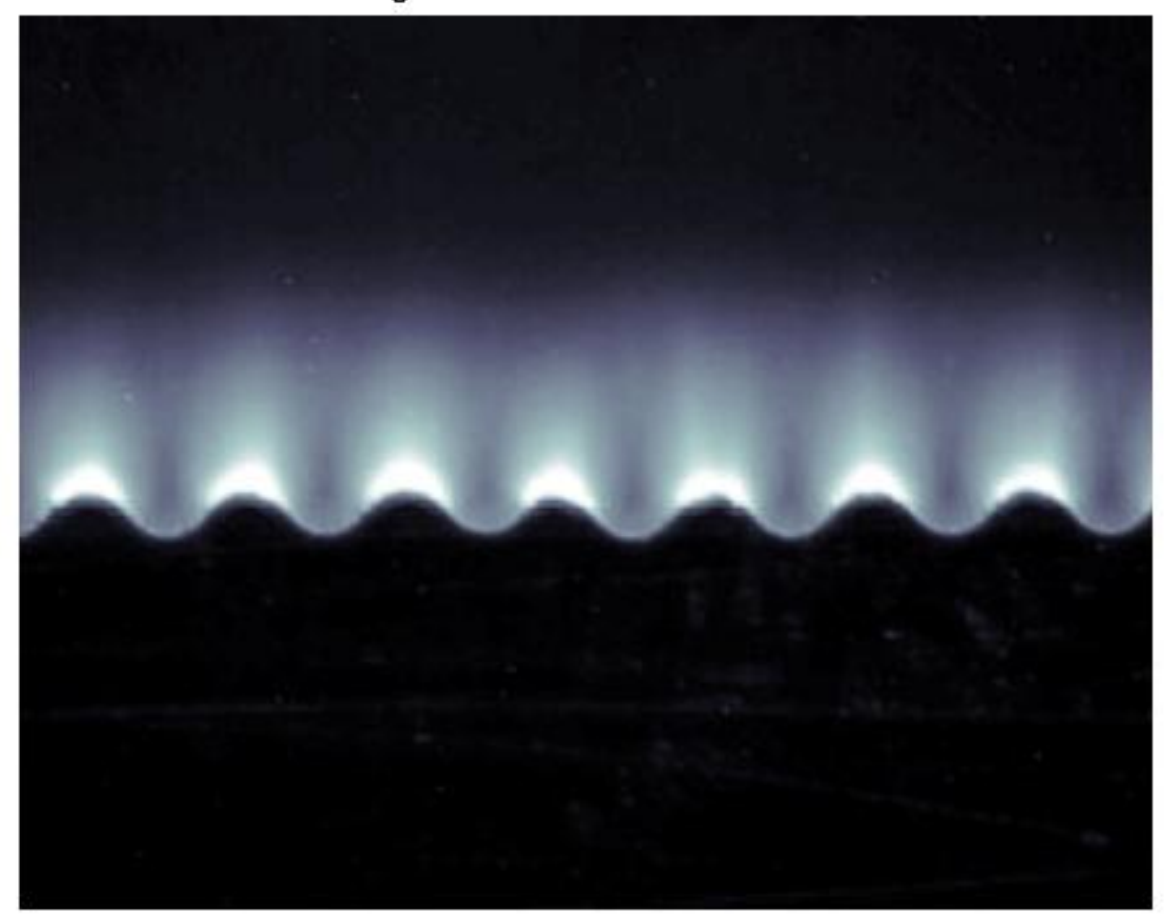

Figura D.4 - Visualização da descarga elétrica da configuração serrilhado-plano. 


\section{Apêndice E}

\section{Magneto-hidrodinâmica}

\section{E.1 Introdução}

Quando se fala de aplicação de forças de campo eletromagnéticos em escoamentos, o primeiro termo que aparece é o efeito Magneto-hidrodinâmico. Esta força de campo é o resultado da aplicação conjunta de um campo magnético ortogonal a um campo elétrico em um fluido condutor ou parcialmente condutor. Como resultado ocorre o surgimento de uma força no conjunto total do fluido, como mostrado na Figura E.1. Métodos magnetoidrodinâmicos foram investigados para aplicações de controle de escoamentos antes dos métodos eletro-hidrodinâmicos.

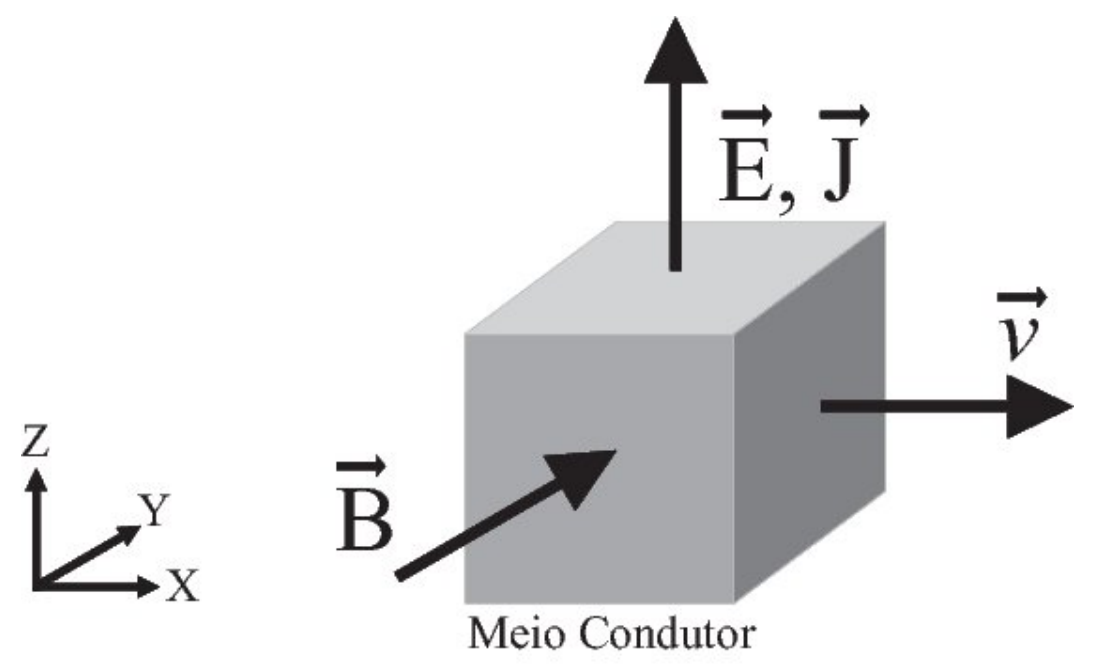

Figura E.1 - Campos Magnéticos e Elétricos aplicados em um Meio Condutor.

De acordo com Sin (2002) a utilização do efeito magnetoidrodinâmico para a redução 
do arrasto de atrito é baseado em se introduzir quantidade de movimento no escoamento por meio da força de campo magnética, ou força de Lorentz, dada por.

$$
\vec{F}=\vec{J} \times \vec{B}
$$

onde,

$$
\vec{J}=e n_{e} \vec{v}
$$

onde, $\vec{v}$ é a velocidade de deslocamento de uma carga positiva, $n_{e}$ é a densidade de elétrons, $B$ é o vetor indução magnética e $J$ é a densidade de corrente no fluido condutor. A transferência de quantidade de movimento da força de campo magnética ao fluido condutor pode ser aumentada aplicando-se altas correntes no fluido condutor e campos magnéticos intensos. Métodos magnetoidrodinâmicos requerem tanto eletrodos robustos, que possam resistir a correntes elétricas intensas, quanto magnetos poderosos para produzirem campos magnéticos intensos. A abordagem magnetoidrodinâmicos não é desejável para aplicações aeronáuticas desde que a fonte de corrente elétrica, bobinas para a produção de campo elétrico e eletrodos não podem ser facilmente instalados na asa de uma aeronave, além do fato que, devido às suas inerentes características técnicas, serem muito pesadas. No entanto, algumas aplicações para a redução de arrasto de atrito na hidrodinâmica estão sendo realizadas mundo a fora. A Figura E.2 apresenta uma proposta de controle de escoamento em hidrofólios por meios magnetoidrodinâmicos estudada por Wier (2000).

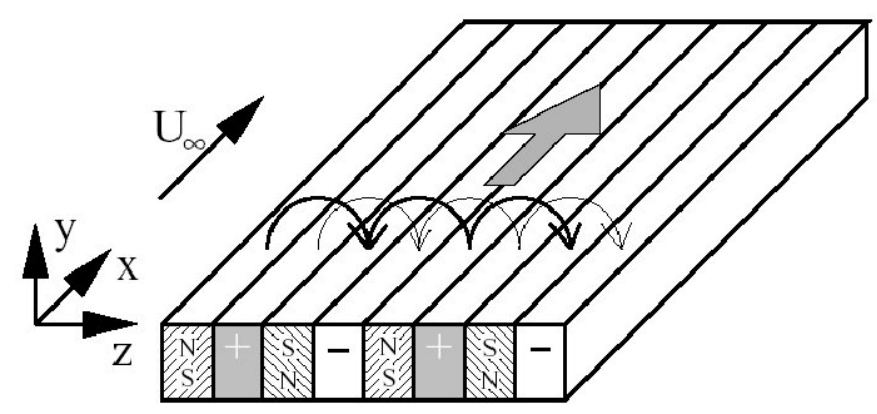

Figura E.2 - Magnetoidrodinâmica no controle de camadas limites (WIER, 2000). 
Nesta configuração um arranjo de magnetos e de eletrodos foram montados longitudinalmente com o sentido do escoamento. Pode-se ver na Figura E.2 que os magnetos de polos norte e sul estão montados alternadamente com os eletrodos positivo e negativo. Esta configuração produz o vetor indução de força de campo de Lorentz de forma normal ao plano de atuação dos dois campos. Resultados de visualização do escoamento em túnel de água realizados com esta configuração por Wier (2000) apresentaram uma grande alteração no campo de escoamento ao redor de uma placa plana para vários ângulos de ataque. A Figura E.3 apresenta a comparação entre duas situações extremas de aplicação da força magnetoidrodinâmica, ou seja, sem a aplicação da força e em sua intensidade máxima obtida nos experimentos.
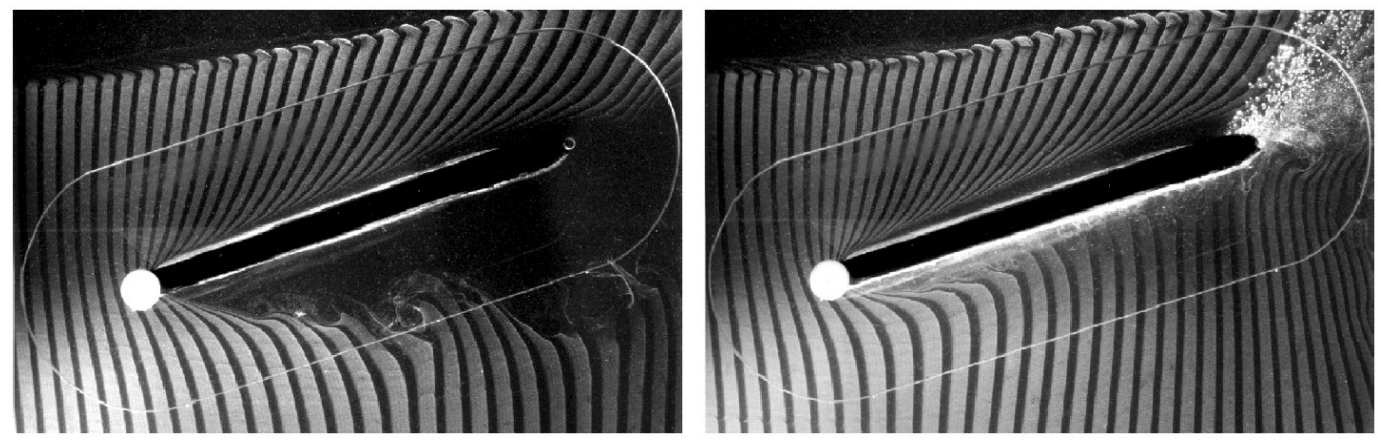

Figura E.3 - Controle de Escoamentos por Meios Magnetoidrodinâmicos (WIER, 2000).

O fato de ser o primeiro item associado com forças de campo em fluidos é que o uso do efeito magnetoidrodinâmico em escoamentos recebeu muita atenção nas últimas cinco décadas do século XX. Conceitos como escoamentos ionizados ao redor de veículos hipersônicos foram já bastante estudadas. Muita ênfase também foi dada na utilização das forças magnetoidrodinâmicas na hidrodinâmica devido à natureza de condução elétrica da água do Mar. Mais recentemente o uso do efeito magnetoidrodinâmico em aplicações aerodinâmicas e de valores baixos ou médios de número de Reynolds vem aos poucos sendo investigados. O uso de forças magnetoidrodinâmicas para o controle do arrasto turbulento viscoso em camadas limites pode ser dado como exemplo. No entanto, como citado por Roth, Sherman e Wilkinson (1998), em termos de gasto de energia, a performance desta aplicação é duvidosa.

Uma alternativa para o uso do efeito magnetoidrodinâmico e seguindo basicamente os mesmos princípios dados pela relação de Lorentz, é o uso de campos elétricos apenas. Quando aplicados em um fluido ionizado, ou parcialmente ionizados, geram o apareci- 
mento de uma força nas partículas carregadas. Sendo o fluido em questão parcialmente ionizado, ocorre a transferência de quantidade de movimento das partículas carregadas para as neutras devido a choques entre elas. Isto resulta na ocorrência de um efeito na região interna ao campo que acarreta a imposição de um movimento, na direção de aplicação do campo, de todo o fluido. Este efeito é conhecido como força de campo eletro-hidrodinâmica. A maior parte do estudo desta força está concentrado em escoamentos hipersônicos ou de fluidos em estado de plasma completo. No entanto, dada as suas características, vem aparecendo uma série de propostas de sua utilização no controle, ou manipulação, de escoamentos parcialmente ionizados e de valores baixo ou médios de número de Reynolds $\left(10>\operatorname{Rey}<10^{6}\right)$. Uma de suas características mais interessantes é que a força eletrostática em uma partícula pode ser significantemente maior do que a força magnética na mesma partícula para valores praticáveis de intensidade de campo elétrico ou magnético. Segundo Roth, Sherman e Wilkinson (1998) o maior valor de campo magnético praticável com ímãs permanentes, em aplicações que não obstruem o escoamento principal, é estimado em não mais do que $B=0,5$ Tesla. Enquanto altos valores de intensidade de campo podem ser obtidos com o uso de eletroímãs, a dissipação pele efeito Joule nos condutores, basicamente o aquecimento dos condutores, comprometeria qualquer aplicação de redução de gasto de energia, como a redução de arrasto.

\section{E.2 MHD versus EHD}

O controle eletro-hidrodinâmico de escoamentos para aplicação na aerodinâmica tem recebido muito menos atenção do que aplicações magnetoidrodinâmicas pois não se acreditava anteriormente que seria possível se produzir suficiente ionização através de descargas elétricas atmosféricas com campos elétricos apenas. No entanto, durante a última década do século XIX, vários pesquisadores desenvolveram várias técnicas para a produção de descargas brilhantes à uma atmosfera com campos elétricos somente. Roth, Sherman e Wilkinson (1998) e Roth, Sherman e Wilkinson (2000), é citado como sendo um dos que mais desenvolveram estas técnicas, principalmente o que foi por ele desenvolvido no Laboratório de Ciências de Plasma na Universidade do Tennessee, denominado de Plasma por Descarga Brilhante Uniforme a Uma Atmosfera (One Atmosphere Uniform Glow Dis- 
charge Plasma).

Uma das formas de melhor mostrar a diferença entre estas duas forças de campo é a mostrar como elas produzem movimento no fluido. A força magneto-hidrodinâmica é o resultado da interação de um campo magnético com um campo elétrico, sendo o vetor indução de força mecânica formado ortogonalmente ao plano gerado pelas duas forças de campo. Já a força eletro-hidrodinâmica age de forma mais direta no fluido. Depois de ionizado o fluido segue as linhas de campo elétrico entre os eletrodos, preferencialmente no sentido do eletrodo positivo ao negativo devido à menor mobilidade das cargas elétricas positivas.

Para efeito de comparação, a força de campo exercida em partículas individuais pode ser tomada como elemento de balizamento entre as duas forças. No caso da força produzida pela presença de um campo elétrico em uma carga elétrica apenas, pode-se escrever,

$$
\vec{F}_{E}=q \vec{E}
$$

onde, $q$ é o valor da carga da carga elétrica e $\vec{E}$ é o campo elétrico. Para o caso de um campo magnético exercendo uma força em uma partícula carregada que se move com uma velocidade de deslocamento, tem-se,

$$
\vec{F}_{M}=q\left(\vec{v}_{d} \times \vec{B}\right)=q \vec{v}_{d} \vec{B}
$$

onde, $v_{d}$ é a velocidade de deslocamento da carga e $B$ é o vetor indução magnética. A razão entre estas duas forças pode ser obtida diretamente através da divisão entre as duas, o que leva à,

$$
R=\frac{\vec{F}_{E}}{\vec{F}_{M}}=\frac{\vec{E}}{\vec{v}_{d} \vec{B}}
$$

Para aplicações aerodinâmicas, onde são considerados dispositivos montados sobre superfícies, pode-se admitir para o campo elétrico um valor razoável de aproximadamente 
$10^{6} \mathrm{Volts} / \mathrm{m}$ enquanto que para campos magnéticos, produzidos por ímãs permanentes embutidos em superfícies, um valor de aproximadamente 0,5 Tesla. Considerando-se aplicações de baixo número de Reynolds, pode-se admitir velocidades de escoamentos não maiores do que $20 \mathrm{~m} / \mathrm{s}$. Utilizando esta velocidade como a velocidade de deslocamento encontrada na Equação E.5, pode-se obter uma razão da força de campo elétrica para a força de campo magnético em uma carga elétrica da ordem de,

$$
R=\frac{10^{6}}{20 \cdot 0,5}=100.000
$$

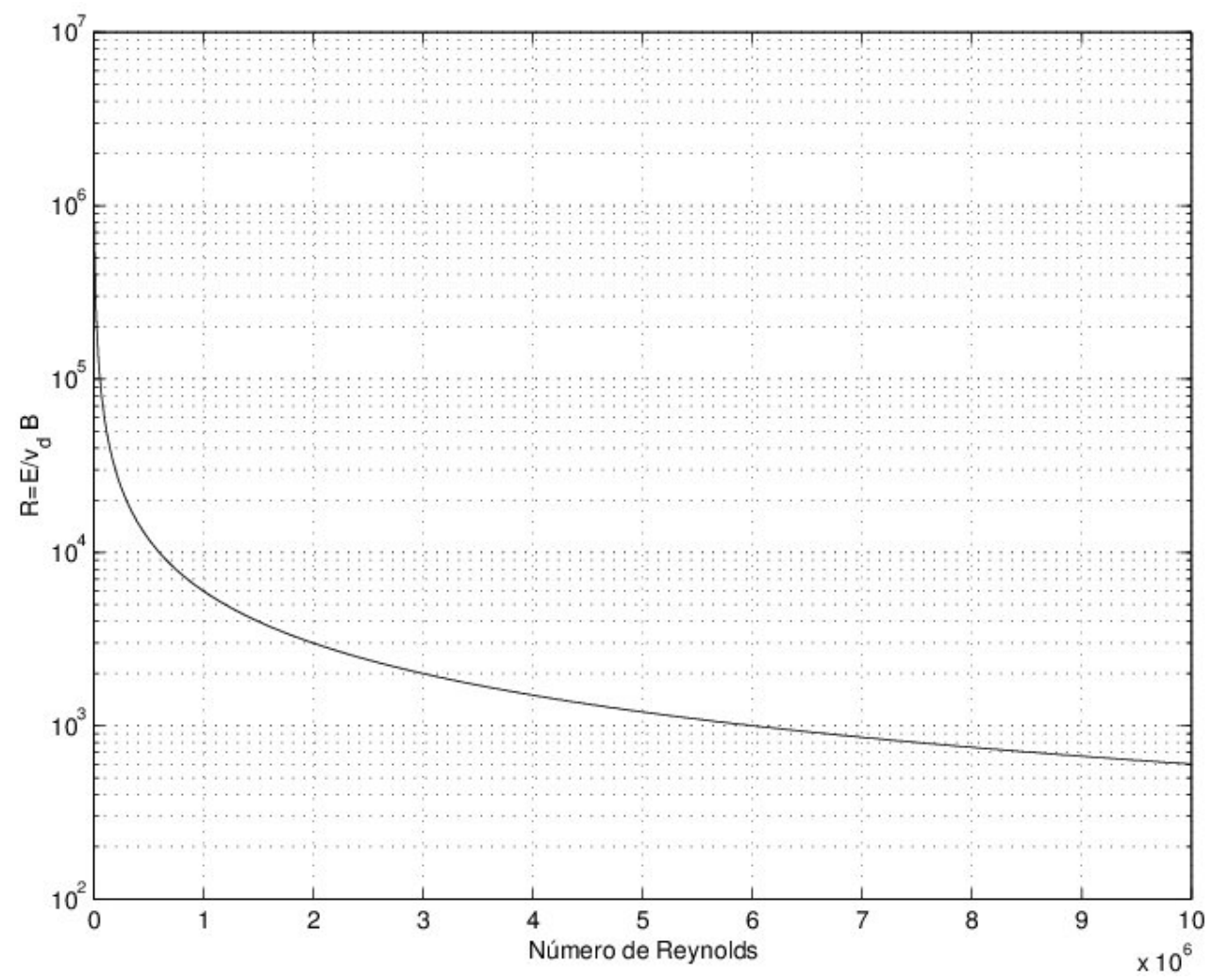

Figura E.4 - Relação entre as forças de campo elétrica e magnéticas.

A Figura E.4 demonstra que a razão entre as forças elétricas para as magnéticas tende a decrescer de forma muito acentuada com o crescimento do número de Reynolds. Isto deve ser levado como mais um ponto favorável para a utilização de forças eletrohidrodinâmicas frente às forças magnetoidrodinâmicas para a manipulação de escoamentos na faixa baixa e média do número de Reynolds. Vale a pena citar o fato de que o efeito magnetoidrodinâmico é muito indicado para a manipulação de escoamentos super ou 
hipersônicos, que estão em velocidades de escoamento muito elevadas e, portanto, em números de Reynolds muito elevados.

Tentativas anteriores de utilizar forças magnetoidrodinâmicas para produzir escoamentos, ou alterar escoamentos já estabelecidos, falharam sistematicamente devido ao fato de que a condutividade elétrica dos gases de interesse aerodinâmicos, como por exemplo o ar atmosférico, não é suficientemente grande. A condutividade elétrica é dada por,

$$
\sigma=\frac{e^{2} n_{e}}{m_{e} \vartheta_{e n}}
$$

A condutividade calculada acima é proporcional à densidade eletrônica, $n_{e}$, que na maioria dos meios ionizados por descargas elétricas atmosféricas é muito baixa para produzir uma condutividade elétrica de magnitude suficiente. Já as forças eletro-hidrodinâmicas utilizam como parâmetro fundamental a densidade de cargas líquidas, $\rho_{c}$, como utilizada na Equação 3.3. Geralmente, é muito mais fácil obter valores adequados desta grandeza para se produzir significantes efeitos eletro-hidrodinâmicos do que valores adequados de densidade eletrônica para produzir efeitos magnetoidrodinâmicos de magnitude utilizável em gases. Nos dispositivos eletro-hidrodinâmicos, densidades eletrônicas de no máximo $10^{16}$ por metro cúbico produzem campos elétricos de alta intensidade, forças de campo eletro-hidrodinâmicas intensas com consequente produção de escoamentos de boas magnitudes.

As vantagens de aplicações eletro-hidrodinâmicas sobre as magnetoidrodinâmicas são sua simplicidade, estrutura robustas dos eletrodos, não necessidade de campos magnéticos e operação em regime permanente. Além disto, um vantagem final do efeito eletrohidrodinâmico consiste no fato de que os campos elétricos requeridos podem ser produzidos com sistemas elétricos simples e utilizando um sistema leve mais robustos de eletrodos. Além de não utilizarem partes móveis, os dispositivos para aplicação de forças eletro-hidrodinâmicas não requerem a introdução de gases ou líquidos condutores, já que produzem o que necessitam com o meio circundante, bem como não produzem resíduos sólidos. 


\section{Apêndice F}

\section{Ionização e Exitação em um Campo Elétrico}

\section{F.1 Lei de Paschen}

Akyuz (2002) cita que F. Paschen, em 1889, publicou um artigo no qual começou o que se tornou conhecido como a Lei de Paschen. Esta lei estabelece essencialmente que as características de ruptura elétrica em uma fenda são função (normalmente não linear) do produto da pressão do gás e largura da fenda, normalmente escrita como $V=f(p d)$, onde $p$ é a pressão e $d$ é a largura da fenda. Atualmente, a pressão pode ser substituída pela densidade do gás.

Para o ar e para fendas da ordem de milímetros, a ruptura elétrica é, a grosso modo, uma função linear da largura da fenda:

$$
V=30 p d+1,35 k \text { Volts }
$$

Muita pesquisa tem sido realizada desde então para prover uma base teórica para esta lei e para desenvolver uma maior compreensão do mecanismo de ruptura elétrica. Algo sobre estas pesquisas será descrito no resto desta seção, mais deve ser percebido que existem muito, muitos fatores que exercem algum efeito na ruptura elétrica em uma fenda, tais como a radiação, poeira, irregularidades superficiais, etc. Excessivas análises teóricas 
pode ajudar a compreensão do motivo que uma fenda rompe eletricamente, mas não necessariamente provê um mais preciso valor da tensão de ruptura em qualquer situação.

A Lei de Paschen reflete o mecanismo de ruptura elétrica de Townsend em gases, ou seja, uma cascata de elétrons secundários emitidos por colisões na fenda. O parâmetro significativo é $p d$, o produto da largura da fenda pela pressão do gás. Tipicamente, o mecanismo de Townsend (e por extensão a Lei de Paschen) aplicam à pd produtos menores do que 1000 Torr mm, ou fendas ao redor de um centímetro à pressão atmosférica. Além disso, algumas modificações são necessárias para gases altamente eletronegativos devido ao fato de que estes recombinam os elétrons secundários de forma mais rápida.

Normalmente, uma equação para a ruptura elétrica é derivada e parâmetros adequados escolhidos para se ajustar aos dados empíricos. Aqui estão três equações:

$$
\text { Tensão de Ruptura } \rightarrow V_{\text {ruptura }}=\frac{B p d}{C+\ln (p d)}
$$

Intensidade de Ruptura do Campo $\rightarrow E_{\text {ruptura }}=p \frac{B}{C+\ln (p d)}$

sendo $: C=\ln \left(\frac{A}{\ln \left(1+\frac{1}{\gamma}\right)}\right)$

onde, $g \gamma$ é o coeficiente secundário de ionização.

Para o ar:

$$
\begin{aligned}
& A=15 \mathrm{~cm}^{-1} \text { Torr }^{-1} \\
& B=365 \text { Volts } \mathrm{cm}^{-1} \text { Torr }^{-1} \\
& \gamma=10^{-2} \\
& \text { Produzindo } C=1,18
\end{aligned}
$$

Nota-se que a tensão de centelhamento é afetada pelo material que compõe o eletrodo; com catodos de Bário e Magnésio tendo uma tensão maior do que o Alumínio. 
Tabela F.1 - Dados de Vários Fluidos

\begin{tabular}{lcc}
\hline Gás & $\begin{array}{r}V s_{\min } \\
(\text { Volts })\end{array}$ & $\begin{array}{c}p d \text { em } V s_{\text {min }} \\
(\text { Torr cm) }\end{array}$ \\
\hline Ar & 327 & 0,567 \\
Argônio & 137 & 0,9 \\
$\mathrm{H}_{2}$ & 273 & 1,15 \\
$\mathrm{Hélio}$ & 156 & 4,0 \\
$\mathrm{CO}_{2}$ & 420 & 0,51 \\
$\mathrm{~N}_{2}$ & 251 & 0,67 \\
$\mathrm{~N}_{2} \mathrm{O}$ & 418 & 0,5 \\
$\mathrm{O}_{2}$ & 450 & 0,7 \\
$\mathrm{SO}_{2}$ & 457 & 0,33 \\
$\mathrm{H}_{2} \mathrm{~S}$ & 414 & 0,6 \\
\hline
\end{tabular}

\section{F.2 Dependência da Temperatura}

A lei de Paschen deve ser realmente estabelecida como $V=f(N d)$, onde $N$ é a densidade das moléculas do gás, as quais, logicamente, são afetadas pela temperatura bem como pela pressão do gás $\left(\frac{n}{V}=\frac{p}{R T}\right)$. Uma equação empírica para o ar (o considerando com um gás ideal) é:

$$
x=293 \frac{p d}{760 T}
$$

$$
V_{\text {ruptura }}=24,22 x+6,08 \sqrt{x}
$$

onde :

$p=\operatorname{pressão~em~Torr~}(\mathrm{mmHg})$

$d=$ distância em $\mathrm{cm}$

$T=$ temperatura em Kelvins

$V_{\text {ruptura }}$ em KVolts 


\section{F.3 Dependência da Umidade}

No ar, o aumento da umidade aumenta a tensão de ruptura elétrica. Este efeito é mais apreciável em campos elétricos uniforme e menos importante em fendas não uniformes (tais como fendas esféricas onde a fenda é uma grande fração do diâmetro da esfera ou em fendas entre agulhas ou barras cilíndricas).

\section{F.4 Ponto de Stoletow}

Em 1890, Stoletow encontrou que em uma configuração de eletrodos planos se o campo elétrico formado entre os eletrodos permanecer constante existe uma pressão na descarga de Townsend onde a corrente elétrica é máxima. Nos seus experimentos Stoletow demonstrou que a pressão para a máxima corrente elétrica é dada por,

$$
p_{\text {máx }}=\frac{\vec{E}}{37200} \quad \text { (Torr) }
$$

onde, $\vec{E}$ é o campo elétrico formado entre os eletrodos em volts por metro. Desta forma, a pressão determinada pela relação acima ficou conhecida como o ponto de Stoletow. 


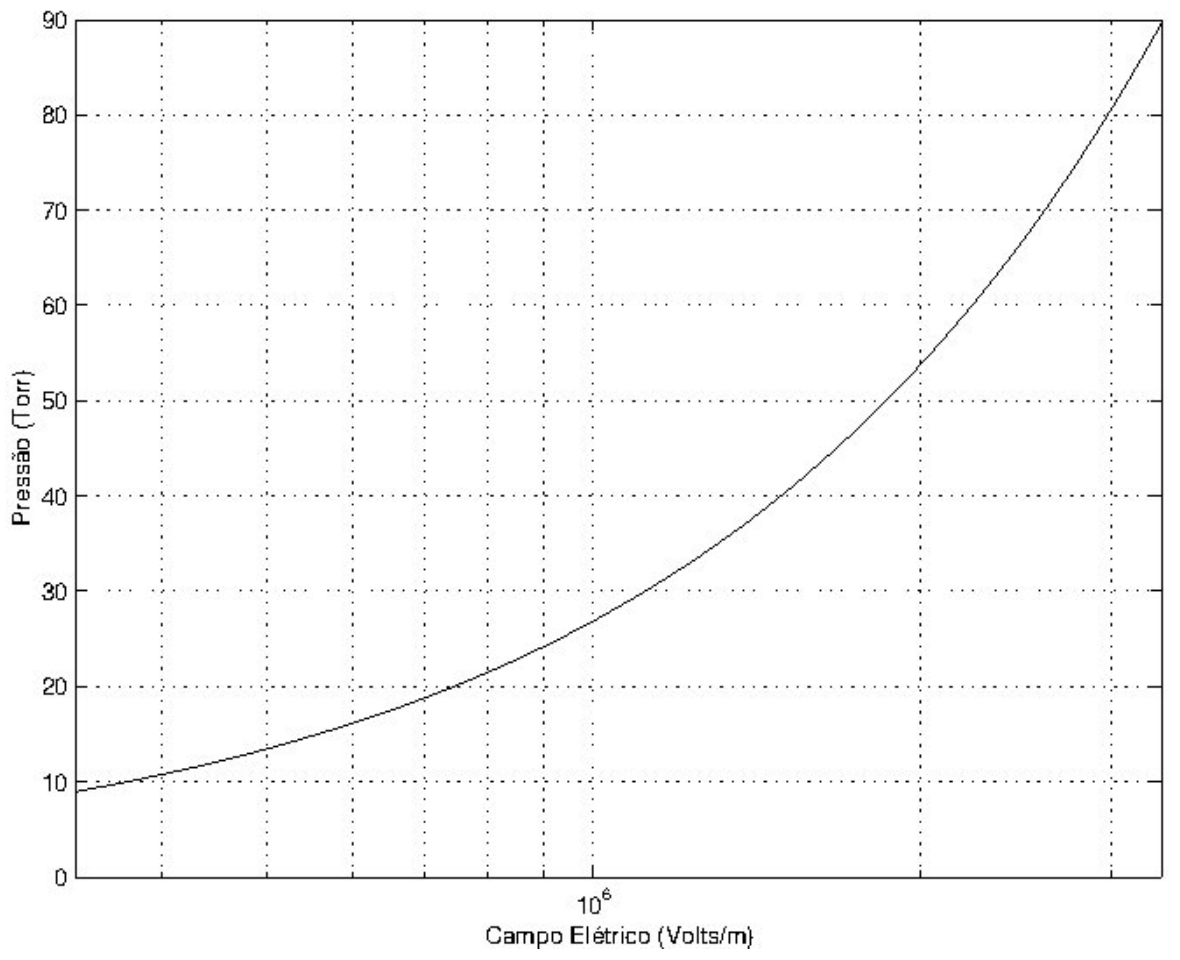

Figura F.1 - Relação de Stoletow 